ON THE

CORPORFALITY OF ATMOSPHERE 



\title{
ON THE CORPOREALITY OF ATMOSPHERE
}

\author{
by \\ Jessica Dawn Walker \\ Bachelor of Architectural Science (Honours), Ryerson University, 2014 \\ A thesis \\ presented to Ryerson University \\ in partial fulfillment of the \\ requirements for the degree of \\ Master of Architecture \\ in the Program of \\ Architecture
}

The Department of Architectural Science

Toronto, Ontario, Canada, 2017

(C) Jessica Dawn Walker 2017 



\section{AUTHORS DECLARATION}

I hereby declare that I am the sole author of this thesis. This is a true copy of the thesis, including any required final revisions, as accepted by my examiners.

I authorize Ryerson University to lend this thesis to other institutions or individuals for the purpose of scholarly research.

I further authorize Ryerson University to reproduce this thesis by photocopying or by other means, in total or in part, at the request of other institutions or individuals for the purpose of scholarly research.

I understand that my thesis may be made electronically available to the public.

Jessica Dawn Walker 



\section{ON THE CORPOREALITY Jessica Dawn Walker \\ OF ATMOSPHERE Master of Architecture 2017 \\ Architecture Program, Ryerson University}

Space is a constant inhabited medium which is inseparable from its role as a lived human environment. Both defined and undefined by concrete matter, it possesses an innate ability to envelop the body in deep spatial experiences. These experiences can be intense, even poetic. This naturally felt presence is a profound relationship between body and surrounding; the vehicle for this experience is atmosphere. Atmosphere is the mode of providing experiential space within architecture, feeding one's presence in their world; without consideration for atmospheric conditions renounces built form void of these experiences. By conceiving architecture through the embodied experience of atmospheres, space can intrinsically permit the body to experience its surrounding. This work is a continuous exploration of designing architecture through its atmosphere; as such, a focus will be redirected back to a bodily experience by activating the innate relationship between atmosphere and the body. 



\section{ACKNOWLEDGMENTS}

I would like to thank the following individuals as this would not have been possible without all the support from every one of you.

Paul Floerke For your guidance, support, and direction in my work with enthusiasm and genuine interest. Your participation made this process an enjoyable and memorable experience.

Michelle Grant For your continual design and research references which forwarded my thinking, design process, and personal progress through this thesis development.

Masha Etkind For your insightful and challenging questions, helpful criticism throughout my research, and support for my ongoing work.

My Dearest Friends, Architecture Family and Companions
For their constant support, encouragement, and enthusiasm; who kept me balanced, overjoyed and confident; for our friendship and experiences which I will never forget and always be thankful for.

My Mother and Sister For their tireless support, both physically and mentally, and their continued encouragement over the years and into the future. 

Authors Declaration $\quad$ v

Abstract vii

Acknowledgments $\quad$ ix

Dedication $\quad$ xi

List of Figures $\quad \mathrm{xv}$

Preface xxiv

$\begin{array}{ll}\text { 01.1 Experience of Natural Environments } & 01\end{array}$

01.2 Nature as an Extension of Atmosphere in Architecture 02

03 ATMOSPHERE, ARCHITECTURE, BODY

03.1 What is Atmosphere? 11

03.2 The Bodily and Mindful Experience of Atmospheres 12

03.2.1 The Profound Relations Between Body and Surrounding Space 14

03.2.2 The Mindful Body 16

03.3 Atmosphere Experienced and Described 18

03.4 Unfolding Sustained and Temporal Experience 21 
04.1 On the Transience of Atmosphere 23

04.2 Hierarchical and Simultaneous Perception 24

04.3 Palpable Qualities 27

04.3.1 On the Surrounding of Space and the Sense of Place 28

04.3.2 On Materiality and Tectonic Experience 33

04.4 Metaphysical Qualities 34

04.4.1 On Lightness and Darkness 34

04.4.2 On the Air of Space 36

04.5 Atmosphere, not Ambiance, nor a Calculated Experience 38

\section{THE CORPOREALITY OF} ATMOSPHERE

05.1 Armatures for Meditation, Contemplation, Presence 43

05.2 The Atmosphere of Mono Cliffs Provincial Park 47

05.3 Atmospheric Installations Within Nature $\quad 51$

05.4 Corporeal Armatures $\quad 54$

05.4.1 Armature of Air 56

05.4.2 Armature of Water 70

05.4.3 Armature of Earth 84

05.5 Reflections 98

$\begin{array}{ll}\text { Postscript } & 100\end{array}$

$\begin{array}{ll}\text { Appendices } & 103\end{array}$

Bibliography 196 



\section{LIST OF FIGURES}

Figure 1: Mountainscape in Italy, 2008

Source: Jessica Walker

Figure 2: Recollection of Atmosphere in Florence and Nice, 2008

a. Interior of Church in Florence

b. Streetscape in Nice

Source: Jessica Walker

Figure 3: Natural landscape in Austria, 2016

Source: Jessica Walker

Figure 4: Natural Settings in Ireland, 2016

a. The Burrens

b. Kilarney National Park

Source: Jessica Walker

Figure 5: Interior of Saint Benedict Chapel, Sumvitg, 2016

Source: Jessica Walker

Figure 6: The overlapped experience of one day of hiking through Mono Cliffs Provincial Park

Source: Jessica Walker

Figure 7: Mapping the personal experience of Saint Benedict Chapel, Sumgvit, Switzerland, 2016Original Image of Space

Source: Jessica Walker

Figure 8: Interior of Herz Jesu Church, Sumvitg, 2016

Source: Jessica Walker

Figure 9: Diagramming Atmosphere's role in Architecture Source: Jessica Walker

Figure 10: Feeling surrounding world in an unconventional manner Source: Jessica Walker

Figure 11: Tate Museum of Modern Art, London, 2016 Source: Jessica Walker

Figure 12: Diagram of atmospheric qualities and experienced qualities Source: Jessica Walker

Figure 13: The Garden of Exile and Emigration at the Jüdisches Museum Berlin, Berlin, 2016

Source Derek Smart

Figure 14: Analyzing the zones of focused and peripheral perception between two buildings on a street in Haldenstein, Switzerland

Source: Jessica Walker 
Figure 15: Brick wall of Copenhagen, 2016

Source: Derek Smart

Figure 16: Saint Benedict Chapel from the street below in the small municipality of Sumvitg, 2016

Source: Jessica Walker

Figure 17: Architecture and Surrounding relationship

a. Interior view, 2016

b. Saint Benedict Chapel overlooking the valley, Sumvitg, 2016

c. Street in Haldenstein, 2016

Source: Jessica Walker, Sahel Tahvildari, Jessica Walker

Figure 18: Grundtvig's Church, Copenhagen, 2016

a. Entrance Door

b. Interior View

Source: Jessica Walker

Figure 19: Analyzing the light and darkness of Shalekhet - Fallen Leaves, Jewish Museum Berlin, Berlin, 2016

a. Perceived space

b. Light and darkness broken down into greyscales

c. Light and dark emphasized

Source: Jessica Walker

Figure 20: Tate Museum of Modern Art Extension, London, 2016

Source Jessica Walker

Figure 21: Dachau Concentration Camp Memorial Site Visitor Center, 2016

Source: Jessica Walker

Figure 22: Images which encapsulate the essence of the sites for each of the corporal atmospheres

a. Water Armature

b. Air Armature

c. Earth Armature

Source: Jessica Walker

Figure 23: Chart of intents for each armature

Source: Jessica Walker

Figure 24: Axonometric of overall loop where armature sites are located

Source: Jessica Walker

Figure 25: Sites for each armature

a. Air Armature Site

b. Water Armature Site

c. Earth Armature Site

Source: Jessica Walker 
Figure 26: Atmospheric on-site installations for each armature, done with solely found on-site materials

a. Air Installation

b. Water Installation

c. Earth Installation

Source: Jessica Walker

Figure 27: Initial sketches and ideas for installations

Source: Jessica Walker

Figure 28: Atmospheric on-site installations

a. Air Installation

b. Water Installation

c. Earth Installation

Source: Jessica Walker

Figure 29: Mapped Overall Experiences

a. Earth Armature

b. Air Armature

c. Water Armature

Source: Jessica Walker

Figure 30 Representation for the intent of the atmosphere for the Air Armature

Source: Jessica Walker

Figure 31: Axonometric of the Air Armature showing its main components

Source: Jessica Walker

Figure 32: Orthographic drawings of armature

a. Plan

b. North Elevation

c. Section a-a

Source: Jessica Walker

Figure 33: Mapped Air Armature experience.

a. Approach and Decent

b. Main Interior Space

c. Ascent and Exit

d. Holistic Mapped Experience of the Armature showcasing the designed embodied experience

Source: Jessica Walker

Figure 34: Representation for the intent of the atmosphere for the Water Armature Source: Jessica Walker

Figure 35: Axonometric of the Water Armature showing its main components Source: Jessica Walker 
Figure 36: Orthographic drawings of armature

a. Plan

b. Section a-a

c. West Elevation

Source: Jessica Walker

Figure 37: Mapped Water Armature experience

a. Approach and Entrance

b. Main Interior Space

c. Exit and Ascent

d. Holistic Mapped Experience of the Armature showcasing the designed embodied experience

Source: Jessica Walker

Figure 38: Representation for the intent of the atmosphere for the Earth Armature. Source: Jessica Walker

Figure 39: Axonometric of the Earth Armature showing its main components Source: Jessica Walker

Figure 40: Orthographic drawings of armature

a. Plan

b. Section a-a

c. Section b-b

Source: Jessica Walker

Figure 41: Mapped Earth Armature experience

a. Approach and Entrance

b. Movement Space and Main Interior Space

c. Exit

d. Holistic Mapped Experience of the Armature showcasing the designed embodied experience

Source: Jessica Walker

Figure 42: Mapped Overall Experiences

a. Earth

b. Air

c. Water

Source: Jessica Walker

Figure 43: Rundetaarn, 2016, Copenhagen

Source: Derek Smart

Figure 44: Model explorations of materiality, various lighting conditions, and the interplay between the two.

Source: Jessica Walker 
Figure 45: Materials were gathered on-site and used in order to further understand each site and its atmosphere. Here, the materials were used to make impressions to see the texture, as well as shadows of each place.

a. Earth site

b. Air site

c. Water site.

Source: Jessica Walker

Figure 46: Original Watercolour demonstrating the initial intent for the resultant atmosphere for the Armature.
a. Air site
b. Water site
c. Earth site.

Source: Jessica Walker

Figure 47: Initial atmospheric intent drawing for the Armature.
a. Air site
b. Water site
c. Earth site

Source: Jessica Walker

Figure 48: In order to personally experience the designed intent, on-site installations were done. Six-foot-tall stakes where then inserted into the ground (and water) at major moments of change for the walls, stairs and roof, as applicable to each site. White fabric was then wrapped around the stakes. The armature was then left for a period of time to simply exist on site, swaying with the wind. The fabric and stakes were then removed from the site, leaving it the way it was found.

a. air site

b. water site

c. earth site

Source: Jessica Walker

Figure 49: For the Air Armature, a built portion of gabion wall was done with bent hardware mesh and rocks found on site. As seen below, there are a variety of rocks located on the site, which have variations in their colouring. What was also interesting was to see some of the rocks having some green on them, hinting at what could happen to the built armature walls.

Source: Jessica Walker

Figure 50: For the Water Armature, a built portion of a rammed earth wall was done with wood planks brought to site and dirt and sand found on site; the sand was in the water and the dirt was along the shoreline. Seen below is the variations in the colouring.

Source: Jessica Walker 
Figure 51: For the Earth Armature, a built portion of weaved birch was done with small wooden dowels which were stuck into the ground. The birch bark was oriented the same direction for the weaving; the white side for the exterior and the darker warm toned side on the interior. I noted that a method for stitching the pieces together would need to be developed.

Source: Jessica Walker

Figure 52: Temporal overlapped experience imagery

a. Air Armature Imagery

b. Water Armature Imagery

c. Earth Armature Imagery

Source: Jessica Walker

Figure 53: Orthographic Drawings for Air Armature

a. Site Plan

b. Interior Plan

c. Section b-b

d. Detail of Interior Plan

e. Section a-a

f. Detail of Section a-a

Source: Jessica Walker

Figure 54: Mapped Experience for Air Armature

Source: Jessica Walker

Figure 55: Models for Air Armature

a. Sketch models exploring various experiences for the armature

b. Looking at the initial ideas and concepts along with the spatial volume and perception

c. More developed models further along in the design process at $90 \%$ design stage

Source: Jessica Walker

Figure 56: Moving from the compressive, dark hallway into the main central space

Source: Jessica Walker

Figure 57: Orthographic Drawings for Water Armature

a. Site Plan

b. Interior Plan

c. Section a-a

d. West Elevation

e. Section c-c

f. Detail of Section c-c

Source: Jessica Walker

Figure 58: Mapped Experience for Water Armature

Source: Jessica Walker 
Figure 59: Models for Water Armature

a. Sketch models exploring various experiences for the armature

b. Looking at the initial ideas and concepts along with the spatial volume, including how the armature could become the transitional space of land and water

c. More developed models further along in the design process at $90 \%$ design stage.

Source: Jessica Walker

Figure 60: Sitting on the wood floor, extending out over the water

Source: Jessica Walker

Figure 61: Orthographic Drawings for Earth Armature

a. Site plan

b. Conceptional order

c. Plan@1200mm from ground

d. Plan@2800mm from ground

e.Plan@4800mm from ground

f. Section a-a

g. Detail of Plan@1200mm from ground

h. Section $b-b$

i. Detail of Section b-b

Source: Jessica Walker

Figure 62: Mapped Experience for Earth Armature

Source: Jessica Walker

Figure 63: Models for Earth Armature

a. Sketch models exploring various experiences for the armature

b. Looking at the initial ideas and concepts along with the spatial volume and procession

c. More developed models further along in the design process at $90 \%$ design stage

Source: Jessica Walker

Figure 64: Walking up the slopped earth between two birch bark walls.

Source: Jessica Walker

Figure 65: Material Installation for Air Armature Source: Jessica Walker

Figure 66: Material Installation for Water Armature

Source: Jessica Walker

Figure 67: Material Installation for Earth Armature Source: Jessica Walker 
Figure 68: Final Orthographic drawings for Air Armature

a. Site Plan

b. Interior Plan

c. Detail of Interior Plan

d. Section a-a

e. Section b-b

f. Detail of Section b-b

g. North Elevation

h. South Elevation

Source: Jessica Walker

Figure 69: Atmospheric Representations of Air Armature

a. Mapped Experience of Air Armature

b. Southwest view from trail

c. Southeast view from trail

d. Top of stairs looking South

e. Decent down stairs

f. Entering tunnel portion of stairs

g. View into main space

h. Interior space looking south

i. Exiting main space

Source: Jessica Walker

Figure 70: Final Orthographic drawings for Water Armature

a. Site Plan

b. Interior Plan

c. Section a-a

d. Section $b-b$

e. Detail of Section a-a

f. North Elevation

g. West Elevation

Source: Jessica Walker

Figure 71 Atmospheric Representations of Water Armature

a. Mapped Experience of Water Armature

b. View from pathway towards water

c. Between land and Armature

d. Entrance to Armature

e. Hallway in armature

f. Sitting with feet in water

g. View entering main space

h. Entering Water

i. Exiting Space

Source: Jessica Walker 
Figure 72: Final Orthographic drawings for Earth Armature

a. Site Plan

b. Interior Plan

c. Detail of Interior Plan

d. Section b-b

e. Section a-a

f. Detail of Section a-a

g. West Elevation

h. North Elevation

Source: Jessica Walker

Figure 73: Atmospheric Representations of Water Armature

a. Mapped Experience of Earth Armature

b. Armature from trail, looking Southeast

c. Before entering armature

d. Moving towards center space

e. Moving towards center space, looking up

f. Upwards from center

g. Exiting center space

h. Exiting armature

Source: Jessica Walker

Figure 74: Final Design Models

a. Overall Context Model 1:2000

b. Air Armature Sectional Model 1:50

c. Water Armature Model 1:50

d. Earth Armature Model 1:50

Source: Jessica Walker 


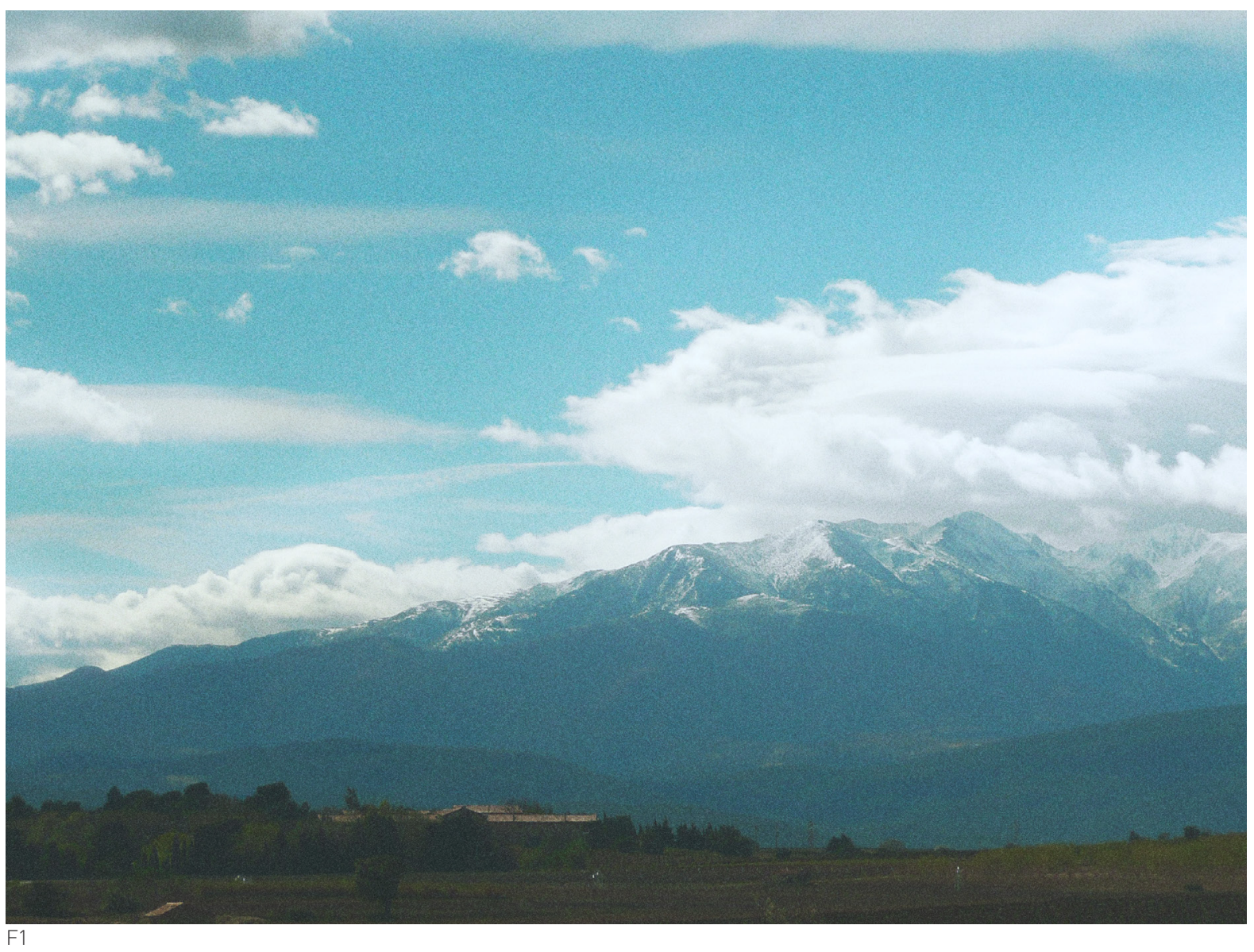




\section{PREFACE}

Figure 1: Mountainscape in Italy, 2008
In spring of 2008, I had the opportunity to go on a school trip, where I traveled throughout Italy, Spain and France for two weeks. It was here where I began to start understanding something fundamental. It was something about the spaces beyond the high school walls and the places outside of my hometown which became compelling and awakened something within me. I remember the alleyways which seemed captivating and exciting, the feeling of the cobbled streets; the foggy morning walks over the misty landscape, and the buildings which I could not stop being in, around, and feeling. I remember moving from the streets to the dimly lit interiors, sensing something overwhelming in the most enlightening of ways. It seemed that this intense feeling was innate, yet I had difficulty describing what was around me. It was in moments like these where a force, a specific milieu, was suddenly there; something immaterial had been felt, as though I started to feel the character of the buildings, the streets, the spaces. This moment was when I started seeing architecture. This was the landscape of my trip, and I since have realized that I was experiencing my physical and mindful presence in an atmosphere. 

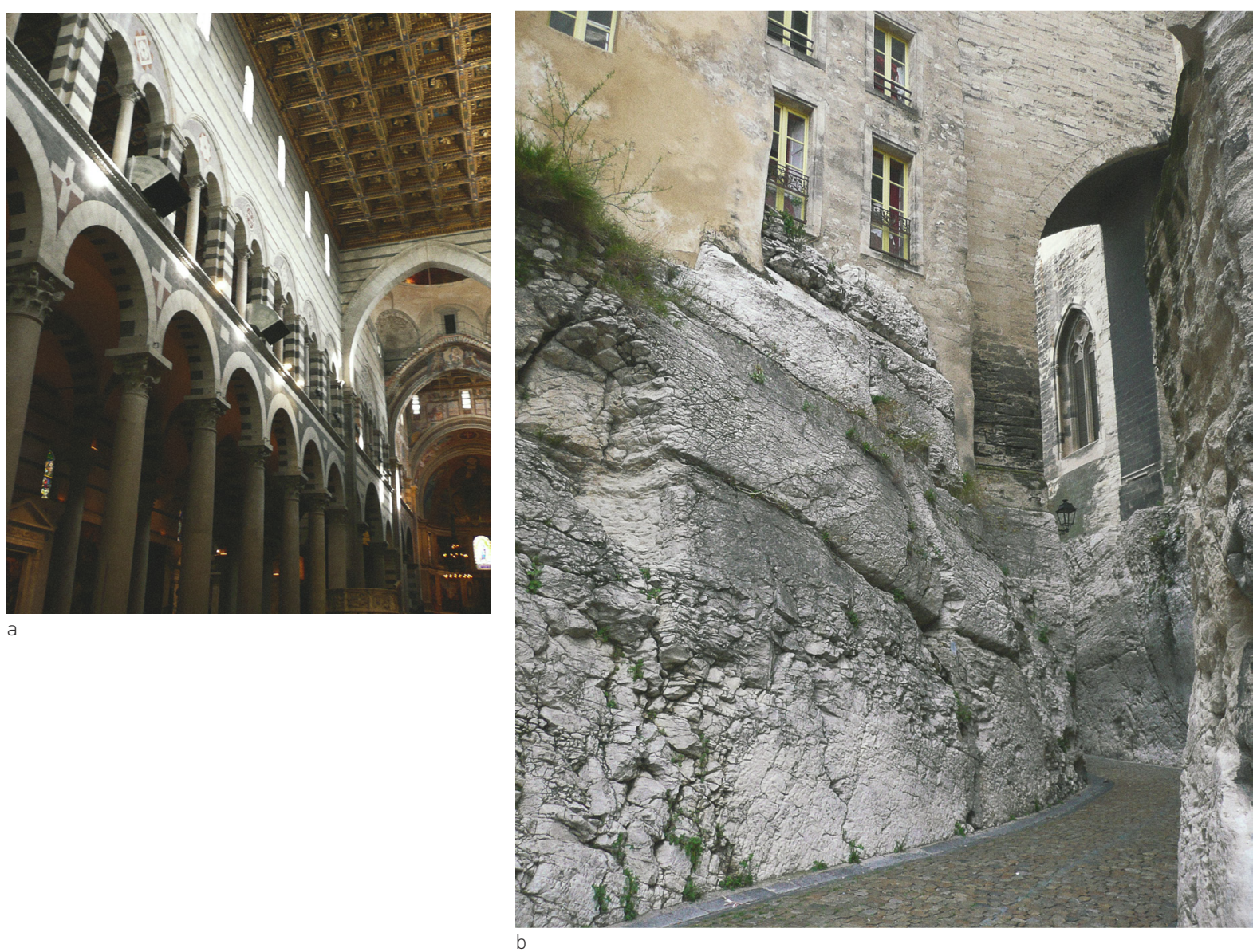
2 John Lobell, Between silence and light: spirit in the architecture of Louis T. Kahn, (Boston: Shambhala Publications, Inc., 1979), 14

Figure 2: Recollection of Atmosphere in Florence and Nice, 2008

a. Interior of Church in Florence

b. Streetscape in Nice
It was such a transforming thought, which all my life I had looked at the building as merely present in life, as a supporter of human activity. It never occurred that this, in fact, had a much greater importance than merely that of shelter, of supporting the basic functions of our life. I thought of architecture just as many do, as elements of the building, the façade, the structure, the program, which come together to create the whole. However, as August Endell points out, "all of that is of second rank. What is to most effect is not the shape, but its inversion, the space, the emptiness that spreads out rhythmically between the walls, is delimited by them, and that vibrancy is more important than the walls." ${ }^{1}$ Moreover, it was the experience of the atmospheric space which I found indescribable. Up until this point, it had not been clear to me that architecture could move me with an intangible force. Why was it that I had not felt this before? Why was it that so many spaces I had inhabited were void of this feeling? Architecture, in general, has been preoccupied with form rather than feeling, surface than materiality and texture, focused imagery than enveloping experience, shape than atmosphere. It is designed and built with a lack of consideration for its atmospheric qualities, acting merely as forms for utilitarian demands and needs, with a focus on the object of the built form rather than the subject of the body. These spaces have flat, mundane, routine atmospheres with little experiential qualities. There are still some spaces which have atmospheres which engage one as a participant in the space.

Like a great piece of music, it is a complex feeling; it has depth; it is layered: it makes the heart beat fast; it makes one take deep breaths. It is an atmosphere. This work is not an attempt to decompose atmosphere's poetic nature. Rather, it is an attempt to understand its poetic condition; its ramifications on architectural design; what it ultimately means to design architecture through atmosphere. As such, this work will begin to explore a change in focus from building to body, from object to subject, as a change in viewpoint from designing architectural objects to enhancing space in an attempt to create more spaces for mindful physical presence in the human realm. The focus will start from the immeasurable and work towards the measurable, while keeping the unmeasurable within the work at all times, as "the poet is the one who starts from the seat of the unmeasurable and travels towards the measurable, but who keeps the force of the unmeasurable within him at all times." 2 Since words are abstract, and not concretized in space, this effort to penetrate architectural meaning through written language will attempt to put atmosphere into words without losing its poeticism. 


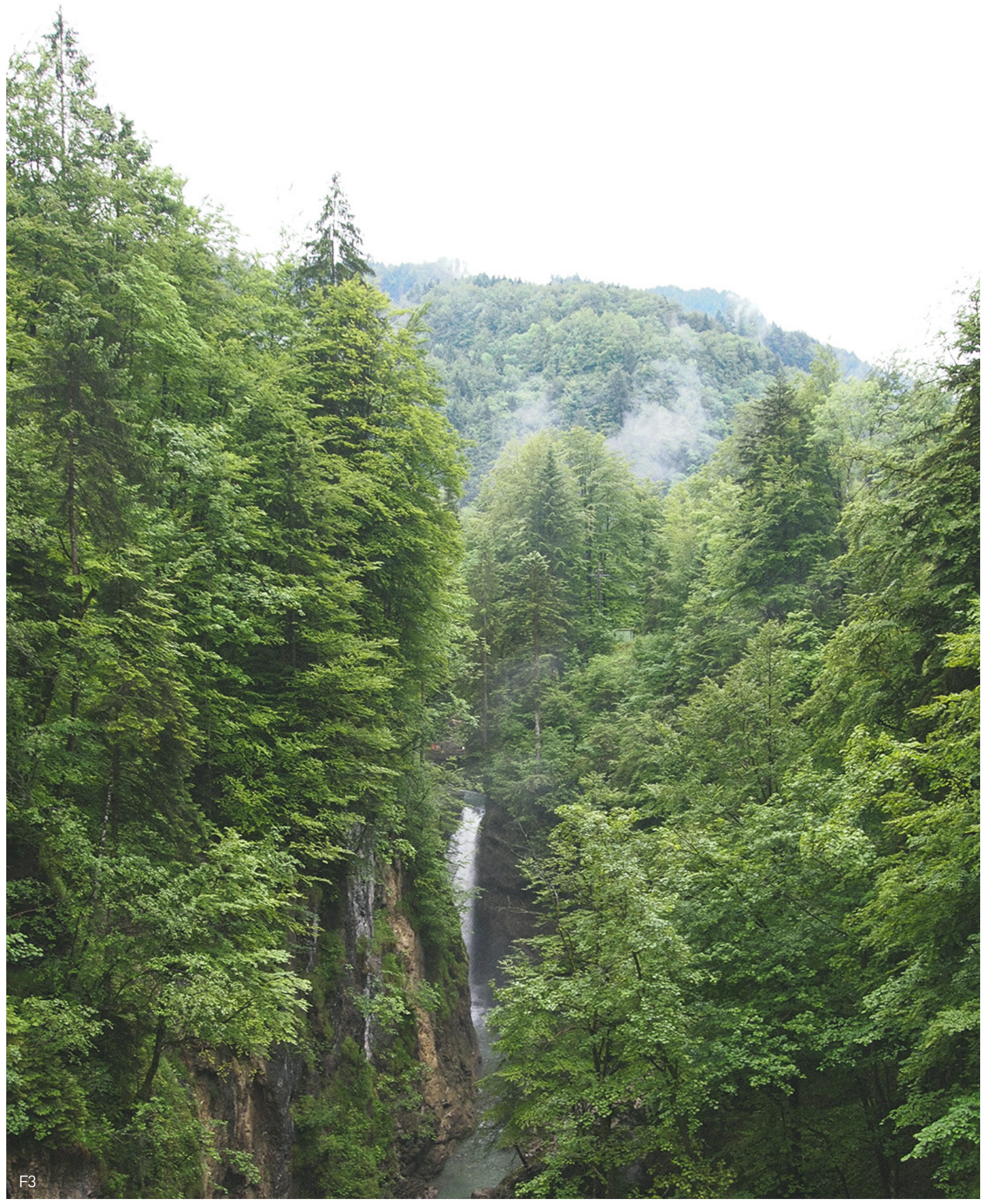




\section{LIKE A TREE}

\subsection{Experience of Natural Environments}

3 Steven Holl, Juhani Pallasmaa, and Alberto Pérez Gómez, Questions of perception: Phenomenology of architecture, (San Francisco: William Stout Publishers,
2006). (30).
4 John Lobell, Between silence and light: spirit in the architecture of Louis T. Kahn, (Boston: Shambhala Publications, Inc. 1979) 24

Figure 3: Natural landscape in Austria, 2016

5 Juhani Pallasmaa, "The Place of Man", Encounters: architectural essays, ed. Peter MacKeith, (Helsinki:
Rakennustieto Oy, 2005), (75)
A forest, a field, in a boat, the sound of a stream, the rustling of the leaves; natures affect on human experience connects with the human body in the most subtle and ordinary of ways. It captures us. It connects with us as an experience which is so powerful, so natural. We may not think twice about why it can make us feel a certain way. This natural atmosphere of environments works its way into man-made spaces, extending the natural means of human experience into constructed form.

Imagine, stepping through a dense forest, the air damp and heavy on one's skin, trees start to move, and streams of light sporadically become visible. The air is crisp and fresh. There is an outlook over the vast of a forest, there is the sound of water, and one thinks of water. However, there are no humans, only the landscape. It seems to have an innate ability to create a sense of belonging. A walk through a forest is invigorating because of the essential interaction of all senses at once working with one another; ${ }^{3}$ its atmosphere is speaking. It has a life that is relatable; the trees move with the wind and the waters rippling movement, the sounds of the leaves in the trees and the changing smell of the bark throughout the day.

Nature encompasses both the measurable and immeasurable qualities of the world, while ultimately growing and altering an experience over time. It gives a unique sense, both consciously and unconsciously, of continuously understanding something ephemeral and grand, while making one aware of themselves. ${ }^{4} \mathrm{~A}$ full experience of the surrounding, vast landscape, the surfaces, textures and colours, the smell of the air and sound of water below, come together and all at once enforce an incredible atmosphere; however, these qualities on their own do not create atmosphere. These elements come together in its creation are a complex combination of the various qualities, where they are in constant flux. As Pallasmaa states, "The intensity and tranquility of our experience of a natural setting stem from the fact that we are using all of our senses." 5 
6 Presence in Architecture, Seven Personal Observations, Performed by Peter Zumthor, (The David Azrieli School of Architecture at Tel Aviv University, 2013), Lecture.

7 Peter Zumthor, Thinking Architecture (Basel: Birkhäuser, 2006), 73 .

01.2 Nature as an Extension of Atmosphere in Architecture

8 Juhani Pallasmaa, The Eyes of the Skin: Architecture and the Senses, (London: John Wiley \& Sons Ltd., 2005), 41.

Figure 4: Natural Settings in Ireland, 2016

a: The Burrens b: Kilarney National Park
Not every landscape or natural setting has an equivalent or same atmosphere. The experience of natural spaces are not prescribed. The forest, the tree, the wind, none say anything, they do not speak works ${ }^{6}$. They are simply there, touching us in various ways. They have the quality of being themselves, as self-evident things. They are natural, there, present, and allow one to feel their corporeal presence within the natural environments. These natural environments seem to have some positive effect on people, where they become happy, feel alive, find some new sense of hope for themselves; it provides some sort of high. "We are in nature, in this immeasurable form that we will never understand and now, in a moment of heightened experience, no longer need to because [one senses] that [they] are part of it." ${ }^{, 7}$ Nature is a selfsufficient artifact, but it directs our attention and existential experience to wider horizons, both physically and mentally, acting as the state of introspection.

This phenomenon which is experienced in natural settings is like that experienced in atmospheric spaces captured in architecture. What is interesting is that the atmosphere acts as extensions of nature into the man-made realm "providing the ground for perception and the horizon of experiencing and understanding the world" ${ }^{\text {. The same }}$ lived experience in nature where one has a heightened experience, where they feel some sort of high, a sense of belonging, as though they are a part of something grand, exists in architecture; the mode of experiencing this is through atmospheres.

Architecture, while seemingly natural, can then allow one to experience their physical presence within space. However, it is important to distinguish still between the naturally evolved and consciously produced atmospheres within architecture, as not all atmospheres are as impactful as others. One can say that every single place on this planet has its own atmosphere; a home has a specific atmosphere, a city street, grocery store, a workspace in a university, a chapel, a mountain-scape. Many various types of atmospheres exist, but only some are considered to engage the body. These atmospheres have the ability to alter on their own, however, when the atmosphere is considered for space, it can connect with the body in a greater, more meaningful manner. 

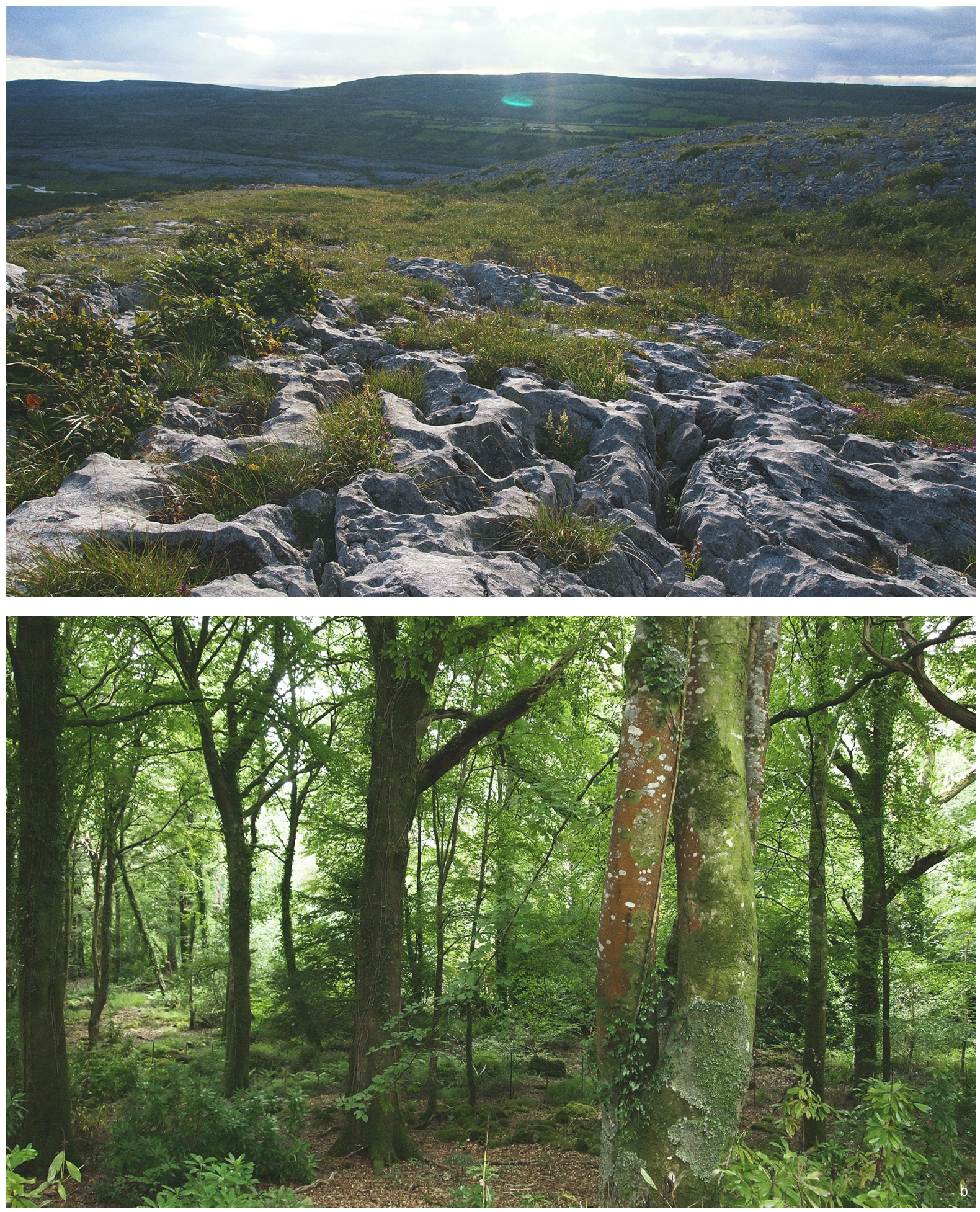


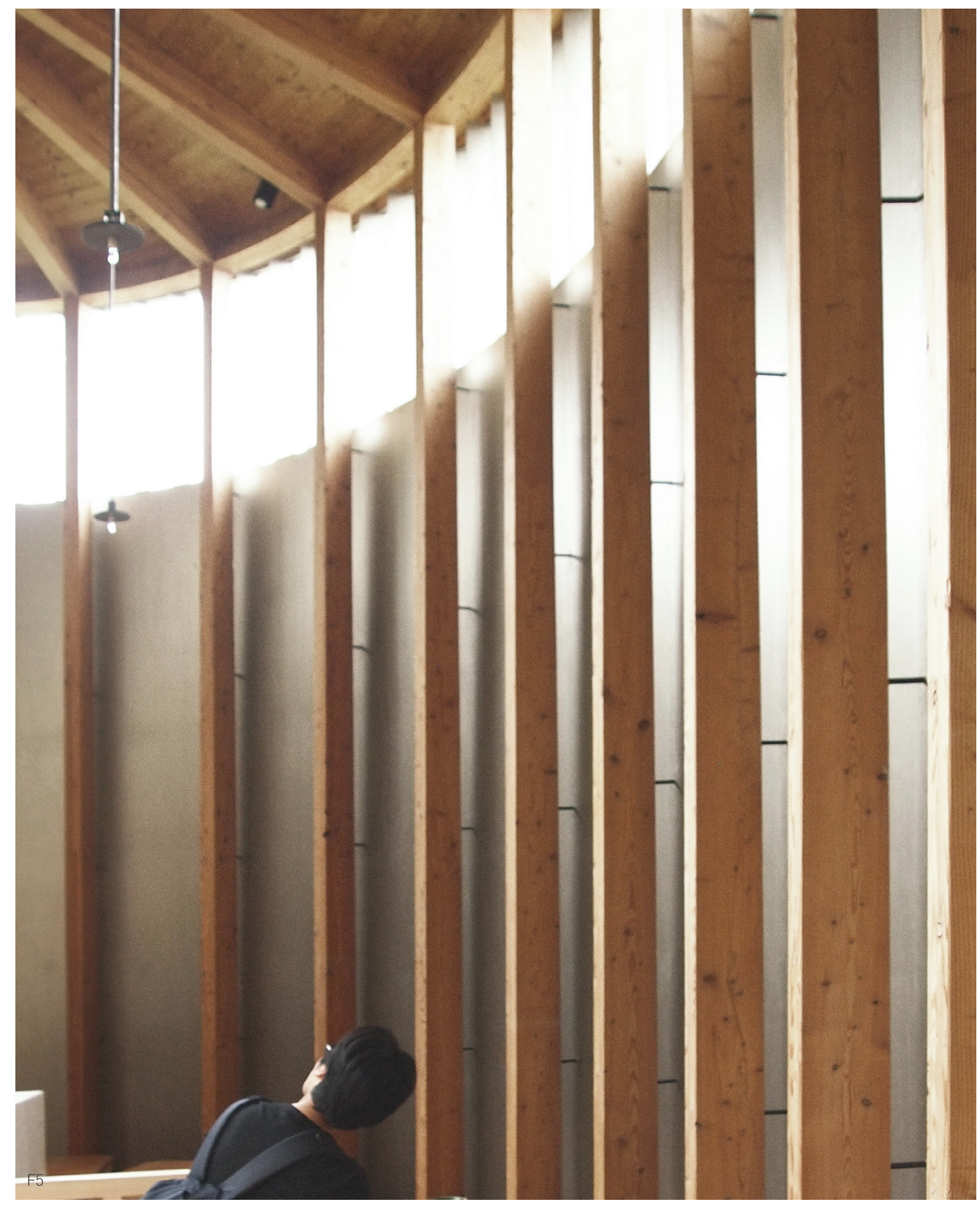




\section{LIVED EXPERIENCE}

\subsection{Space as a Spatial Experience} of an Inhabited Medium

9 Peter Zumthor, Thinking Architecture (Basel: Birkhäuser 2006), 12.

10 Jean Baudrillard, "The Aesthetic Suicide." In Mass, identity, Architecture: Architectural Writings of Jean Baudrillard ed. Proto Francesco, (Chichester: Wiley-Academy, 2006).'

11 Otto Friedrich Bollnow. Human Space, ed. by Joseph Kohlmaier, trans. by Christine Shuttleworth, (London:
Hyphen Press, 2011), (23).

12 Pallasmaa, Juhani. "The Place of Man" Encounters: architectural essays, ed. Peter MacKeith, (Helsinki: Rakennustieto Oy, 2005), 76

Figure 5: Interior of Saint Benedict Chapel, Sumvitg, 2016

13 Gernot Böhme, Architektur und Atmosphäre, (Munchen: Wilhelm Fink Verlag, 2006), 118
Space is that which is inhabited, the medium which we live in, every moment of our lives, renders the bodies relationship to space inseparable. A barrier does not define this space, but just exists, and is measured by the body; an experience of space is defined by its interaction with the body over a series of temporal events. The experience of such space takes on its own time, independent from clocks, driven by perception.

One may find it hard to think back and distinguish between architecture and life, between spatial situations and the way they are experienced, as if architecture has been the unconscious realm for life to carry out; it acts “... as an envelope and background for life which goes on in and around it, a sensitive container for the rhythm of footsteps on the floor, for the concentration or work, for the silence of sleep." 9 Space, although prior to architecture, takes on a new purpose with architecture as a supporter of life. Architecture is inhabited space which life occurs, one which covers its own tracks, ${ }^{10}$ acting as a spatial envelope. However, it would be naive to think of humans as simply present in space as objects. Rather, there is a relationship between humans and space, one which cannot be separated, as one is always conditioned in relation to a surrounding space. ${ }^{11}$ In this sense, space is "...neither an external object nor an inner experience. It is not that there are men, and over and above them space ..."12

There have been two traditional ways of looking at the concept of space; topos from Aristotle and spatium from Descartes. Topos, as defined by Aristotle, is "defined as the inner surface of the surrounding body. Space in this sense is acted as something in which something is located, the place."13 Spatium looks at space as the "distance between bodies." ${ }^{14}$ What both concepts have in common is that they are both related to the body as a fundamental notion. A body is that which limits space, inhabits space, space is the extension of the body, and is that which a body moves. Space and body are in constant dialogue with one another, rendering space inseparable from its human environment. One measures the world with the entirety of their body, allowing the existential world to become articulated and defined by it. The body and its movements are in constant interaction with space; the surrounding and the 
body then self-inform and redefine each other. Space compresses, expands, directs, and is informed by both with material and immaterial boundaries; these variations in the spatial volumes inform the body of the spatial experience. "The percept of the body and the image of the world turn into one single continuous existential experience; there is no body separate from its domicile in space, and there is no space unrelated to the unconscious image of the perceiving itself." ${ }^{15}$ The relationship between body and space renders it impossible to separate one from their spatial existence. ${ }^{16}$ "We sense the kind of space that surrounds us. We sense its atmosphere."

The spatial experience is one which has been defined as inseparable from the body due to the nature of its relationship with life. It must be understood that space is not an immaterial substance delineated by material surfaces, but is the experienced matter which life occurs. ${ }^{18}$ Due to this relationship, space has been divided into measured portions, defined by activities and objects demarcated by life. "We contain portions of space with boundaries, though, it does not mean that our portion is detached from the greater collective space." ${ }^{19}$ The two main ways humans interact with space within their daily lives through routine and ritualistic moments. The routine is defined by the mundane, as a fixed portion of life rather than for an apparent reason; thus, it lacks purposefulness, its celebrated experience. The ritual holds something magnificent and sacred to it; it implies a purposeful action. These modes are the way our conscious minds experience space, a sense of attitude that one enters a space with. It can have a significant impact on the overall experience of the space.
14 Böhme, 118.

15 Juhani Pallasmaa, The Eyes of the Skin: Architecture and the Senses, (London: John Wiley \& Sons Ltd. 2005), 40.

16 Pallasmaa, 64

17 Gernot Böhme, "Atmosphere as the Subject Matter of Architecture, Herzog \& de Meuron: natural history, ed. Philip Ursprung, (Montréal: Canadian Centre for Architecture, 2002 402.

18 Professor Fred Thompson Quoted on Juhani Pallasmaa, The Eyes of the Skin: Architecture and the Senses, (London: John Wiley \& Sons Ltd., 2005), 65.

19 Katherine Benzel, "Spatial Relationships," The room in context: design beyond boundaries, (New York; Toronto: 1998, 1998),
(17. 17.

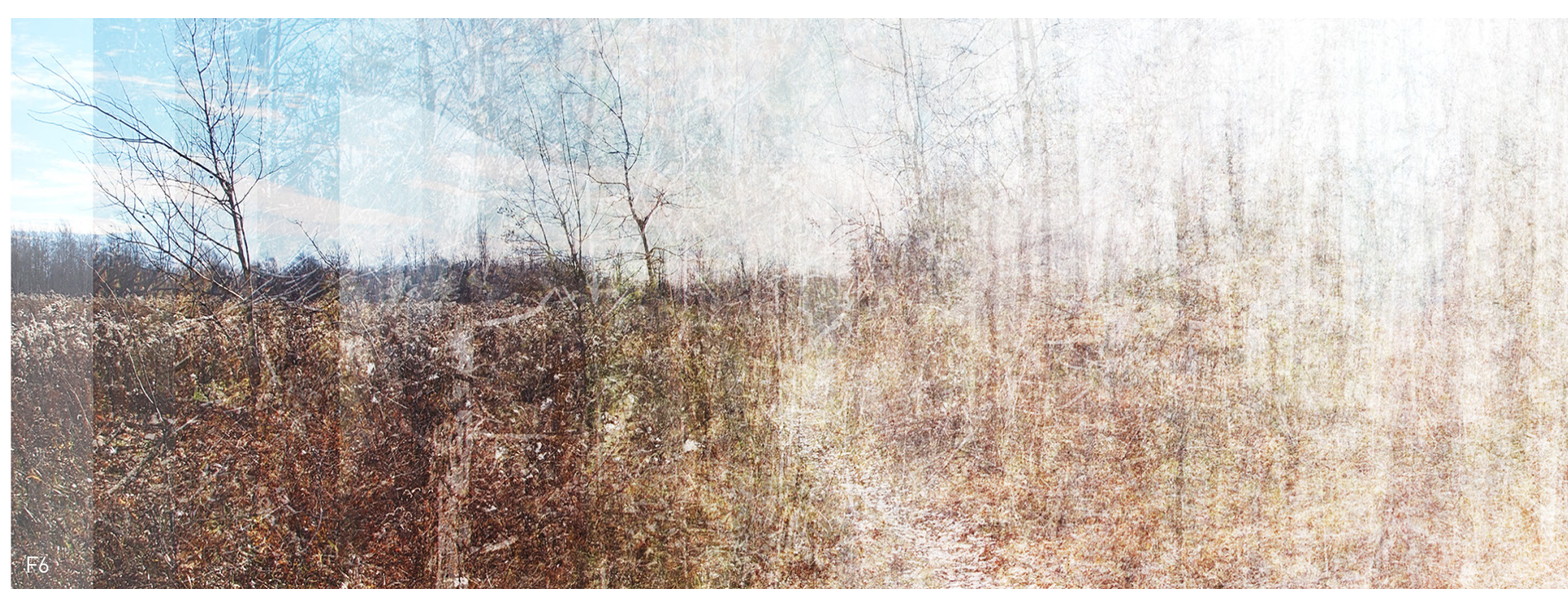




\subsection{Time and Space}

20 Gernot Böhme et al., "Space, place, and Atmosphere: Architetcural Atmopsheres: On Experience and Politics of Architetcural Atmopsheres: On Experience and Politics of
Architecture, (Basel: Birkhäuser Verlag GmbH, 2014), 20.

21 Juhani Pallasmaa, The Eyes of the Skin: Architecture and the Senses, (London: John Wiley \& Sons Ltd., 2005), 52

Figure 6: The overlapped experience of one day of hiking through Mono Cliffs Provincial

Park
Space is experienced temporally. Day by day, space becomes the lived experience of the body, experienced through time. This sensation cannot be experienced as a single image as it does not provide a true understanding of the physicality of the experience. As scientific time is constant, one must consider the experienced time and how it varies depending on experience. Pallasmaa argues that the atmosphere of architecture "emphasizes a sustained being in a situation, rather than a singular moment of perception" ${ }^{20}$, which insinuates that atmospheres can change how time is experienced. It can slow it down or speed it up as if time and space were connected in such a way which they are not dependent on each other, but emphasis one another in specific situations, where "space and time fuse into one singular elemental experience, the sense of being." ${ }^{21}$ During this period, there is some perceptual layering occurring, one which brings a sense of narrative into a setting. This narrative can be an emotional memory, or state, which is infused as a tracing of the experience. In this state, various times and experiences come together to reinforce the current situation.

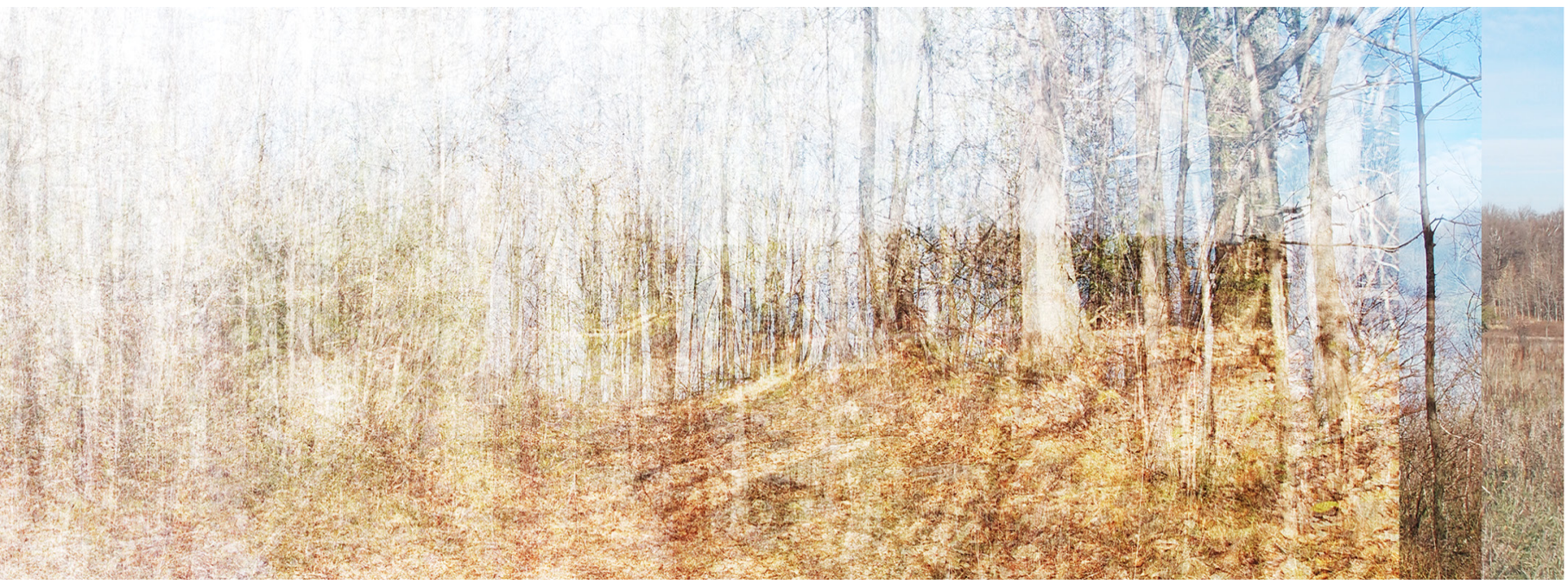




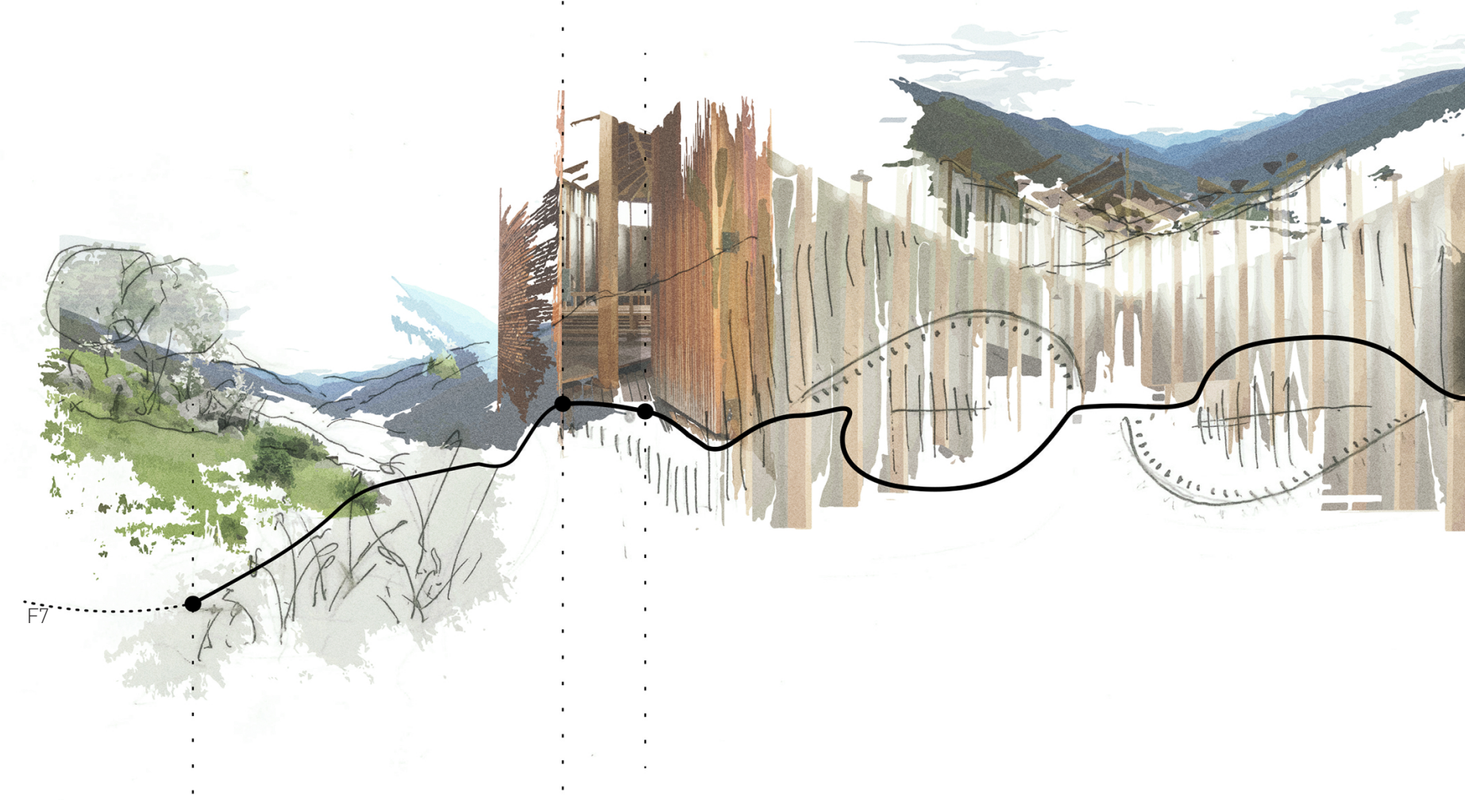

02.3 Lived Space as the Overlay of Atmosphere and Purpose

22 Peter Zumthor, Thinking Architecture (Basel: Birkhäuser,

23 Gernot Böhme et al., "The Politics of Atmospheres: Architecture, Power, and the Senses," Architectural atmospheres: on the experience and politics of architecture,

Figure 7: Mapping the personal experience of Saint Benedict Chapel, Sumgvit, Switzerland, Daidalos, 1998: 19
By collecting various tangible and intangible things from the world, space is understood as atmosphere, to be further later defined; this creates the body of architecture. The omnipresent nature of atmosphere is a by-product of our built world, a world of architecture. The result is a landscape of atmosphere which is concerned with one space among an infinity which surrounds the earth. ${ }^{22}$ As Christian Borch states, “... every encounter with architecture contains the possibility that we are being seized by its atmosphere, even if some atmospheres are felt more intensely than others." 23 As valid as this is, many people may not be acutely aware of this, whether they are fully conscious of it or not, they are widely affected by the atmosphere of the spaces which they inhabit. This is the power of architecture, as it is the background to life, as "[people] are rooted in [atmospheres] just as a plant is in the soil in which it is planted." 24 This space is experienced with atmosphere, which is either consequently or purposefully shaped.

Just as there are ritualistic and routine spaces, there are several forms of atmospheres; the consequential and the purposeful. A consequential atmosphere is one which is 


$$
\text { : }
$$

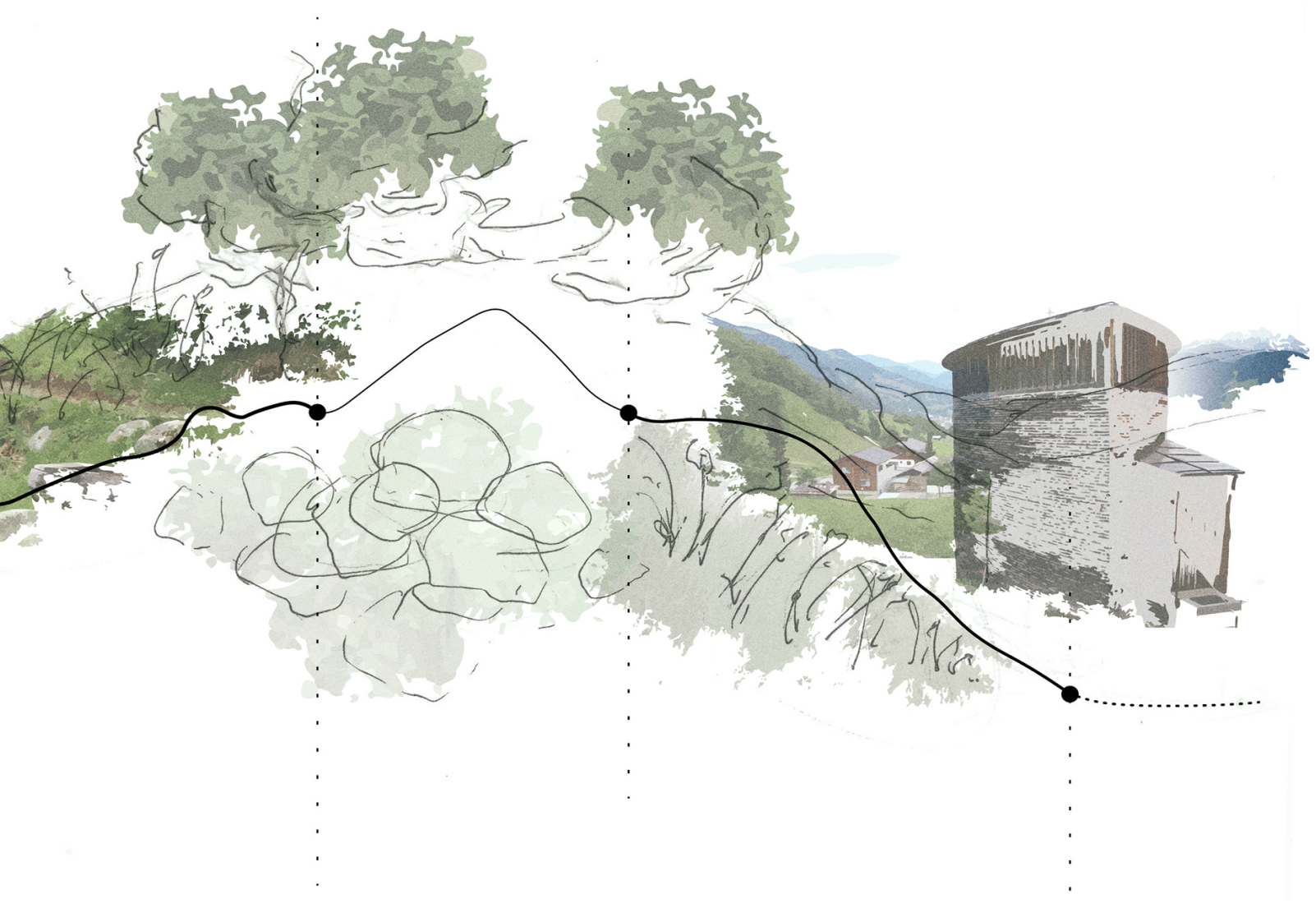

mundane, which does not have a purposeful experience, but one which is consequential part of the built environment. They are those which come into being without any designed thought, as it would be naïve to think that the only atmospheres which exist are those which are intended to exist. Many of these atmospheres are the result of conventional design; these are atmospheres of the mundane, which provide more of an ambiance rather than a purposeful atmosphere. These are the product of a lack of consideration for atmosphere within architecture and the body's experience. Unfortunately, these atmospheres account for a significant portion of the current built realm, due to an extended focus on building and a lack of understanding of the importance of the body's experience of the space. However, the purposeful atmospheres, ones which are designed for, provide a greater opportunity for the body to connect with space, with architecture; these atmospheres are constructed with the architecture, not added after. Purposeful atmospheres are formed when there is a clear consideration and appreciation for the spatial experience of the body, to form a greater connection between body and building; the atmospheres become the subject matter, and the focus, of the architectural design. They look to acknowledge the multivalent experience of an atmosphere, looking at the various means of perception and how one's body could respond and interact with it. These atmospheres are what this work will further explore. 


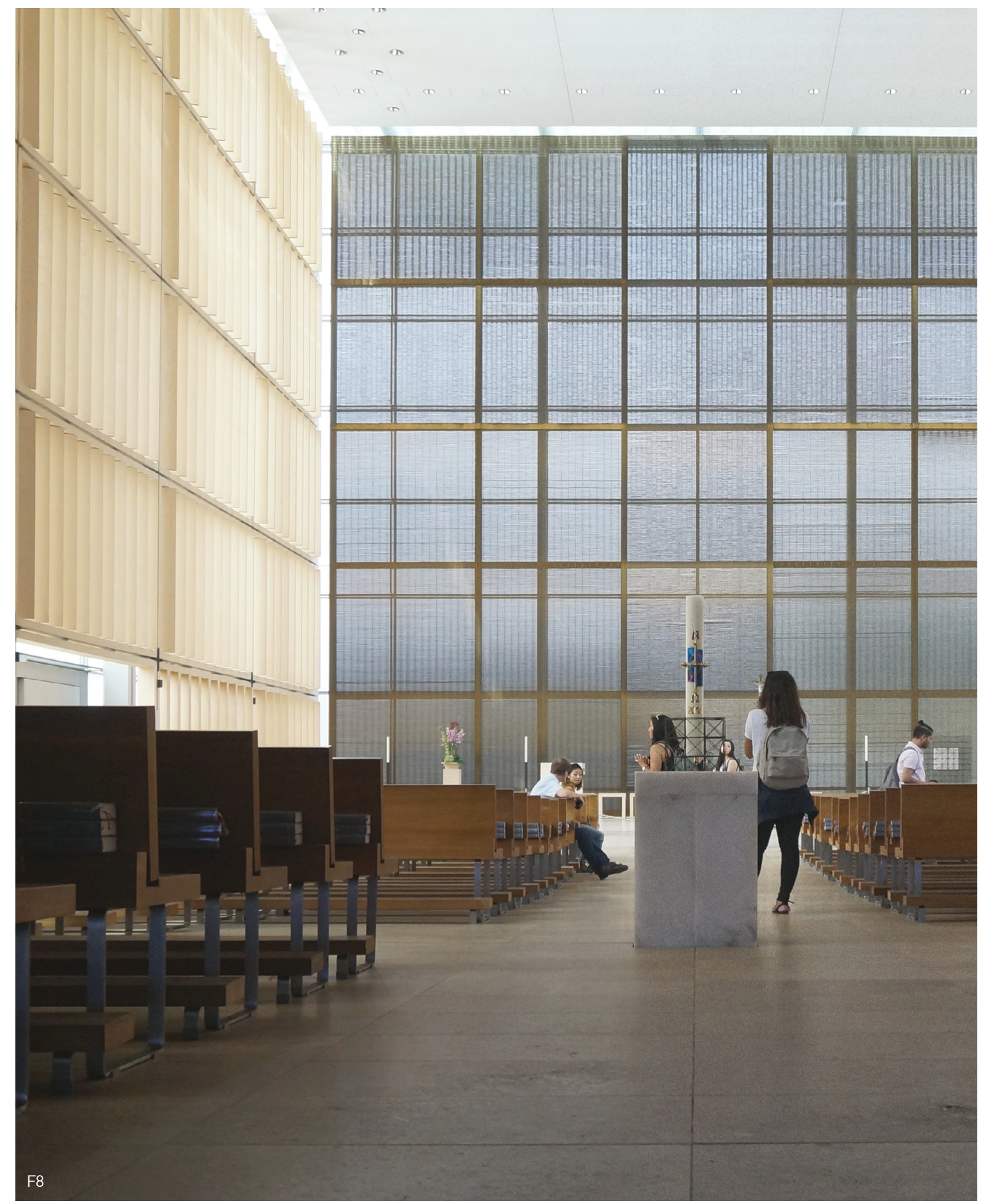




\section{ATMOSPHERE, ARCHITECTURE, BODY}

\subsection{What is Atmosphere?} 25 Mark Doty, Still Life with Oysters and Lemons, (Boston:
Beacon Press, 2001), 3-4.

26 Gabriele d'Annunzio, as quoted in Gaston Bachelard, The Poetics of Space, (New York: Penguin Books, 2014), 16.

27 Mark Wigley, "The Architecture of Atmosphere."

28 Jorge Borges, This Craft of Verse, ed. Mihailescu CalinAndrei, (Cambridge: Harvard University Press, 2000), 5.

Figure 8: Interior of Herz Jesu Church, Sumvitg, 2016
The poetic, intangible form, which seems to evade immediate definition or explanation constantly: atmosphere. It touches one subconsciously and consciously, both mind and body. The ever-changing form of atmosphere roots one in that place, exact that moment. When one feels their presence in a physical space, it is the experience which touches one's existential sense; it allows one to feel part of something larger. Atmosphere is that mode for this in architecture.

Atmosphere is that which seems to escape an instant definition or explanation. It is composed of both the visible and invisible, material and immaterial, tangible and intangible; consequently, it seems to evade description. The intriguing energy of atmospheres can be understood through Mark Doty's account of "Still Life with Oysters and Lemon":

"I have felt the energy and life of the painting's will; I have been held there, instructed. And the overall effect, the result of looking and looking into its brimming surface as long as I could look, is love, by which I mean a sense of tenderness toward experience, of being held within an intimacy with the things of the world." 25

Atmosphere is the poetic nature of the built form, the thing which grasps you both consciously and unconsciously; it is an experience which happens long before the soul takes notice, and when the consciousness realizes what the unconscious has already experienced, it is understood and enlightening. ${ }^{26}$ As Mark Wigley points out atmosphere "by definition, [...] lacks definition. It is precisely that which escapes analysis." ${ }^{27}$ It is a phenomenon, although seemingly undefined, which can be intuitively understood and identified, and oddly enough, “...can only truly know it when [one is] unable to define it..."28

This is the poetic masterpiece of atmosphere; that which is undeniably experienced, present, and all at the same time free from any definition which can fully capture it. However, one can say the following about atmospheres of architecture: it is something which one innately comprehends while at the same time has difficulty describing; it is composed of both tangible and intangible means; it is defined by that which 
29 Wolfgang Meisenheimer, "Von den Hohlräumen in der of the architectural body," Daidalos, September 1984: 103.

\subsection{The Bodily and Mindful Experience of Atmospheres}

30 Gernot Böhme, "Atmosphere as Mindful Physical Presence in Space," OASE: Architectural Journal, no. 91 (2013): 27.

31 Gernot Böhme et al., "Space, place, and Atmosphere: Peripheral Perception in Existential Experience," Architetcural Atmopsheres: On Experience and Politics of Architecture, (Basel: Birkhäuser Verlag $\mathrm{GmbH}, 2014), 22$.

32 Juhani Pallasmaa, "The Place of Man," Encounters: architectural essays, ed. Peter MacKeith, (Helsinki: it is comprised of; it seems to be produced by material and immaterial things; an amalgamation of intangible effects generated from sound, light, darkness, heat, smell, moisture, air, material, and place." [Atmosphere's] peculiar characteristic is precisely the fact that they close us in. Yet their reality, which is so very suggestive of a wholeness around our body, exists only in our imagination, for we see and hear only varying fragments of them and they are not in the least palpable..."29 The strength and energy of atmosphere are possible due to its ability to live as a concurrent body within life. It is a living thing among a world of living things. Its life is composed of its various characteristics.

The experience of architecture as consequence of the body's implied action with space is experienced both physically through the body and mentally through the consciousness, building one's world; this duality is necessary for the experience of purposeful atmospheres. However, there is a distinction between the bodily experience and the minds experience of space. Space itself gives a self-understanding to the body, returning the experience towards oneself, making the mind aware of one's body; the mindful physical presence is the interplay between the two. ${ }^{30}$ The place, the space, the moment, all come together and become a part of the experience for the body and the consciousness, where the atmosphere "emphasizes a sustained being in a situation, rather than a singular moment of perception." 31 This sustained experience is, in essence, the role of architecture. It is where an architectural space touches something deep inside of us, where it feels as though one is intensely listening to oneself in a sustained moment, where all the senses become engaged with the surrounding. This concept is one which is encapsulated by the German term Gesamterlebnis, loosely meaning the overall experience. ${ }^{32}$ 
However, the difference between a bodily experience and a mindful experience is the element of time. It is when space is experienced through our physical presence, when the space is felt physically through the body, where the experience of the mindful body occurs; the mindful body is that which allows the experiences to merge into one of presence. ${ }^{33}$
33 Gernot Böhme, Architektur und Atmosphäre, (Munchen: Wilhelm Fink Verlag. 2006), 88.

Figure 9: Diagramming Atmosphere's role in Architecture

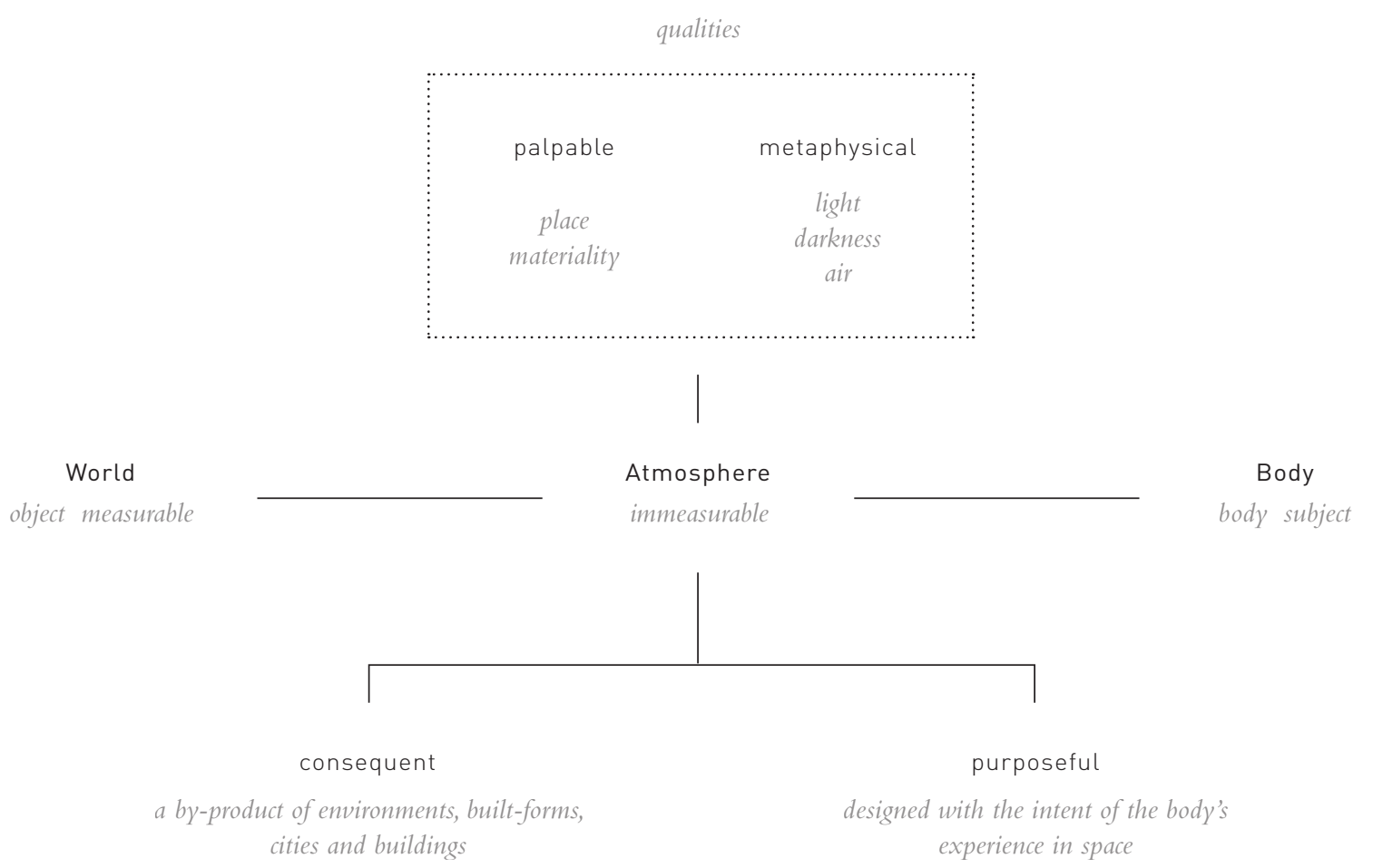




\subsubsection{The Profound Relations Between Body and Surrounding Space}

34 Dalibor Vesely, "The Architectonics of Embodiment," Body and Building: Essays on the Changing Relation of Body and Architecture, ed. George Dodds, \& Robert Tavernor, (London: The MIT Press, 2002), 29.

35 Gernot Böhme, Architektur und Atmosphäre, (Munchen: Wilhelm Fink Verlag, 2006), 88-89.

36 Böhme, 16-18.

37 Ibid, 16.

Figure 10: Feeling surrounding world in an unconventional manner
The human body has a variety of roles in day to day life. However, one of the most critical is the role of the body in "understanding reality is the relation between the body and that which truly exists...Thereafter, the body is used to designate not only conceptual but also material reality." ${ }^{34}$ The body is that which provides an understanding of the physical world to the mind; the physical space is neither the space the body occupies, or the volume the body takes. Physical space is a sphere for the body's sensuous presence which is constantly transcending the limits of the body. Böhme uses an example of a blind man, who scans the ground with a stick. When doing so, feels a pebble there, but does not experience it directly with the surface of his body. He feels it on the skin of his hand, from the stick which he holds touching the pebble on the surface of the ground. ${ }^{35}$ The same principle applies to architecture, as the most powerful experience is not necessarily that which physically touches, but one which is present and felt. 
Atmospheres are experienced when the body "[enters] into them and experiencing their character in the way that they modify our condition or seem to us at least." ${ }^{36}$ The atmosphere is felt and alters the way the body experiences the space itself. It is when the body allows itself to feel this condition that an atmosphere is felt in a new light; this leads to the minds experience of the atmosphere. It is in the space of physical presence, in corporal atmospheres, those surroundings modify one's feelings, altering their condition. ${ }^{37}$ When this altering occurs, the body acts as a link between the soul and the animated structures of reality as a whole. ${ }^{38}$ It connects the soul to the surrounding.

When the body creates a connection to an atmosphere, the body connects into a larger network of extended atmospheres. Atmospheres act as the landscapes of space which satisfy the unconscious desire for connection to one's environments; the architecture of atmospheric spaces creates the vital link between people and their surroundings. ${ }^{39}$ The impression of the atmospheres impact may seem local while at the same time somehow connecting to the whole world. Atmospheres have a series of associated relationships, where they connect to an increasingly extensive network of atmospheres, landscapes of them, where everything is related to each other in some way. ${ }^{40}$ It is a sense of being-inthe-world or the surrounding becoming the "inner space of the world", DerWeltinnenraum, experienced by the body and mind. ${ }^{41}$ It is the "...sense of being in the world, and in a specific place and moment, the actuality of existence, that is the essence of atmosphere." ${ }^{22}$ This changes the body's experience of space, of the architecture, to one of embodiment. "This is inevitable because the reality of the world is not structured around identifiable independent entities such as isolated human bodies or isolated architectural elements and their corresponding meanings. Rather, it is organized through degrees of embodiment, which represent a continuum of mediation between the human and divine, terrestrial and celestial, sensible and intelligible levels of reality." ${ }^{43}$ This profound feeling is instilled through atmospheric space, which comes into existence through the intersection and overlapping of its qualities, when the atmosphere has a natural presence, as though it is meant to be there, while also innately connecting with the body through perception. This experience is where one enters a "...mindful physical presence into which one enters or finds oneself, owing to the type of experience involved."44
38 Dalibor Vesely, "The Arc hitectonics of Embodiment," Body and Building: Essays on the Changing Relation of Body and Architecture. ed. George Dodds, \& Robert Tavernor, (London: The MIT Press, 2002), 31 .

39 Kengo Kuma, Natural Architecture, Trans. by Birnbaum, \& Alfred, IVol. 2. London: Architectural Association 2015), 14.

40 Katherine Benzel, "Spatia Relationships," The Room in Relationships," The Room in
Context:Design Beyond Boundaries, (New York: Toronto: 1998, 1998), 15.

41 Juhani Pallasmaa, "Lived Space," Encounters: architectural essays, ed. Peter MacKeith, (Helsinki: Rakennustieto Oy 2005), 128.

42 Gernot Böhme, "Encountering Atmosphere: A Reflection on the Concept of Atmosphere in the Concept of Atmosphere in
the Work of Juhani Pallasmaa
and Peter Zumthor," OASE: and Peter Zumthor," OASE: (2013): 99.

43 Dalibor Vesely, "The Architectonics of Embodiment," Body and Building: Essays on the Changing Relation of Body and Architecture, ed. George Dodds, \& Robert Tavernor, (London: The MIT Press, 2002), 32

44 Böhme, Gernot. "Atmosphere as Mindful Physical Presence in Space." OASE: Architectural Journal, no. 91 (2013): 27. 


\subsubsection{The Mindful Body}

45 Juhani Pallasmaa, "The Place of Man," Encounters:
architectural essays, ed. Peter MacKeith, (Helsinki:
Rakennustieto Oy, 2005), 75.
46 Juhani Pallasmaa, "Lived Space," Encounters:
architectural essays, ed. Peter MacKeith, (Helsinki:
Rakennustieto Oy, 2005), 129.
7 Gernot Böhme, Architektur und Atmosphäre, (Munchen:
Wilhelm Fink Verlag, 2006), 121-122.

48 Böhme, 52.

Figure 11: Tate Museum of Modern Art, London, 2016

49 Juhani Pallasmaa, The Eyes of the Skin: Architecture and the Senses, (London: John Wiley \& Sons Ltd., 2005), 52.

50 Gernot Böhme, "Atmosphere as Mindful Physical Presence in Space," OASE: Architectural Journal, no. 91
(2013): 27.

51 Juhani Pallasmaa, The Eyes of the Skin: Architecture and the Senses, (London: John Wiley \& Sons Ltd., 2005), 11.

52 Pallasmaa, 11.
In the experience of an environment, there is an unconscious identification between body and object, where the body projects itself into what is experienced. Every real place has a unique experience with the body, partly because it is unique, and partly due to its effect on the body, generating enough associations to hold it in our personal worlds. ${ }^{45}$ This place which the body has formed an identification with becomes lived space, in which the inner space of the mind and the outer space of the body fuse with one another; this forms the mindful experience of the world, ${ }^{46}$ and physical presence is the act of the mindful body. The experience of one's physical presence innate in this is, as the element of sensitivity, central to mindful physical presence. The central concept, from which the phenomenon of physical presence must be described, is the idea of mental condition. As such, both mind and physical space are connected through the body, through their physicality, their corporeality, and are, in a sense, one thing; in one's mind is where they feel the space which they are in. ${ }^{47}$ The mindful body disassociates itself with its problems, its thoughts, its outside life and brings focus to the present moment, essentially slowing to its dimensions in space. When the mindful body participates and envelopes itself in an atmosphere, it allows one to discover their corporeality as the medium of existence, ${ }^{48}$ becoming the corporal state.

As the body becomes the center of experience of atmospheric spaces, it creates a corporeal state, personal presence, one which opens to the idea that one is in the world, a part of it, and there is something in the world that is bigger than them. These feelings not only allow the space to be felt, but enable the user to self-reflect on how they are in fact feeling; "a powerful architectural experience silences all external noise; it focuses our attention on our very existence, and as with all art, it makes us aware of our fundamental solitude." 49 No matter the extent of the atmosphere, it unconsciously asserts a basic mood within one's mind, and although they are not necessarily aware it, it is of exceptional importance to the mindful body. "This is the reason the atmospheric effect of spaces needs to be taken seriously not only for special situations, be they of a touristic or festive nature, but also for the everyday world of work, transport and living." ${ }^{50}$ It directs one's consciousness back to the world, toward one's sense of self, strengthening an existential experience and one's sense of being in the world, ${ }^{51}$ acting as a gentle buffer between the fragility of life and the world. Architecture articulates this experience of being-in-the-world, of physical presence, and strengthens our sense of reality and self. ${ }^{52}$ 


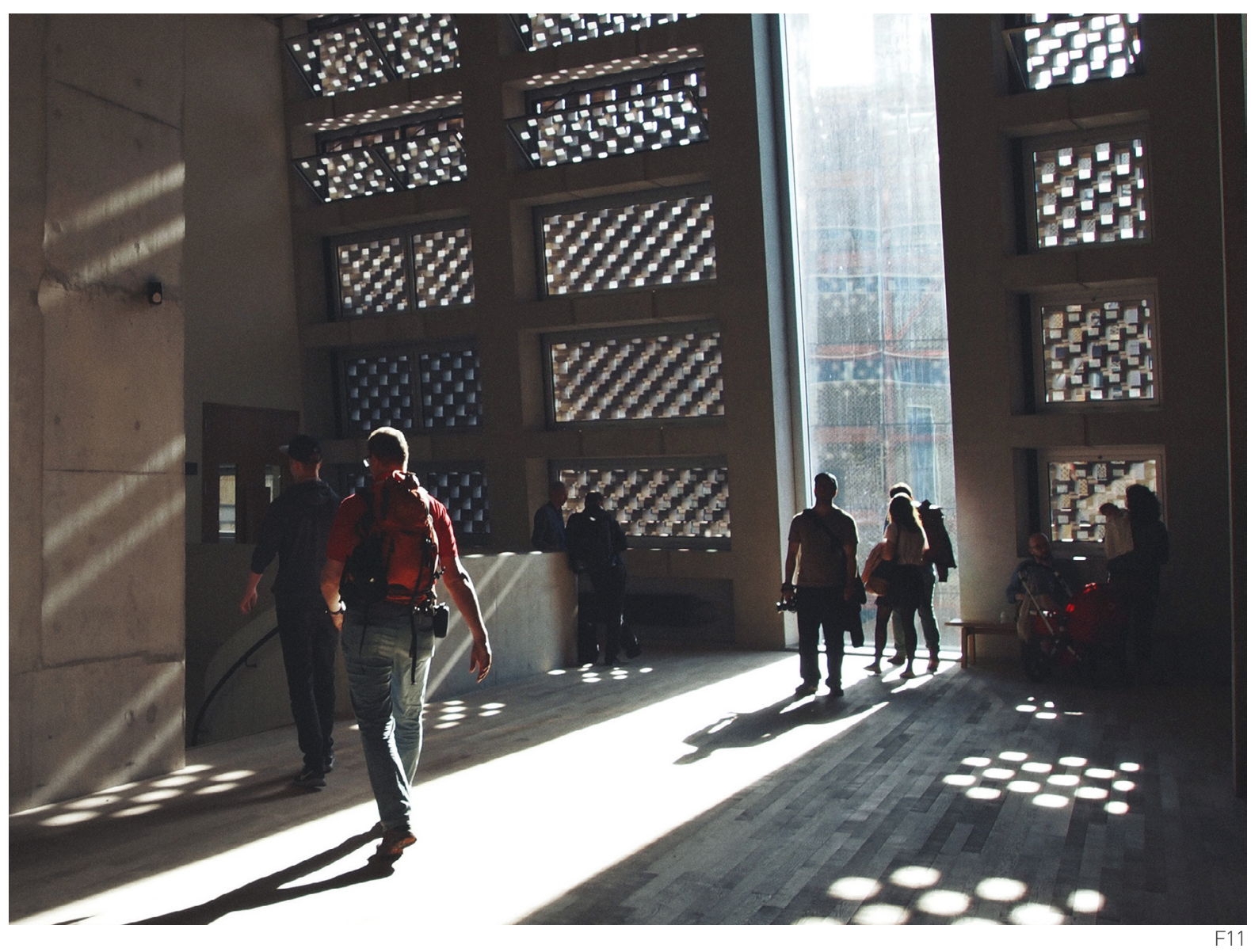


palpable

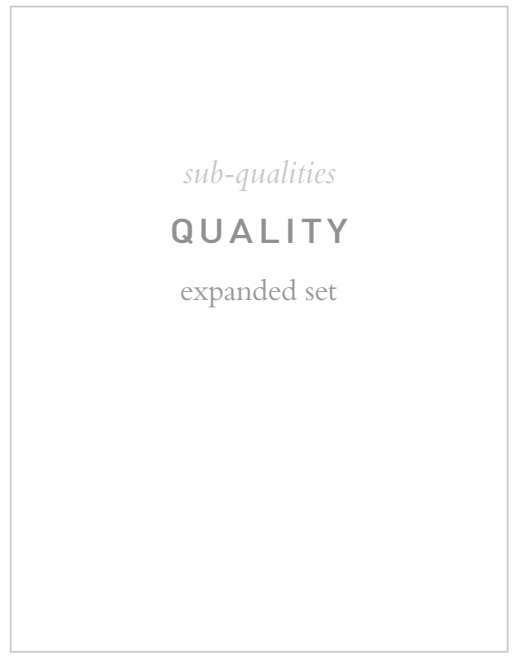

\subsection{Atmosphere Experienced and Described}

53 Gernot Böhme, Architektur und Atmosphäre, (Munchen: Wilhelm Fink Verlag, 2006), 49

54 David Foster Wallace, Infinite Jest: a novel, (New York: Back Bay Books, 2006), 5-6.

55 Gernot Böhme, "Atmosphere as Mindful Physical Presence in Space," OASE: Architectural Journal, no. 91 (2013): 27.

Figure 12: Diagram of atmospheric qualities and experienced qualities

56 Gernot Böhme et al., "Space, place, and Atmosphere: Peripheral Perception in Existential Experience," Architetcural Atmopsheres: On Experience and Politics of

57 Juhani Pallasmaa, The Eyes of the Skin: Architecture and the Senses, (London: John Wiley \& Sons Ltd., 2005), 46. atmosphäre
atmosphère
atmosfera
atmósfera

ATMOSPHERE

thick - thin deep - shallow light - heavy nature

sound

toned

density

\section{PLACE}

natural - artificial

dense - vast

busy - quiet

Atmospheres are imbued with characteristics from both the tangible and intangible realms; without both sets of characteristics, atmospheres would not be successful. The materiality of the wall, the soft lighting through the opening, the texture of the floor, the smell of the air present; smell, temperature, light, shadow, transparency, colour, texture, material, detail. Space speaks its own language, each with its uniqueness, and is interpreted through the body; atmospheres are areas of felt physical presence. These facets work together in creating atmosphere, becoming an articulated and specific, wordless, experience. However, the every0day language has its ways of describing atmospheres - the cool forest, the tense atmosphere of conversations, the cheerful atmosphere of spring or the exciting atmosphere of a particular decade. Atmospheres have their character, and they are commonly described by stating that character which is outlined as moods, movements, or qualities; they are articulated as a sense prevailing in a space, understood as a mood which exists in the air. ${ }^{53}$ These ways of describing atmospheres derive from the way they are innately and intrinsically experienced through the senses, and as such, are a personal experience. As expressed by David Foster Wallace in the Infinite Jest: 


\section{texture \\ tactility \\ tectonics \\ colour \\ $\operatorname{aging}$}

\section{MATERIALITY}

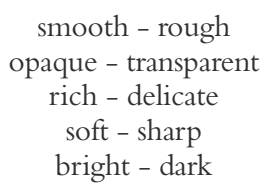

$$
\begin{aligned}
& \text { contrast } \\
& \text { visibility } \\
& \text { density }
\end{aligned}
$$

colour

\section{ILLUMINATION}
dim - bright diffused - direct harsh - soft full - dappling

\section{temperature \\ weather \\ humidity \\ smell \\ density}

\section{AIR}

dense - light

dry - humid

thick - thin

hazy - clear

metaphysical

"My silent response to the expectant silence begins to affect the air of the room, the bits of dust and sportcoatlint stirred around by the AC's vents, dancing jaggedly in the slanted plane of windowlight, the air over the table like the sparkling space just above a fresh-poured seltzer." ${ }^{54}$

Wallace describes the atmosphere of space based on his personal world, in a way of his bodily experience of it. One may find it hard to grasp what atmosphere is, but as mentioned, they are typically associated with a set of descriptive words as moods, feelings, or sensations, just as seen with Wallace's description. This is because the atmosphere is understood through their personal perception of the physical environment; thus, it is vital to comprehend the things which define one's personal world, which happen to be those that define the experienced world. The bodily connection to space constantly brings forth its own sense, which shapes the condition of the experience. ${ }^{55} \mathrm{It}$ is the synthesis of the material and immaterial qualities of atmosphere, the body and mind which inform the phenomena of the complex experience.

The experience of atmosphere is one which is multi-sensory in its very essence, but it also involves senses beyond the five Aristotelian senses; these include senses of orientation, gravity, balance, stability, motion, duration, continuity, scale, and illumination. ${ }^{56}$ Alongside the subject matter of the perception, the way it is perceived it is also of utmost importance; just as "foggy landscapes give rise to an unfocused way of looking, evoking a trance-like, meditative state", ${ }^{57}$ focused and unfocused vision enhances the experience of space's purposeful atmosphere. "The very essence of the lived experience is moulded by hapticity and peripheral unfocused vision. 
Focused vision confronts us with the world whereas peripheral vision envelopes us in the flesh of the world. Alongside the critique of the hegemony of vision, we need to consider the very essence of sight itself." ${ }^{58}$ Thus, the immediate response is one which calls upon a completely embodied and existential sense, perceived in a diffused and peripheral manner rather than an exact, precise and conscious observation.

Even in the thoughtful application of the above principles, it must be recognized that atmospheres are always a subjective experience on an individual's perspective of how they see themselves and the world around them. How one experiences their personal corporeality, as well as the moment of the state of mind, are central to the experience of corporeal atmospheres. This desire to feed one's corporeal presence is also feeding into their vitality, the quality of their life. As follows, architecture can continue to provide an opportunity to experience the atmosphere to be present, but this cannot be a prescribed experience. ${ }^{59}$ One will identify with space, the place, the moment, and combine to form the basis of one's existence. Architecture, then, becomes "the art of reconciliation between ourselves and the world, and this mediation takes place through the senses" ${ }^{\circ 0}$, defined by the body, defining the minds experience of the space.
58 Pallasmaa, 10.

59 Gernot Böhme, Architektur und Atmosphäre, (Munchen: Wilhelm Fink Verlag, 2006), 125.

60 Juhani Pallasmaa, The Eyes of the Skin: Architecture and the Senses, (London: John Wiley \& Sons Ltd., 2005), 72 


\subsection{Unfolding Sustained and Temporal Experience}

61 John Lobell, Between silence and light: spirit in the architecture of Louis T. Kahn, (Boston: Shambhala
Publications, Inc., 1979), 3.
Atmosphere's strength is that it can not be broken down into certain elements or separated pieces, it exists as a coherent whole. It can create the profound relationships with people; it can live with inhabitants, having a seemingly natural presence. It is only when architecture is developed as the meeting of the measurable and immeasurable that purposeful atmospheres can exist. ${ }^{61}$ An atmosphere can change and alter as it is experienced, as a multi-layered thing which unveils itself. It is complex with layers which continually alter and change, and as one's body moves through, by means of movement of time, the experience of the atmosphere unfolds, opening itself up to be experienced. Therefore, this body of work will focus on both the immeasurable and measurable attributes of atmosphere in the creation of purposeful atmospheres: lightness and darkness, materiality and tectonics, place, and the air of space.

The qualities of atmospheres, although necessary in the creation of specific atmospheres, have their own characteristics to describe their spirit or energy; each have their own specific features, effects, and states which add to the overall creation of an atmosphere. The main qualities can each fit within the sustained or temporal aspects of the space. The palpable aspects of space refer to those who are affected by time within the space, permanently or temporarily changing the experience of it. The place is ever-changing; it ages, trees grow, rivers expand, landscapes change. These aspects also change seasonally throughout the year, altering the atmosphere of the place. Materials are also closely linked with temporality, as the materials age over time; the embedded life within materials continues past the point where they are used in the construction of something. The metaphysical aspects of space are those which are intangible, yet intensely add to the spirit and experience of space. These include the light, darkness, and the air of space. 


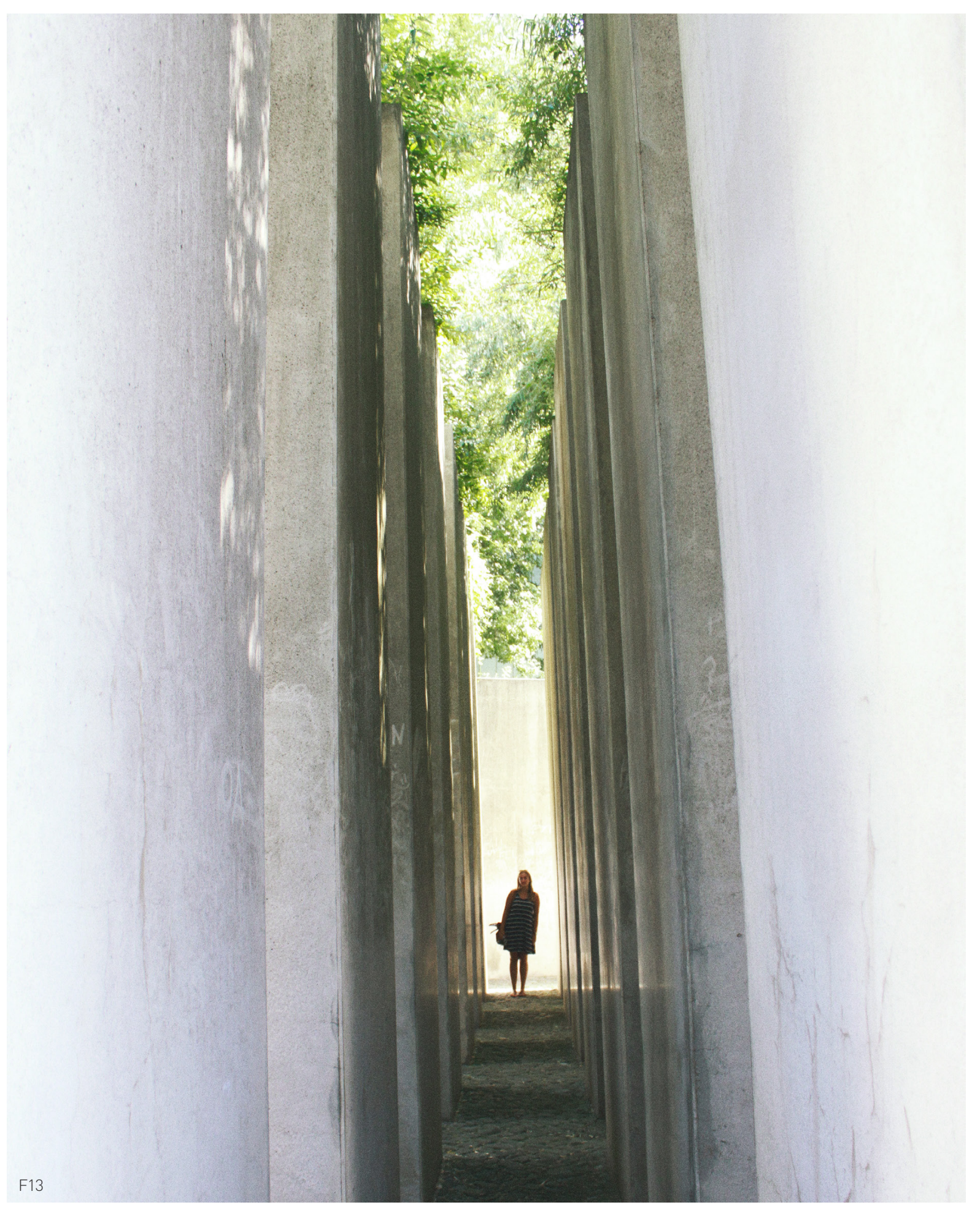




\section{ATMOSPHERIC QUALITIES}

\subsection{On the Transience of Atmosphere}

62 Bertrand Russell, Routledge Classics: History of Western Philosophy, (London: Routledge, 2004), 52.

63 Juhani Pallasmaa, The Eyes of the Skin: Architecture and the Senses, (London: John Wiley \& Sons Ltd., 2005), 12.

Figure 13: The Garden of Exile and Emigration at the Jüdisches Museum Berlin, Berlin, 2016
It is made of many layers, overlapping and working with one another to create what is perceived. Some are more obvious, while others invisible, unseen, but felt. Atmosphere maintains its ability to take palpable and metaphysical elements and merge them together to create an intangible form which touches the body. Place, materiality, lightness and darkness, air, all come together in this subjective experience. It is born from uncertainties, embodied experiences, and sensitivities.

The term 'all things are flowing' was articulated by the Greek philosopher Heraclitus. Everything in the world is in constant state of flux, ever changing with time; this includes atmospheres. This sentiment comes from the philosopher's observation that "you cannot step twice into the same river, for fresh waters are ever flowing in [and] upon you." ${ }^{2}$ The atmospheres which define spaces are the same of that of the river. An atmosphere does not have anything which remains constant. In essence, it is the same thing one moment to the next, the same qualities, the same relative feeling, but the nature of atmospheres is temporal, with all of its qualities and elements which create it altering at every moment. They are things which live, develop, and grow over time and through the seasons of the year. It is similar to the experience of the environment, which is always transient, always unique, and cannot be defined as a singular moment of experience of expression. "An architectural work is not experienced as a series of isolated retinal pictures, but in its fully integrated material, embodied and spiritual essence."63

Material weathering and aging, varying humidity levels, lighting conditions; each quality independent of one another, changing at a different rate. Some changes daily, by season, by the weather, but they all have one thing in common; for example, it is interesting to note the effect of the rapid seasonal change in relation to the effect of the weathering of materials. The various elements have their temporal cycles which come together in the creation of the overall experience. This temporal aspect of the atmosphere, maintaining this living quality, generates a greater relationship between building and being; it becomes something which two living things interact; it becomes mindful and embodied; it is alive yet ageless; the atmosphere becomes the life which body and building live together. 


\subsection{Hierarchical and Simultaneous Perception}

64 Klaske Havik and Gus Tielens, "Concentrated Confidence: A Visit to Peter Zutnthor." OASE: Architectural Journal, no. 91 (2013): $71-73$.

65 Maurice Merleau-Ponty in Juhani Pallasmaa, "Hapticity and Time: Notes on a Fragile Architecture," The Architectural Review, May 2000: 78

Figure 14: Analyzing the zones of focused and peripheral perception between two buildings on a street in Haldenstein, Switzerland.

66 Gus Tielens and Klaske Havik, "Atmosphere, Compassion and Embodied Experience: A Conversation about Atmospheere with Juhani Pallasmaa," OASE Architectural Journal 91 (2013): 45.

67 Gernot Böhme et al., "Space, place, and Atmosphere: Peripheral Perception in Existential Experience," Architetcural Atmopsheres: On Experience and Politics of Architecture, (Basel: Birkhäuser Verlag GmbH, 2014), 38.

68 Gus Tielens and Klaske Havik, "Atmosphere, Compassion and Embodied Experience: A Conversation about Atmospheere with Juhani Pallasmaa," OASE: Architectural Journal 91 (2013): 41

69 Gernot Böhme et al., "Space, place, and Atmosphere: Peripheral Perception in Existential Experience," Architetcural Atmopsheres: On Experience and Politics of Architecture, (Basel: Birkhäuser Verlag GmbH, 2014), 38-39.

70 Gernot Böhme, Architektur und Atmosphäre, (Munchen: Wilhelm Fink Verlag, 2006), 124.
Atmospheres are constructed from many different elements which come together - materiality, texture, sound, temperature, light, darkness, humidity, nature, smell all separate things simultaneously working together in generating the atmosphere and its continuously varying experience. However, this does not mean that one experiences all of these elements separately. The very experience of atmosphere lies in the simultaneity of all these aspects, their qualities and experiences, coming together in the atmospheres formation. ${ }^{64}$ The atmosphere is experienced as the whole entity down to its details as an immediate experience of the whole, the entity, where one cannot distinguish the details or aspects which are a part of it. Thus, atmospheres are experienced as a complex multi-sensory fusion which is immediately grasped as a feeling, mood, or experience, maintaining the role of the body as the locus of perception. One's perception is not a sum of the visual, tactile, and audible, but as a totality where the body and atmosphere speak to each other through all of the senses. ${ }^{65}$ This makes atmospheres, and architecture, an embodied experience and, by definition, multi-sensory, integrated and haptic; in a way, atmospheres are experiences through, and as part of ones' sense of existence, ones' existential sense. ${ }^{66}$

Defined by the nature of the experience as centered on one's existential experience, the experience of atmospheres is understood as more of an internalized experience rather than solely a visual one. As such, "the all-encompassing and instantaneous perception of atmospheres calls for a specific manner of perception - unconscious and unfocused peripheral perception." ${ }^{67}$ This mode of perception allows the body to participate in the space, lending to bodily involvement, for when something is in focus or becomes conscious, one becomes an outsider to it, prohibiting the body's participation and lose the atmospheres power. ${ }^{68}$ The unfocused perception is the way atmospheres are grasped by the body, allowing other non-visual sense to be included in the encompassing experience - this is also why focused images of space can be so misleading on the reality of the experience. ${ }^{69}$

The qualities which construct atmospheres are not perceived in the same manner, as the body perceives these qualities in a sort of hierarchical method, where some have a greater impact on the atmosphere than others. For instance, the lighting in a space 
could be so powerful that it captures the attention of the body, but what is not recognized immediately is all of the other aspects creating that atmosphere which aid in the powerful experience of the light.The darkness of this space may have the second greatest impact of lights affect, along with all other contributing qualities. These qualities also begin to take on other types of sensibilities, for instance, this is where synaesthesia can also occur. Synaesthesia is understood as qualities which belong to several senses at the same time, such that a sharp tone, a cold blue, a warm light exist. However, the reason for this is that they are actual experiences of bodily feeling and can therefore only be distributed to ambiguous areas in an ambivalent way. ${ }^{70}$

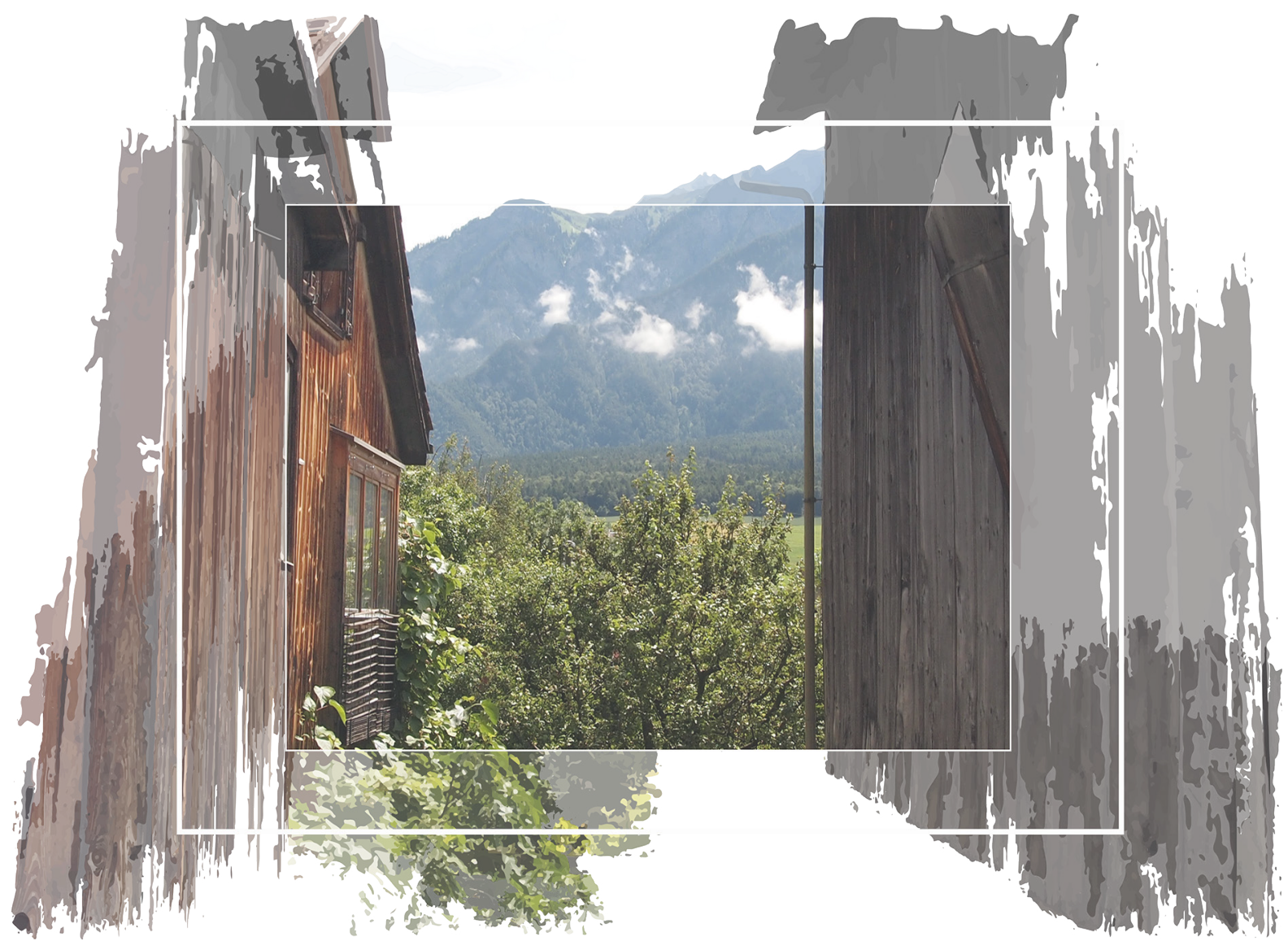




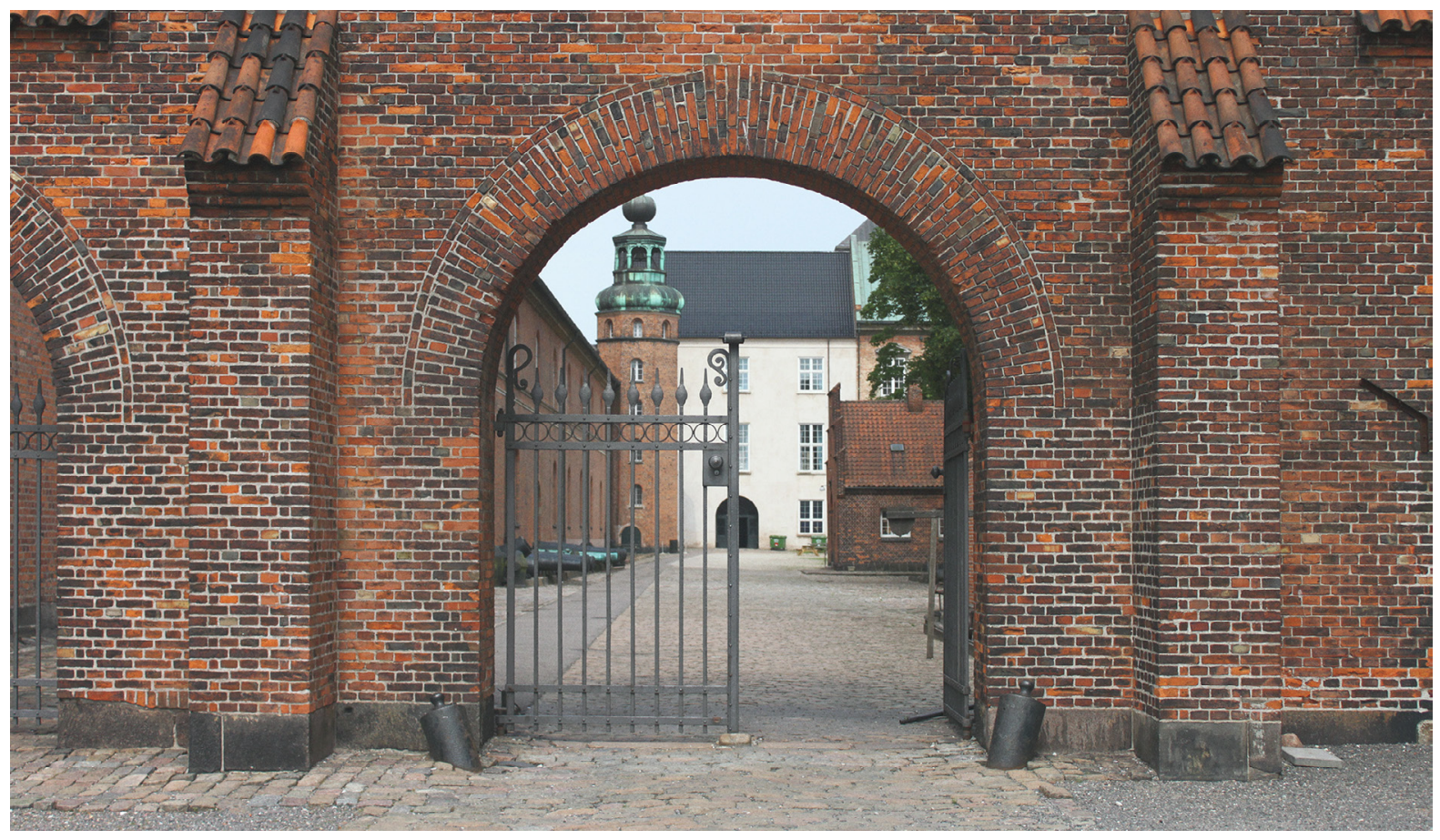

F15 
04.3 Palpable Qualities

Figure 15: Brick wall of Copenhagen, 2016
In the construction of atmospheres, one can note the qualities within it which are physically present; these are recognized by the palpable elements of atmosphere. These qualities in themselves do not generate the atmosphere, but it is their sensation which lends themselves to the sensory experience of the atmospheres, allowing the body to experience the atmosphere physically. The palpable qualities act as something physical for the body to relate to, to be able to physically touch and form the boundaries which inform the atmospheres, in other words, create the architecture. The boundaries, thresholds and physically defining elements maintain an important position in the corporeality of the atmosphere as they extend into the language of which they can be described and embedded in a bodily. 
04.3.1 On the Surrounding of Space and the Sense of Place

71 Gernot Böhme, "Atmosphere as Mindful Physical Presence in Space," OASE: Architectural Journal, no. 91

72 Peter Zumthor, Thinking Architecture (Basel: Birkhäuser 2006), 17.

Figure 16: Saint Benedict Chapel from the street below in the small municipality of Sumvitg, 2016

73 Juhani Pallasmaa, "The Geometry of Feeling: A Look at the Phenomenology of Architecture," Theorizing a New Agenda for Architecture, ed. Kate Nesbitt, (New York: Princeton Architectural Press, 1996) 452.

74 Juhani Pallasmaa, "Orchestrating Architecture: Atmosphere in Frank Lloyd Wright's Buildings," OASE: Architectural Journal, no. 91 (2013): 55

75 Kengo Kuma, Natural Architecture, Trans. by Birnbaum, \& Alfred, (Vol. 2. London: Architectural Association, 2015)',

76 Wolfgang Meisenheimer, "Von den Hohlräumen in der Shale des Baukörpers = Of the hollow spaces in the skin of
Space is the inhabited medium which is continuous around the world. Aristotle defined space as topos, which was defined as the inner surface of the surrounding body; "space in this sense is mainly delimited, something in which something else is located, the place." 71 The place is defined in relation to the body existing within it. Thus, the place has a great importance in constructing an atmosphere of a space, each with its unique presence; they have their sense of place about them, and as such the surrounding has a constant, unique, effect on the body. As Peter Zumthor puts so eloquently;

"The presence of certain buildings has something secret about it. They seem to be there. We do not pay any special attention to them. And yet it is virtually impossible to imagine the place where they stand without them. These buildings appear to be anchored firmly in the ground. They give the impression of being a self-evident part of their surroundings..." 72

The architecture produced with purposeful atmosphere seems to be a part of the essence of the place as if it has always been there; but at the same time, this one space speaks to the world as a whole. Its unique presence becomes a part of some intense experience, which somehow has the impression of something scared. ${ }^{73}$ It is a feeling, a quality, which can only be circled in with words to reach a nearness close to the experience, similar to that of the experience previously discussed within nature. This architecture seems to arise from the landscape while giving the surrounding a new meaning and understanding. ${ }^{74}$

Similar to this is the design of Japanese gardens which evolve from drawing a kekkai between the natural and the devised; kekkai, Buddhist in origin, refers to a spiritual or magical force field. ${ }^{75}$ The gardens draw from the physical surrounding to create a new atmosphere, having the atmosphere of the surrounding imbued within it. The essence of the place is imbued into an atmospheric space; this phenomenon exists because the place has a resultant atmosphere on its own. It has already identified itself with the surrounding, the pre-given topography of the surrounding, weather, lighting, the air. The place has a continuous flow of atmosphere, where "artefacts, mountains, trees, and rivers, as well as houses, vehicles, and streets, appear to be placed" as part of it. ${ }^{76}$ Space 


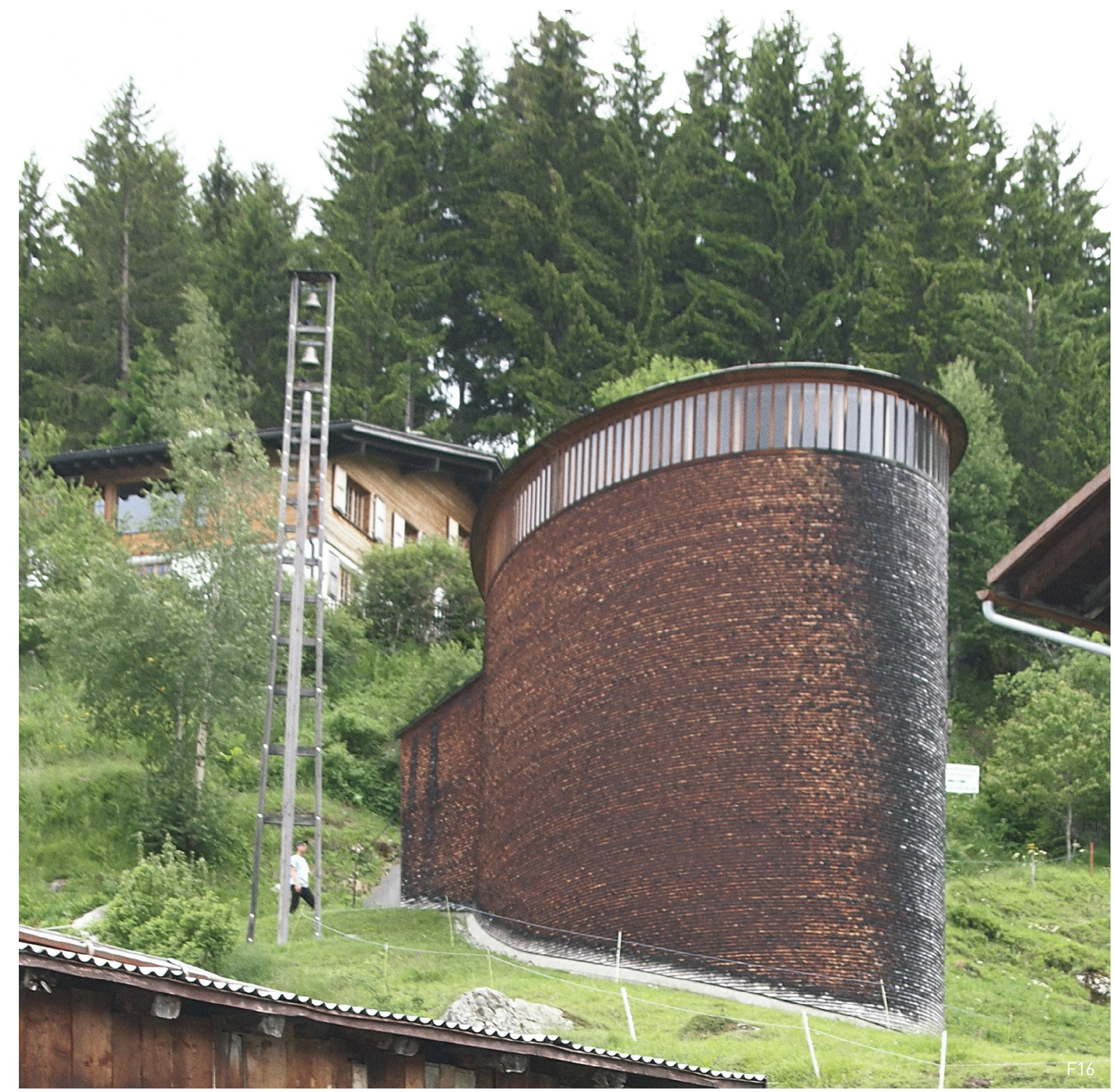


77 Mark Wigley, "The Architecture of Atmosphere." Daidalos, 1998: 24

78 Wolfgang Meisenheimer, "Von den Hohlräumen in der Shale des Baukörpers = Of the hollow spaces in the skin of the architectural body," Daidalos, September 1984:103.
Figure 17: Architecture and Surrounding relationship

a. Interior view, 2016 b. Saint Benedict Chapel overlooking the valley, Sumvitg, 2016 c. Street in Haldenstein, 2016
79 Dalibor Vesely, "The Architectonics of Embodiment," Body and Building: Essays on the Changing Relation of Body and Architecture, ed. George Dodds, \& Robert Tavernor, (London:
The MIT Press, 2002) 32

80 Juhani Pallasmaa, "Hapticity and Time: Notes on a Fragile Architecture," The Architectural Review, May 2000: 84. which is built within the place is thus penetrated and filled with the atmospheric setting and effects of the surrounding. "Since the physical context has its ambiance, the building is a kind of device for producing a special atmosphere within another one. [...] Architecture is to be found in the relationship between atmospheres, the play between micro-climates. The meeting of these seemingly ephemeral atmospheres can be as solid as any building." 77 It is a natural occurrence for the surrounding to affect the atmosphere of architecture, where it feels appropriate and incorporated in its surrounding.

Even if the surrounding cannot be seen or visually experienced while in a boundary, the idea of the surrounding is embedded within the experience as a subconscious background; one which cannot be seen. The surrounding leaves an impression on the body, thus on the experience. As Wolfgang Meisenheimer states, "the surrounding space, which is perceived from the interior of the building as the "space outside", is experienced outside as a continuous spatial area rather, into which the buildings themselves appear to have been set." ${ }^{, 78}$ The body is always engaged with the place within the network of spaces, undifferentiated and included within the environment. Aristotle explains, "If a thing [body] is not separated from its embracing environment, but is undifferentiated from it, it is indeed 'included in' it - not however as in its place, but only in the sense in which a part is said to be 'included in' its whole."79 This essence also exhibited in vernacular architecture, where everything which exists seems to exist from its direct surrounding as a by-product of it. This nature of a pleasurable experience vernacular settings "... arises from a relaxed sense of appropriateness, causality and contextuality rather than any deliberate aspiration for preconceived beauty..." 80 

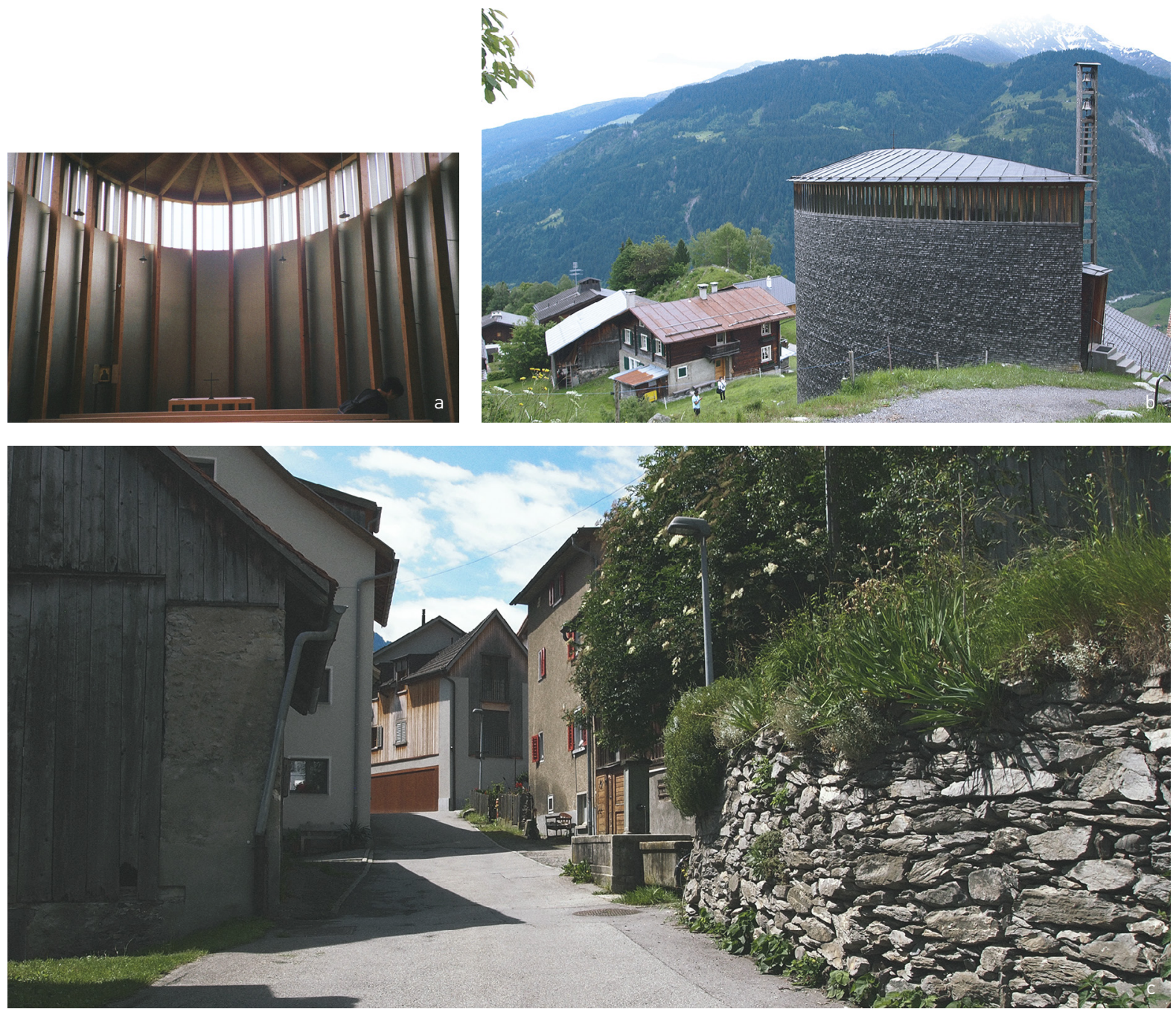

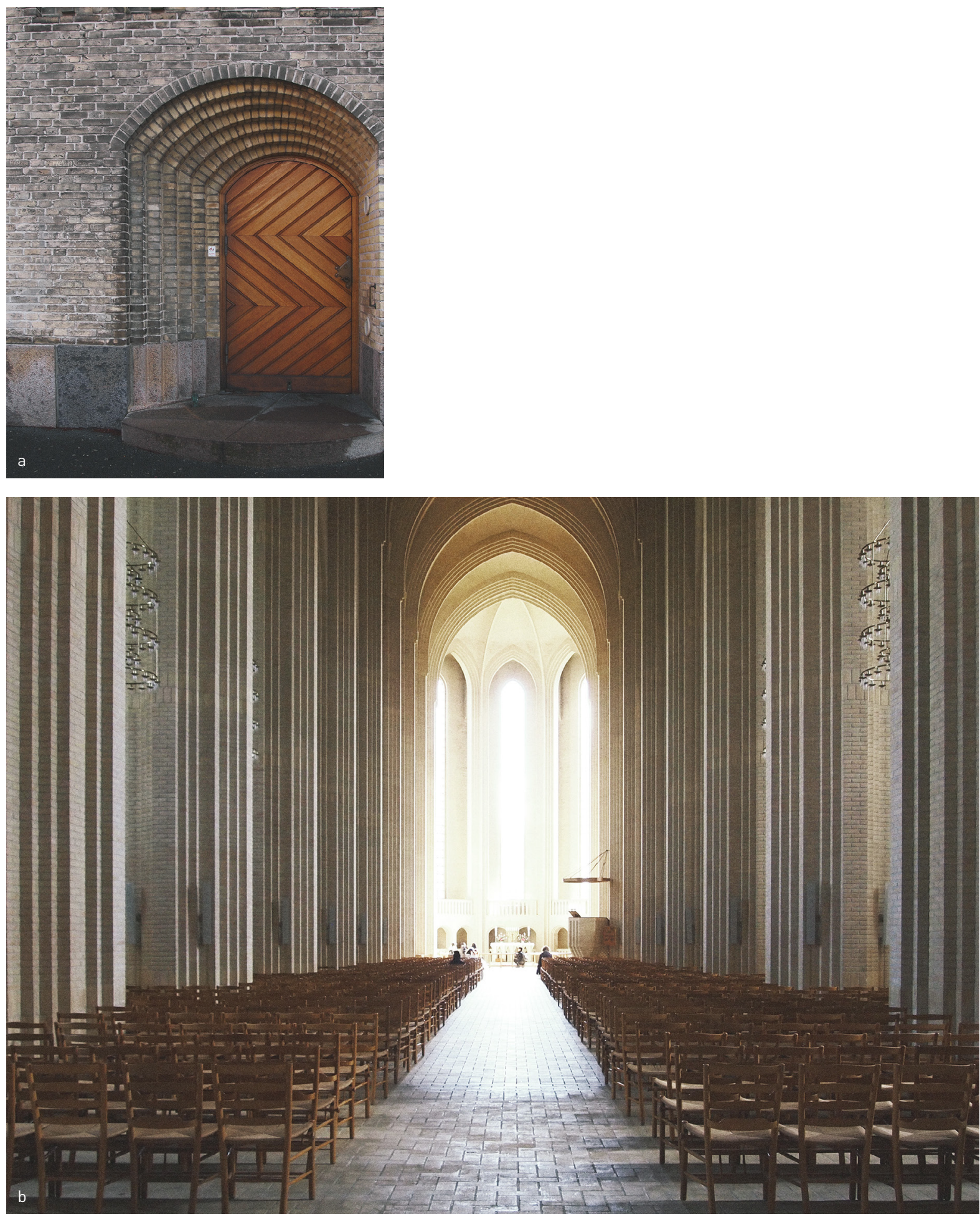


\subsubsection{On Materiality and Tectonic Experience}

81 Jonathan Hill, Immaterial Architecture, (Oxon: Routledge, 2006), 160.

82 Kengo Kuma, Natural Architecture, Trans. by Birnbaum, \& Alfred, (Vol. 2. London: Architectural Association, 2015),

Figure 18: Grundtvig's Church, Copenhagen, 2016

a. Entrance Door b. Interior View
Materiality within a designed architectural space is something which is typically, and exclusively, understood as a visual position, excluding it from human experience; however, there are many facets which materiality bring to the experience of space. Even though many choose materials based off of its appearance or cost effectiveness, a material can be understood through all the senses and have a much greater impact than simply a visual one. Materials add a richness to space, a depth which speaks to so many of the senses all at once; it brings colour to space, texture, an implied temperature and mood, and a sense of tactility. It allows the body to physically place itself within the space, associate itself with something physical.

One must consider how a material has come into existence, just as the atmosphere has; it has an embedded life associated with it. Take a piece of wood for example. That material has not magically come into being but sprouted; it grew in a certain place, it has documented its life through its associated grain, its colouring has developed and grown through the energy which is obtained from the solar and water systems. It itself is the embedded energy and life of the planet. The embedded life of material does not stop when it is constructed into an atmosphere; the extended life of material must also be considered. The effect of the natural and temporal forces on a material adds to the atmosphere, orienting one's understanding of the built form beyond the idealized state; rather it extends one's understanding of the atmosphere into a transient state of living. ${ }^{81}$

The subtle change in the use of how materials are used can largely impact the way the atmosphere is perceived. ${ }^{82}$ This begins to touch on the detailing, the finish, the tactility of the material - how does the light affect it? Does it absorb water? Will it be porous? The way a material is used will change not only how it adds to the atmosphere but also changes how other aspects of the atmosphere will come to life. This is mainly because the material will uniquely interact with the body. Grundtvig's Church, located in Copenhagen, through the majority of the building uses a pale-coloured brick. The incredible part of how the atmosphere within that space takes on a feeling of lightness - one of uplifting, soft, delicate while being constructed of heavy bricks. 


\subsection{Metaphysical Qualities}

83 Gabriele d'Annunzio, as quoted in Gaston Bachelard, The Poetics of Space, (New York: Penguin Books, 2014), 16.

\subsubsection{On Lightness and Darkness}

Figure 19: Analyzing the light and darkness of Shalekhet - Fallen Leaves, Jewish Museum Berlin, Berlin, 2016

a. Perceived space b. Light and darkness broken down into greyscales c. Light and dark emphasized

84 Katherine Benzel, "Spatial Relationships," The room in context: design beyond boundaries, (New York; Toronto: 1998,
Alongside the palpable qualities of atmospheres are qualities which cannot necessarily be defined as physical, but are present and felt in some way; they are understood as the metaphysical elements of atmosphere. These qualities are associated with the invisible, even though light can be seen, these qualities can be experienced without the visual support as they actively touch the skin. ${ }^{83}$ The creation of atmospheres is reliant on both the palpable and metaphysical qualities of atmosphere; the metaphysical carry immense importance, as they directly speak to all of the senses, but highly regarding the non-visual senses, creating a rich and encompassing experience.

Natural lighting innately acts as an orchestrator of space with the ability to intangibly enhance physical characteristics. This is evident in both natural and man-made settings, as lighting enhances an experience given its capacity to make visible the physical realm. Take for example lighting within a hiking trail; light shines through trees ahead, piercing the eye and giving a soft illumination to other trunks, while a speckled dappling of light moves through the dense forest behind. Lighting also gives rise to the darkness and depths of shadows because of the undeniable connection between the two; one can say even when there is no light, there is light through the darkness. The asymmetry between light and darkness exists in how they are perceived. The duality of the two act as a pair of contrasts which work in tandem to give a mutual understanding of one another, while summoning a clearer reading of one another.

The range between the lightness and the darkness defines the chiaroscuro of the space, together completing a whole, where differences are seen as perfection and beauty, and the "...light adds to the pleasure of dark." 84 The appearance of things in the light is a hysteresis from the darkness, when not fully eradicated the interplay with darkness gives things in light contour, depth, and definition. ${ }^{85}$ The greater the range between 
the two adds to the reading of the space, allows the body to interpret a multiplicity of lighting experiences; it permits the intangibility of light to become tangible by the more material matter it touches in space. Light spans a space and becomes an issue of experienced space. The body interprets the light of day and night, constantly experiencing light throughout the day like an endless loop; an array of light and shadow patterns surround spaces, each changing to capture the intensity of the natural light and create a new experience. ${ }^{86}$ The body experiences the physicality of the room through the light. This array of lighting experiences diminishes the homogeneous lighting within a space, which cripples the whole bodily experience.
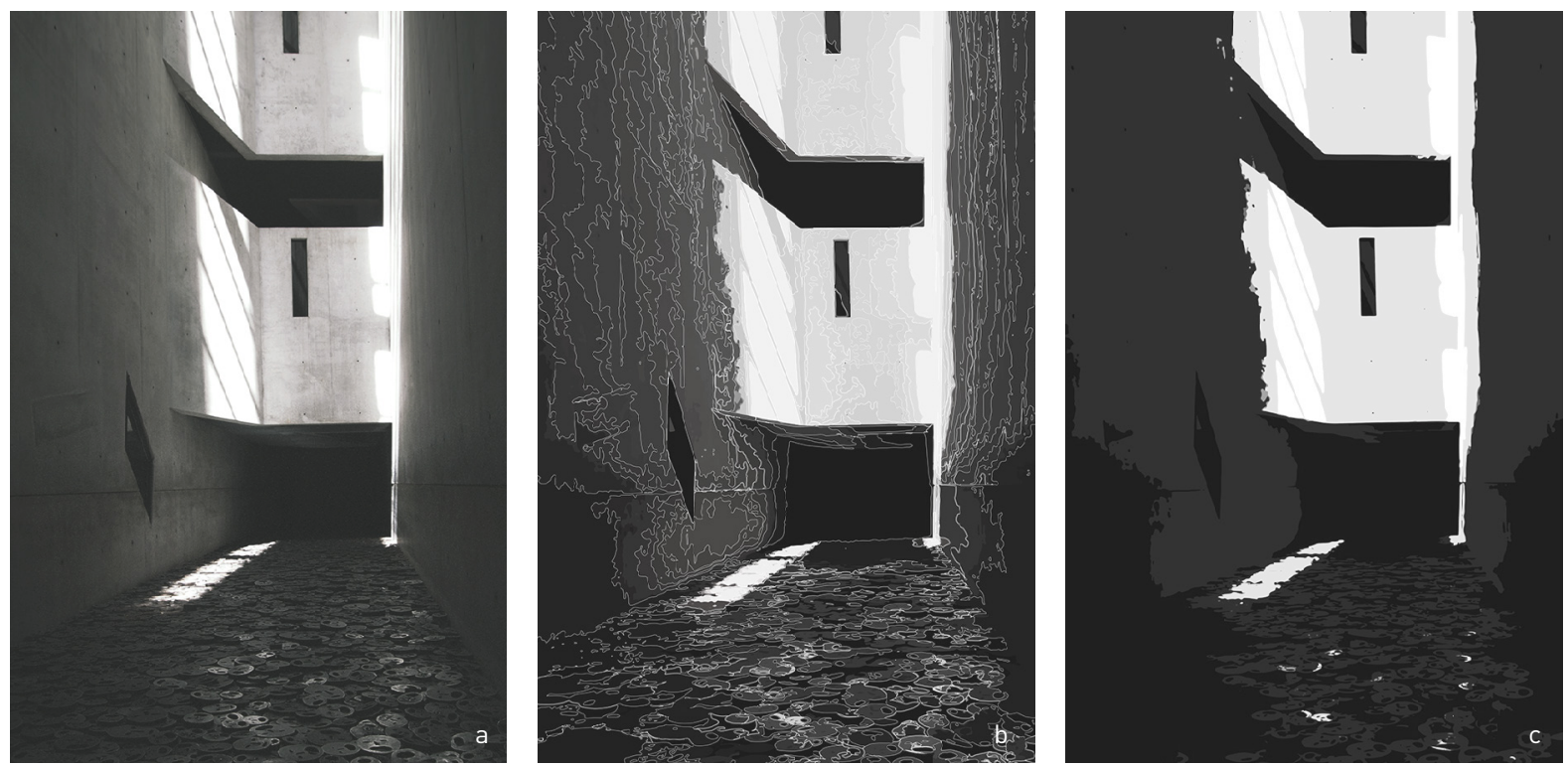

85 Gernot Böhme, Architektur und Atmosphäre, (Munchen: Wilhelm Fink Verlag, 2006), 102.

86 Amanda Aizpuriete, et al, Poetische Landschaft. II. Druck. Faltbuch - zur poetischen Landschaft, ed. Brigitte Labs-Ehlert, Lippe, 1999], 19 \& Peter Zumthor, (Detmold: Literaturbüro Ostwestfalen- 
Figure 20: Tate Museum of Modern Art Extension, London, 2016

87 Juhani Pallasmaa, The Eyes of the Skin: Architecture and the Senses, (London: John Wiley \& Sons Ltd., 2005), 46.

88 Steven Holl, Juhani Pallasmaa, and Alberto Pérez Gómez, Questions of perception: Phenomenology of architecture, (San Francisco: William Stout Publishers,

2006), 34.
Light and darkness are essential to each other within atmospheric spaces, as they create ranges of lighting experiences, adding to the ambiguous and unconscious understanding of space, past the visual perception of it. ${ }^{87}$ Light is a condition which allows one to see; darkness intersects the condition of light, so visual perception has a limitation, greater articulation, allowing other means of perception to aid the experience. As such, deep shadows and darkness become essential to the experience, as they dim the sharpness of visual perception and allow the unconscious, peripheral vision to come forward, lending to a greater experience of the place. ${ }^{88}$ Light as atmosphere then becomes a sort of generator, a quality which is touched, seized and understood in a certain way. Light allows visual perception to exist in the human experience, acting as a means of participation in the world by seeing things in certain ways.

An image of a landscape in itself could be thought of as a physical structure of space, having its own characteristics and visual attributes; however, there is something intangible, namely the air of the place, which belongs to it. Several of the non-visual aspects of atmosphere can be categorized into the air of the space, many of which are associated with the physical place. The subtle movements, temperature, humidity of the air all seem to be captured; all of these attributes of air add drastically to the body's experience of a place, of an atmosphere. These experienced qualities of humidity, temperature and moisture, act as synesthetic qualities, which are the by-product of the 


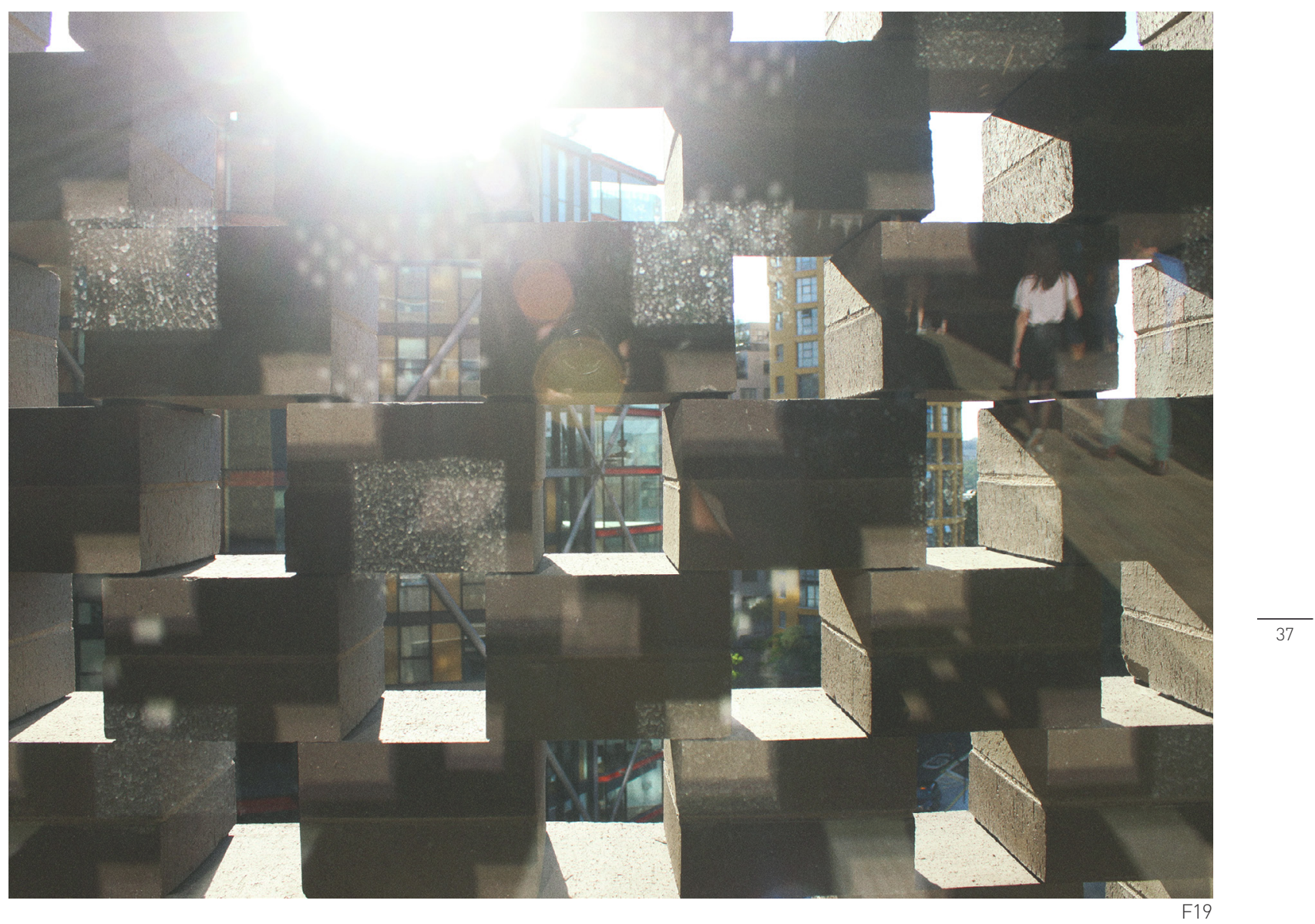


89 Juhani Pallasmaa, The Eyes of the Skin: Architecture and the Senses, (London: John Wiley \& Sons Ltd.,
2005), 64.

90 Gernot Böhme, "Atmosphere as Mindful Physical Presence in Space," OASE: Architectural Journal, no. 91
(2013): 29.

91 Gus Tielens and Klaske Havik, "Atmosphere, Compassion and Embodied Experience: A Conversation about Atmospheere with Juhani Pallasmaa," OASE: Architectural Journal 91 (2013): 39.

04.5 Atmosphere, not Ambiance, nor a Calculated Experience interaction of air with qualities. It is not unusual for these experiences to be enhanced by the warming or cooling effect of light acting on a physical object, adding the character of the subject matter to the air. Their interaction contributes to the creation of other non-visual perceptions, such as smell, tactile and even taste. Similar to the quality of light, air can bring forth new experiences of the physical things in space. It becomes a means to feel the temperature of a material, its moisture content, without actually touching it.

The movement of the air flow also has a significant role in the experience, as it reminds the mind and body of the place it is in because of the air movement that it feels. It also gives rise to the sense of movement in the space of the materials, place, and season, as well at the body's orientation. These enhance the minds and body's perception of the environment as an overlay with the existing experience. Consideration for the air's qualities become directly tied to the space, the physical materials, the lighting, and the surrounding environment, whose forces are effectively creating and enhancing the atmosphere.

The question of the formation of atmosphere is brought to attention as to whether it is a part of the architectural design, or if it acts more as a separate entity which can be added after the fact.Atmosphere is not what some may refer to as ambiance; atmosphere is something which is ingrained within the architecture. It is something which is guided by and produced from the materials, the spatial experience, the physicality of the place, the lighting and the air of the space; these things are all part of the design, which is the creation of the architecture. One could say that in creating atmosphere, one is creating architecture. It is something which is authentically experienced by the body. The ambiance is that which is added to an architectural space after the fact; after a space has been created, the materials chosen, the lighting and air has flowing through, resting in place. An atmosphere is already established. Ambiance suggests that space is to be presupposed as such and then remains as a kind of tone, mood. It can be added to and changed after the fact, where the atmosphere remains its own thing, which alters on its own. 
The perception of architecture is a unique process, based on sensory experience both intangible and physical characteristics. Due to the experiential nature of atmospheres, it must be understood that atmosphere cannot be a calculated or a defined experience but must be an authentic experience directed for one to perceive the space through their body and mind, allowing themselves to explore and unearth it on their own. Each space is experienced differently for different individuals based on how it is perceived through their bodily experience, as "...the experiential world becomes organized and articulated around the center of the body." ${ }^{\prime 9}$ One uses their subjectivity when asked how a space is experienced and what is experienced in space which they are in; space is experienced through the body's physical relations to it. It is because of the nature of the bodily experience of atmospheres that they are subjective to each individual, perpetually geared to each within the space. The person and space feed off each other, adding to an atmosphere amongst themselves. Different people build a connection to their environment in various ways, which shapes their experience of that space.

One may question the intention of this thesis as producing specific atmospheres, to be experienced in precise ways; this is not at all the case. Due to the immateriality and formlessness of atmospheres, they are difficult to identify, analyze, not to mention to aim at in the design process. A certain poeticism is lost when they are exact. Thus, atmospheres are bound to the reflection of the designer's existential sense, their sensitive feeling of being, as they embody their experience into the space they are designing; this fuses the experience with the atmosphere produced. It all comes down to the purposeful intention which is placed on the atmosphere during the design process. As Böhme states, "when designing a space is not what properties [one] seeks to give the objective space, but what sensitives [one] wishes to create for the space..." ${ }^{90}$ when designing these spaces, there needs to be a sensitivity to atmosphere, and a constant strive for the embodied experience. Joseph Brodsky has a beautiful way of describing this: "for a maker, experience is not gathering expertise but uncertainties." 91 This is when the work can gain a character of its own; it obtains its own self. This is when atmosphere begins to enter the work in its own manner. Designing architecture is very technical but much is spent striving for this connection that allows the architecture to reach someone, allowing them to feel their corporeal presence in the space. This is the meta level of approaching the architecture created, beyond technocratically fulfilling requirements, codes or artificially constructed limitations. 
92 Mark Wigley, "The Architecture of Atmosphere." Daidalos, 1998: 27

93 Adam Sharr, Heidegger for Architects, (Abingdon: Routledge, 2007), 88

Figure 21: Dachau Concentration Camp Memorial Site Visitor Center, 2016
Thus, the design of architecture through atmosphere is not done so through a formula; rather, the atmosphere is developed through the sensibility of the body's experience of the space as the approach to design. "After all, atmosphere is something personal, vague, ephemeral, and difficult to capture in text or design, impossible to define or analyze. Although atmosphere can perhaps be the essence of architecture, it is not easily defined, let alone constructed or controlled." 92 Just as Heidegger categorized good or bad building on whether or not it fit his conception of poetry and poetic making, architecture can be designed through atmosphere by the "...creative attempts to make sense of the world by helping humans to measure the conditions of their existence." ${ }^{93}$ The intended general atmosphere can only be achieved by taking part in the designed space through active participation, tuning into the conceived space as an extensions of one's existential condition. Architecture should not specify an emotion or an experience, but should actively invite one to feel their own experience; the atmosphere envelopes the body and authorizes it to feel what it is feeling, which may otherwise be suppressed. It is a liberating aspect of these atmospheres. They do not specify what to think. One is permitted to have feelings, yet they are one's feelings. It permits one to provide their own meaning, invite the body to participate in its surrounding. 


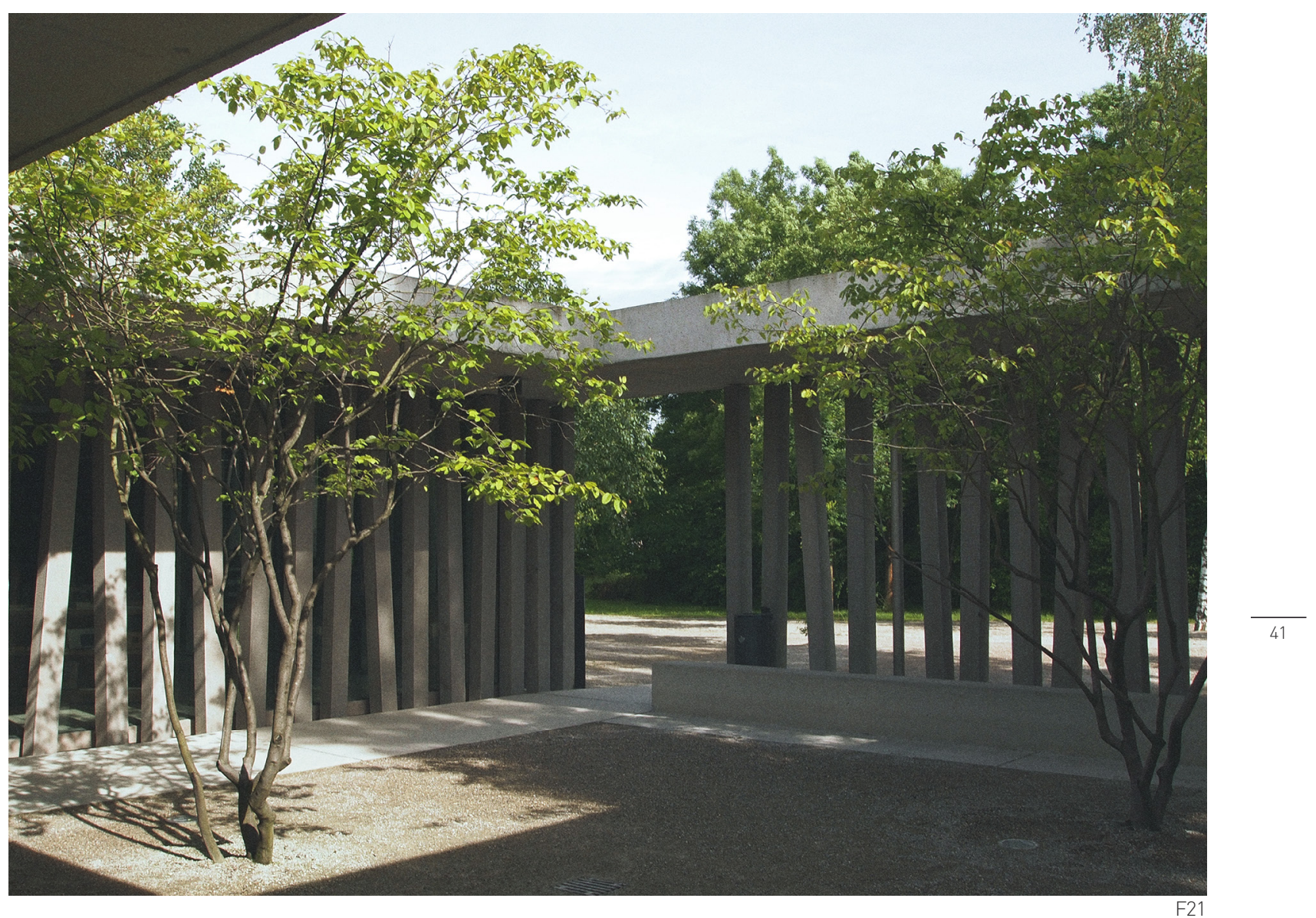



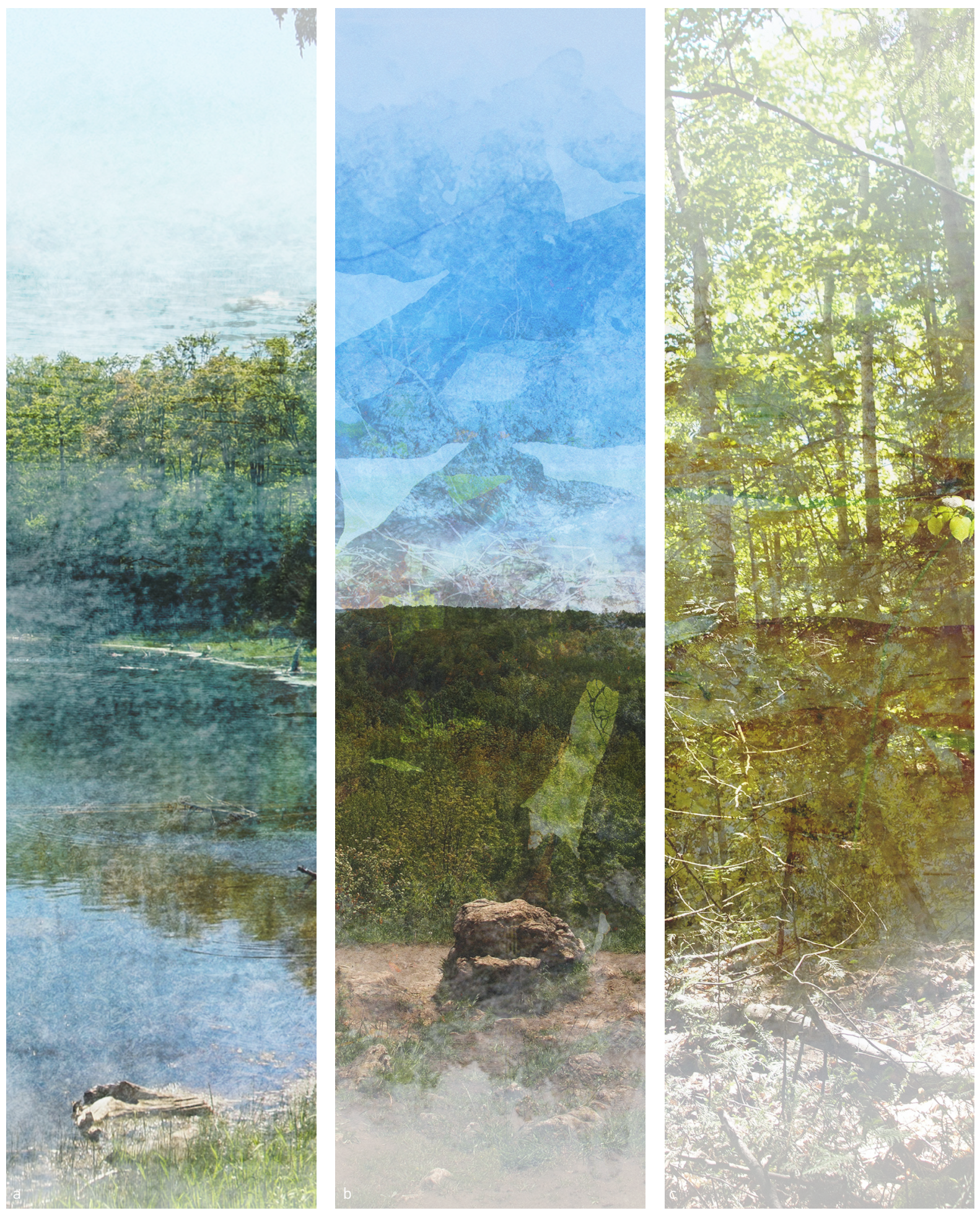


\section{THE CORPOREALITY OF ATMOSPHERE}

\subsection{Armatures for Meditation, Contemplation, Presence}

Figure 22: Images which encapsulates the essence of the sites for each of the corporal atmospheres.

a. Water Armature b. Air Armature c. Earth Armature
94 Steven Holl, Juhani Pallasmaa, and Alberto Pérez Gómez, Questions of perception: Phenomenology of architecture, (San Francisco: William Stout Publishers,

95 Mark Wigley, "The Architecture of Atmosphere."
When atmosphere is corporeal is when the body feels the physicality of it, as an acting force in the experience of space. Corporeal is defined as "having, consisting of, or relating to a physical material body", in this case, that body is architecture or the physicality of the atmosphere. A series of armatures along a hiking trail will act as a means of investigation as designed places of contemplation, meditation, for one feeling their physical presence. The present investigation aims to make evident, in an initial, preparatory manner, the importance, and the productiveness of the question of corporeal atmosphere in architecture.

An armature acts as something which frames something, acting as a means which something physical can occur. The armatures, in this case, serve as a means for an introduction of new atmospheres which enhance the physical landscape and atmosphere of an existing natural path while creating space for the mindful body to experience its physical presence. The life of a building is experienced through its atmosphere, which becomes a part of the experiential world for the body; the building acts as the armature for the experience of atmosphere. It is when the atmosphere has a natural presence that the body has a greater connection with it, where it links the body and surrounding, allowing the body to feel its physicality in the world, feeling the atmospheres corporeal presence. Each armature acts to enhance the trails existing atmospheres, extending an experience into a holistic experience of each armature along the trail.

Architecture is the thing which frames experience of atmospheres in the built world, where an architectural experience is encountered;“.... approached, confronted, related to one's body, moved about, utilized as a condition for other things." 94 As such, the focus when designing the armatures will be on the body in space, where the body and mind relate and connect with atmosphere. This implies a shift from the typical design focus from building to body; object to subject; built to atmosphere; the armatures physical form will be "...seemingly modeled by the atmosphere rather than the other way around." 95 The armatures are designed in a non-sequential order, but rather as an ensemble. Just like the atmospheres, the armatures cannot be a calculated or forced experience, and cannot be dictated how they are to be read and understood. They exist along a trail which is multi-directional, has various entrances and exits, and does 
not specify a route. As such, one may experience one, two, or all three of the armatures depending on their path. The order of visiting does not impact the overall experience in a natural manner. There is no wrong or correct movement or pace. Nature already acts as a means to which the body enters a state of relaxation, peace and presence; as such, each armature will focus on enhancing the natural elements which are located at specific sites, naturally contrasting one another, as each have distinct qualities, seemingly as though they are in vastly different places.

The armatures allow the focus of the design to be on that of the atmosphere; the specifics of the lighting, the materiality, the detailing, the spatial volumes which enhance the atmospheres experience, the air which takes on new qualities. The modest program focuses on the creation of the atmospheres, each armature designed for a body's experience of space, both interior and exterior, rather than an emphasis on the physicality of the built form. There is no need to have to 'avoid' certain programmatic requirements, as they exist within these spaces; these spaces allow designing through the atmosphere to be the forefront of the exploration.

The design of each armature looks at all the qualities of atmosphere, entirely focusing on each element in tune to how it will enhance the atmospheres, purposefully designed, crafted and explored, allowing the atmospheres to come into their own through an embodied experience. They are intended to invite emotion, welcome uncertainty, and obtain their own character. The intent is to design through an embodied experience, in tune with the body in these spaces, embedding the conscious act of making architecture. 
Creating a condition where the body's presence becomes more apparent - these will act as a mediator between the physical and the immaterial. They will invite emotion, welcome uncertainty, and obtain their own character. Design will be through about through an embodied experience of the space as a conscious act of making architecture.

NATURAL EMPHASIS

Location

Hierarchy of Qualities Consideration, more prevalent to least

Perception Focus

Intent with Natural Emphasis

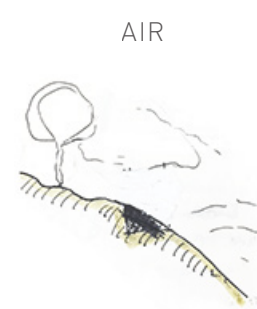

On the Edge of a Cliff

Air

Materiality

Lightness and Darkness

Sound and Touch

Feel expanse of the park while floating over it
WATER

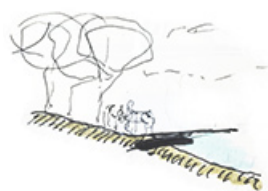

Precipice of Land + Water

Lightness / Darkness Air

Materiality

Smell and Touch

Feel the moisture of the water through various means
EARTH

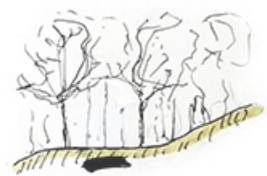

Within a Clearing of Trees

Materiality

Lightness and Darkness Air

Sight and Sound

Feel as part of and within the : surrounding forest

Each armature uses a set of design criteria based around the atmospheric qualities and their hierarchy, perceptual focus and the natural characteristic to be emphasized based on each individual site. This design criteria was extensively used through an embodied design process. 


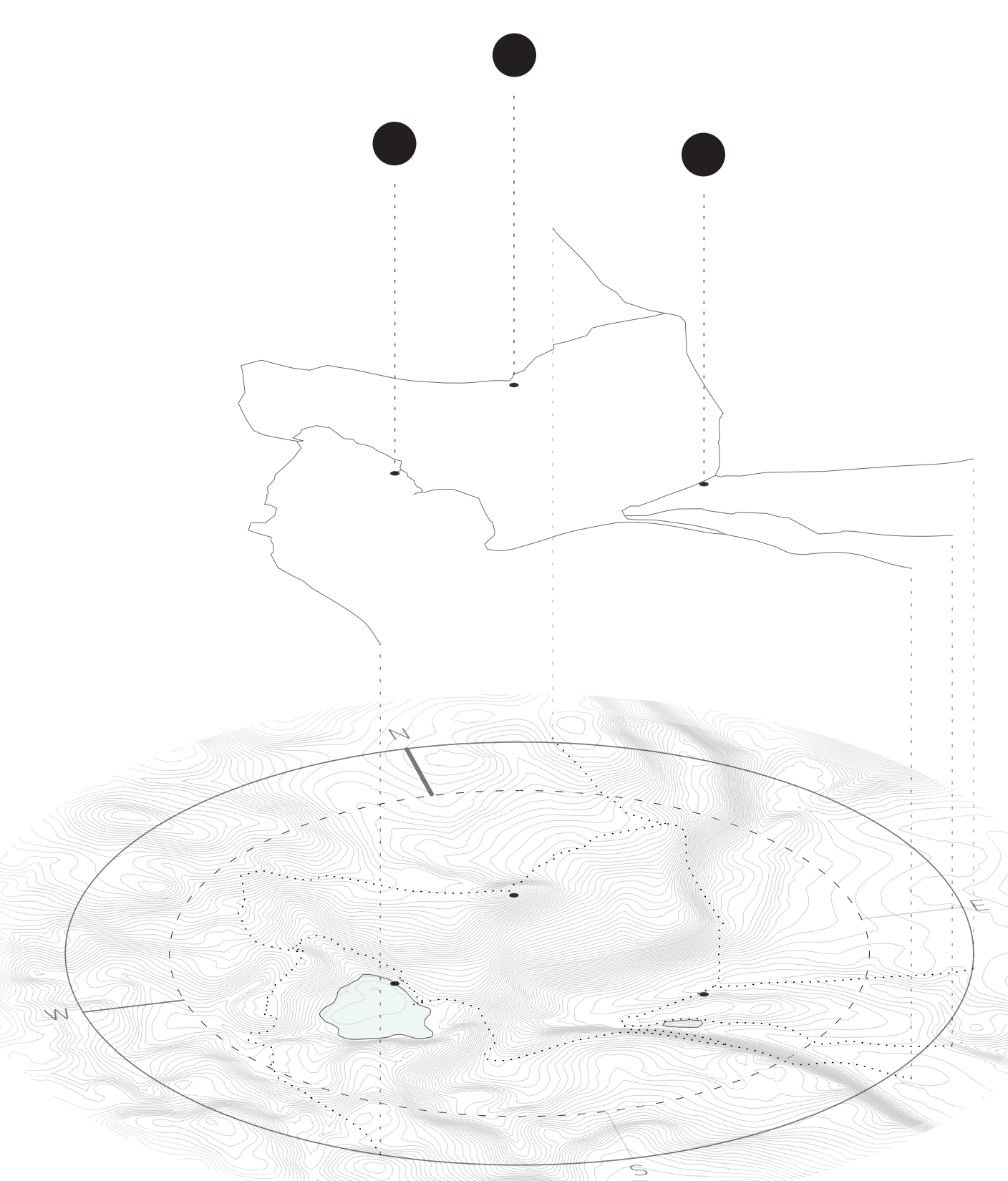




\subsection{The Atmospheres of Mono Cliffs Provincial Park}

96 Amanda Aizpuriete, et al, Poetische Landschaft. II. Druck. Faltbuch - zur poetischen Landschaft, ed. Brigitte Labs-Ehlert, \& Peter Zumthor, (Detmold: Literaturbüro OstwestfalenLippe, 1999), 18

Figure 24: Axonometric of overall loop where armature sites are located.
A decision for a natural location was due to the temporal nature of the landscapes; the landscape impressions change at short intervals, flow into one another, lose themselves in the ambiguity of the transitions, condense to places of distinct shape. ${ }^{96}$ Natural spaces have their unique atmospheres, their own means to which a body connects with the surrounding. The intention is for this to then extend into the design of the armatures, and the armatures to extend into the natural atmospheres, where they become a part of, and an enhancer of, the experience of the surrounding.

The armatures are in a portion of The Bruce Trail. The Bruce trail spans from central Ontario in Tobermory, to Southern Ontario in Niagara Falls, acting as one of Canada's longest and oldest footpaths. The trail follows along the Niagara Escarpment, running through large natural reserves and highly populated cities. It provides continuous access to the vast natural Escarpment, spanning 890 kilometers of main trail and 400 kilometers of associated side trails. The Bruce Trail is divided up into nine sections. The main trail is marked with a vertical white line, where side trails are marked in blue.

The Hi-Dufferin area of the trail was chosen for its vastness in character, from open fields to heavily forested areas, lakes and rivers, look-outs and caves. The character is rural, almost intimate feeling. The intention for the location of the armatures was to be on a portion of the trail which had multiple access points, had a variety of sites to choose from, and was able to be completed in one day. Small portions of the trail were explored near Orangeville, Ontario, each chosen based on potential full route length and general location; a part of the explored trail was in Mono Cliffs Provincial Park. The loop which was selected includes the main trail, two side trails, and a usercreated portion of the trail; the total distance for this loop is 6.1 kilometers and has five separate access points. Much of this part of the trail has the trail markings on trees. The trail was experienced during every season of the year, in rain, snow, and beautiful sunny days. It is a trail which is used yearly.

The trail has its distinct character, one which changes as one moves throughout the various zones, having its own unique set of thresholds between the different areas, which merge in the overall experience. The body feels at rest, yet it is exerting force, but the mind feels calm and content. These areas of transition in the naturals spaces exist because of the atmospheric qualities of the zones along with the spatial areas that are created with the physical natural elements. 
The air site is characterized by rock formations, partially covered by thin layers of soil and smaller mosses and grass; there are many areas where rocks emerge from the ground. It is from this area that one can see over the entirety of the park, its changing topography, the change in vegetation and the layers of surrounding highlands. The wind comes in multiple bursts of movement, rustling the surrounding trees; the movement of the air is made abundantly apparent by the by-product of the wave of sound from the branches, leaves, and shrubs. Access to this point is from the East or West: East access is up a steep, rock stepped, heavily deciduous and coniferous forested slope. It is dim, only lit with the dapples of light from between the high trees, which sway with the lightest touch of wind. The west access is a gradual slope to the top, through a sparsely deciduous forested area; both access points very quickly open to the expanse of the provincial park at the highest point of the slopes.

Thresholds of trees, tall weeds and water characterize the Water site. As a point of entry and departure from the side trail, an intimate user-made path was created down to the water, weaving through trees and then weeds. From the path, the light shining on the water can be seen for brief seconds, as the densely-forested area continuously blocks direct views to it. At the point of entry and exit, the trees spread a little, acting as a natural entrance down to the water, where a steep dirt path flows down. The intimate lake is lined with soft, tall plants. Light appears to be dancing around the trees and plants. The air is lightly moving, calm and cool.

The earth site is characterized by the surrounding tall, well-aged trees, acting as a clearing in the trees. Closest to the path, along the north edge of the clearing are evergreen trees. Birch trees populate the other side of the clearing, along with a small grouping of evergreen trees behind, soaring up into the sky. Light shines through the trees into the clearing, changing its amount throughout the various seasons and time of day. It is accessed just off the site, as a point of exit and entry through the lining of coniferous trees. The ground is populated with branches, other small shrubs, and birch bark which has naturally fallen from the surrounding trees.

Each of these places, different from one another, have their other various atmospheres which extend into one another; they act together as an overall experience over the procession through the trail. These contexts have their individual atmospheres, where the armatures serve as a mode of producing a new form of the atmosphere within another, where "the meeting of these seemingly ephemeral atmospheres 9 Mark Wigley, "The Architecture of Atmosphere." Daidalos, 1998:

can be as solid as any building." 97

Figure 25: Sites for each armature

a. Air Armature Site

b. Water Armature Site

c. Earth Armature Site 

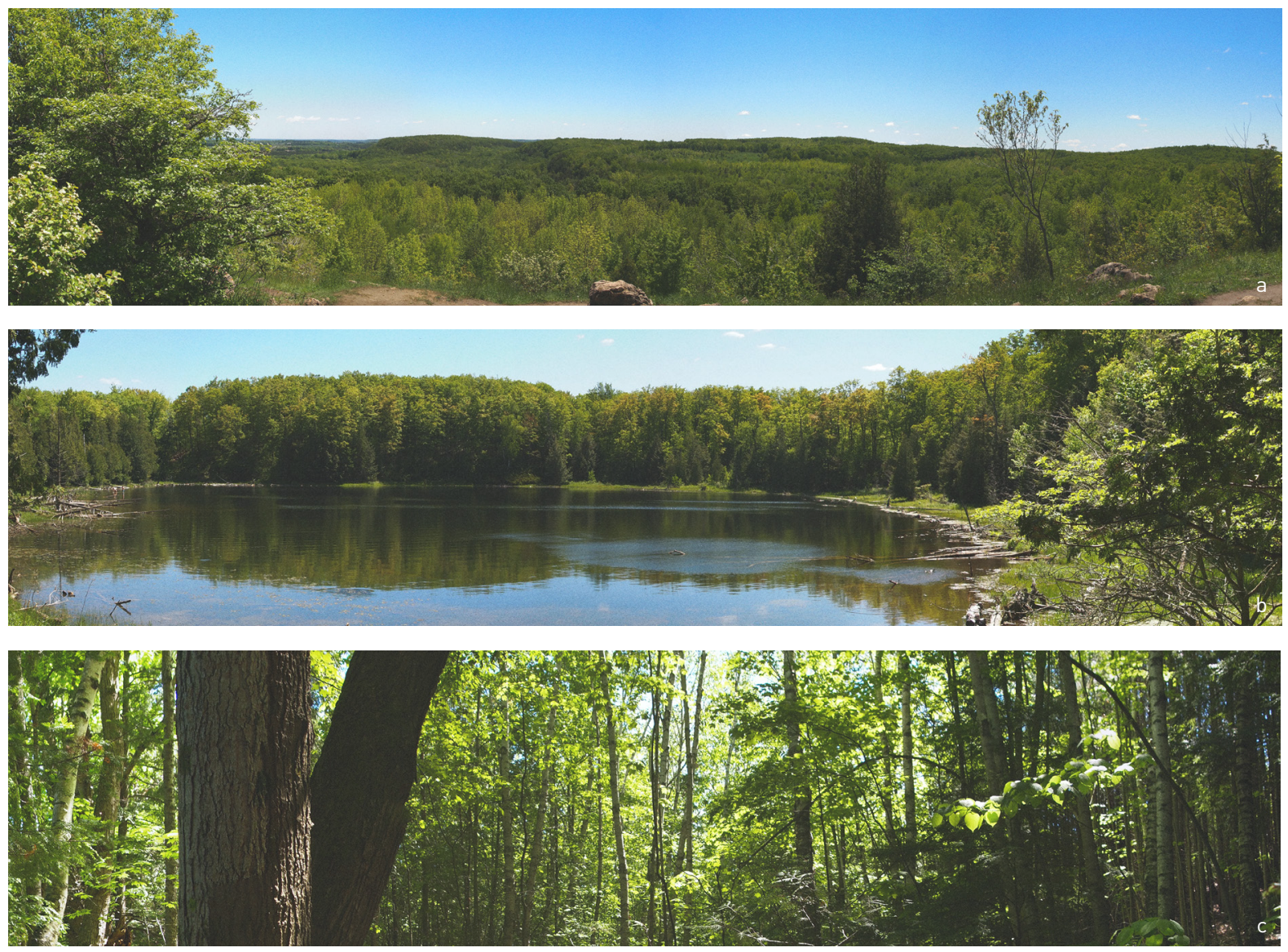

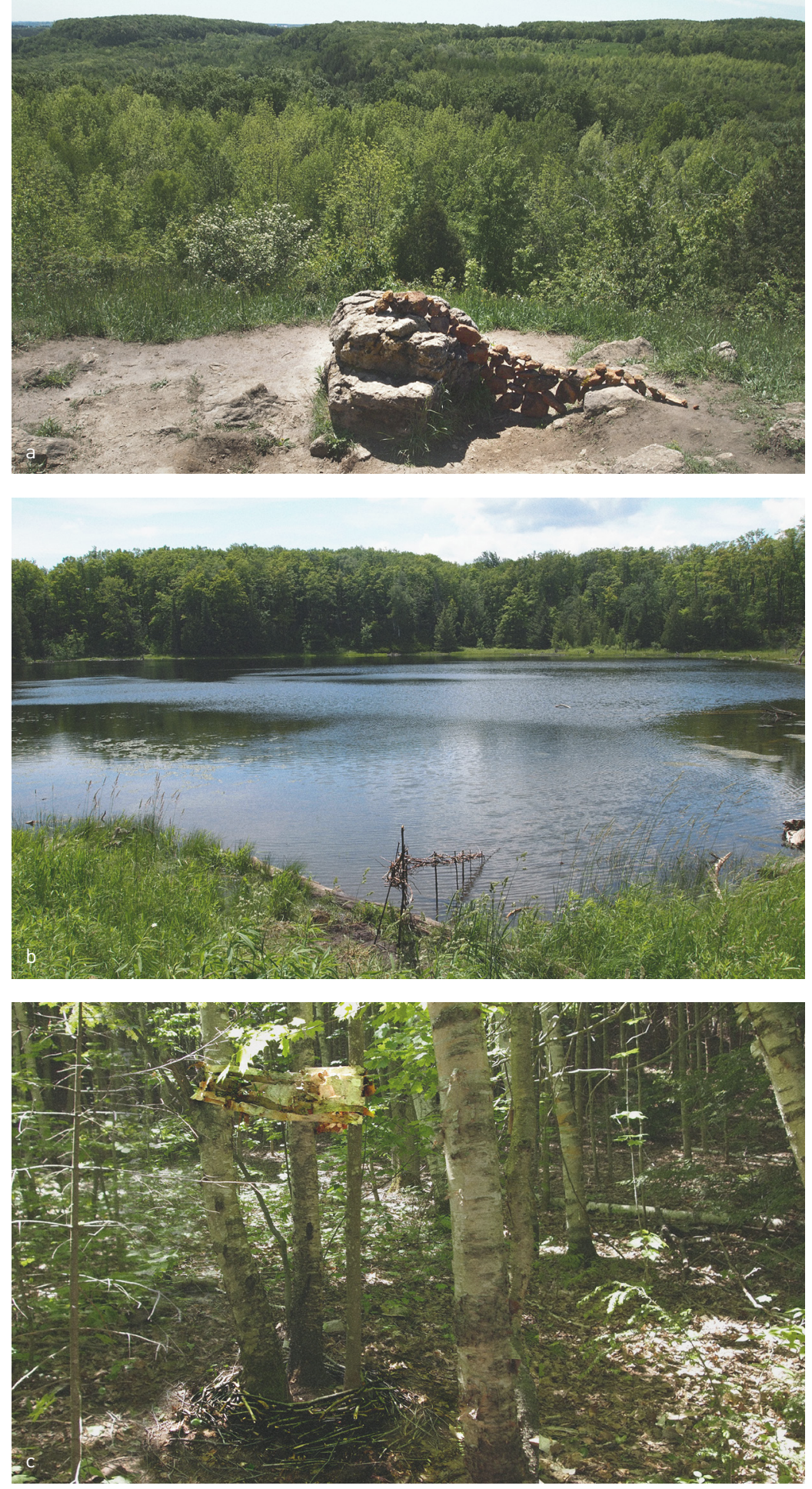


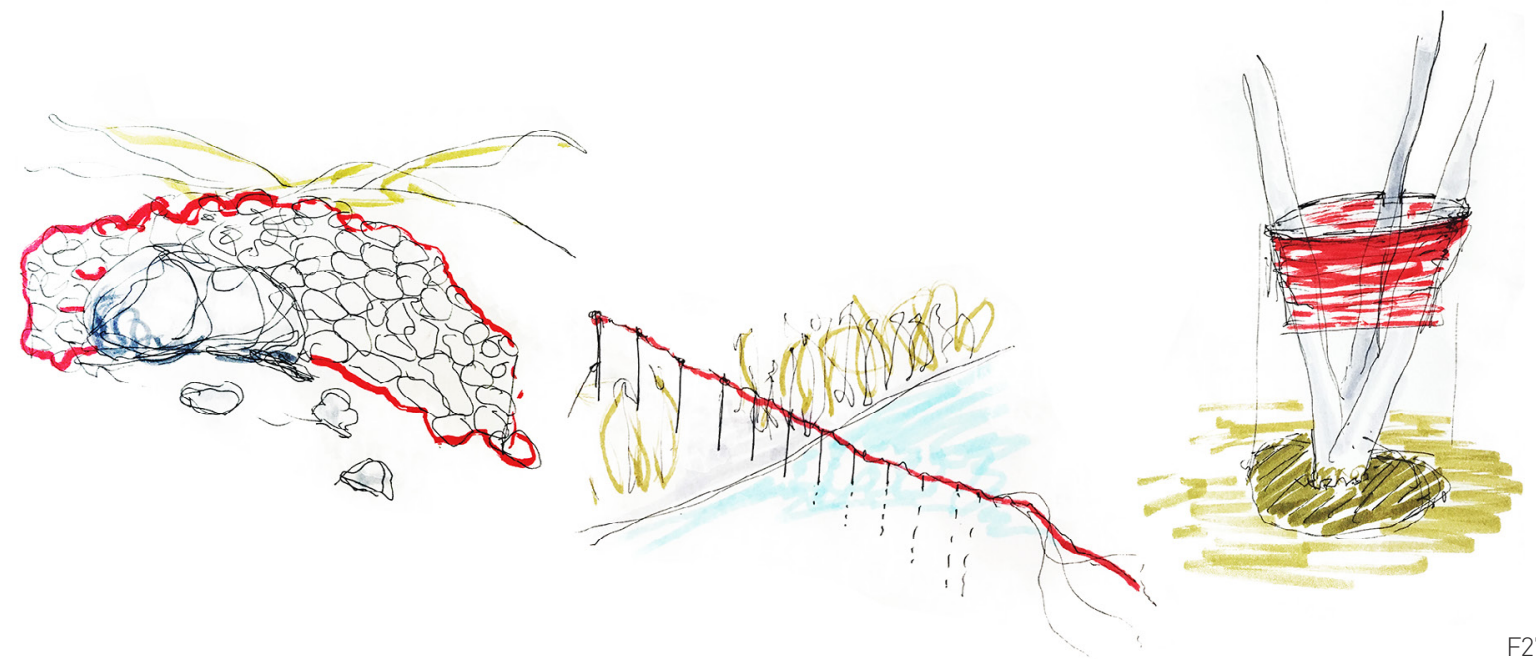

\subsection{Atmospheric Installations Within Nature}

Figure 26: Atmospheric on-site installations for each armature, done with solely found on-site materials

a. Air Installation b. Water Installation c. Earth Installation

98 Rivers and Tides: Andy Goldsworthy Working with Time, directed by Thomas Riedelsheimer, performed by Andy Goldsworthy, (2001)

Figure 27: Initial sketches and ideas for installations
There is a lot to be learned about a place by how it exists, where great inspiration can be drawn from in the creation of something ephemeral and beautiful. Analyzing, understanding, experiencing a place uncovers great unexpected things, giving the light to the potential of the place. The meeting of the pre-existing and the intent of experienced atmosphere occurred within installations constructed on site.All efforts of analyzing, understanding and taking from a place should ultimately go into something which feels effortless, as though it has always existed there. One gets to know the qualities a little bit more, the subtleties of the natural condition, exploring how the installation can alter the perception of elements of the place, and the changes it brings to the body. The intent of these installations was to act as a temporal installation, something which would allow insight into each specific place, and ultimately fall back into the surrounding on its own with time. The intent was to feel as though the heart of the place has in some way been touched. "That is the way of understanding; seeing something that was always there before, but that you were blind to." ${ }^{98}$

Each installation acted as informed material concept of each armature merged with the intended experience. In creating and being within these installations, a certain sensibility was gained in relations to various aspects about each site, the materials used, and the unconscious desire for experiential qualities. Having previously visited the sites, and having general design intent for each armature, the installations concretized and informed various design aspects for each armature in various manners. 

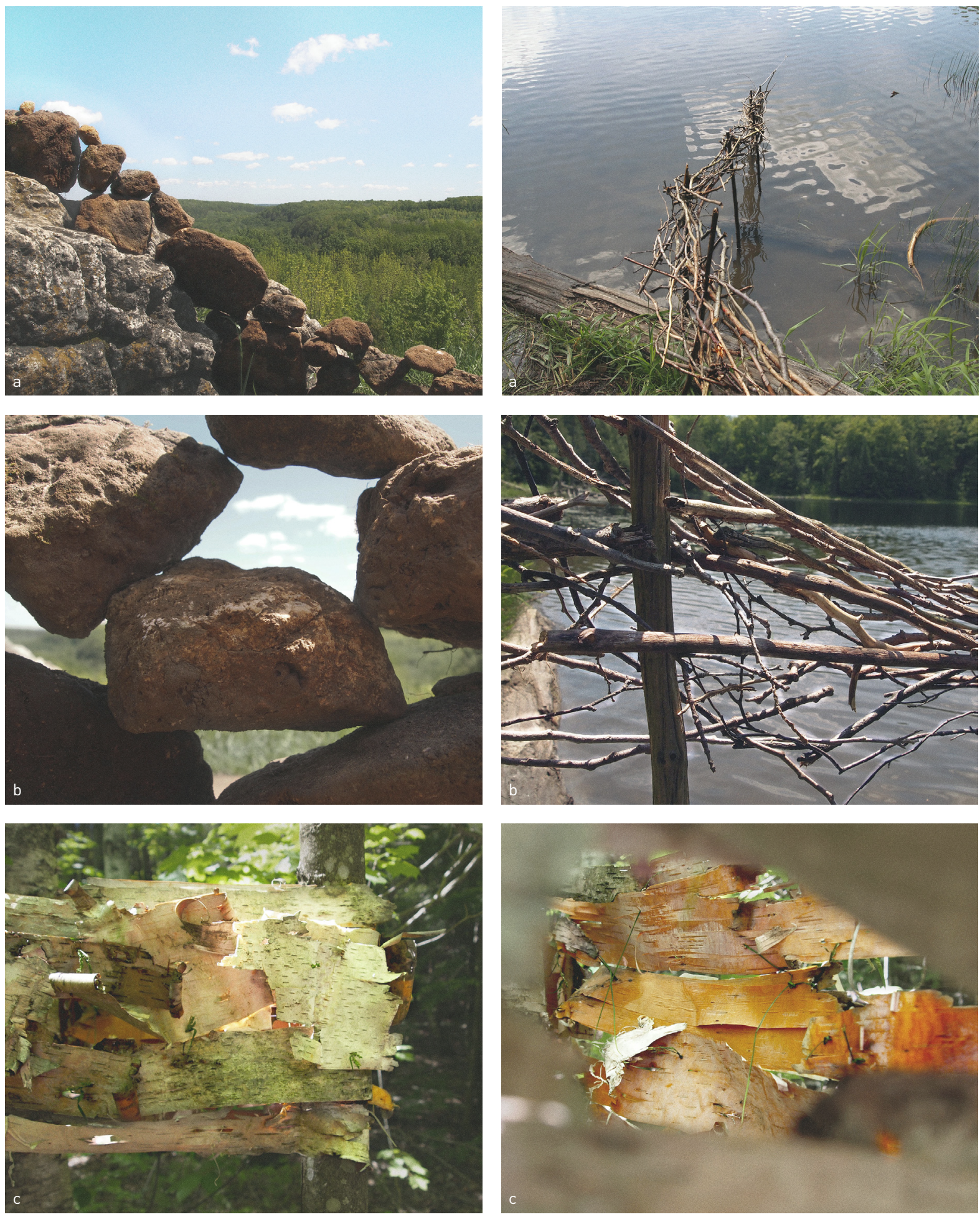
Date: June 2017

Site: Cliff Side

Materials used: small to medium size flat or slightly rounded rocks

The installation is composed of numerous sizes of rocks were gathered on site, flat or slightly rounded stones perched one above the other, as an infill between two large rocks embedded in the earth, with wide spaces between them. Snaking between the embedded rocks is the balanced stones, delicate, breathing light and shadow through the voids between the stacked stones. The idea of the light seen beyond or through is essential to see the surrounding lookout from one direction and from the other appears to be merging from the ground. The openness of the construction of the rock pieces adds to the sense of infinite space since they seem to be defying gravity.

Date: June 2017

Site: Trail Side, amongst the woods

Materials used: strips of birch bark, varying in length, small sticks, pieces of grass.

Strips of birch were to be fastened to one another to then wrap around three trunks of closely located trees. Each piece weaving into one another, fastened with pieces of grass through the slits in the bark. From the surrounding, the birch blends with the background, at times glowing from the sun touching it coming down between the tops of the trees. While within the installation, the birch starkly contrasts its surrounding. It is bright, orange, warm and allows snippets of views out to the surrounding. Shadows from above lay on the inner of the birch bark, giving depth to the sheet which has been created.

Date: June 2017

Site: Lake Side

Materials used: one-inch diameter branches, smaller wood sticks varying in length and size

Figure 28: Atmospheric on-site installations

a. Air Installation b. Water Installation c. Earth Installation
Moving from land into the water, wooden branches staked into the ground act as anchor points for a general route which disappears into the water. Smaller branches of numerous lengths weave together to hold themselves up to move along the tops the stakes, touching down into the water. The weaving of the branches provides various amount of densities through the sticks, providing a gradient of visibility through. The physical installation and reflection of the installation meet at an intersection in the water.

These installations began to inform the armatures in their own way, bringing a new sort of life to them on their own. They began to define themselves with their own character. Drawing from these installations, along with an embodied attitude towards the design, the atmospheres for the armatures developed into something experienced in a way. 
05.4 Corporeal Armatures

Figure 29: Mapped Armature Experiences

a. Earth Armature b. Air Armature c. Water Armature
The armatures each intend to represent atmosphere in a way which highlights the experiences of the various aspects it composes. Intent images represent the intended experience that was extended as the embodiment while designing the armatures. Using means of experiential mapping, as seen in Figure 31, 35 and 39, the armatures follow a series of experiential imagery which corresponds to the embodied experience through the design process; the work aims to represent the reality of atmospheric and bodily experience of the spaces. Rendered imagery is shown in an experiential and whimsical manner highlighting various elements of the atmosphere and their impact on the experiences. Line-work extending through the drawing illustrates the body's independent movement through the physicality of the armature and the various physical and experiential thresholds the body crosses. These drawings look at the various forms of bodily and sensorial experience. 

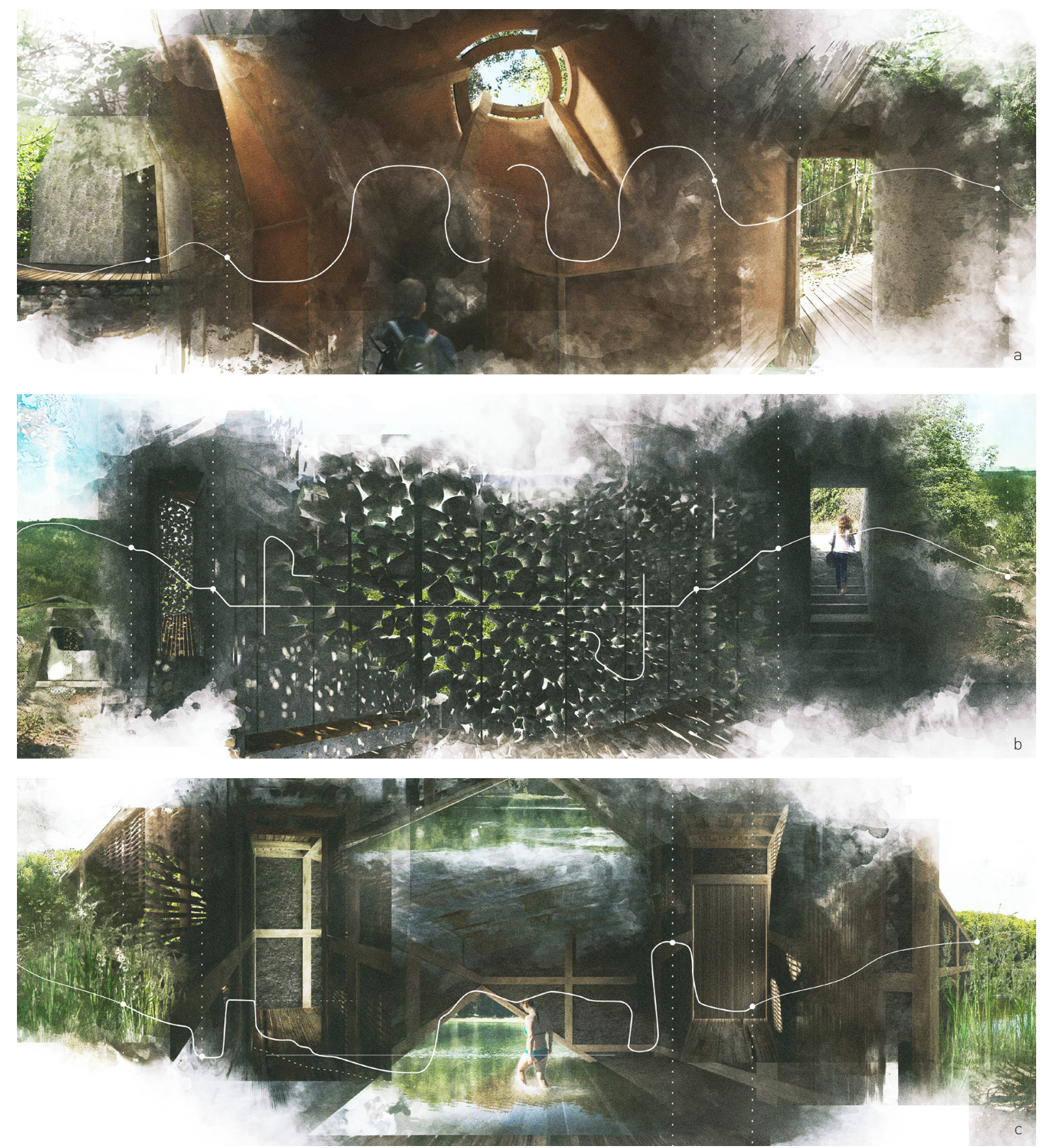


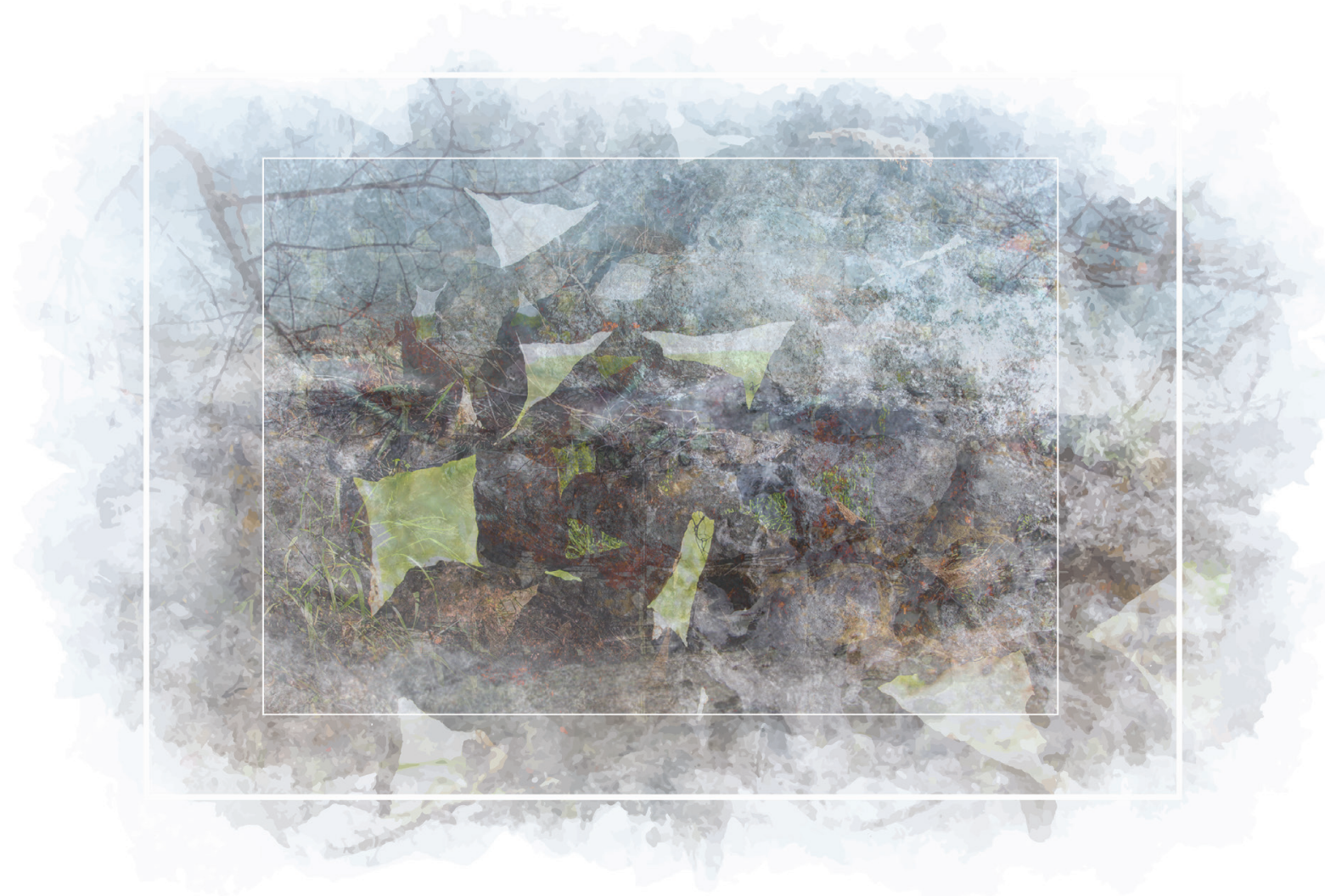


05.4.1 Armature of Air

Figure 30: Representation for the intent of the atmosphere for the Air Armature
The intent of this experience is making the body aware of its presence with movement, both in the air and of the body. As such, the experienced atmosphere is based on feeling and hearing the moving air and light from outside, allowing the surrounding to infuse the space. However, that which infuses the experience is not directly seen from within the armature, where only moments or snippets can be seen; the expanse of the forest is in one's memory while experiencing the air and the subtle orientation given by the movement of the shadows and light from within. 


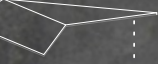

Wooden Roof Structure

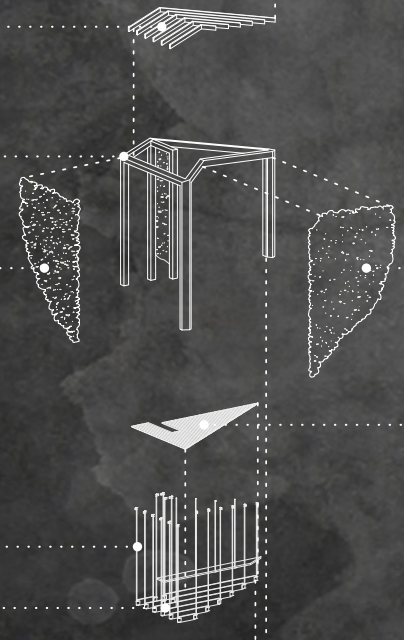

Structural Concrete Ring Beam

Stone Wall w/ Point Mortar
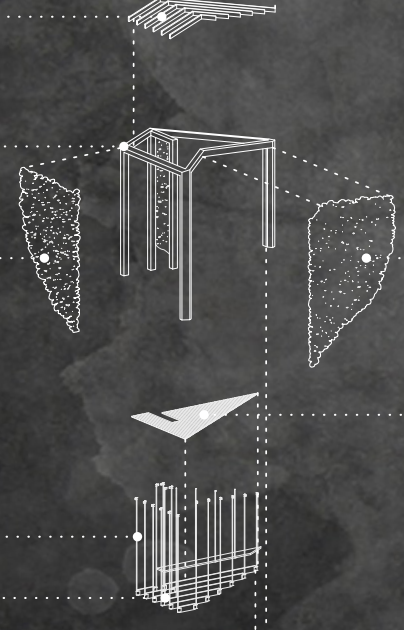

Stone Wall w/ Point Mortar

Hung Metal Rods Holding

Floor Structure

Joists

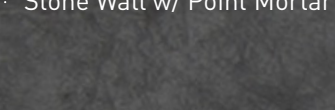

Wall Plank Flooring

Concrete and Stone Stairs

Rock Embedded Concrete Walls

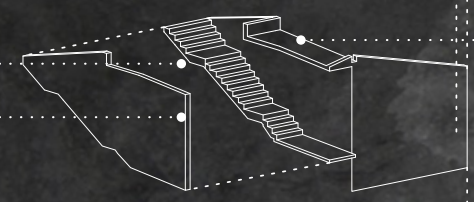

Concrete Roof

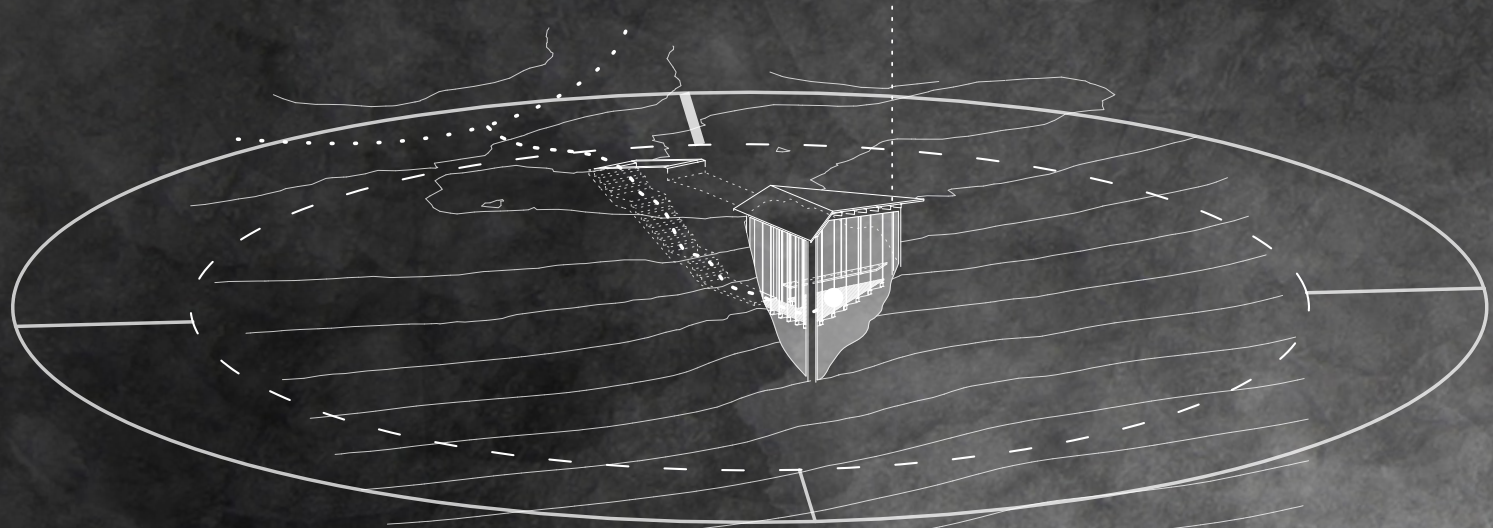


Figure 31: Axonometric of the Air Armature

showing its main components

\section{$\cos 2$}

Figure 32: Orthographic drawings of

armature

a. Plan

(1)

$0.0 \mathrm{~m} \quad 2.0$

The armature speaks to its surrounding with its use of materiality and its presence on the slope, using sharp contrasts between light and dark, heavy and light, compression and expansion, as the main design drivers for this armature. The design revolved around the ability of the air to move through the space with the intension of it becoming highlighted. The armature is oriented south, with the longest angled wall facing south east towards the deepest view of the park; the angle created at the moment of turn from hallway to central space gives an impressionable volume for air to move through along the cliff face.

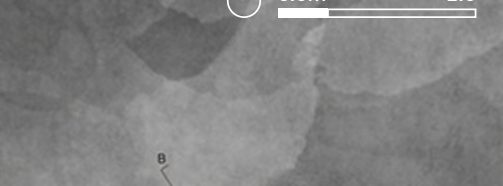


The main roof follows similar lines to those of the hills viewed in the background, blending into the overview of the park, leaving the armatures visual impression on the site minimal. The walls are constructed from rough concrete and stacked large stones found on site; these walls extend out from the ground. Spatial compression is used when descending the stairs into the ground to accentuate the contrast between the heavy ground and the feeling of floating. Air moves though the openings in the stacked stone walls, through the openings in the hung floor board, and the intentional opening where the roof meets the top of the walls. The body can feel the air movement through the openings in the space, physically placing itself over the cliff. The spatial volume moves and sways on its own through

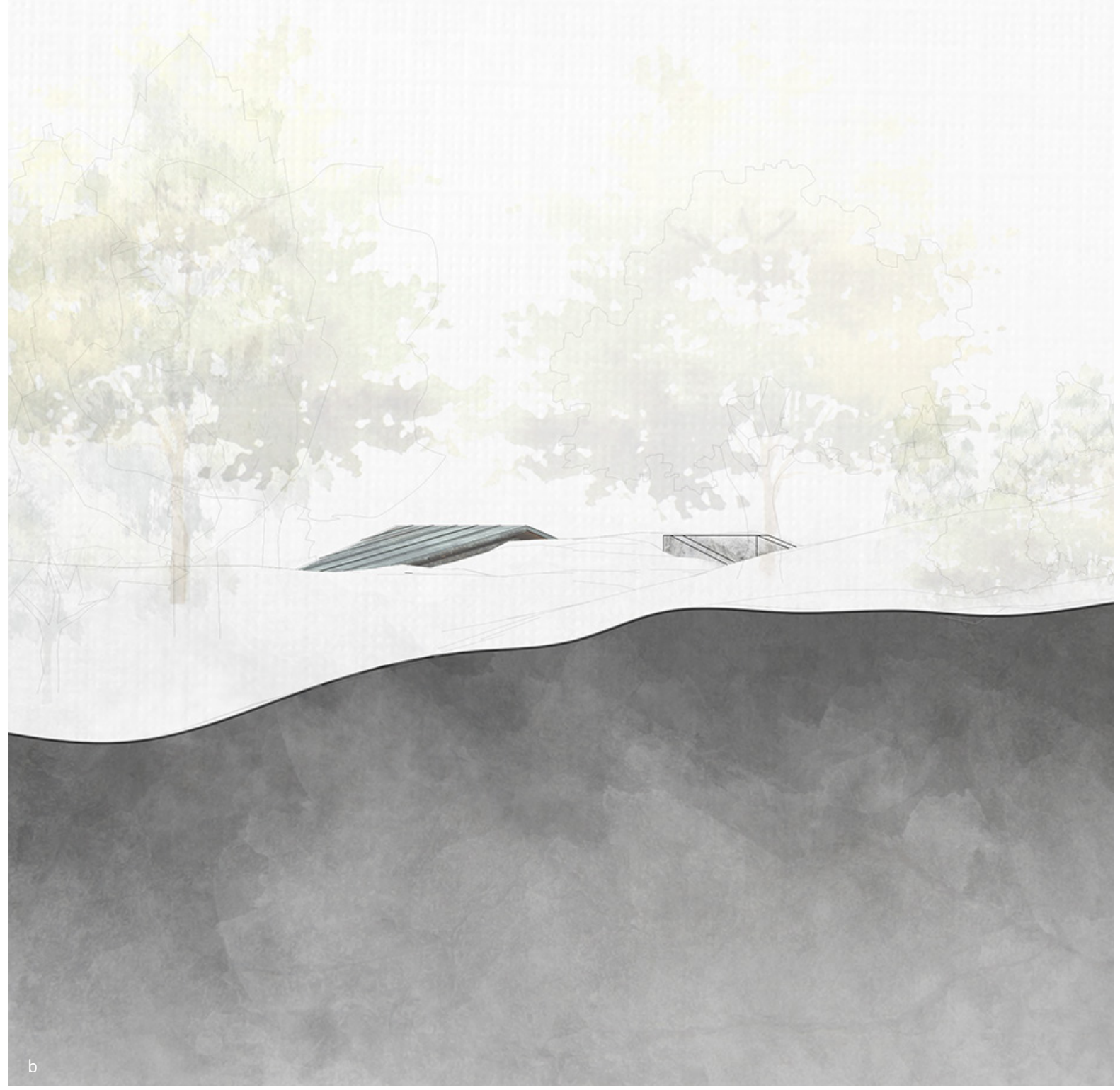


the hung floor system. Metal rods connecting to the top main structure supports the hung wood floor, which not only accentuates the body's feeling of floating over the

b. North Elevation c. Section a-a

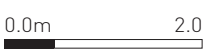

cliff but also allows air to come up from below. The hung bench along the edge of the northern solid wall of the armature encourages a visitor to sit and experience the movement of the immaterial in the space. Thresholds between various areas are accomplished through material and immaterial elements; the roof, walls, light and shadow; these thresholds are seen in the mapped experience through the armature.

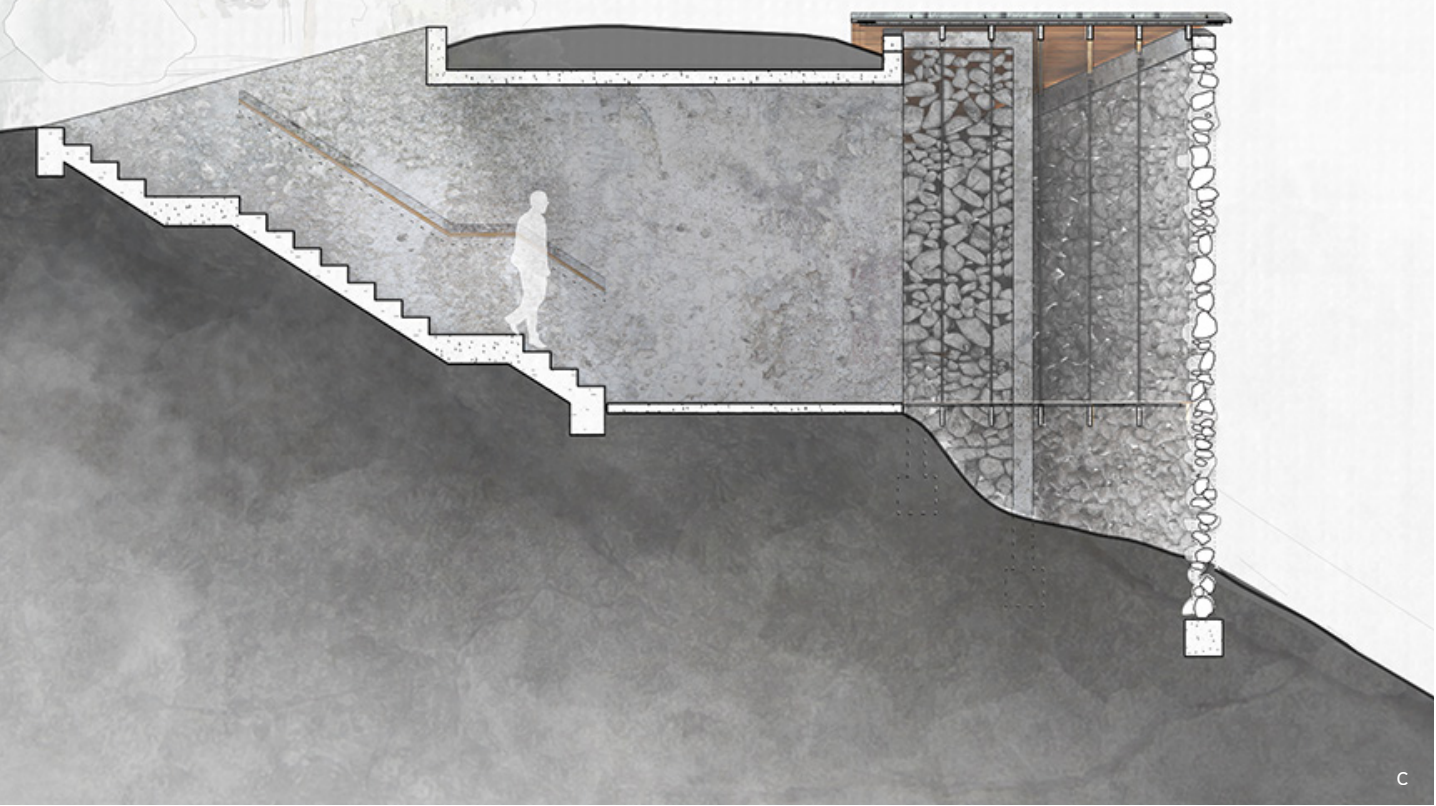




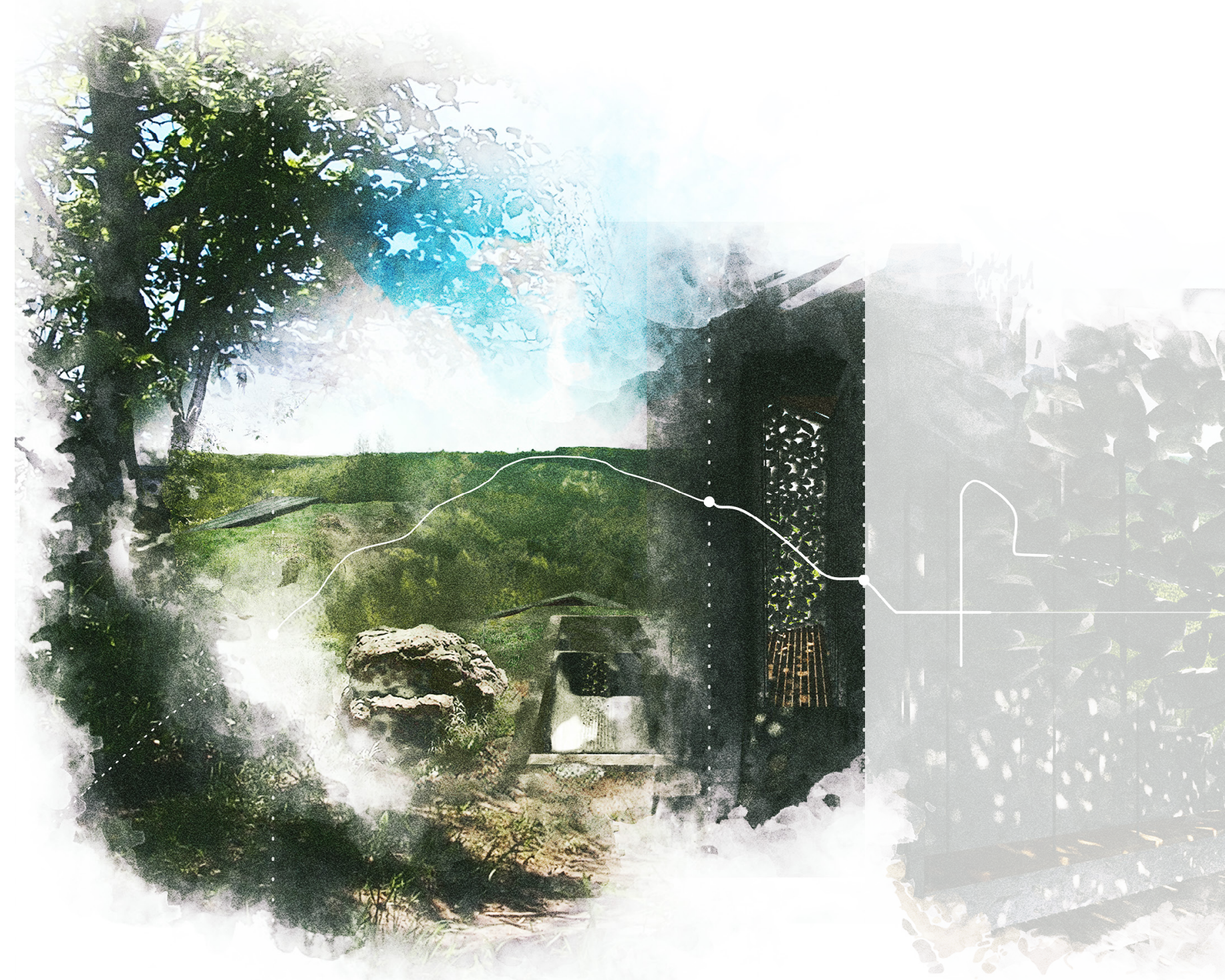

a 
Figure 33: Mapped Air Armature experience a. Approach and Decent

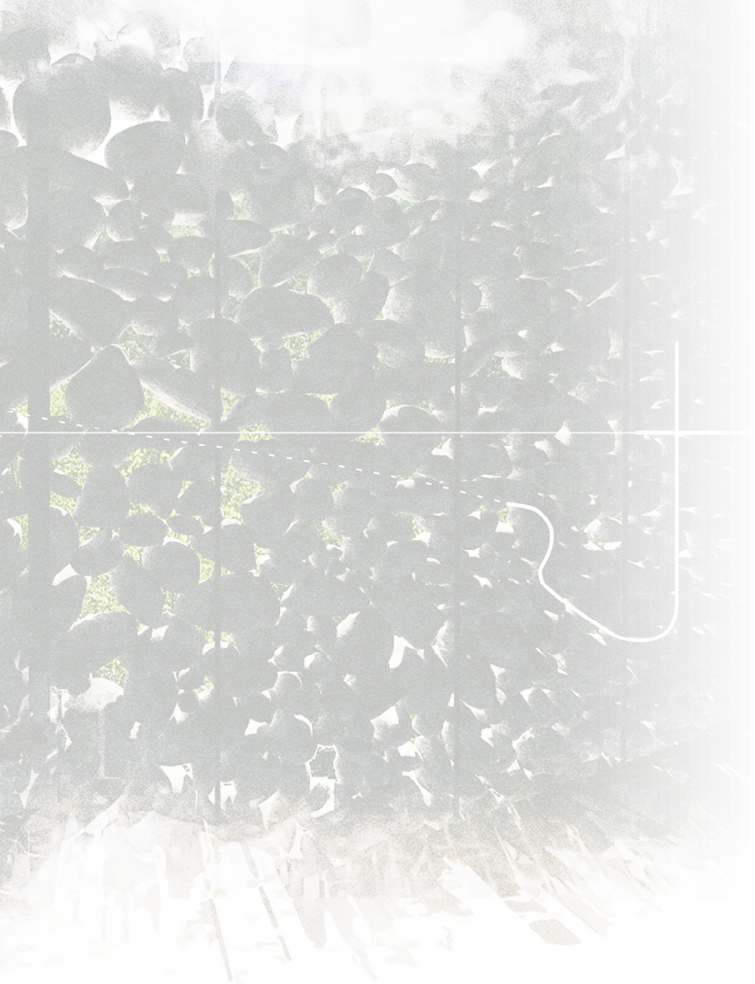

Approaching the armature through the forested area, the visitor moves from a naturally covered area to a drastically different environment; opening to the outlook over the park. Unseen to the visitor, the armature exists within the ground. From the approach, it acts as an extension of the cliff's slope, somewhat blending with the rolling topography behind. As the walls of the armature begin to form, the transition from the dirt path to a concrete stair descent begins, a wood-toped handrail embedded into the concrete wall leads the way. The walls are rough with concrete and cool to the touch. Two-thirds of the way down, a landing occurs, polished concrete, where a roof overhead forms and one becomes fully surrounded by earth; the overview of the park is lost as one descends into the ground.

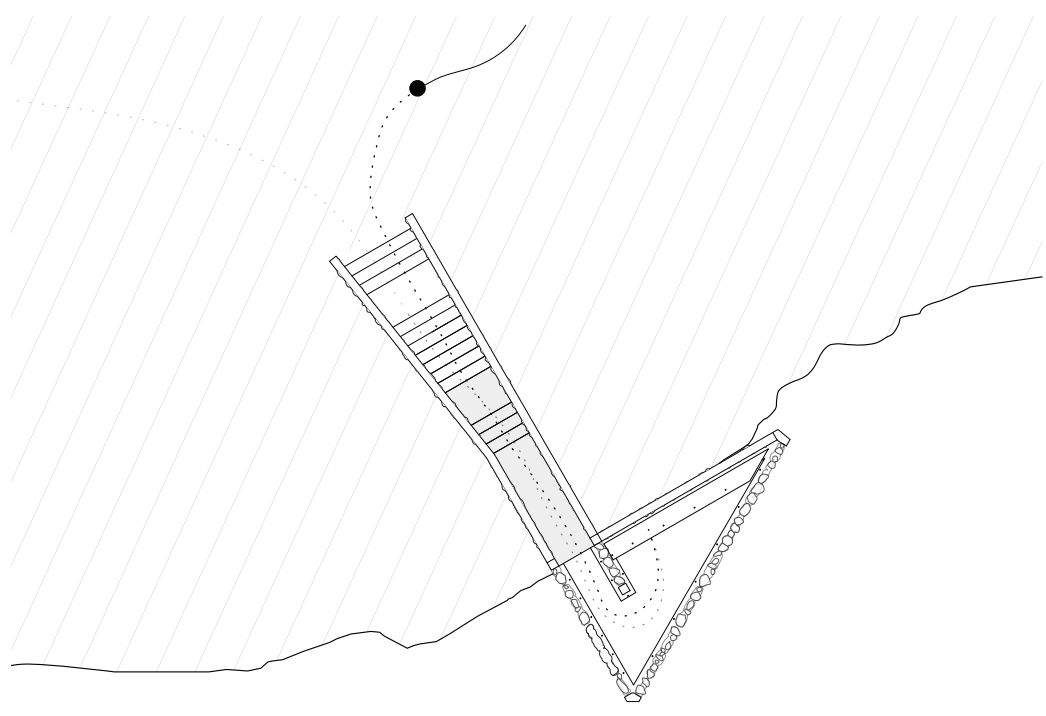




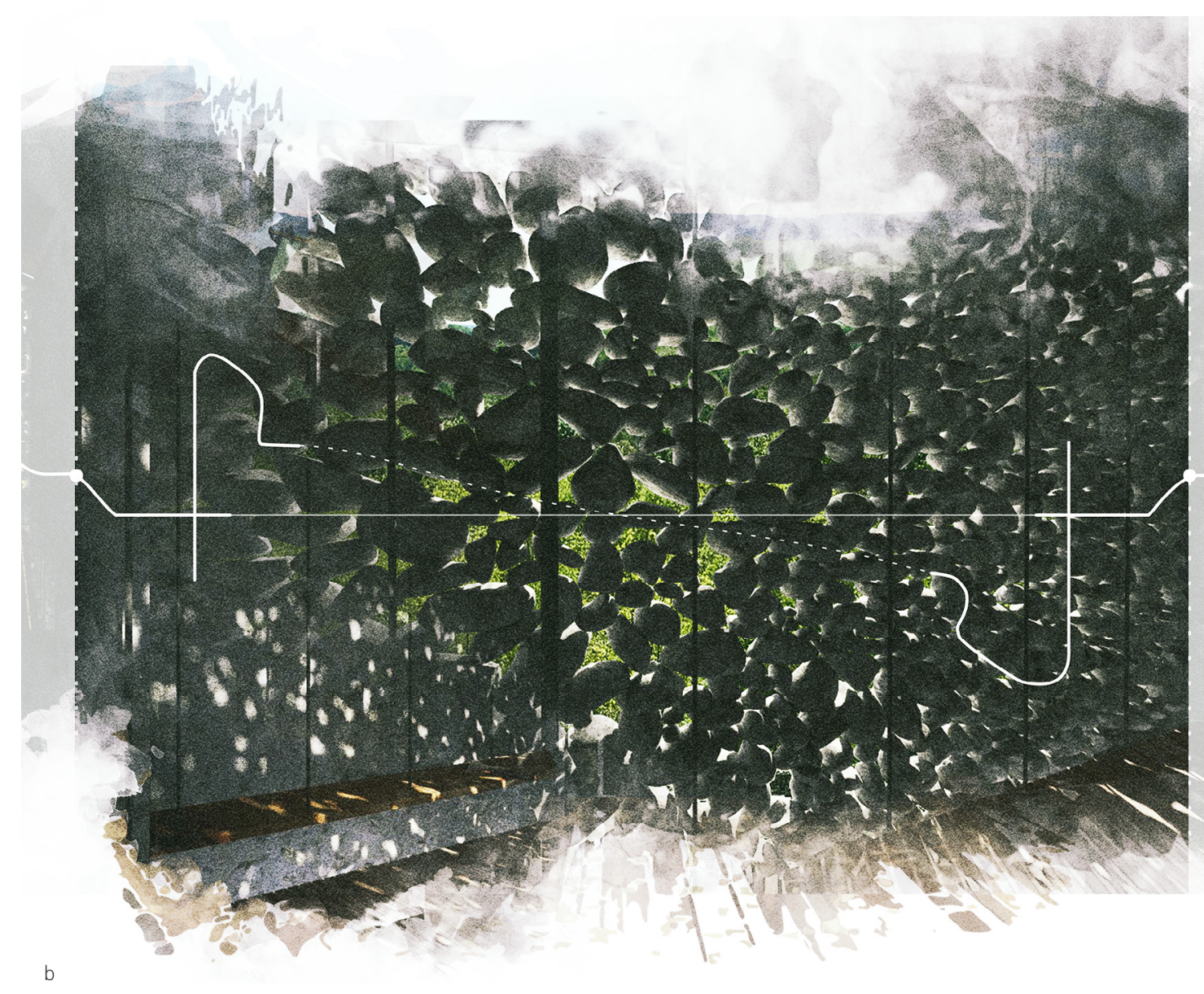


At the bottom of the steps, a change from the concrete to the wooden boards signifies a change from being in earth to floating above it. Smooth and cool to hollow and rough, the reverberations are heard and felt. The swaying nature of the space emphasizes movement of the air and the body. Flashes of surrounding can be seen through small openings in the walls. The wind is heard as it whistles through the walls. The visitor comes to a moment of turn, where space opens to a small area with a hung bench. The floating floor is accentuated by a reveal between the walls and the floor, allowing one to hear and feel their movement in the space. The air stirs among diffused streams of light. The floor reverberates as the body moves through space. Sitting, one can feel the change in movement of the air and the movement of the sun by the streams of light coming in. Wind pushes up through the floor boards and slows as it enters the floating space.

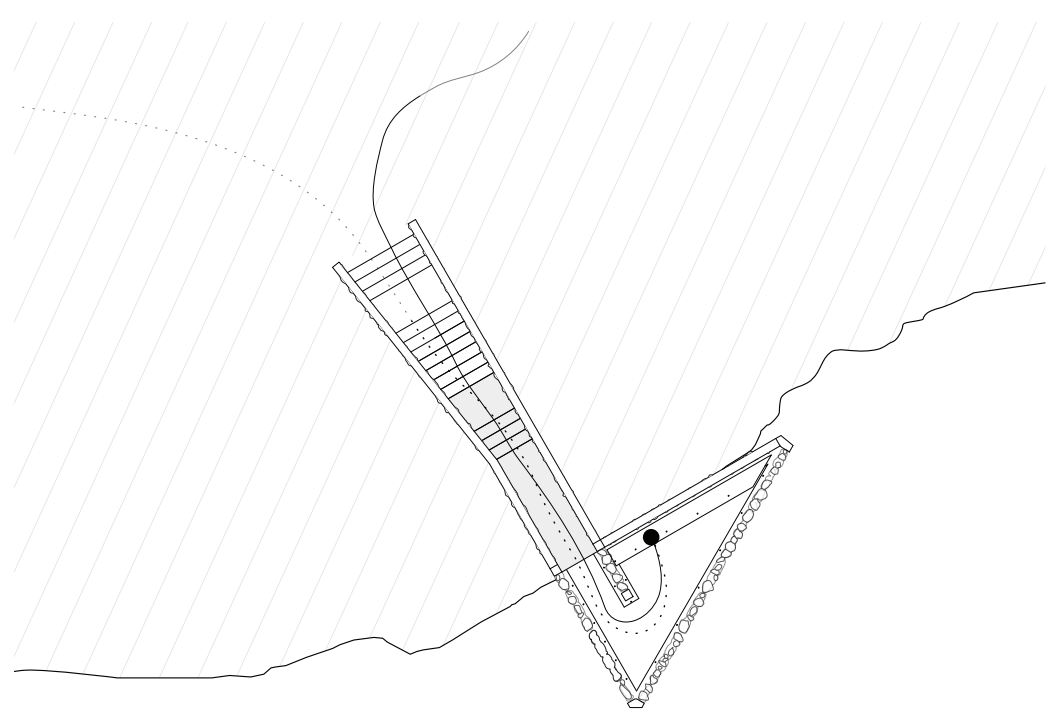




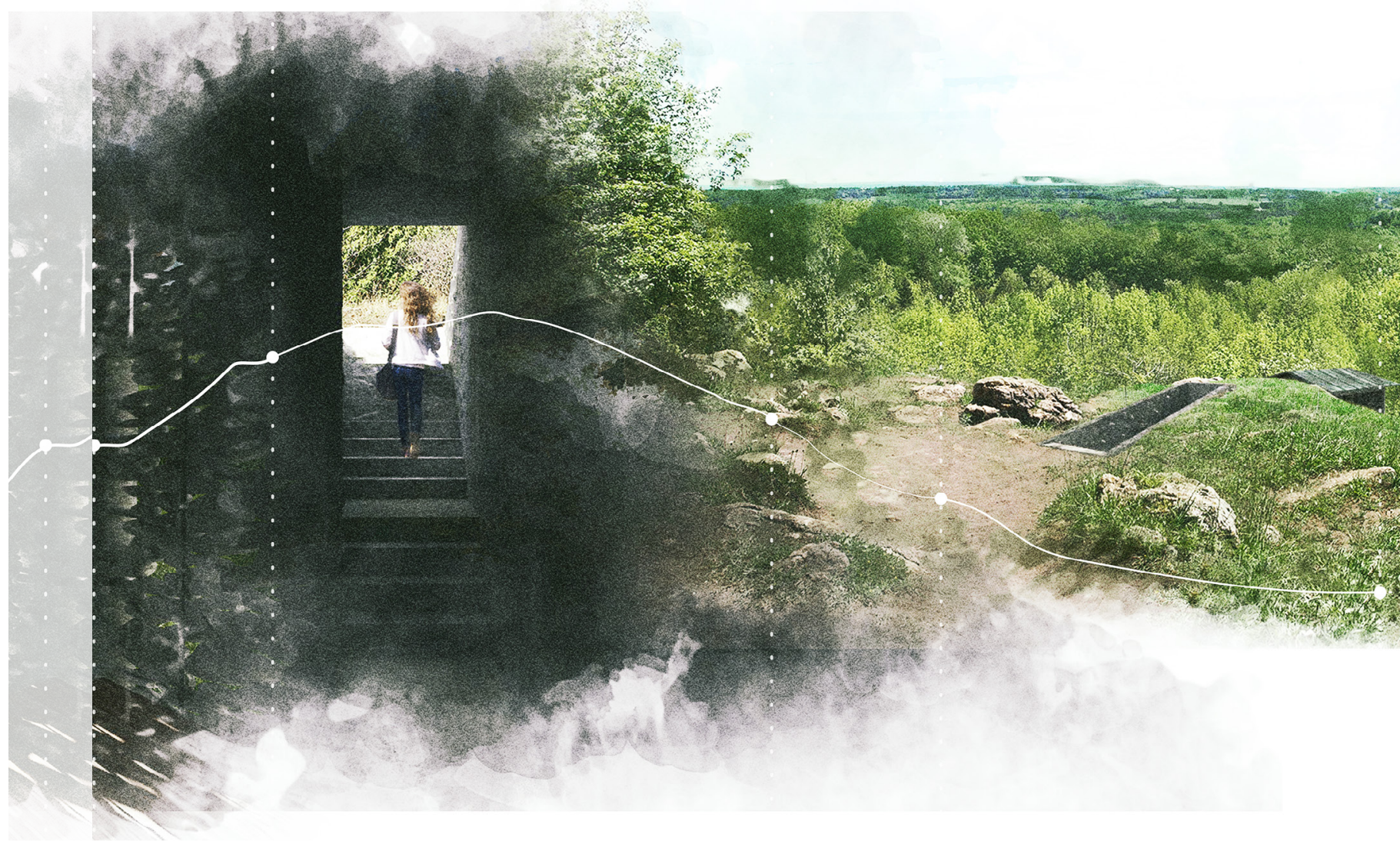

C 
Unlike before, the visitor turns from a dimly lit space to one of darkness, where light pours in from above. One moves from the floating to the grounded, with the roof above closing in as they enter back into the heavy earth. The visitor ascends the stairs as they open to become larger. The roof above disappears and the visitor is drenched in light once again, the outlook behind them. Once in the open area, the visitor moves back into the forest, continuing their hike.

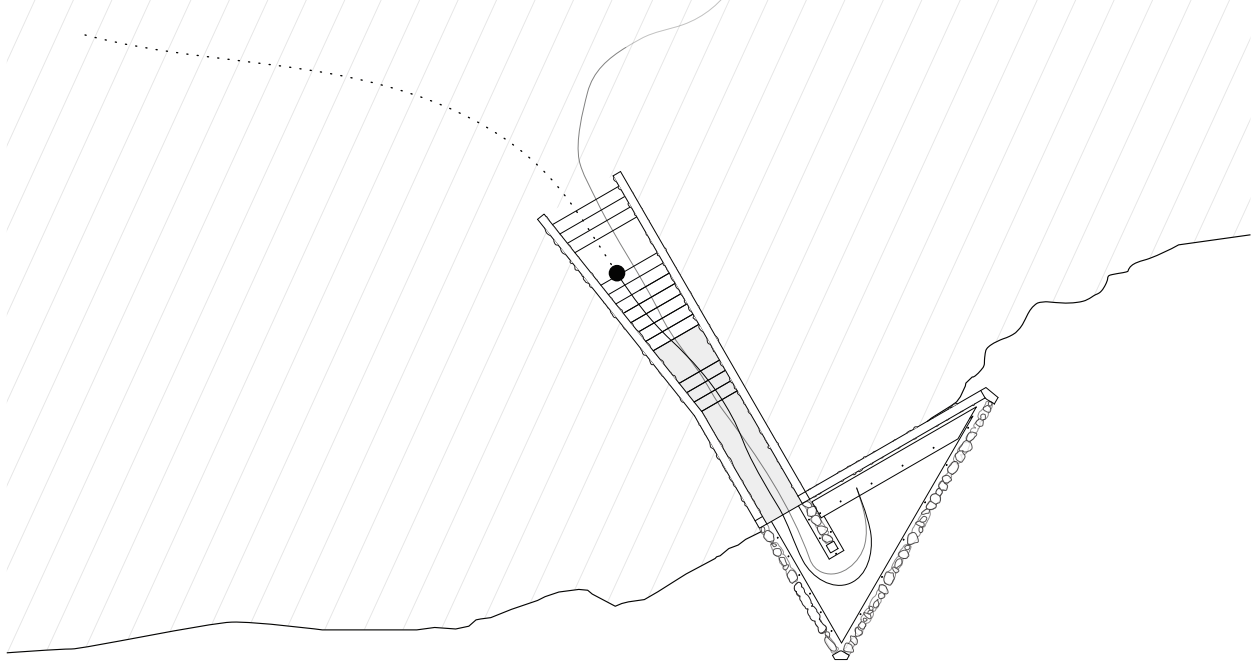




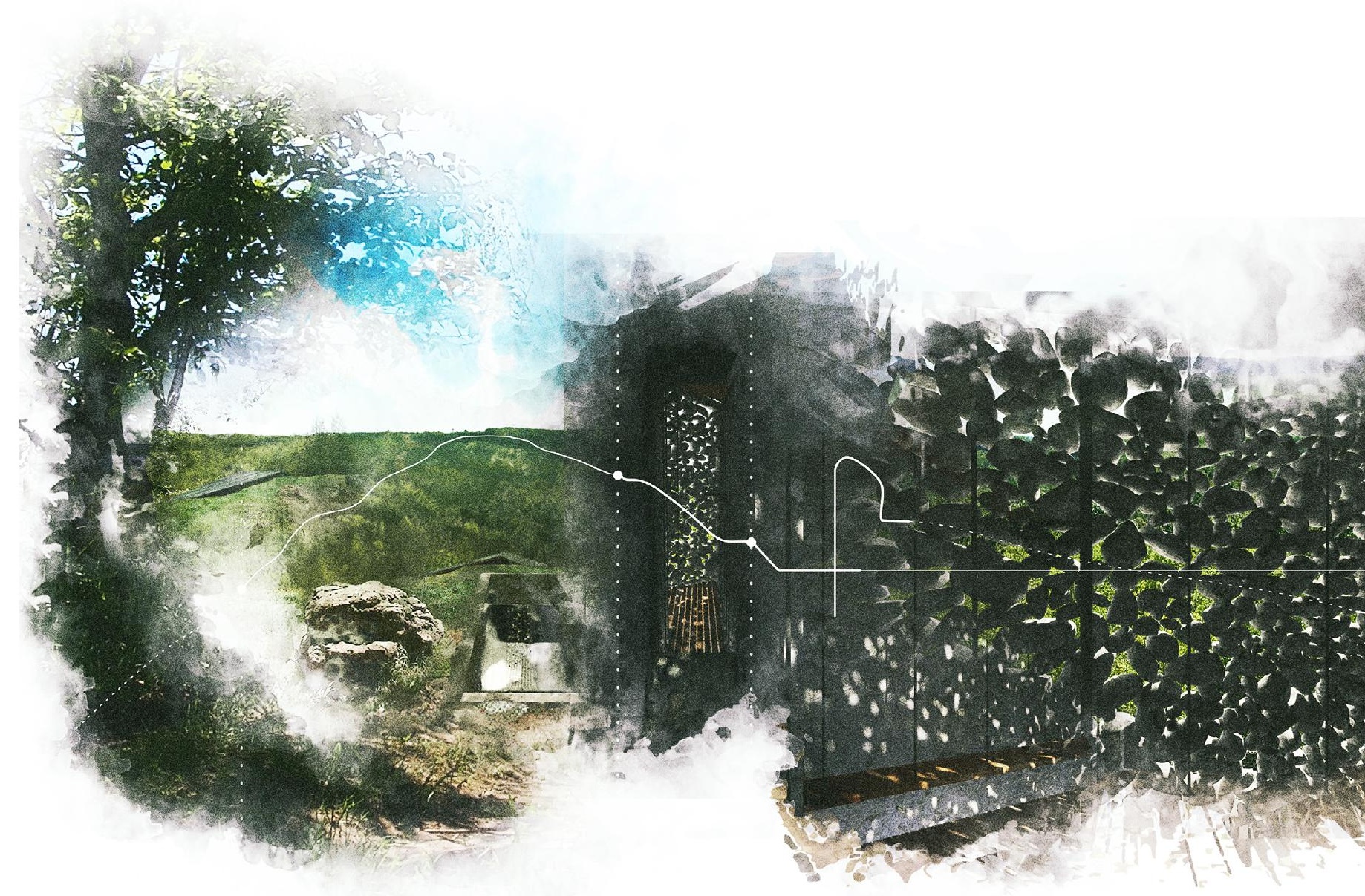


The overall experience of this armature leaves the impression of the enhancement

d. Holistic Mapped Experience of the Armature showcasing the designed embodied experience of the air by the extension of the cliff over the whole park and the light feeling of the space contrasted against the heavy, dark, rocks holding the floor the visitor stands upon.

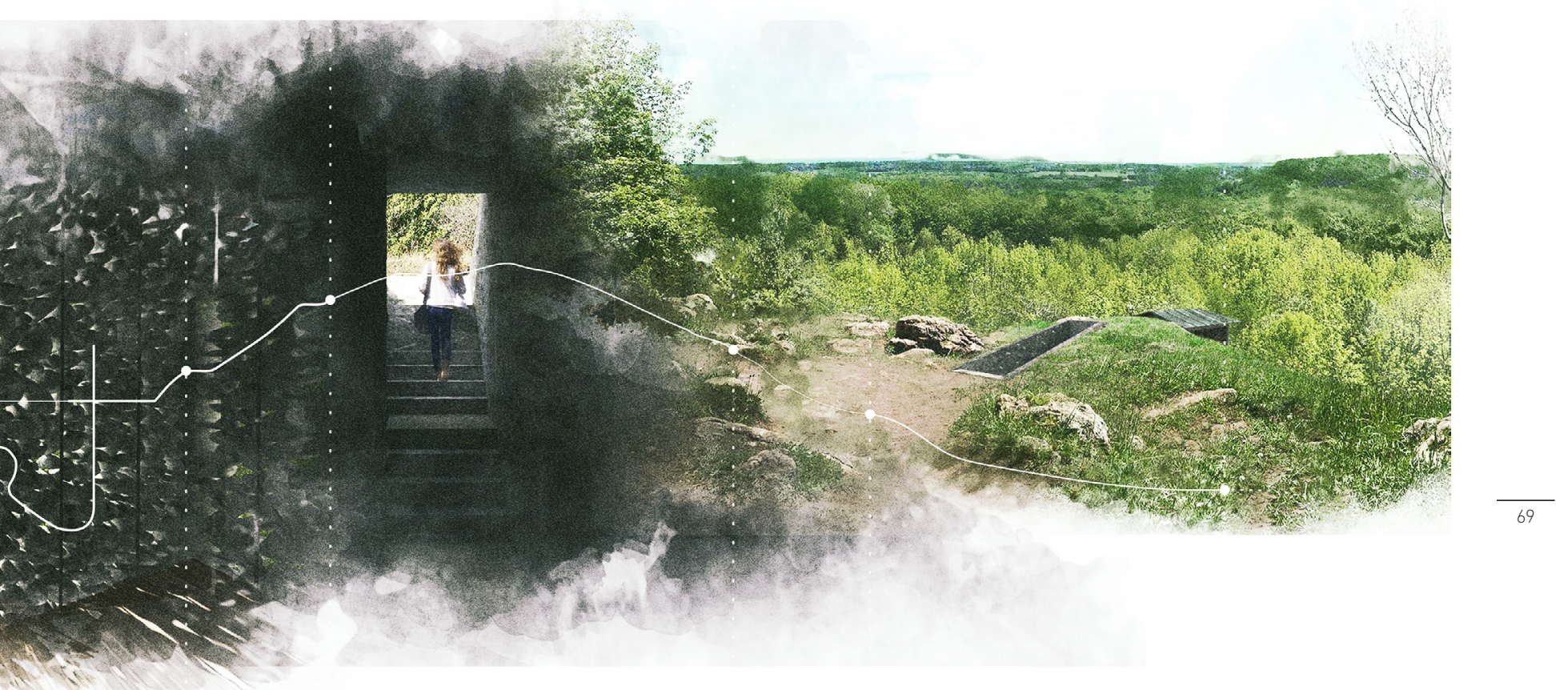


05.2 Armature of Water

Figure 34: Representation for the intent of the atmosphere for the Water Armature
The intent of this experience is making the body aware of its presence with moisture. As such, the experienced atmosphere is based on the feeling and smelling the moisture of the space in different forms; in the air, materials, and as water, all of which are directly related to the surrounding. This armature then acts as the enhancer of the pre-existing lake condition, where one is meant to feel as though they have entered 'water' when experiencing the armature. 


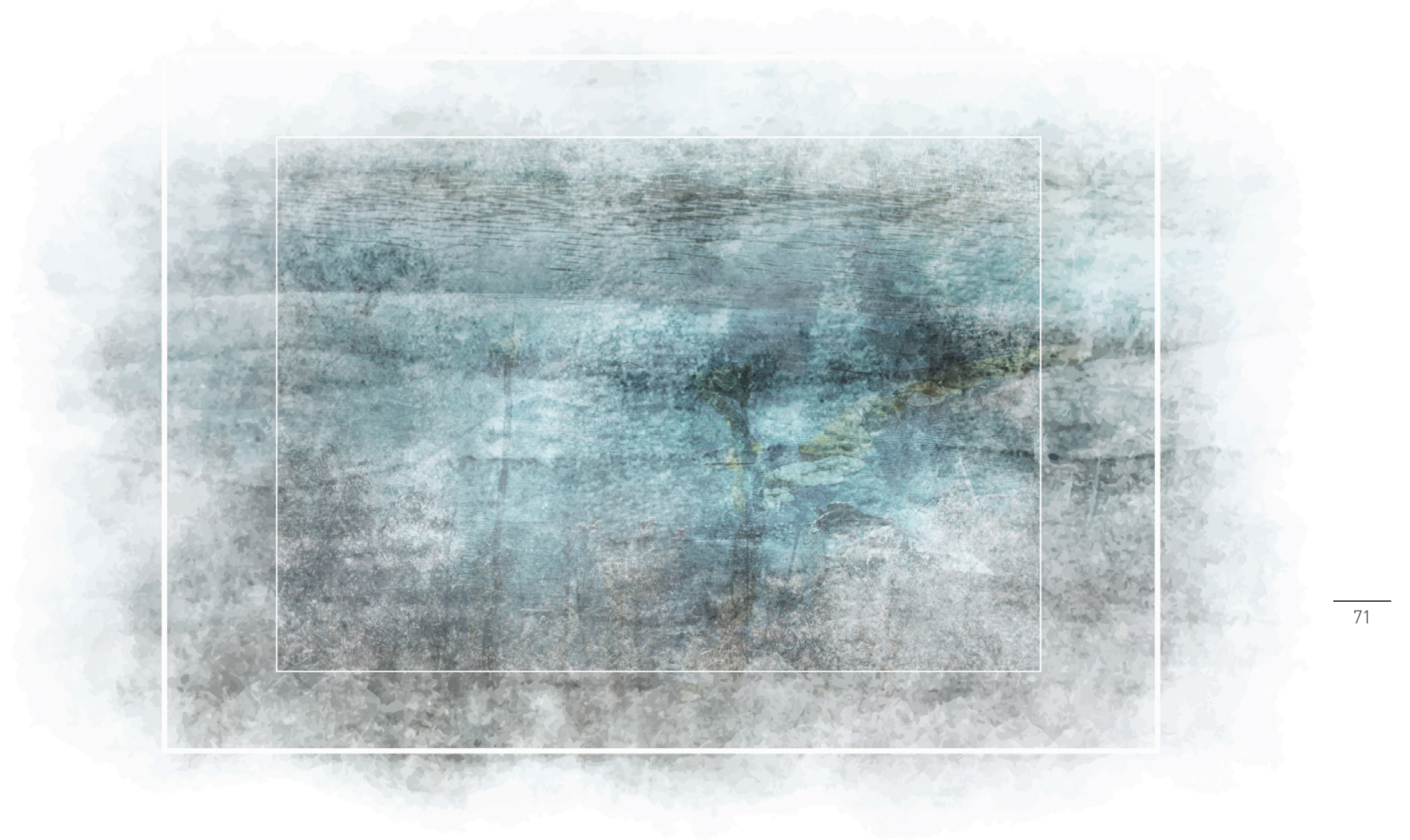


Wood Whingles

Wood Roof Structure
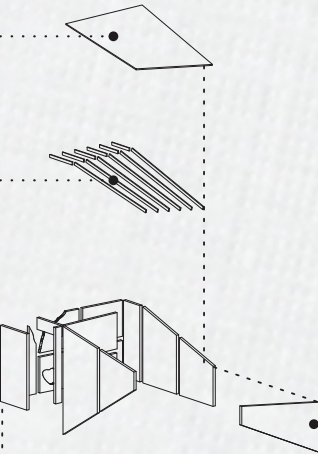

Dirt, Sand and Straw

Composing Solid Wall of

Wattle Structure

Wattle and Stave

Structure

Heavey Timber Framing

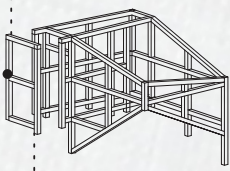

Wood Decking

Solid Wood Door

$\bullet$

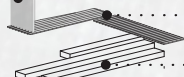

Smooth Stone Steps

Embedded into Earth

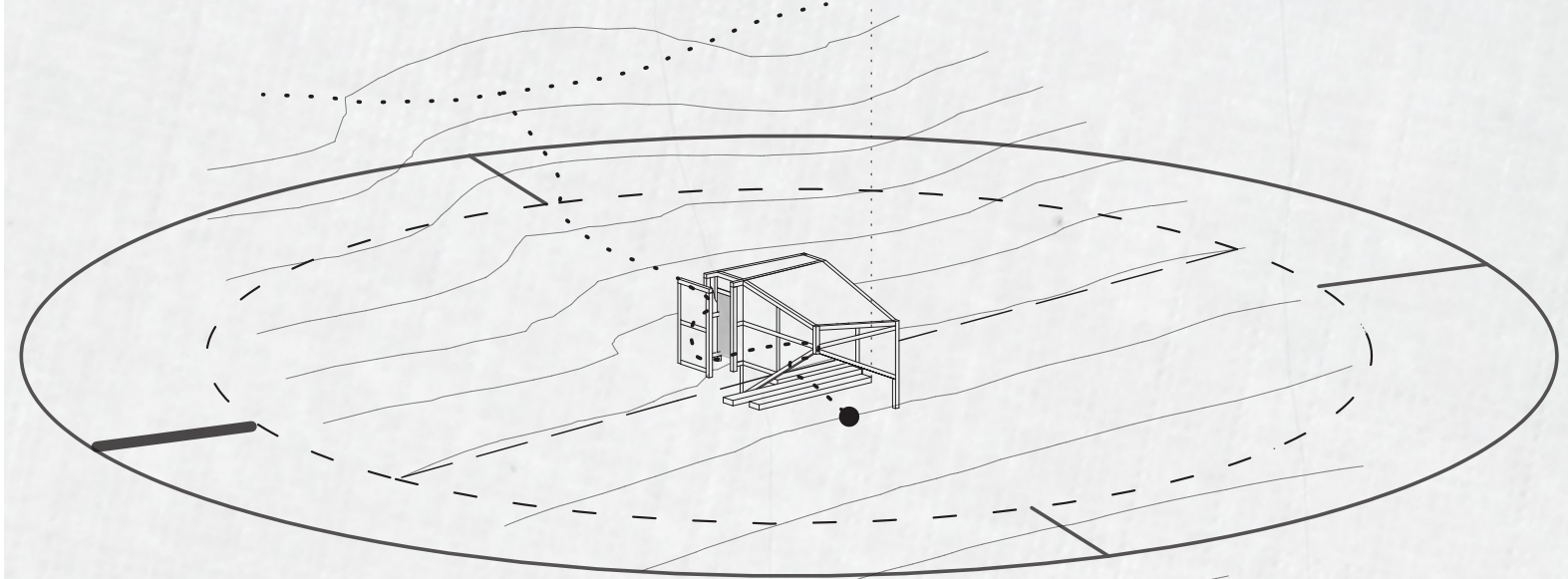


Figure 35: Axonometric of the Water

Armature showing its main components

Figure 36: Orthographic drawings of armature

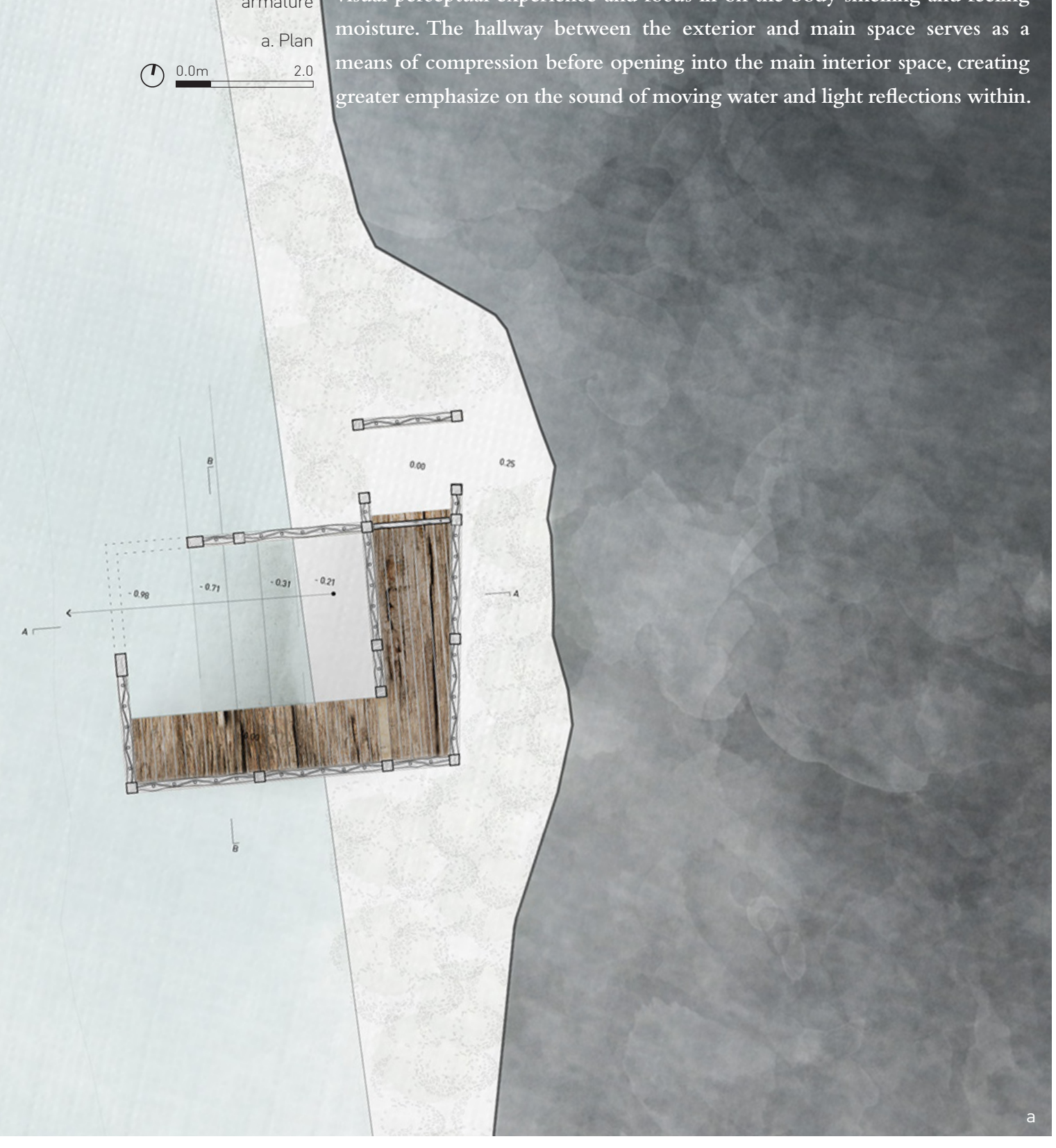
a contrast from the exterior, the transition from the exterior to the interior is one of darkness, allowing the eyes to adjust to the lighting experience of the inner space. Light and darkness where used in the armature to lessen the visual perceptual experience and focus in on the body smelling and feeling moisture. The hallway between the exterior and main space serves as a means of compression before opening into the main interior space, creating

The armature sits half on the land, half on the water, extending out and reaching between the two; it acts as a precipice between land and water. As 
The movement of the water acts as an interactive lighting experience throughout the spaces. The armature uses materials on site to construct the envelope, mainly the dirt and beach wood to create the wattle and daub walls. These walls then soak up the water, exude the moisture, and dry out naturally and with the movement of the water. The walls and roof extend out into the water, allowing the visitor to choose an action or direction within the space. The visitor can move out above the water along

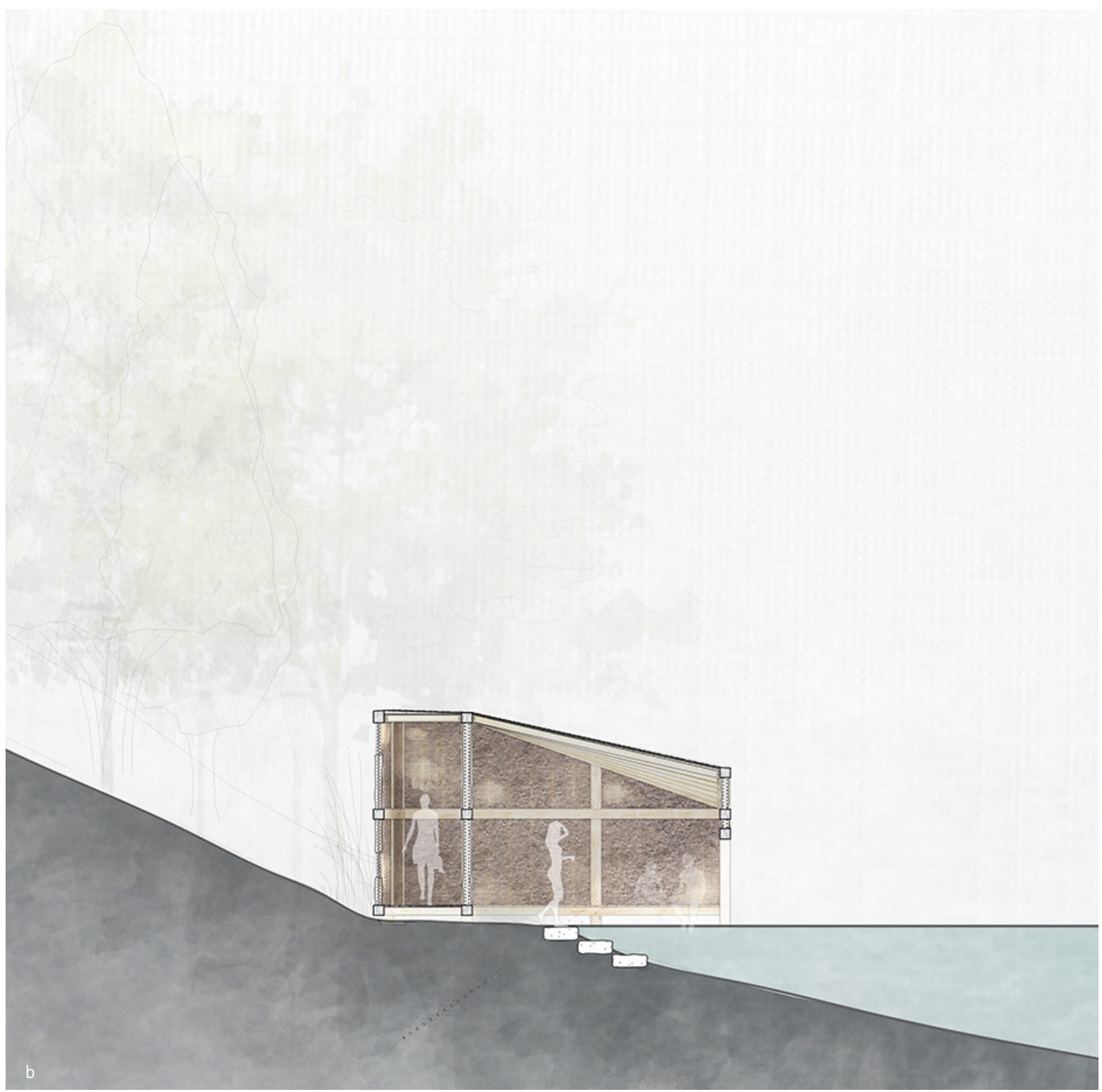


an elevated wood path and put their feet in, or step down onto land and walk into the

b. Section a-a c. West Elevation

$0.0 \mathrm{~m}$ 2.0 water, enabling them to swim out into the lake. Stepping into the water, the visitor feels cool smooth stone steps before the coolness of the lake floor. The main space's roof angles down toward the water, and towards the extension of the wood deck, motioning the visitor to enter the water, or to sit on the deck.

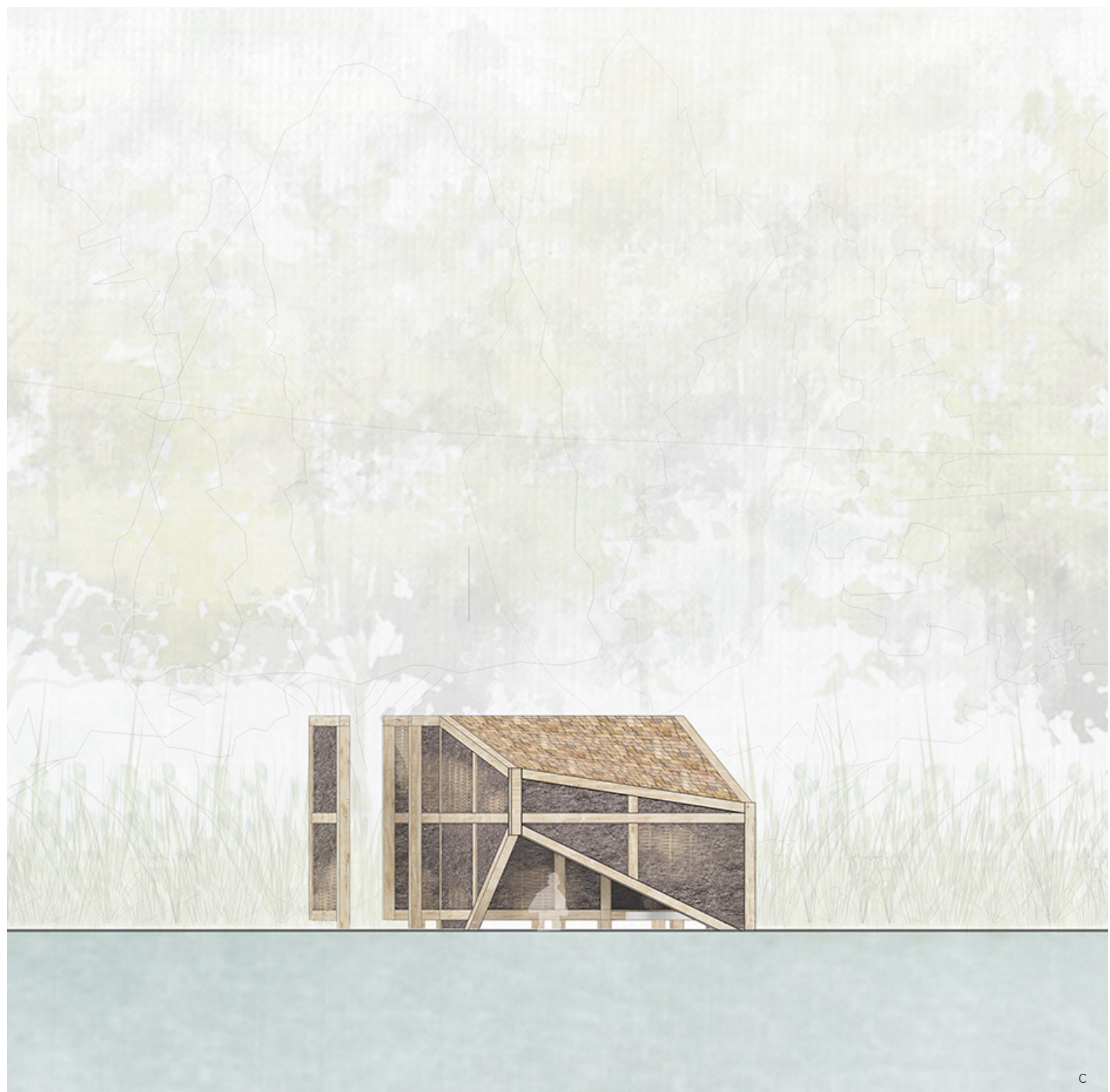




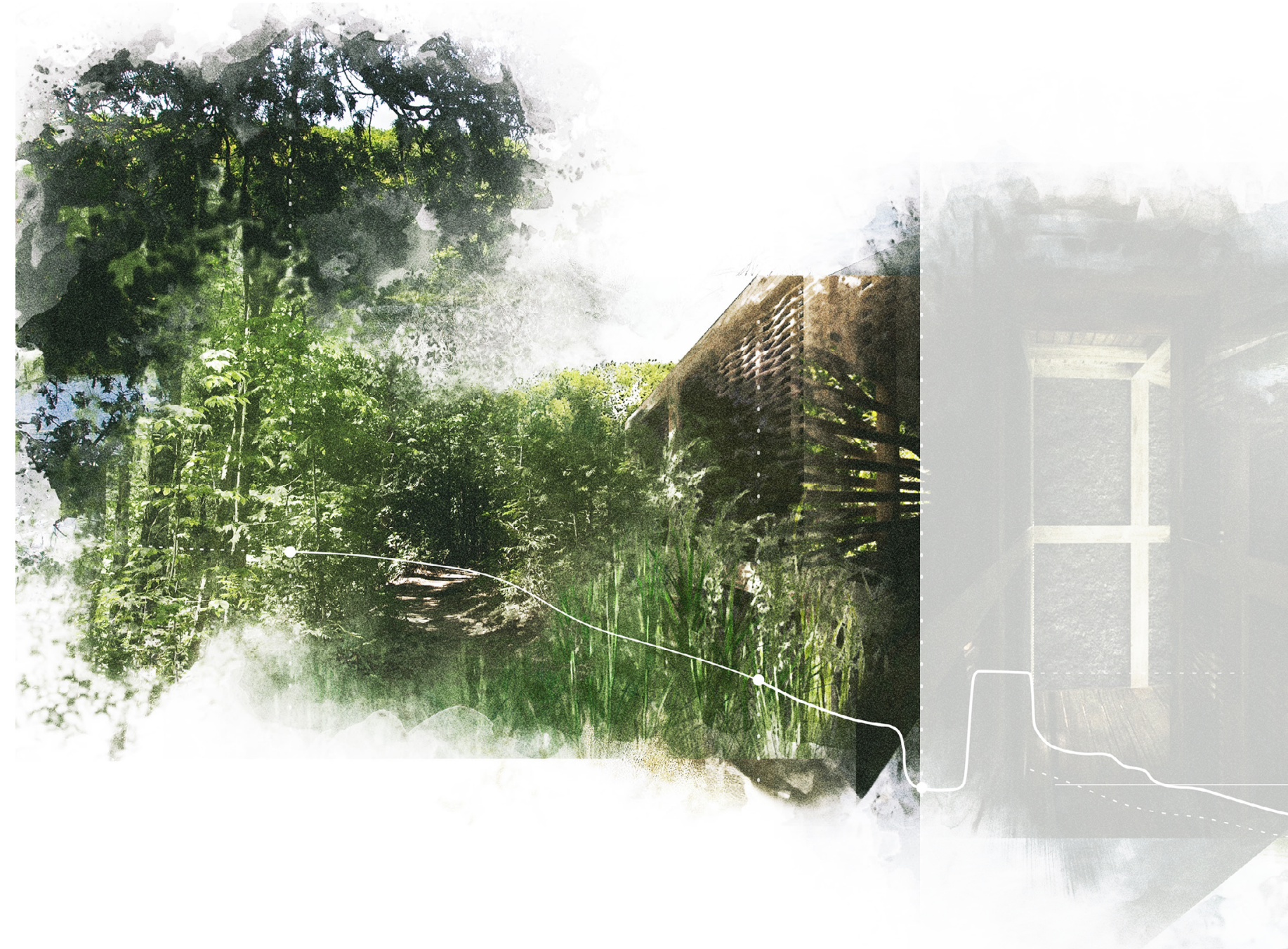


Approaching the armature through a heavily forested slope, glimmers of light are seen from the sheet of water, moving with the sweeps of air one moves from covered

Figure 37: Mapped Water Armature experience

a. Approach and Entrance to open space adjacent to the lake, bringing cool smells of the water to the nose. The trees above move overhead. Glimpses of the earth walls are seen through the tall grasses lining the lake, which shift slightly as the warm sun shines down. At the entrance, glimpses of the adjacent lake can be seen briefly through the tall grasses to the right, with a tall aged wooden door to the left. 


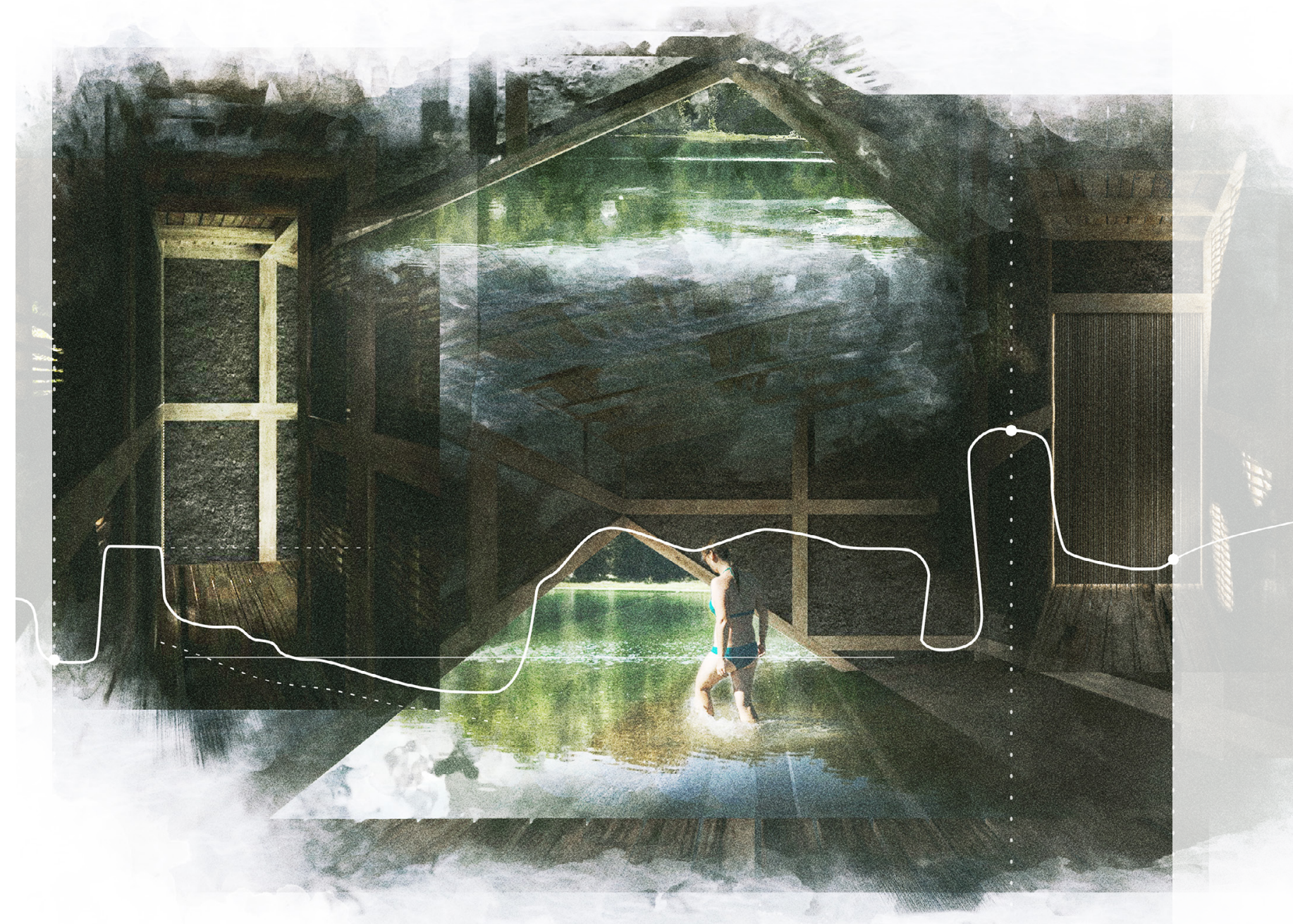


The visitor moves though a large pivoting door entering a dark, damp, compressive space. Small openings provide snippets of the exterior grasses swaying in the wind. At the end of the hallway, light is seen dancing along the wall; the space is quiet and feels smaller as one moves towards the end. Turning the corner, the space extends out into the water. The air is heavy and thick. The visitor steps out over the water toward the end of the wood floor. Sitting on the edge, one can feel the water on their feet, light pouring in from the opening; the coolness of the space almost feels submerged in the water. Moving from sitting on the edge, the visitor stands, walks to where land meets the wooden floor, and steps down onto cool wet ground. The moving water gives vague glimpses of a smooth hard material directly below the surface of the water, revealing itself with the low-point of waves. The visitor steps into the water, feeling the coolness of the steps, then the lake bottom and out into the water. The light, the air, and the material work as an acted gesture of entering the water. Exiting the main space, the visitor re-enters the dark transitional space with diffused light pouring in from small holes in the wattle and daub walls.
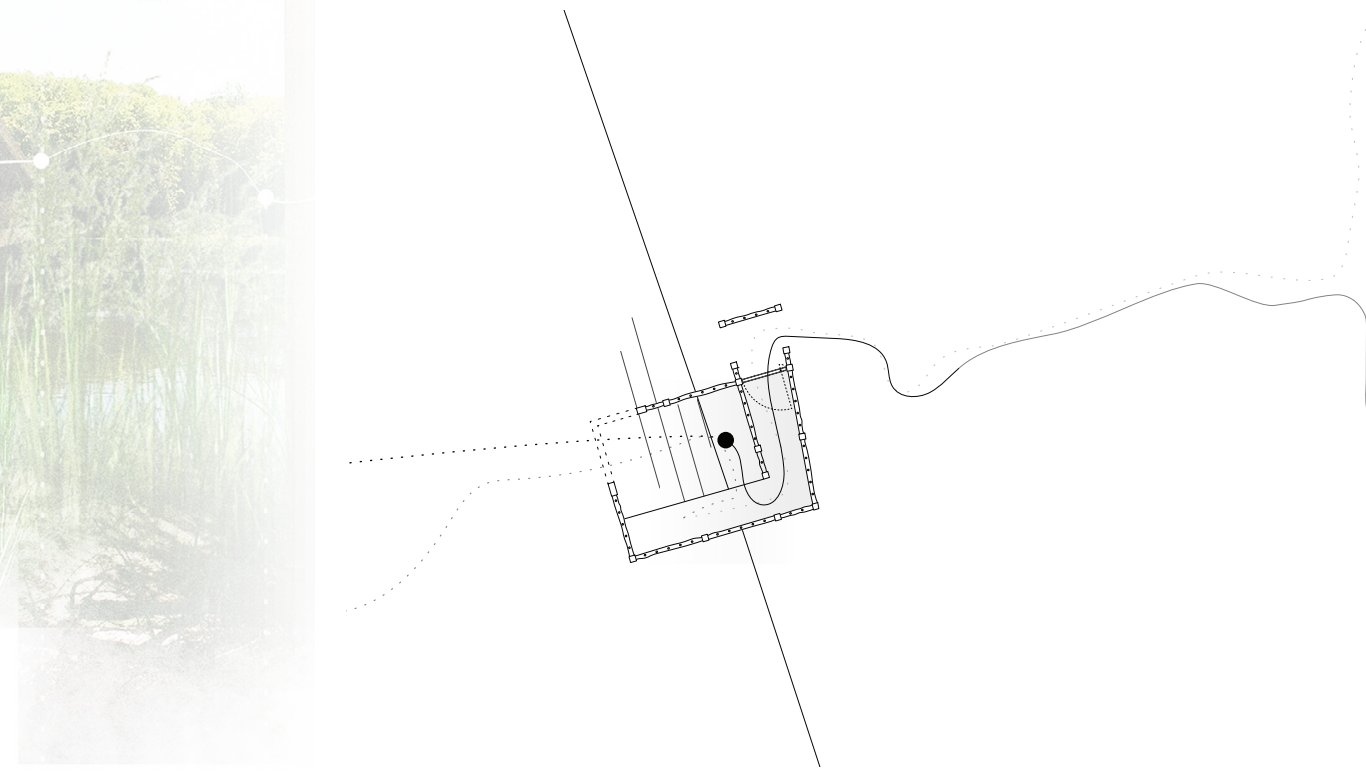


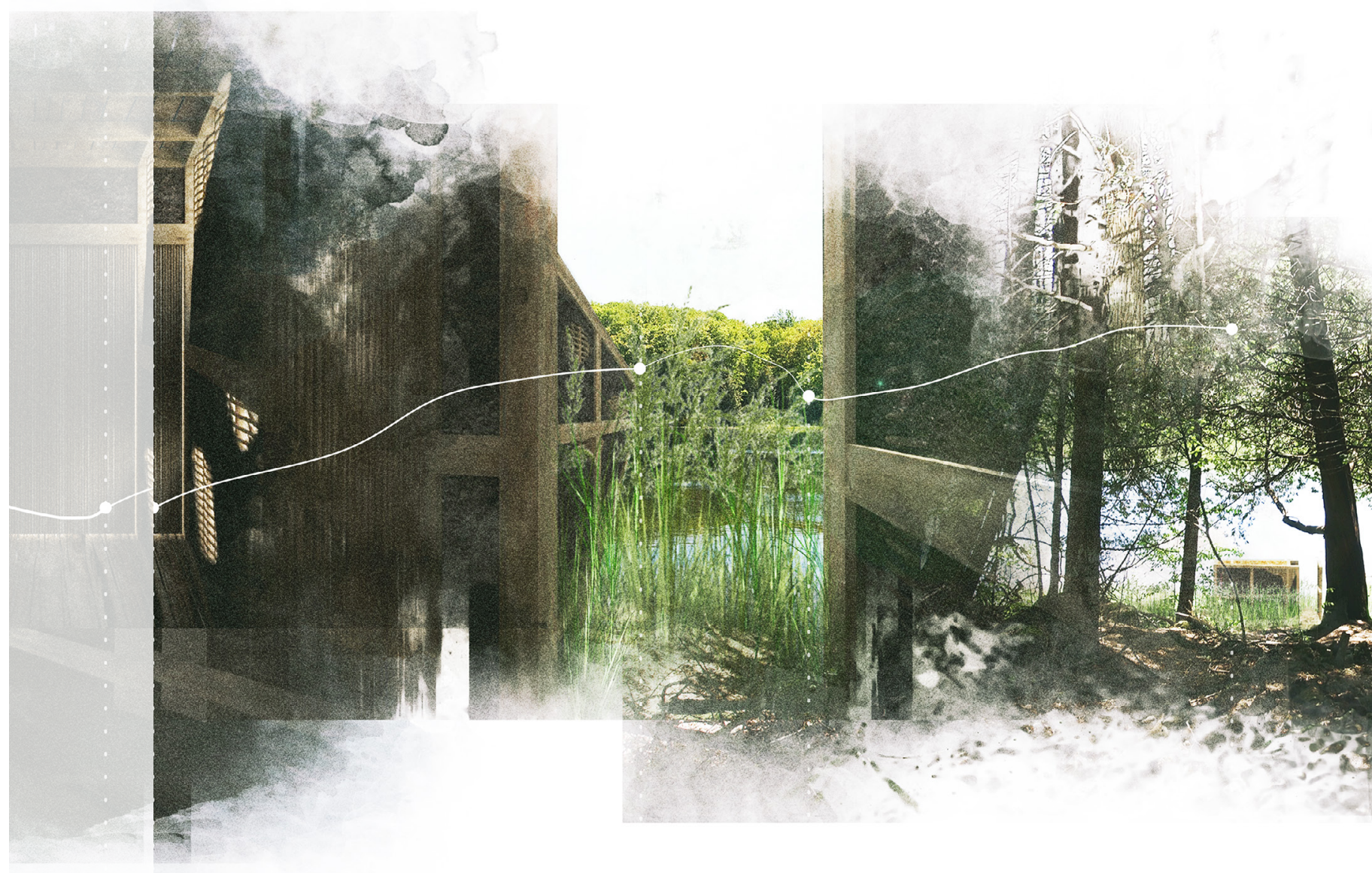


The visitor pulls open the heavy wooden door. Blinded by the bright light from the exterior, one shifts back into the grassy area surrounding the armature, facing back into the forest. Moving up the hill, one is covered overhead again with tall aged trees, moving with the wind. 
The light, the air, and the material work as an acted gesture of entering the water. The various means of moisture touch the body in different ways, making it aware of the physical experience of the space. In the quiet space, the water is accentuated, feeling as though one is already in the water from the atmosphere. d. Holistic Mapped Experience of the Armature showcasing the designed embodied experience

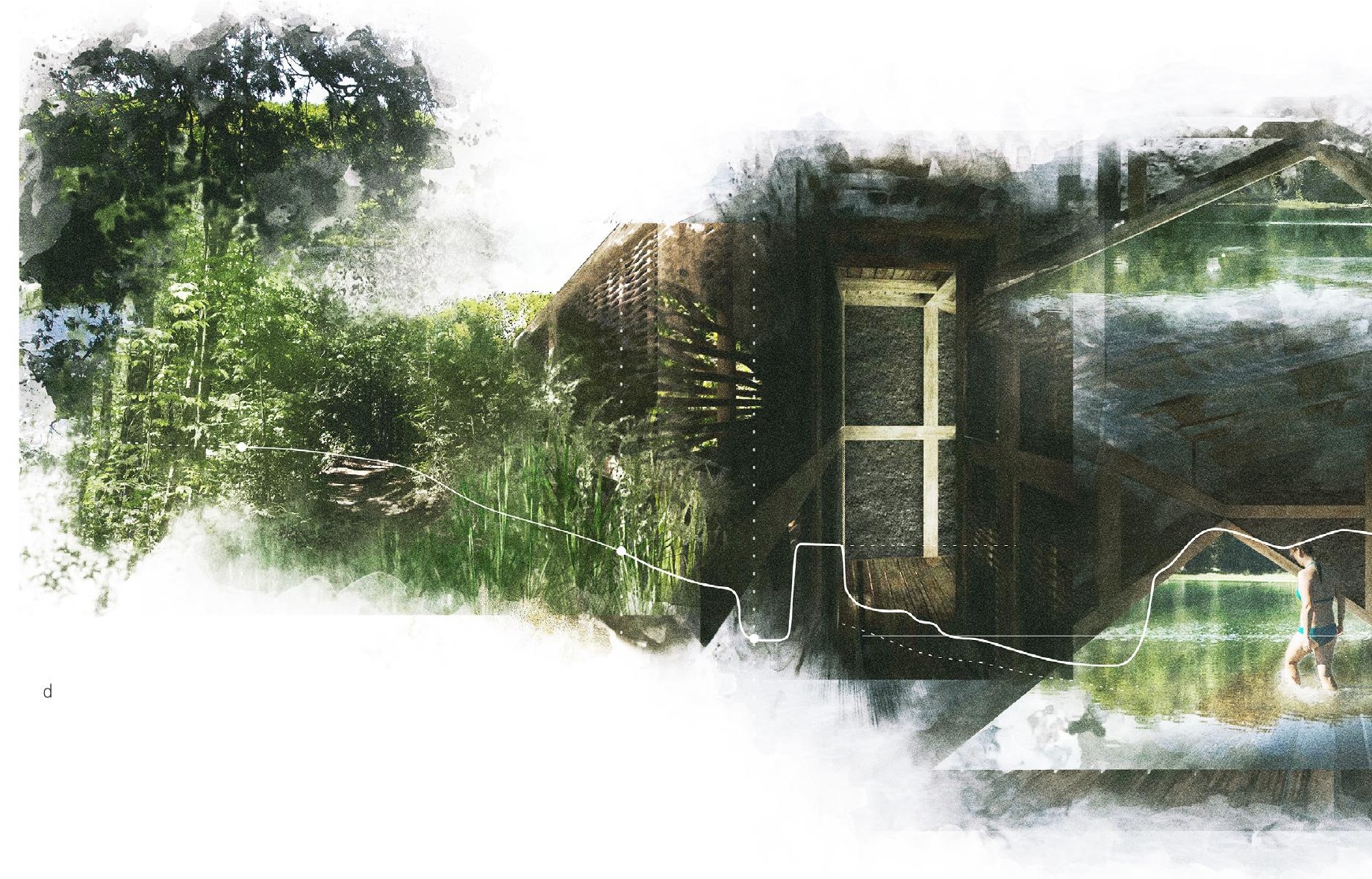


05.2 Armature of Earth

Figure 38: Representation for the intent of the atmosphere for the Earth Armature
The intent of this experience is making the body aware of its presence through the use of shelter, materiality, and the body in relation to them. The armature speaks to the transient nature of its surrounding, allowing various lighting conditions to affect the experience of the materiality. The surrounding can only be seen once one has entirely moved through and encompassed by the armature. Once inside, one is meant to feel as though they are a part of and within the forest simultaneously. 


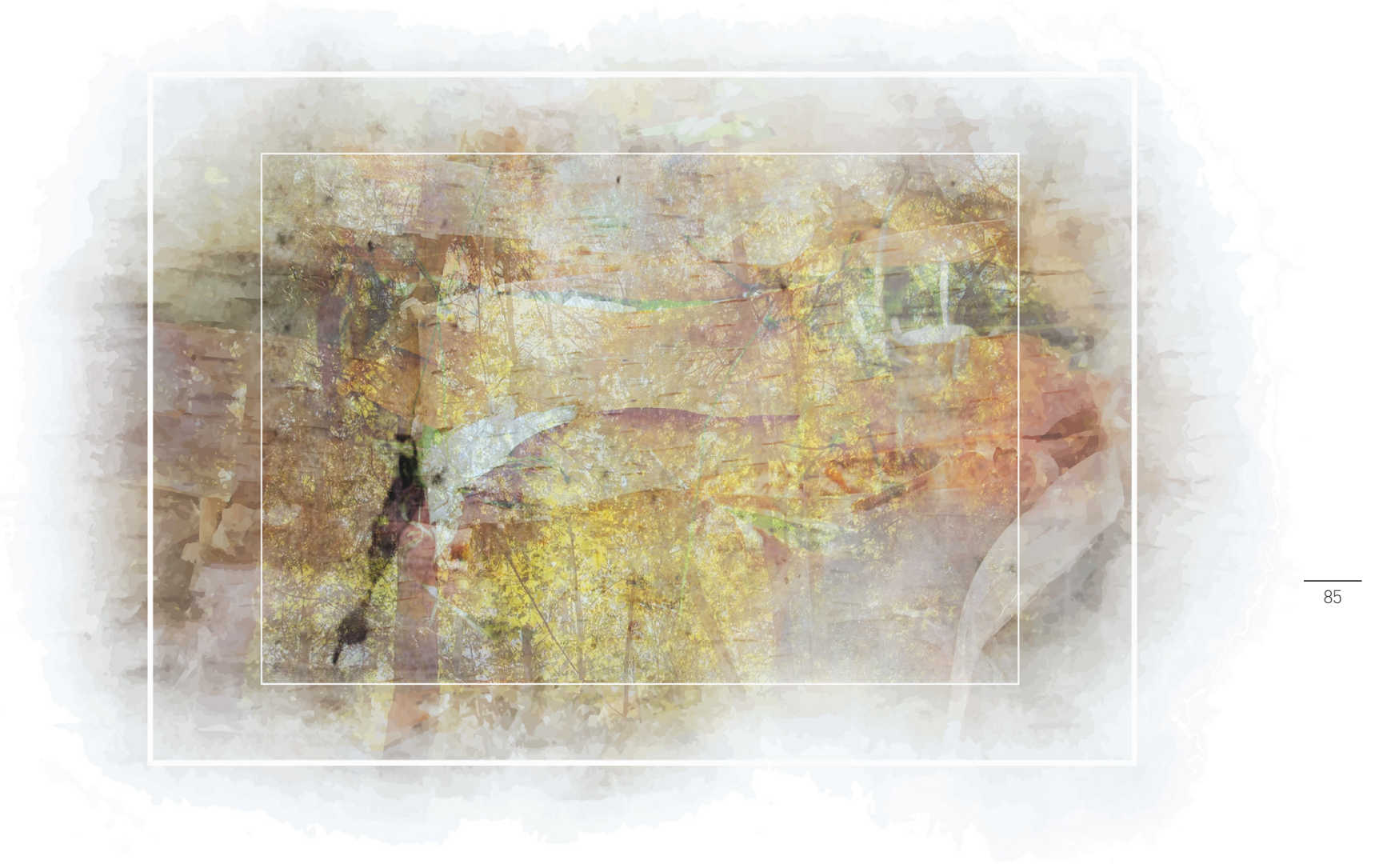




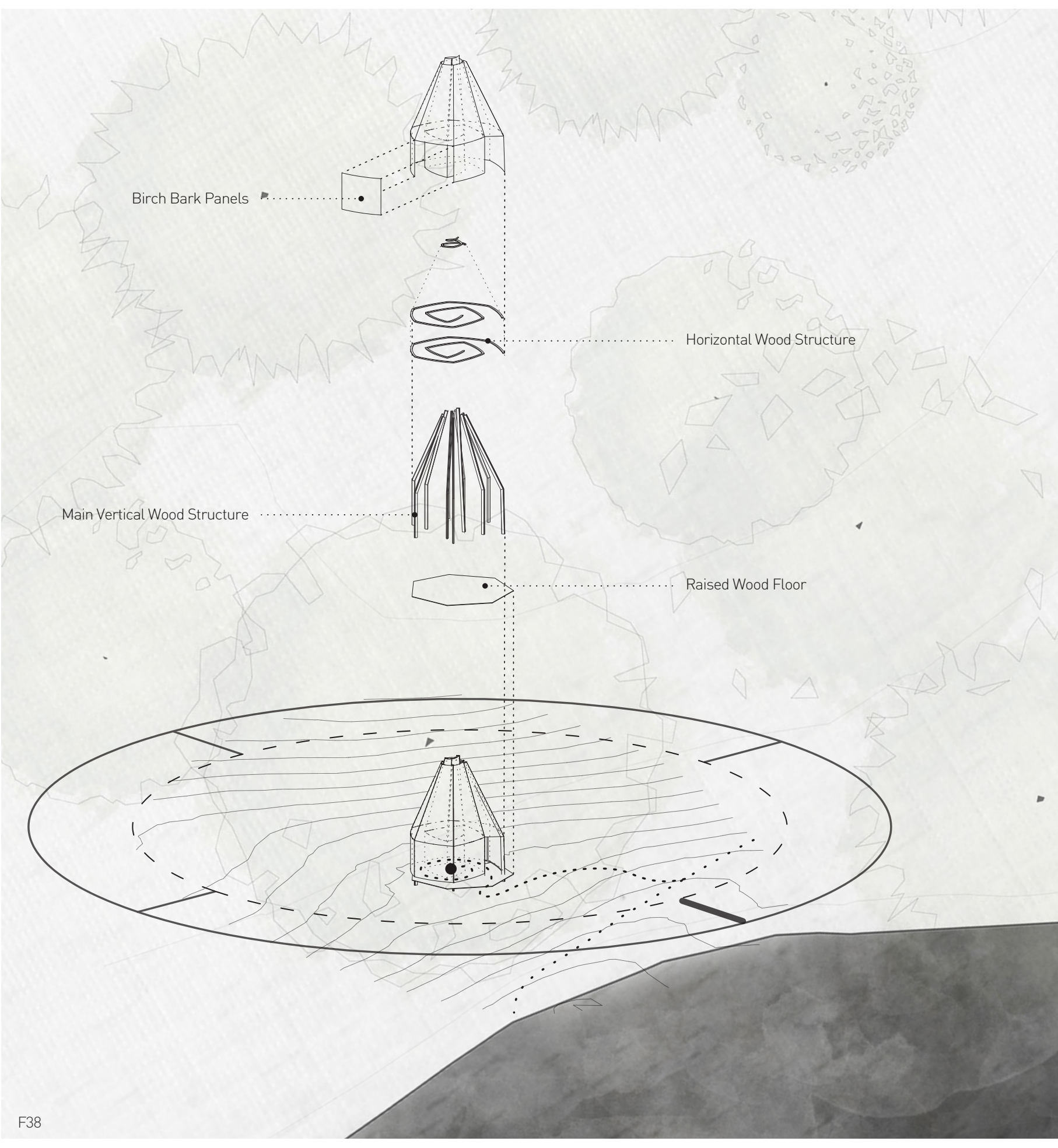



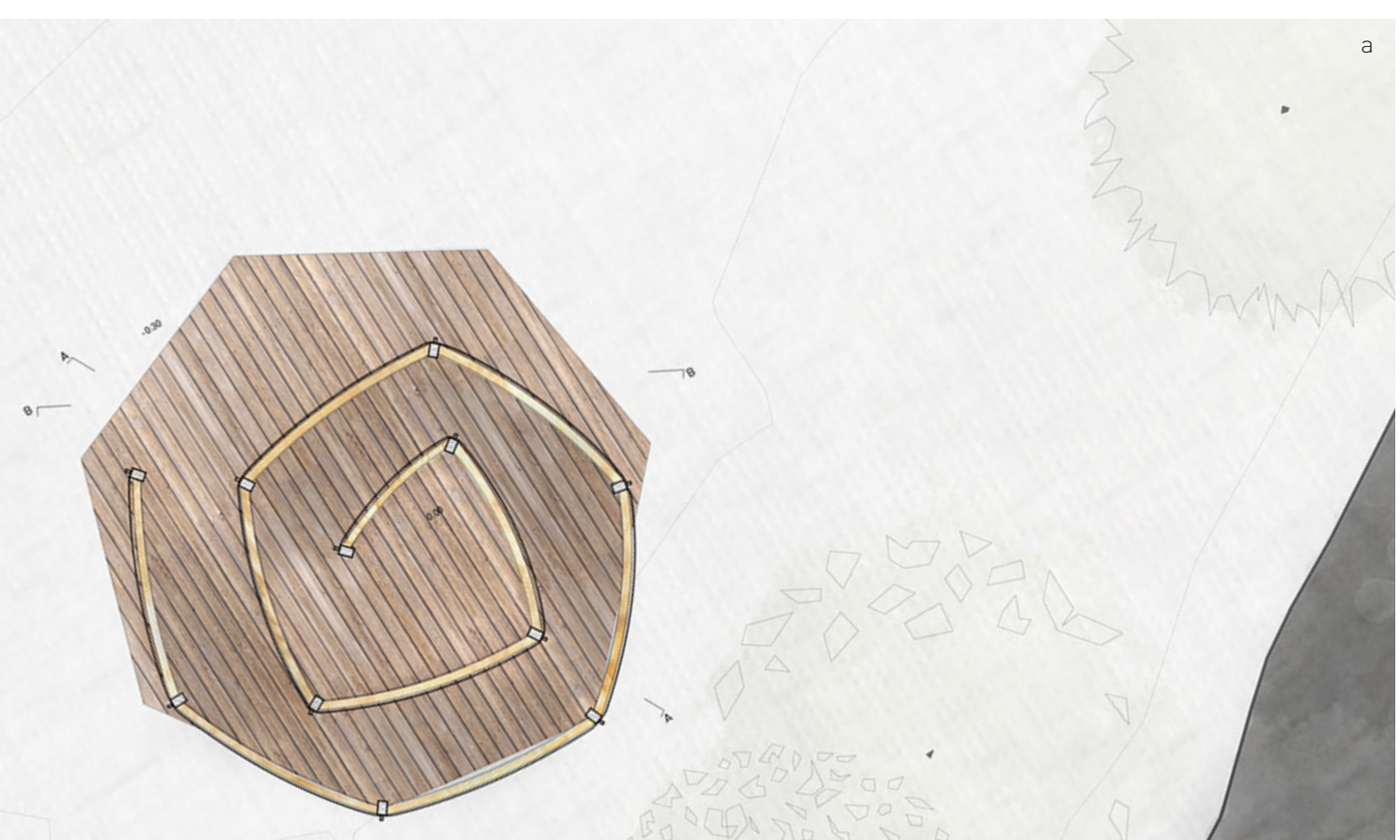

Figure 39: Axonometric of the Earth Armature showing its main components

Figure 40: Orthographic drawings of armature

a. Plan

The spiral shape of the path was based on the same main measurement: 2.5 meters. An equilateral triangle was made, then placed within a square matching one of the edges of the triangle, inside a pentagon, inside a hexagon, inside an octagon. A continuous line was then drawn to create the wall bases. What was created was a path which moves the visitor from the exterior, turning in on themselves until within the center of the armature. The variations in the volume make one aware of how their body is moving through space, regarding how much room they have to move, how close the

$0.0 \mathrm{~m}$ wall is to their body and the space which they exist in. 
Using expanding and compressing of spatial volumes and the tactile envelopment of the materiality of the site, the visitor feels a varying of space around them as they move through the armature. The armature directly relates to its surroundings through its materiality and sweeping gesture upwards towards the canopy of the trees. The entrance into the armature appears as a parting of the walls, allowing one to slip within the opening. The enclosure is constructed of vertical wood members and horizontal wood braces. Birch bark is then sewn together and weaved together and placed spanning between two main verticals. The spatial volumes vary with the movement

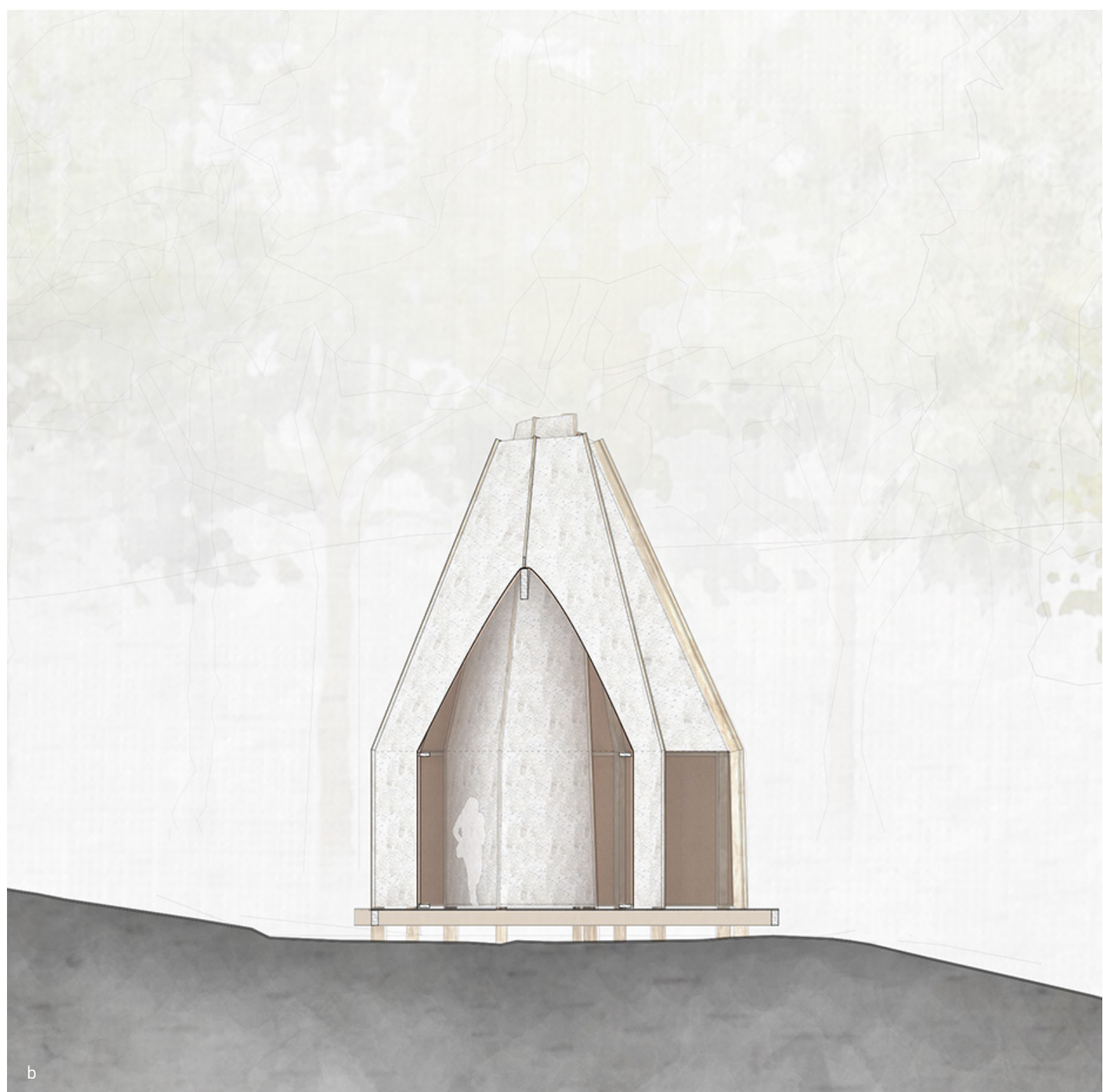


through the armature, with the vertical posts arching over the pathway at varying degrees, creating the outer wall, extending overhead. The design revolved around the body turning in on itself, moving towards a moment where a specified view was

b. Section a-a c. Section b-b center, where the armature opens to the sky above. While in this densely woven and enclosed space, shadows from the trees outside will move along the surfaces. Dappling of shadows slightly moving, a direct result of the surrounding. The moving air around will not be permitted within.

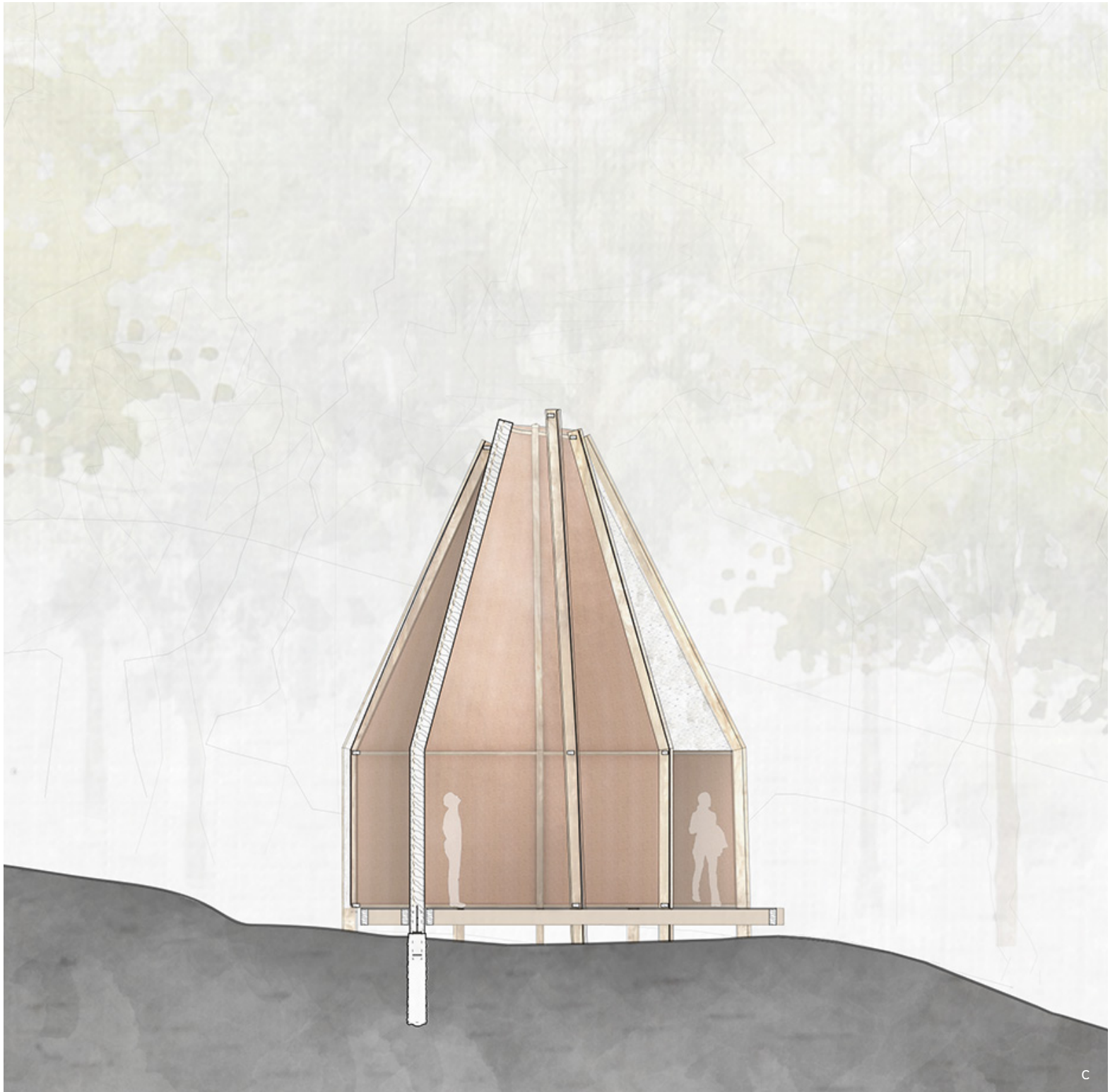




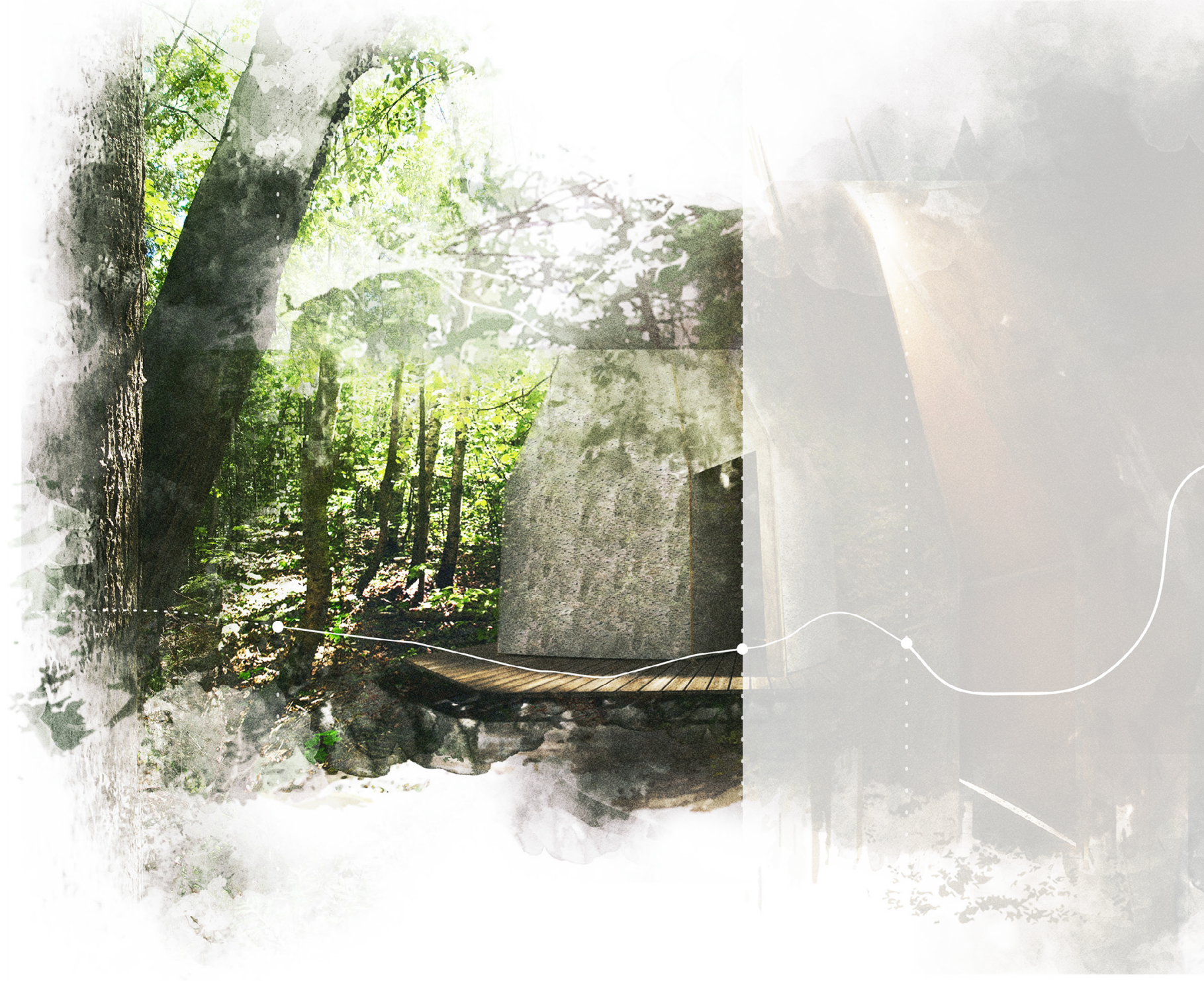


aygives

Figure 41: Mapped Earth Armature experience

a. Approach and Entrance
Approaching the armature along a forested trail, and opening in the heavily forested areas appears. The definitive edges of the trees become apparent due to the abundance of light pouring through the opening in the canopy. White birch trees line the edge of the clearing, as the wind shuffles through the trees. The armature acts as though it belongs with the birch trees around it, camouflaging itself with white birch bark exterior, standing tall. Stepping from the clearing to the raised floor, the armature opens creating an opening, within looking dark and warm.

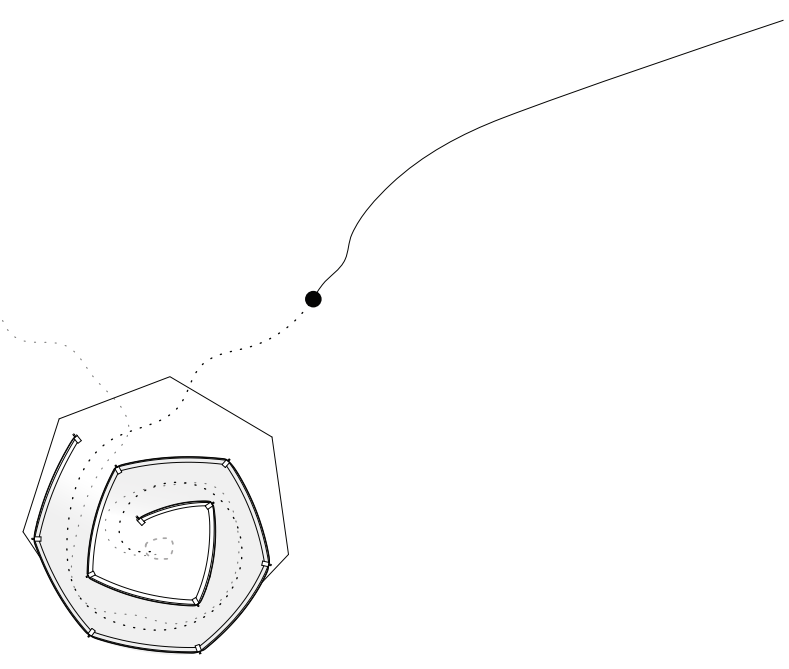




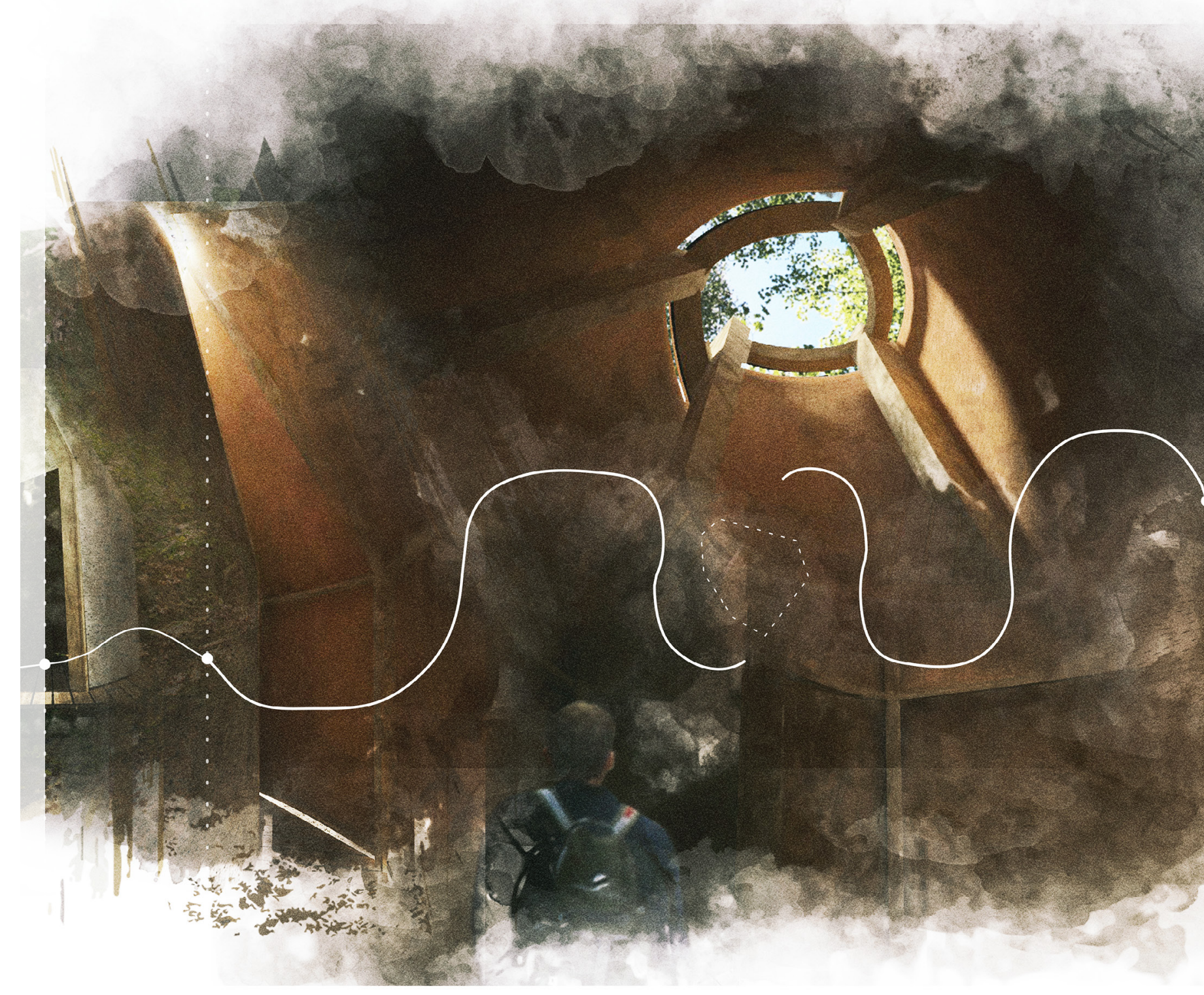


As one moves within the entrance, the walls reach up and over one's head, touching the innermost wall which one is turning in on, while the light begins to fade into a cool darkness. It is a wall, or perhaps a roof. It is indistinguishable. The vertical arms are all directed toward an unknown center. The outer wall is warm and orange from the inner of the bark, while the inner wall is white, just as the armature is from the exterior. Light is streams in from a slit overhead, while shadows move on the outer wall. Reaching the center, only the dark warm toned inner portion of the birch bark is visible. It is quiet, warm, secluded, protected. The visitor cannot help but be drawn to the opening overhead, directing one's gaze out to the sky above. The view, lighting and the materiality in the space comes to the forefront, grounded and lite by mystical shadows, dancing along the warm birch surfaces. The wood floor feels grounded, yet raised towards the opening of the armature with smells of leaves and fresh scents of bark. The air is still and quiet, sheltering the body from the surrounding space. 


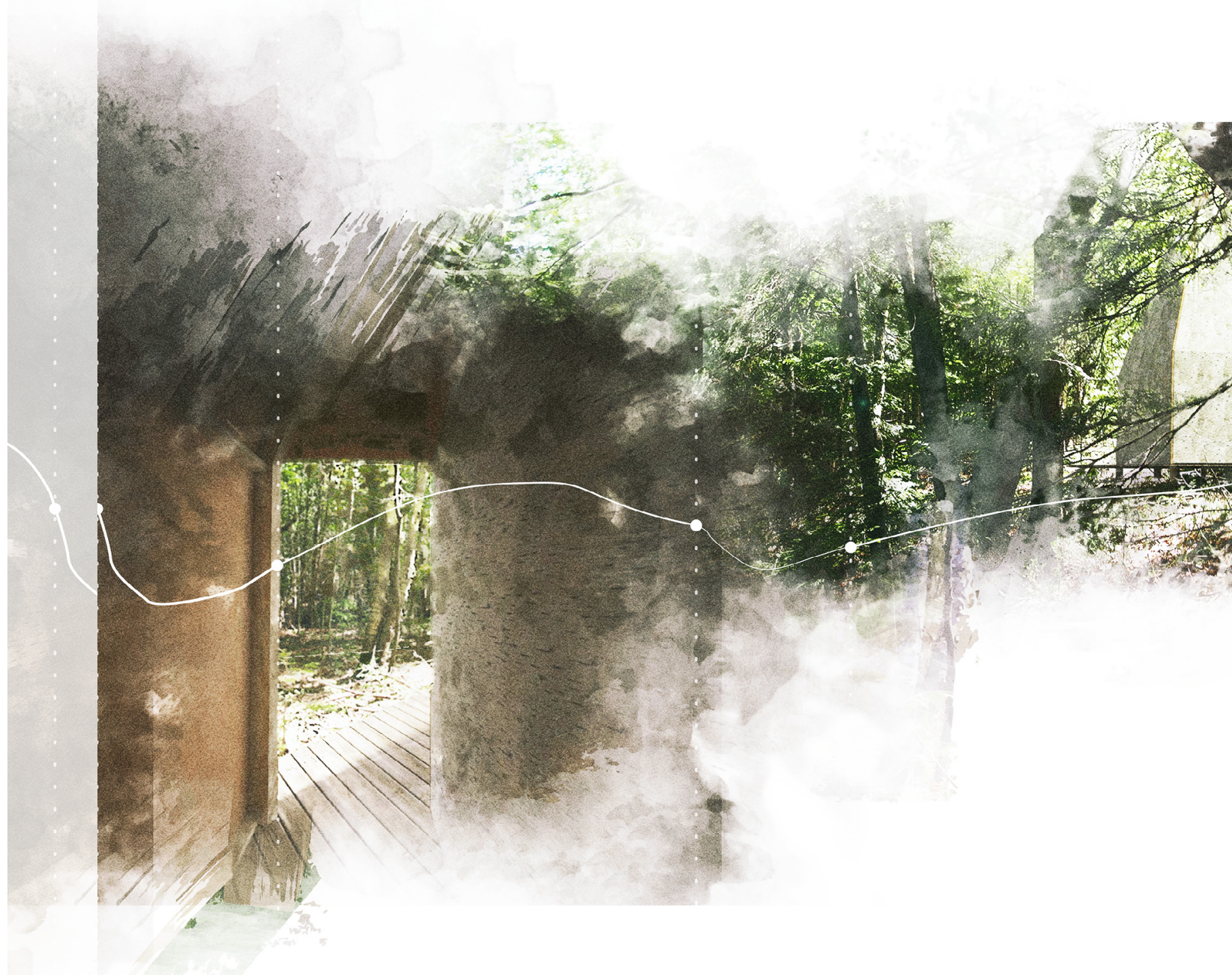


After watching the sky, the light, and the surrounding exist, the visitor begins their exit. One moves back within the movement space, enclosed within dark and duel toned birch bark. This time, the visitor sees the space get lighter as they move around, moving towards the opening in the birch bark exterior. One exits out into the clearing, towards the line of trees along the trail.

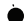

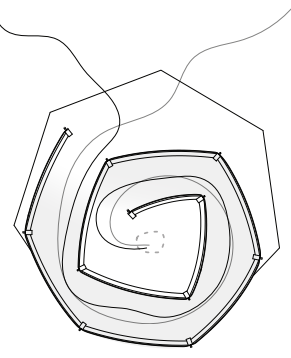


One experiences the physicality of the place in the creation of the atmosphere in the silence of the protected center space, where the view, lighting and the materiality in the space comes to the forefront. It is here, in this central space, where one is protected d. Holistic Mapped Experience of the Armature showcasing the designed embodied experience

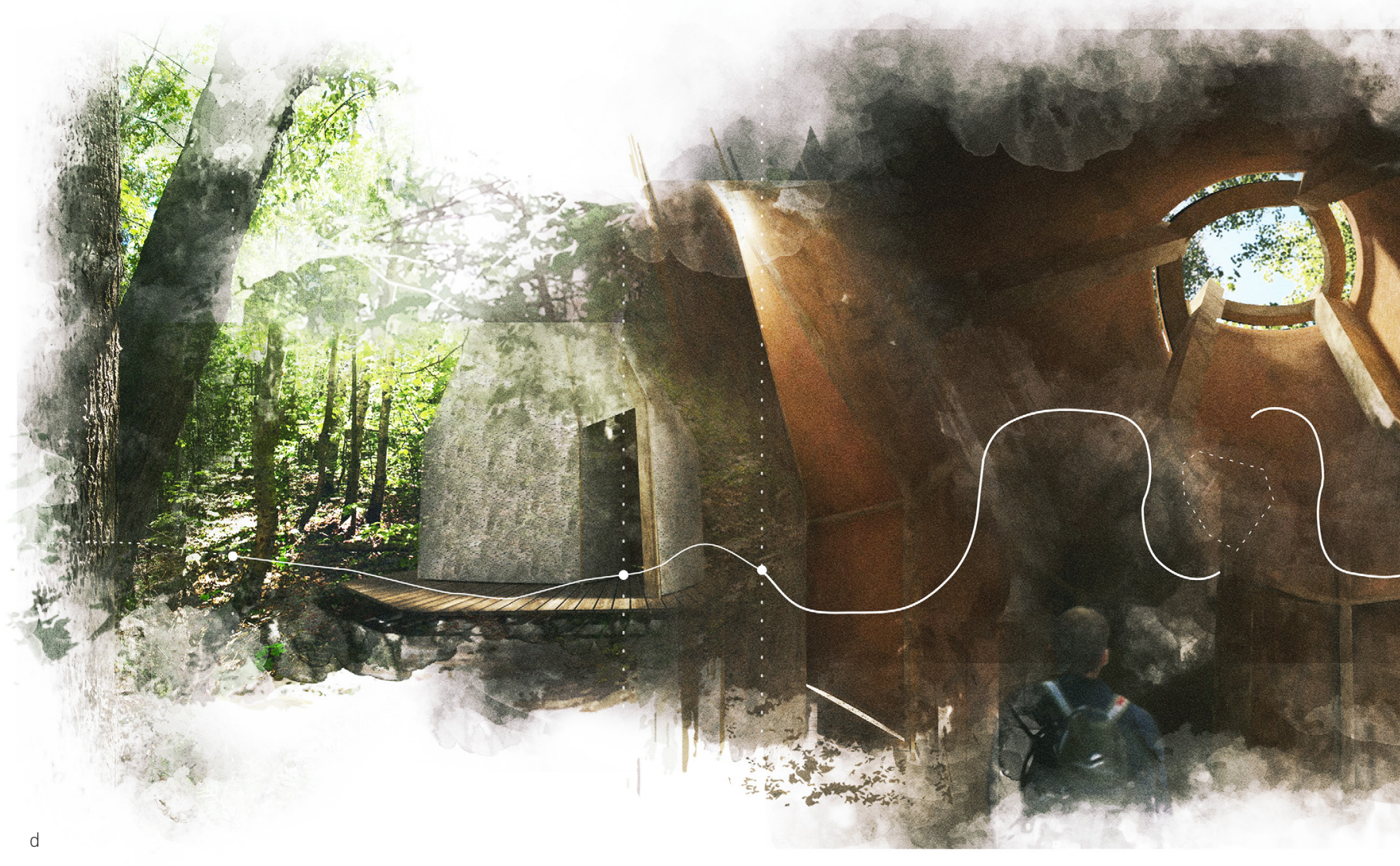




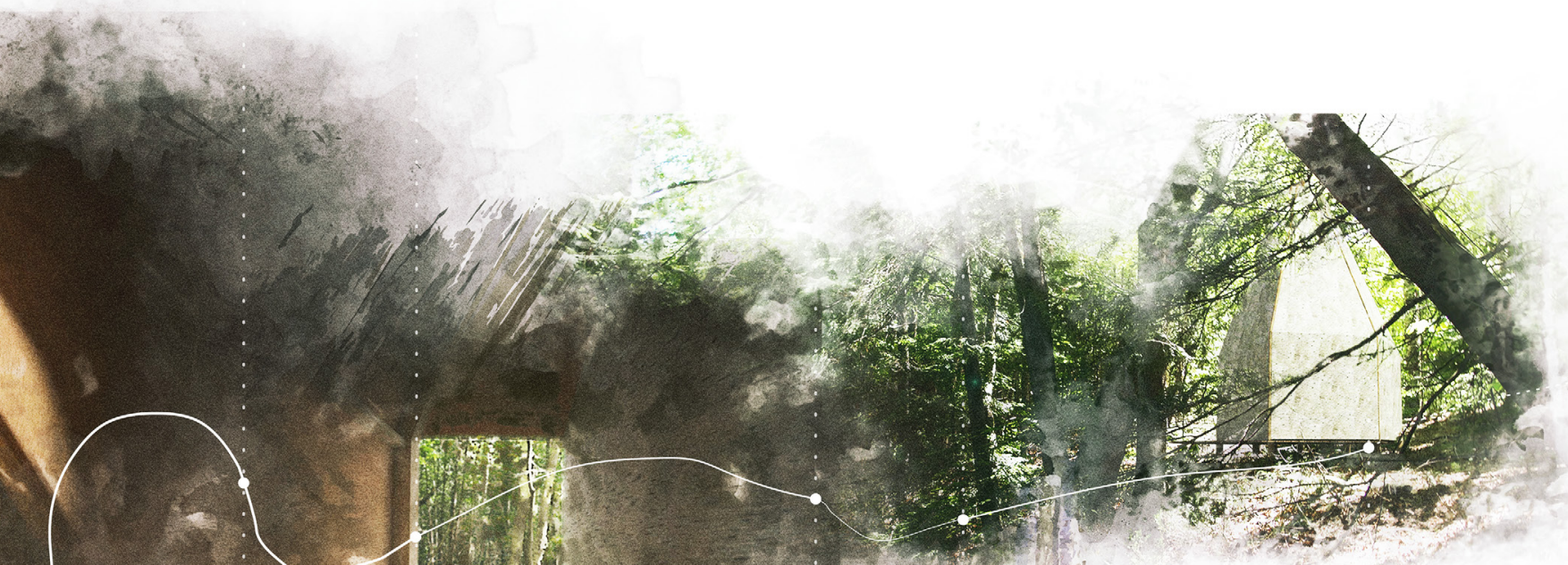




\subsection{Reflections}

Figure 42: Mapped Overall Experiences

a. Earth Armature

b. Air Armature

c. Water Armature
In the contemporary world, architecture has been seemingly preoccupied with form, surfaces, focused imagery, and general shapes. It has left much consideration for atmosphere, feeling, materiality, textures, and experience, to become secondary and an afterthought. It is designed and built with a lack of consideration for its atmospheric qualities, acting merely as forms for utilitarian demands and needs, with a focus on the object of the built form rather than the subject of the body. As such, this work has intended to think about actions and experience of the of atmospheres, designing experiential space through embodied design. These armatures were designed with the intention of the focus being on atmosphere while maintaining emphasis on the subject of the bodily experience. Tangible and intangible qualities were used and explored with the intent of creating possibilities for the body to experience the atmosphere in various ways, allowing the body to feel its own physical presence, and the corporeality of the atmosphere.

Struggling with the various means of expressing my thoughts and the bodily experiences of atmospheres, various explorations were developed over time and used throughout the thesis progression. These explorations aided in a more personal design approach, wherein personal experiences of places, materials, lighting, spatial volumes, and air where used to design physical forms from immaterial qualities and ideas. They took the emphasis from the actual representation of the physicality of the thing and gave it to the experience of it. This not only provided me with a re-framed approach towards thinking about or designing architecture, but a more sensitive way of approaching every single architectural project which I touch. Taking this further by means of building mock-ups of experienced details would allow me to further this awareness into the built project.

This thesis has begun a personal journey of developing a process and sensibility which I plan to continue and bring into my professional career. The development and process which has lead me to this point in my research has expanded my thoughtful design process, whether the projects are in an urban or rural setting, large or small, residential or commercial. 

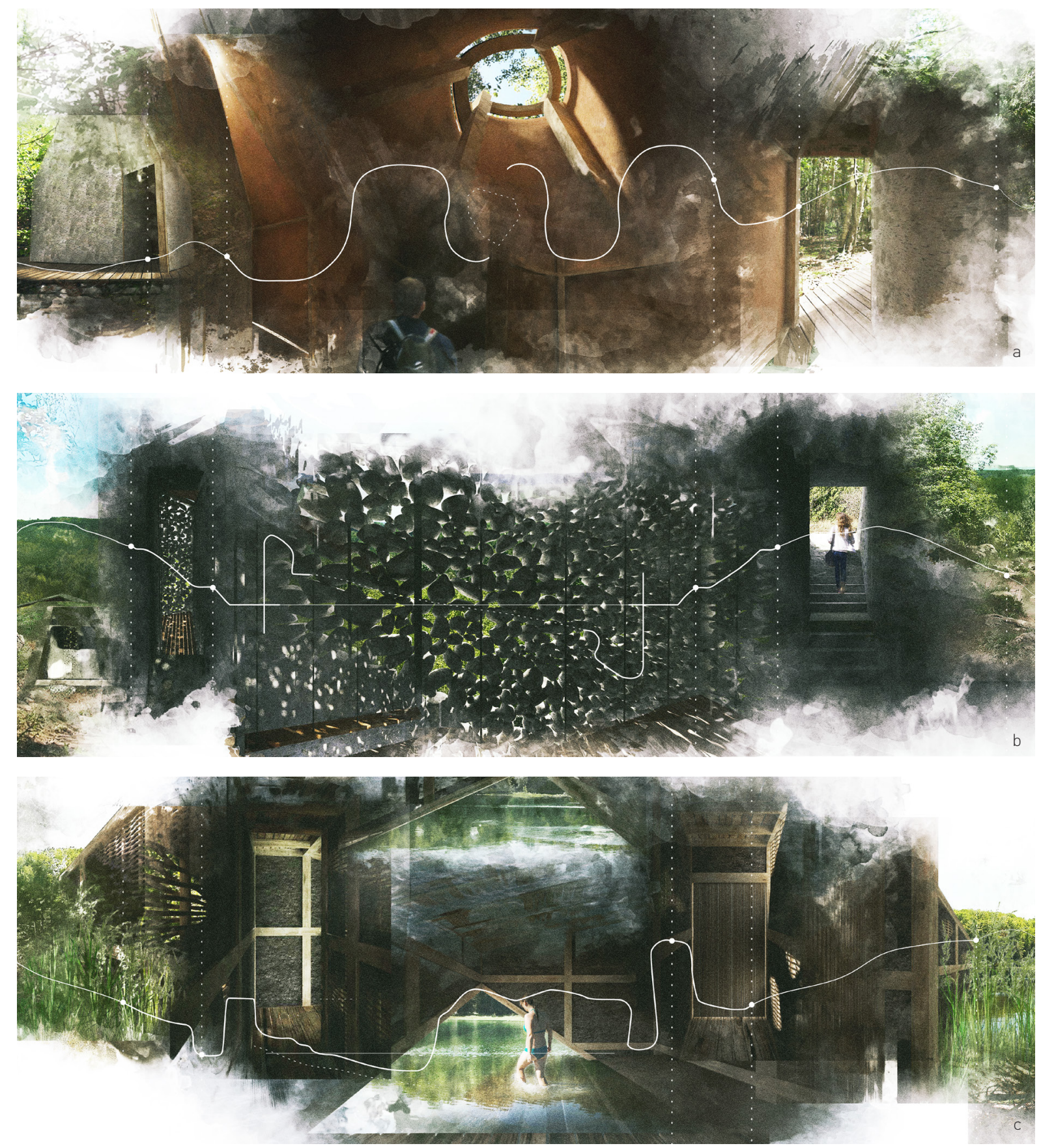


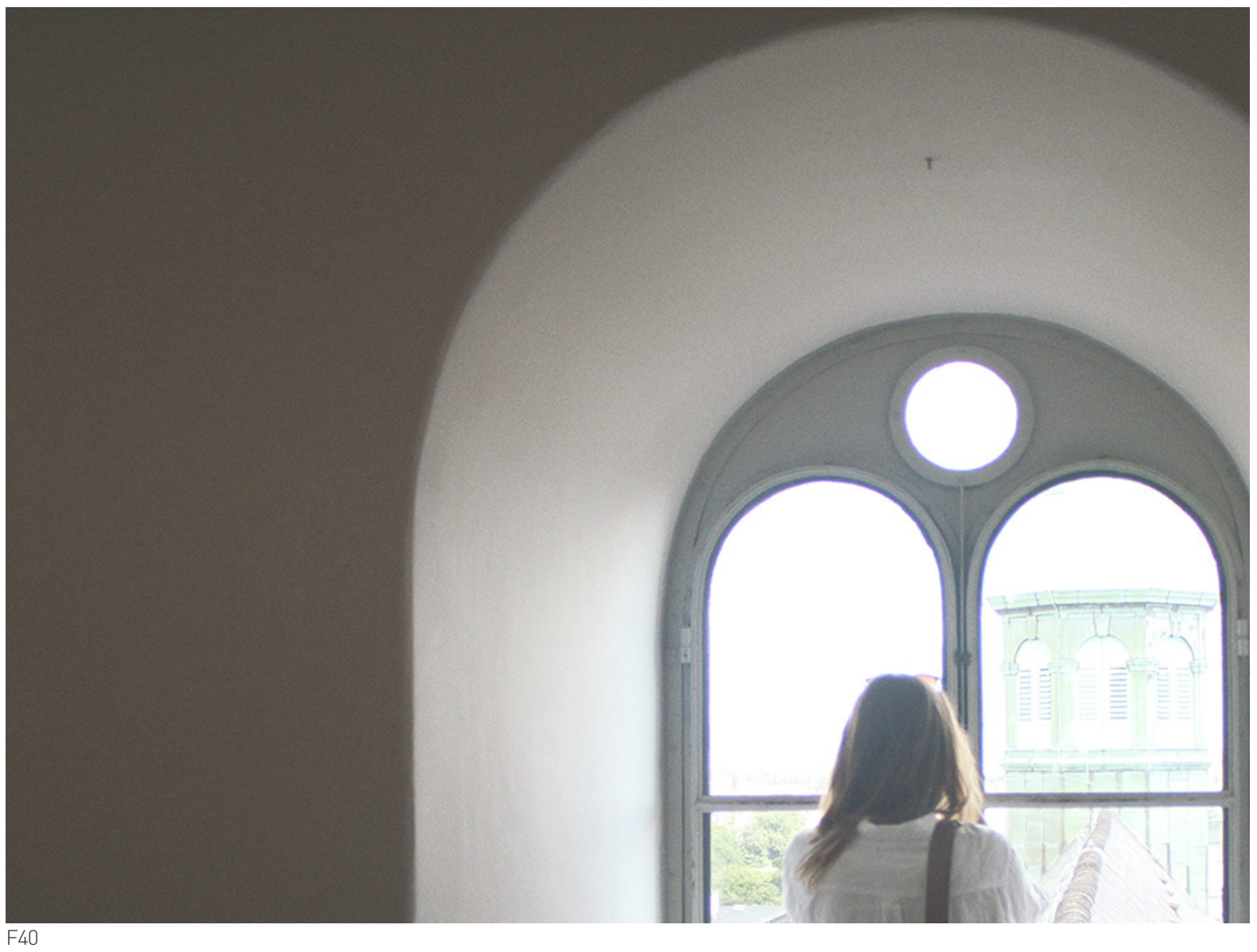




\section{POSTSCRIPT}

99 Ludwig Wittgenstein, Tractatus Logico-Philosophicus, Trans Frank P. Ramsey, \& Charles Kay Ogden, (Austria: W. Ostwald's Annalen der Naturphilosophie, 1921), 7.

Figure 43: Rundetaarn, 2016, Copenhagen
Atmosphere is the thing which is of utmost importance in the human environment. It would be impossible for any discussion to illuminate anything about them due to their profoundly subjective experience, where attempts to discuss them could degrade our intuitive understanding of them. Just as Ludwig Wittgenstein once stated, "whereof one cannot speak, thereof one must be silent." ${ }^{99}$ However, the attempt is to understand the poetic nature of atmospheres and how to design for them.

I believe that atmosphere is something which is of immense importance within our built environments; its significance lies within the fact that we inhabit it, not in a singular moment, but throughout life, acting as the basic human perception in which a person feels at the same time where they are. In this sense, atmospheres are something which determine physically being in the world, and one's relationship to their surroundings, people, and things. Thus, it is important to make apparent the significance of one's experience and to question what it means to be physically present in space. Feeling the physicality of space allows one to feel their existential sense, and atmosphere is the mode of doing that in architecture. 



\section{APPENDICES}

The following are images from process work, initial design work and final design work for the three armatures and other explorations completed. It is organized in a sequential order, grouping the phases for the armatures.

$\begin{array}{ll}\text { Appendix A } & \text { Initial Material and Light Explorations } \\ \text { Appendix B } & \text { Intent Experiment } \\ \text { Appendix C } & \text { Volumetric Installations } \\ \text { Appendix D } & \text { Schematic Design } \\ \text { Appendix E } & \text { Material Installations } \\ \text { Appendix F } & \text { Final Design Drawings } \\ \text { Appendix G } & \text { Final Models }\end{array}$




\section{APPENDIX A Initial Material and Light Explorations}

Figure 44: Model explorations of materiality, various lighting conditions, and the interplay between the two.
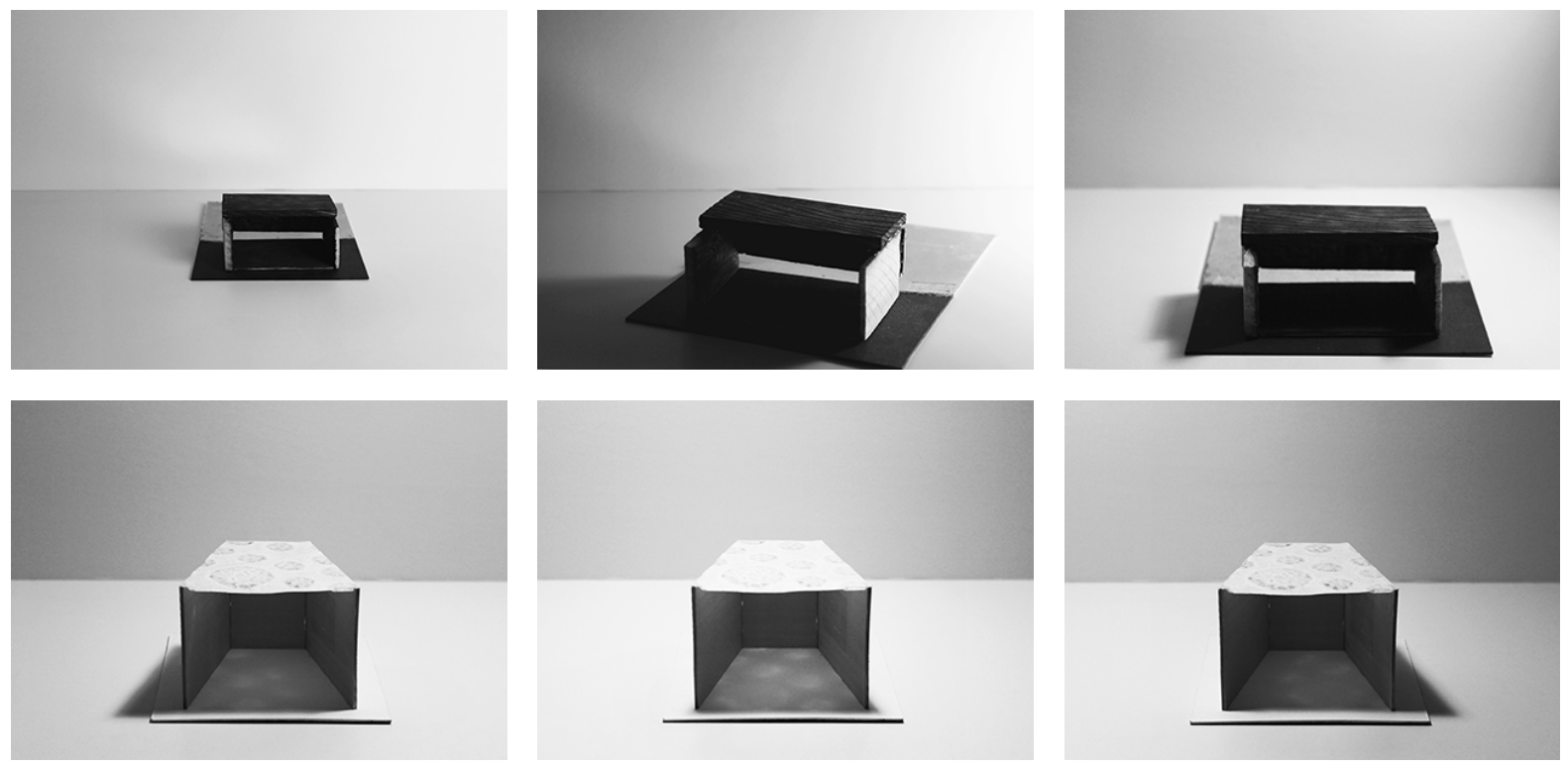

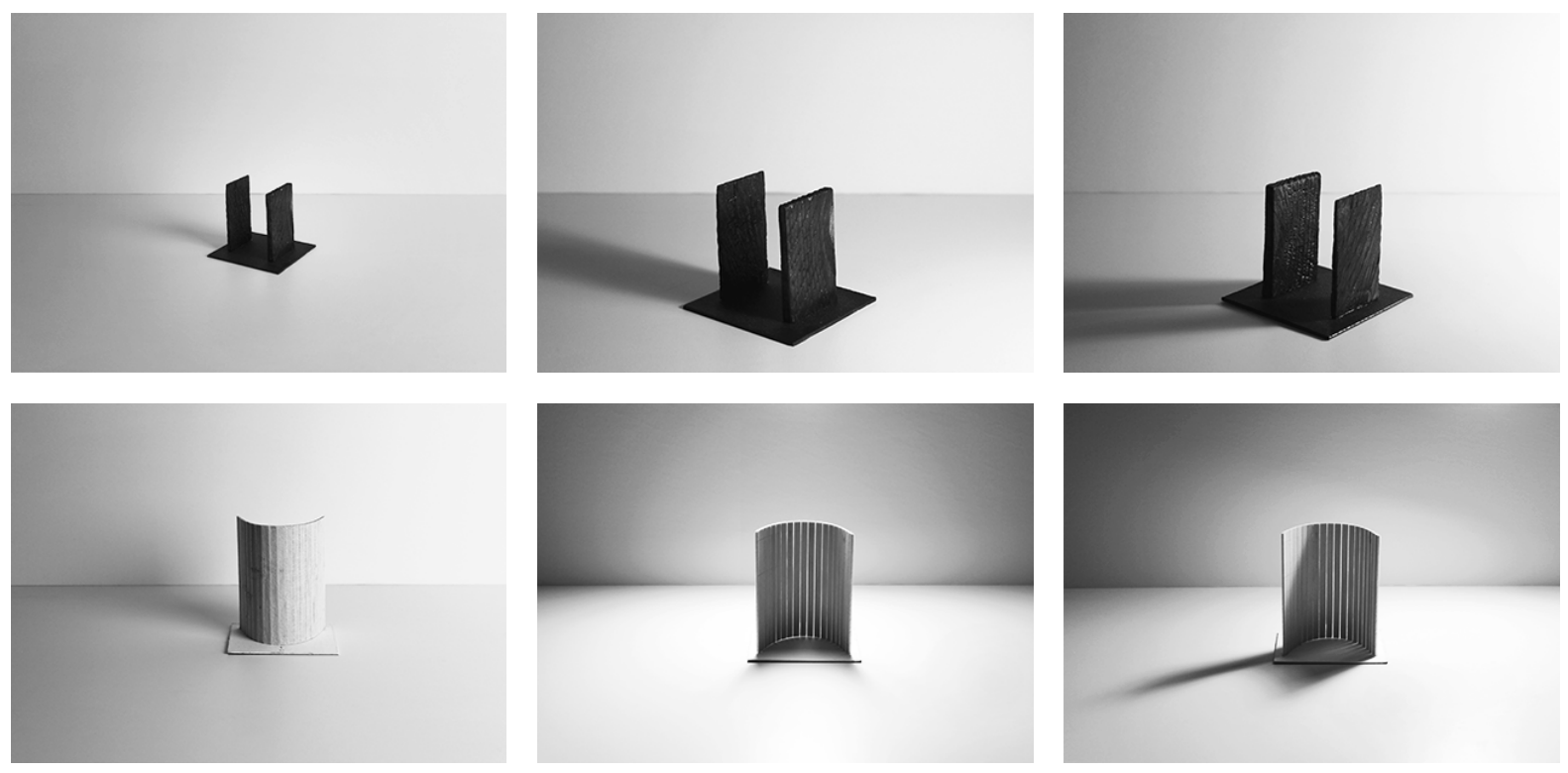


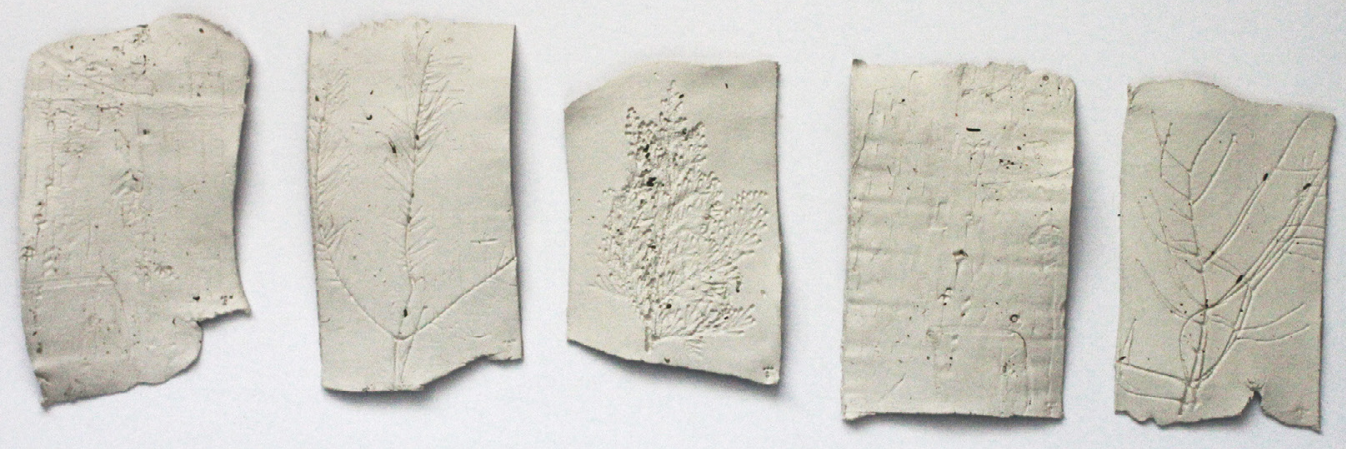

a

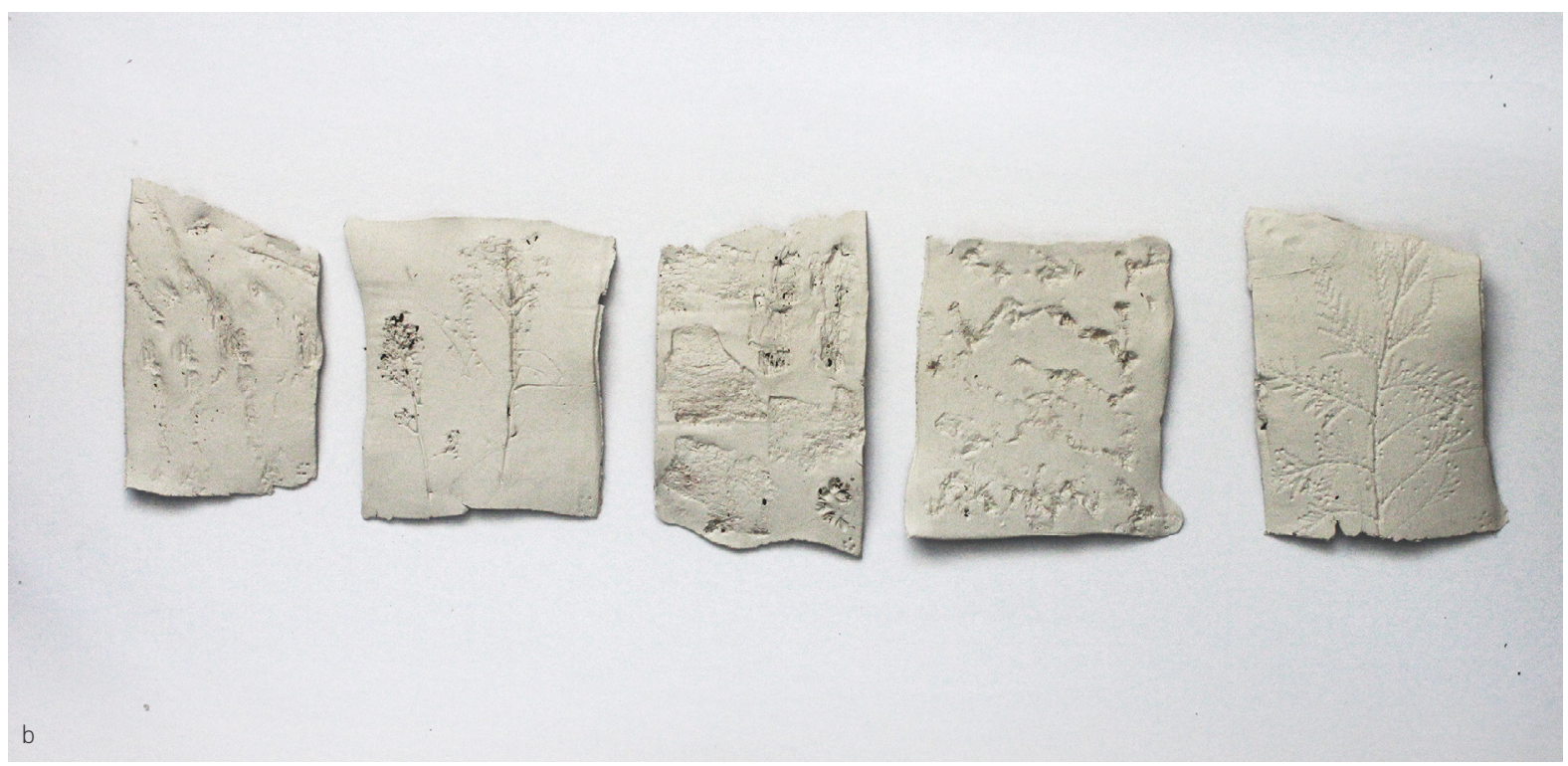




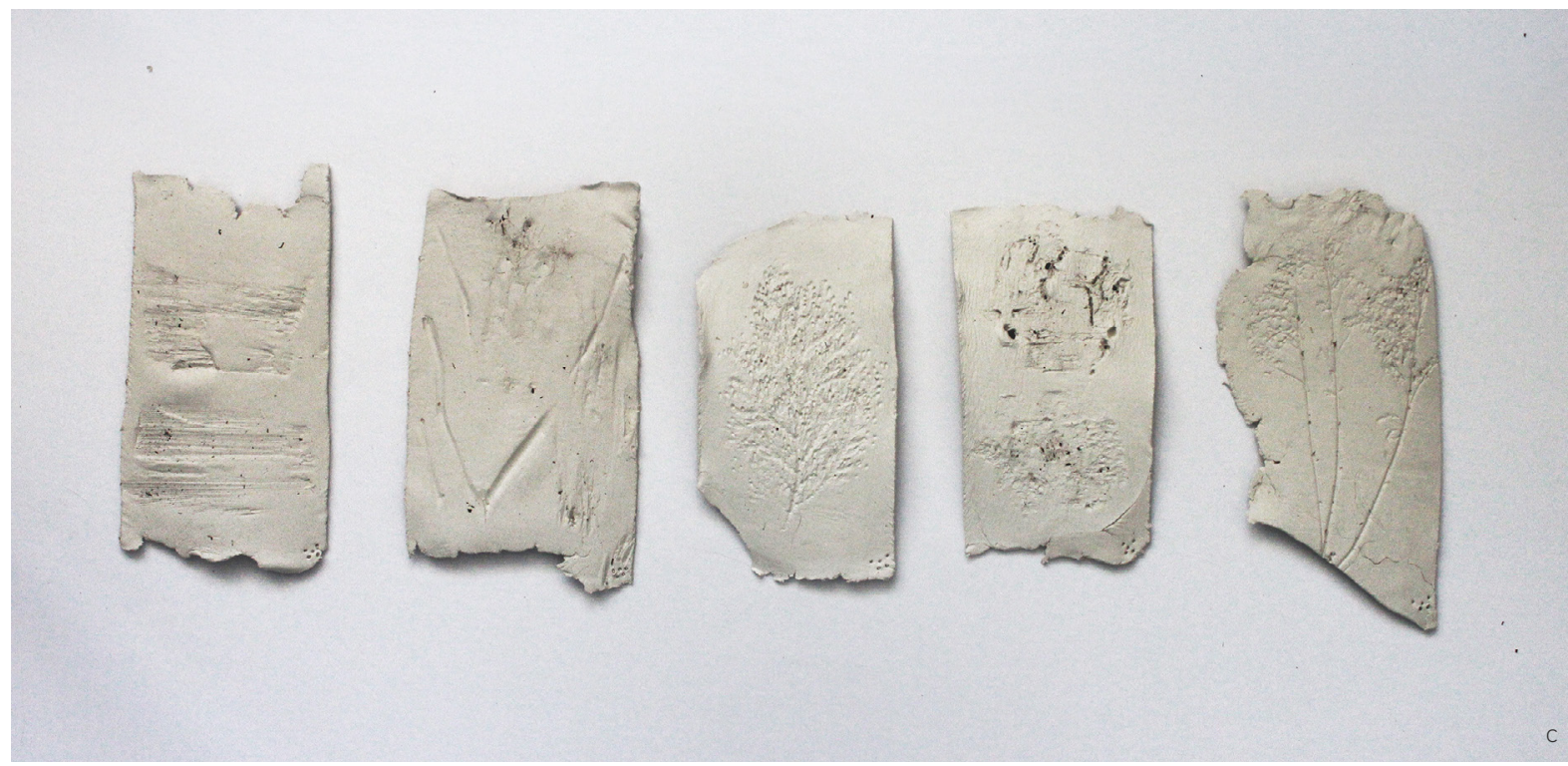

Figure 45: Materials were gathered on-site and used in order to further understand each site and its atmosphere. Here, the materials were used to make impressions to see the texture, as well as shadows of each place.

$$
\begin{array}{r}
\text { a. earth site } \\
\text { b. air site } \\
\text { c. water site. }
\end{array}
$$




\section{APPENDIX B Intent Experiment}

Figure 46: Original Watercolour

demonstrating the initial intent for the

resultant atmosphere for the Armature.
a. Air site
b. Water site
c. Earth site. 

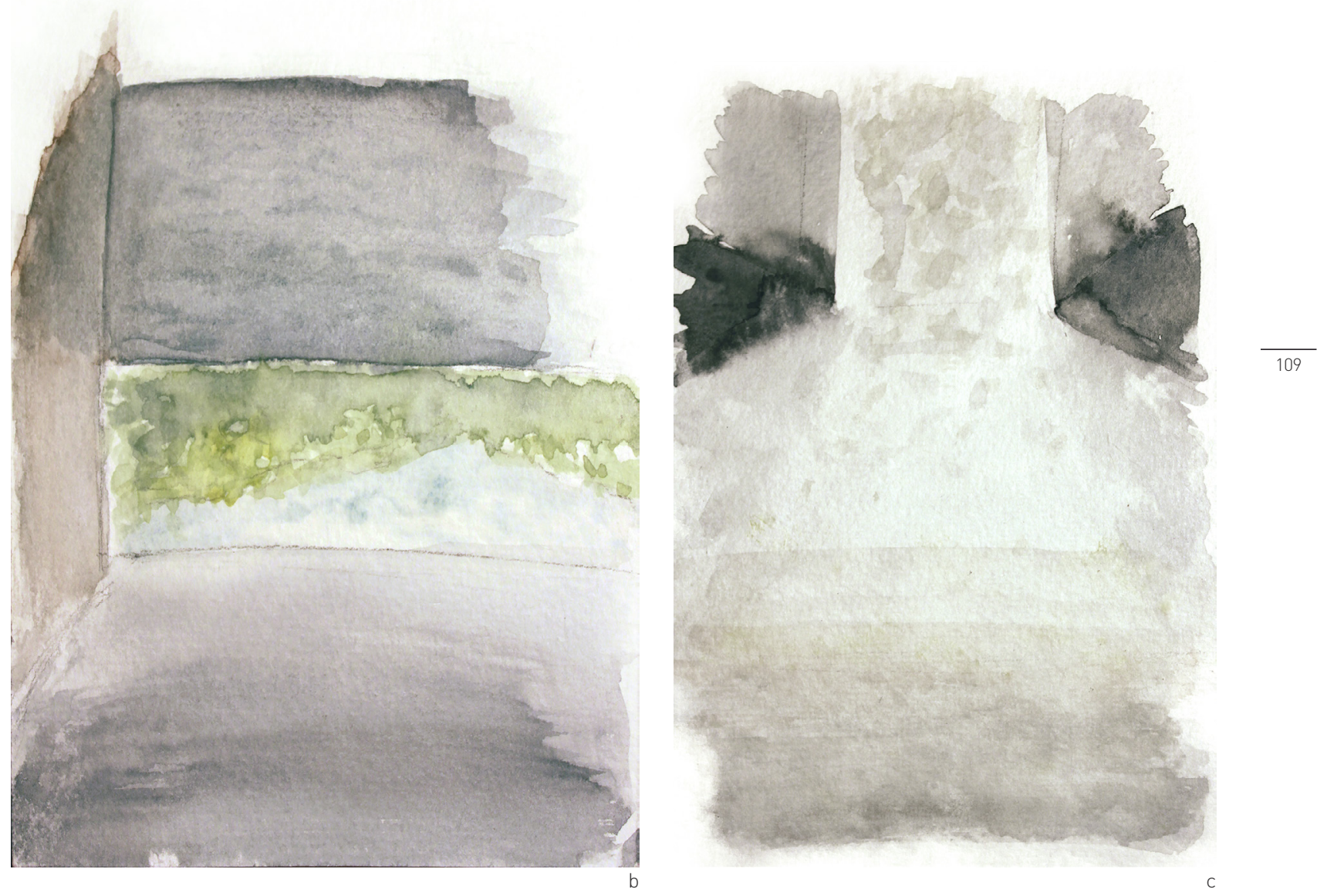
Figure 47: Initial atmospheric intent drawing for the Armature
a. Air site
b. Water site
c. Earth site.

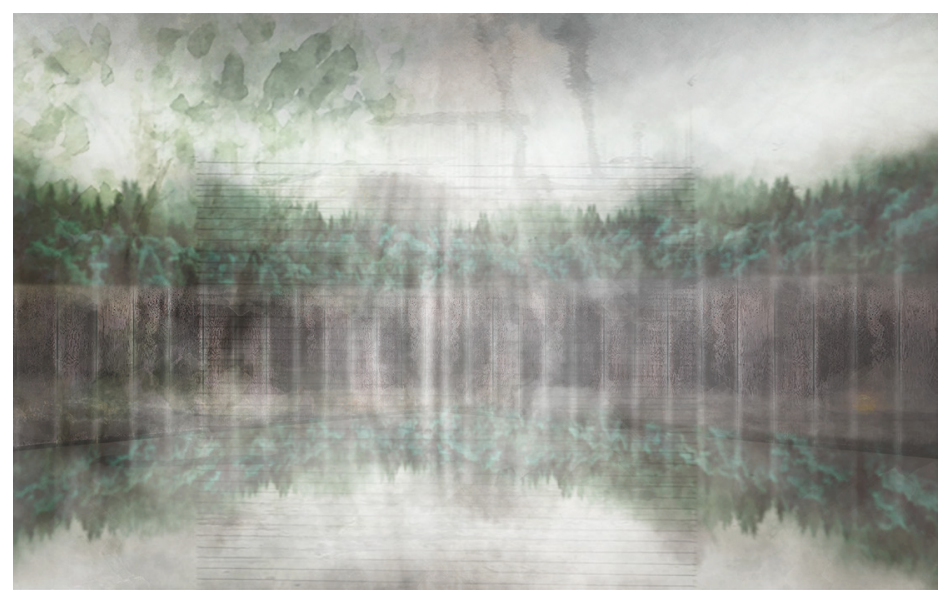

a 
INTENT EXPERIMENT
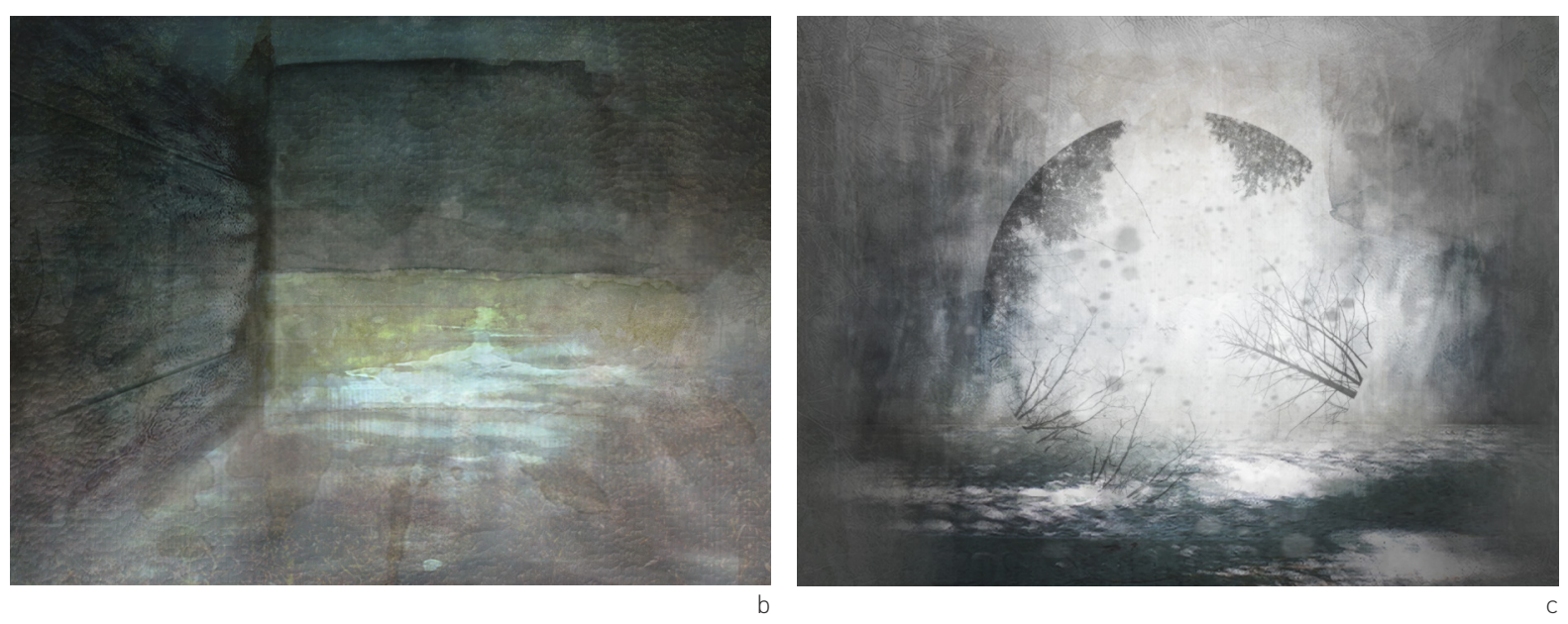


\section{APPENDIX C Volumetric Installations}

Figure 48: In order to personally experience the designed intent, on-site installations were done. Six-foottall stakes where then inserted into the ground (and water) at major moments of change for the walls, stairs and roof, as applicable to each site. White fabric was then wrapped around the stakes. The armature was then left for a period of time to simply exist on site, swaying with the wind. The fabric and stakes were then removed from the site, leaving it the way it was found.
a. Air site
b. Water site
c. Earth site.

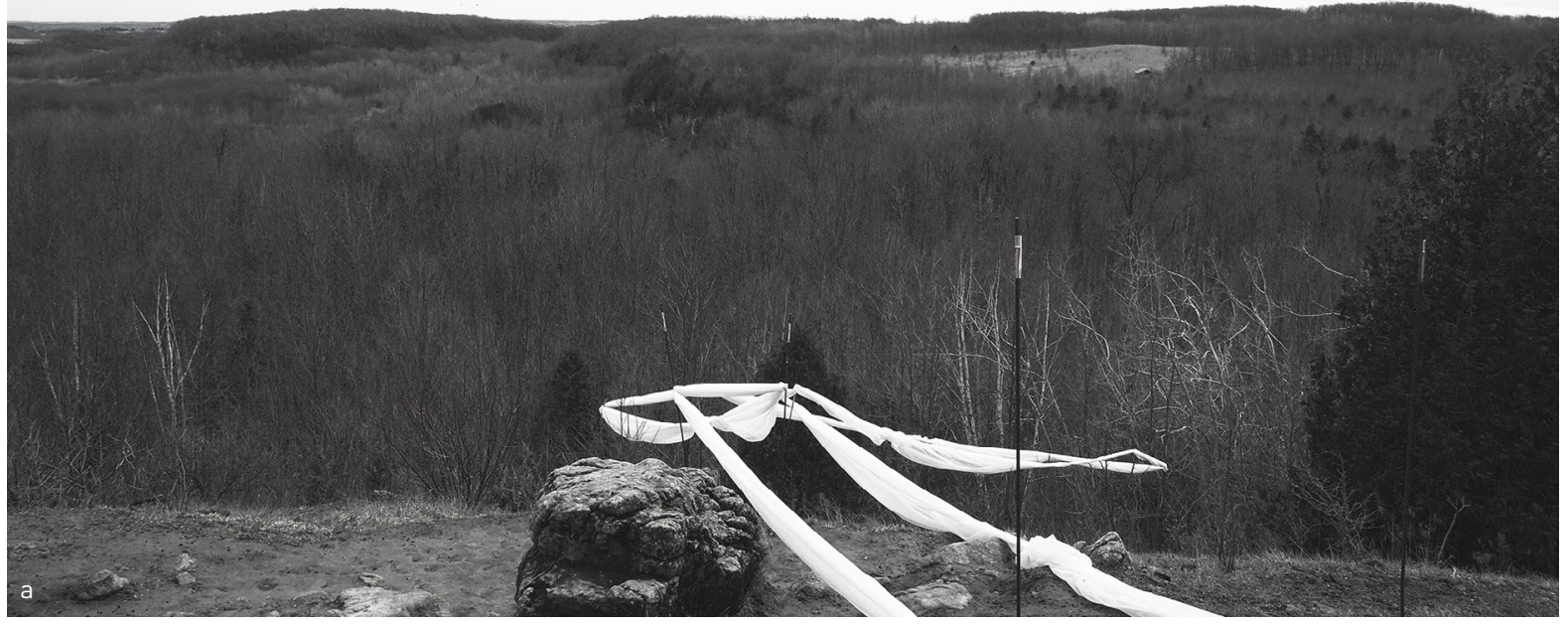



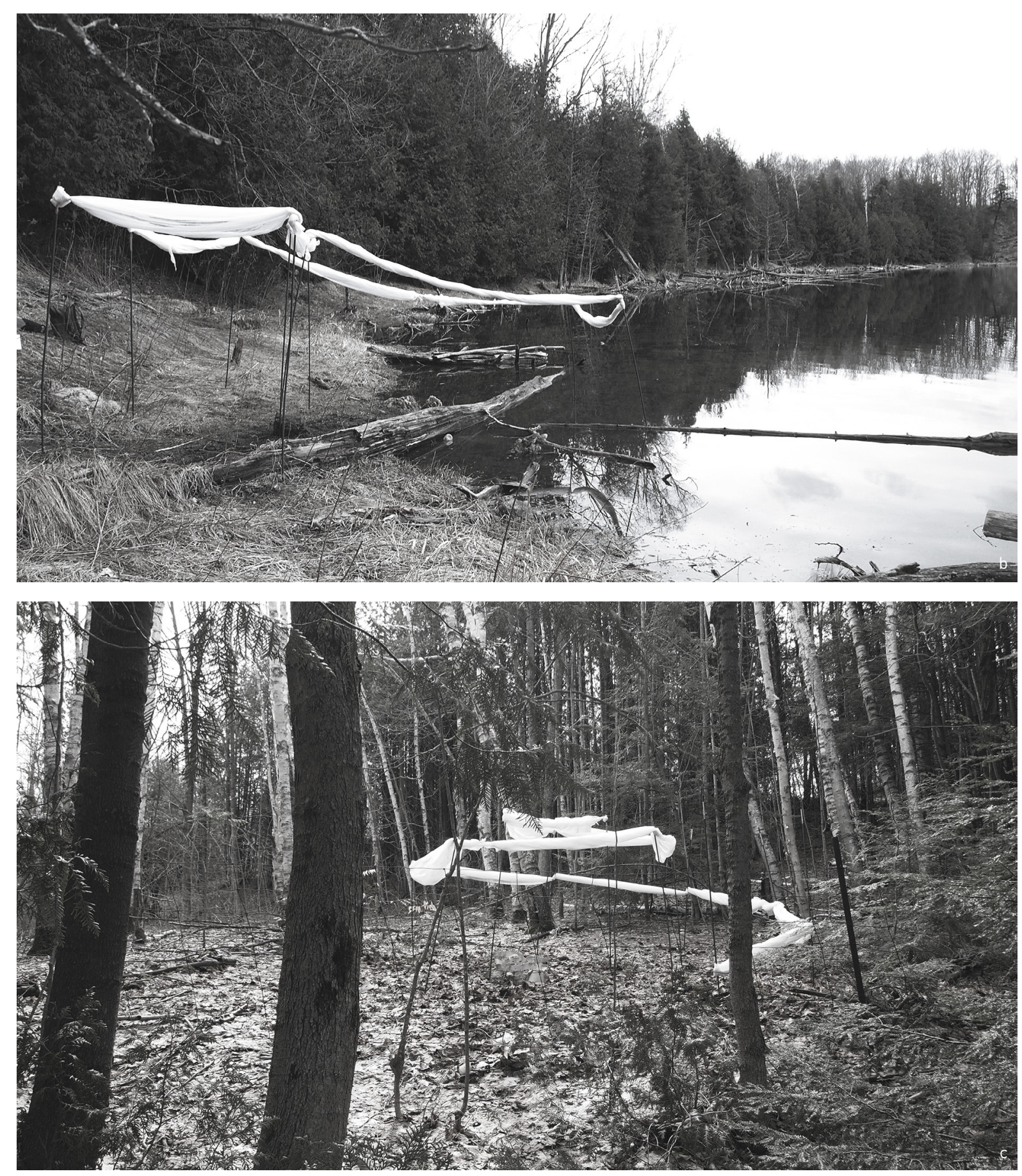
Figure 49: For the Air Armature, a built portion of gabion wall was done with bent hardware mesh and rocks found on site. As seen below, there are a variety of rocks located on the site, which have variations in their colouring. What was also interesting was to see some of the rocks having some green on them, hinting at what could happen to the built armature walls.

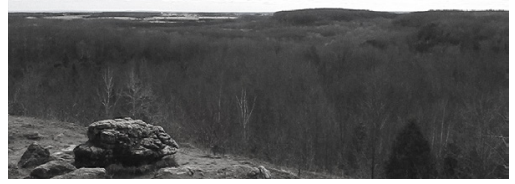

01

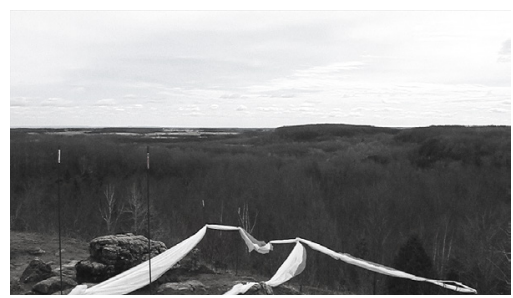

07

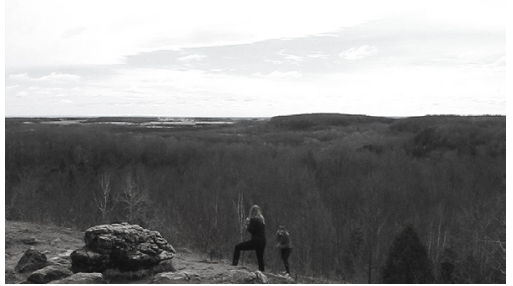

02

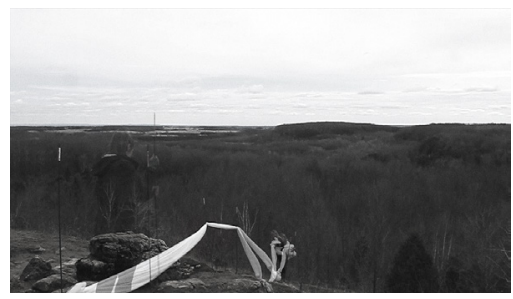

08

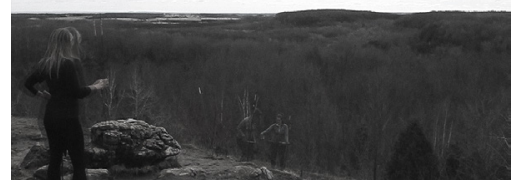

03

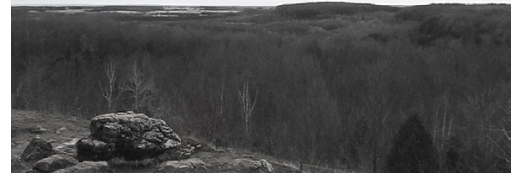

09 


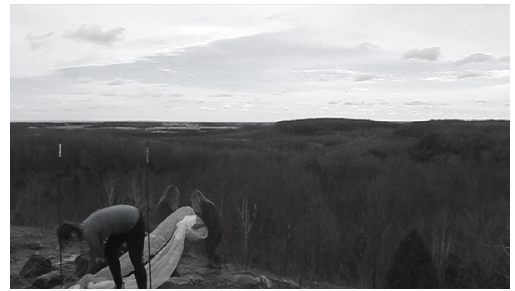

04

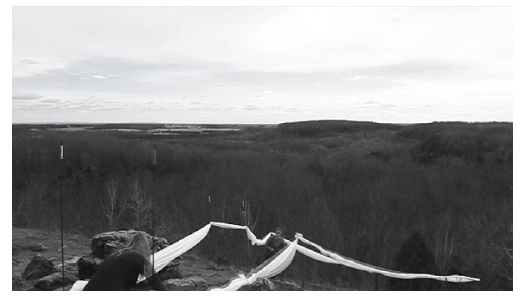

05

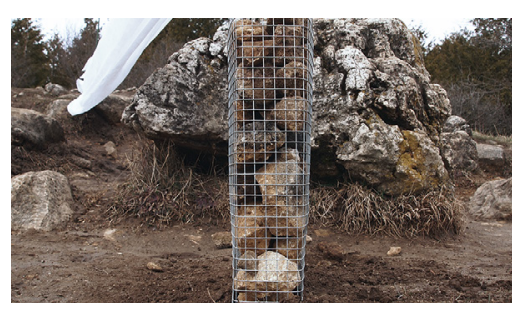

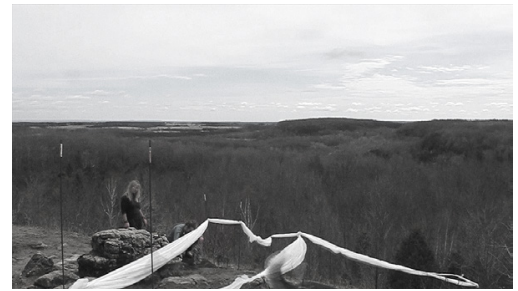

06

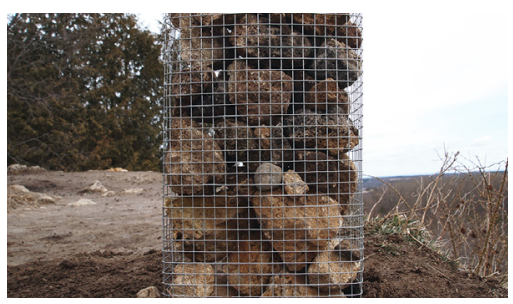


Figure 50: For the Water Armature, a built portion of a rammed earth wall was done with wood planks brought to site and dirt and sand found on site; the sand was in the water and the dirt was along the shoreline. Seen below is the variations in the colouring.

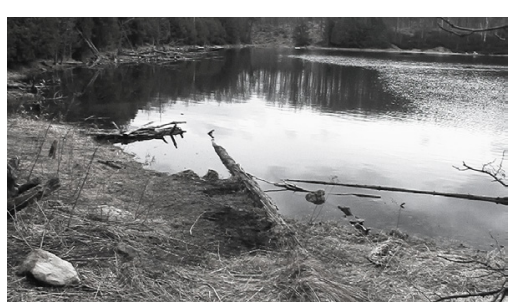

01

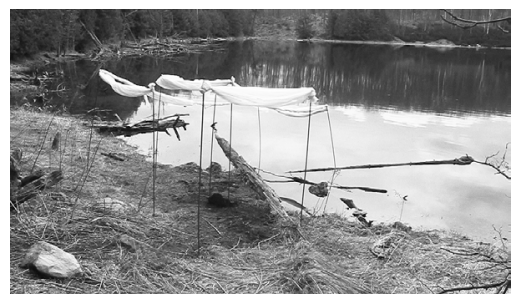

07

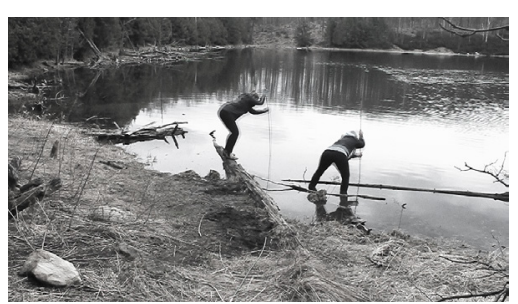

02

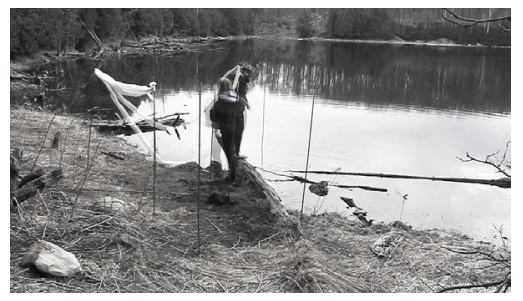

08

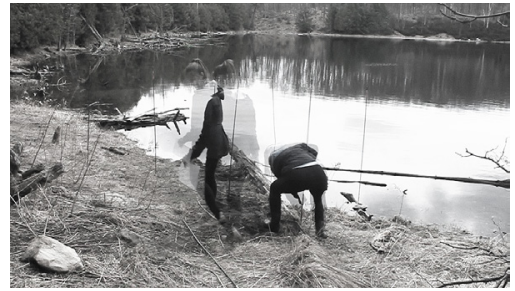

03

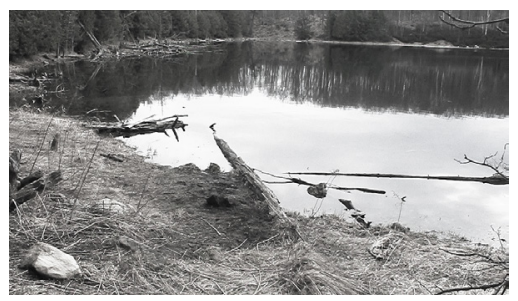

09 


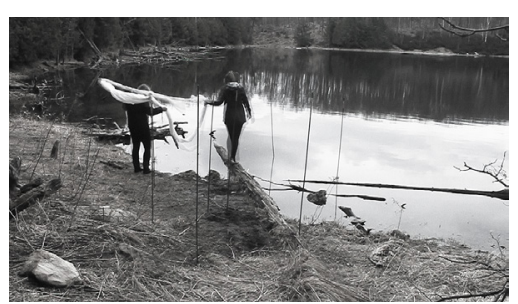

04

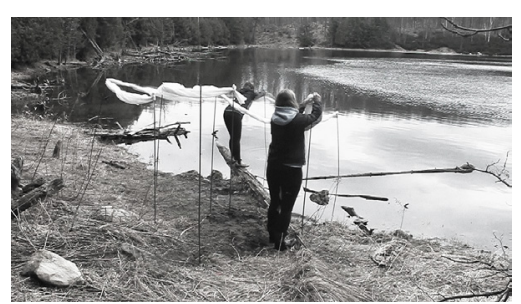

05

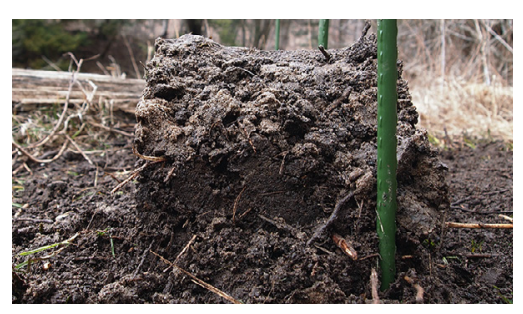

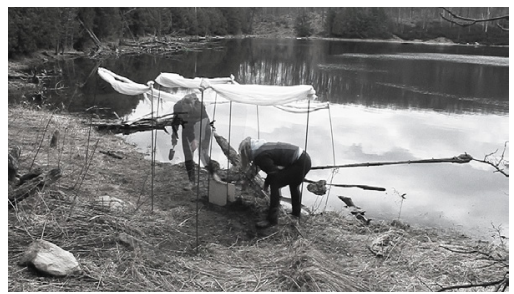

06

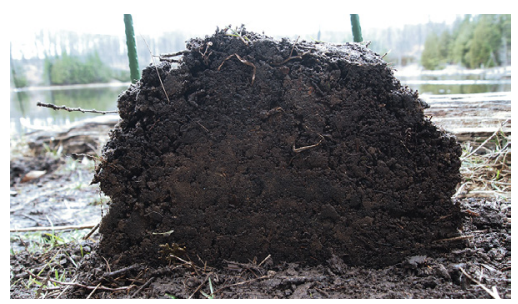


Figure 51: For the Earth Armature, a built portion of weaved birch was done with small wooden dowels which were stuck into the ground. The birch bark was oriented the same direction for the weaving; the white side for the exterior and the darker warm toned side on the interior. I noted that a method for stitching the pieces together would need to be developed.

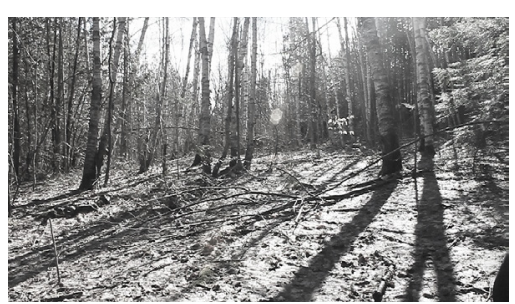

01

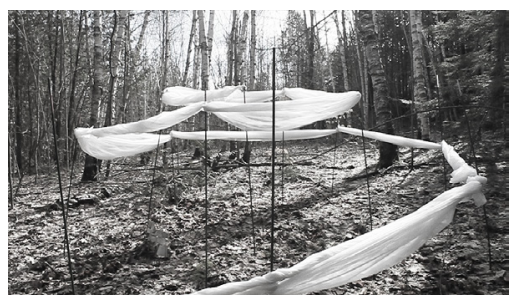

07

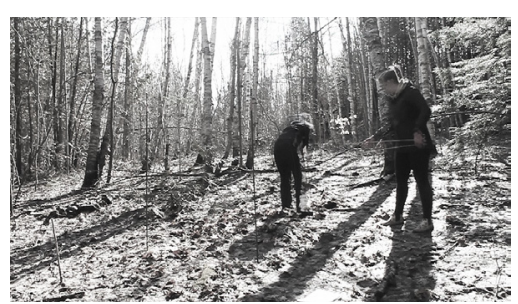

02

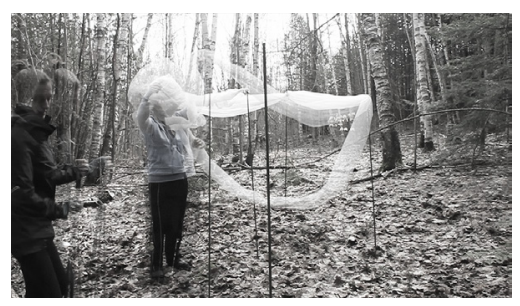

08

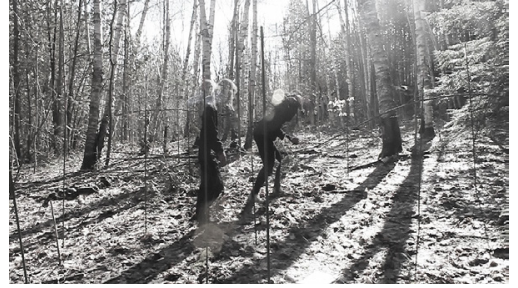

03

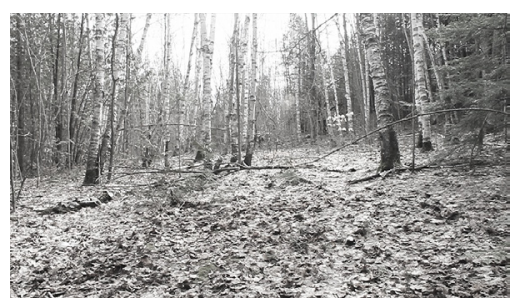

09 


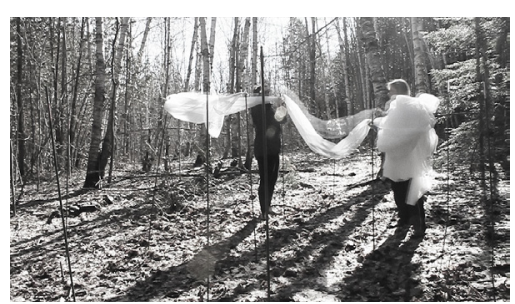

04

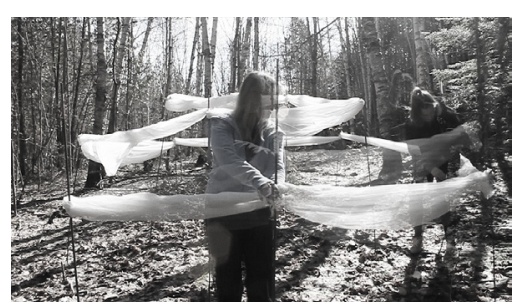

05

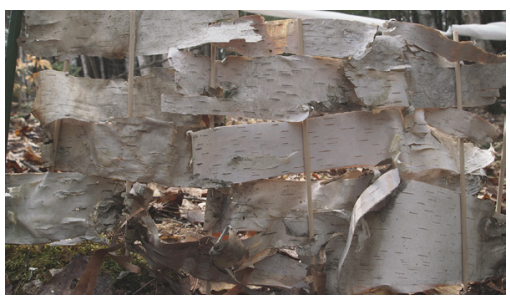

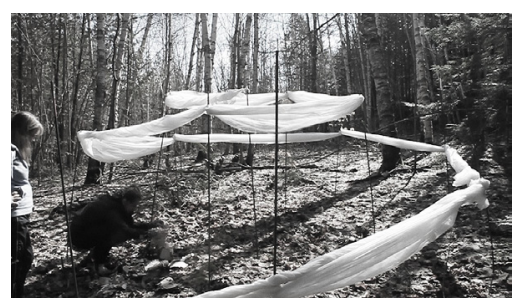

06

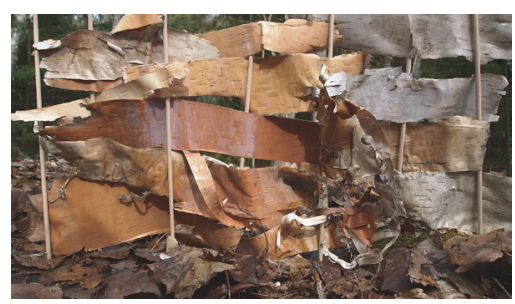




\section{APPENDIX D Schematic Design}

Figure 52: Temporal overlapped experience imagery
a. Air Armature Imagery
b. Water Armature Imagery
c. Earth Armature Imagery

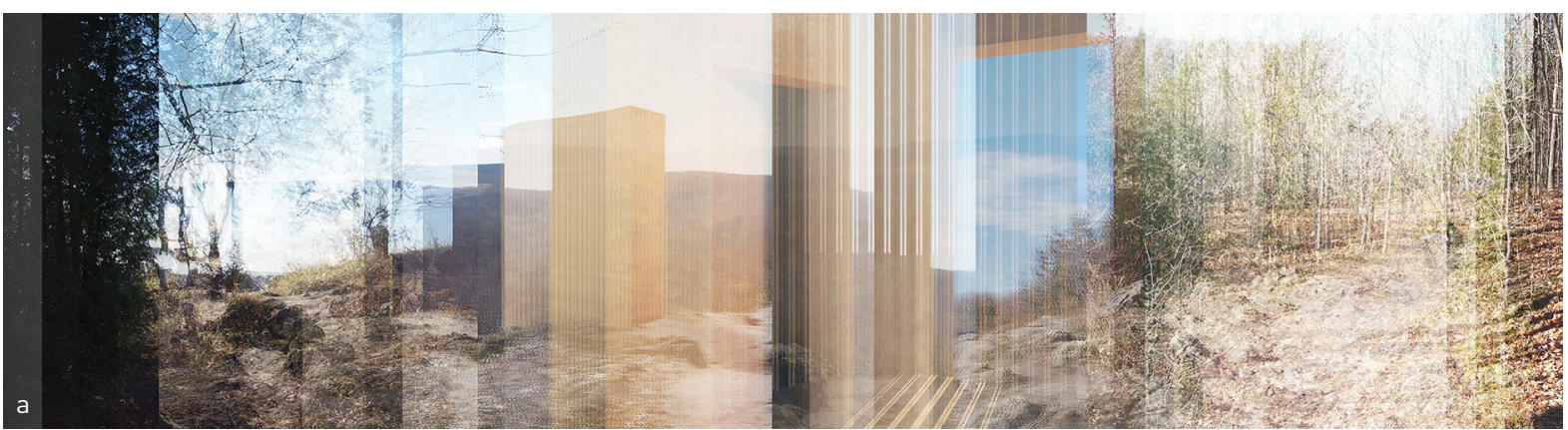



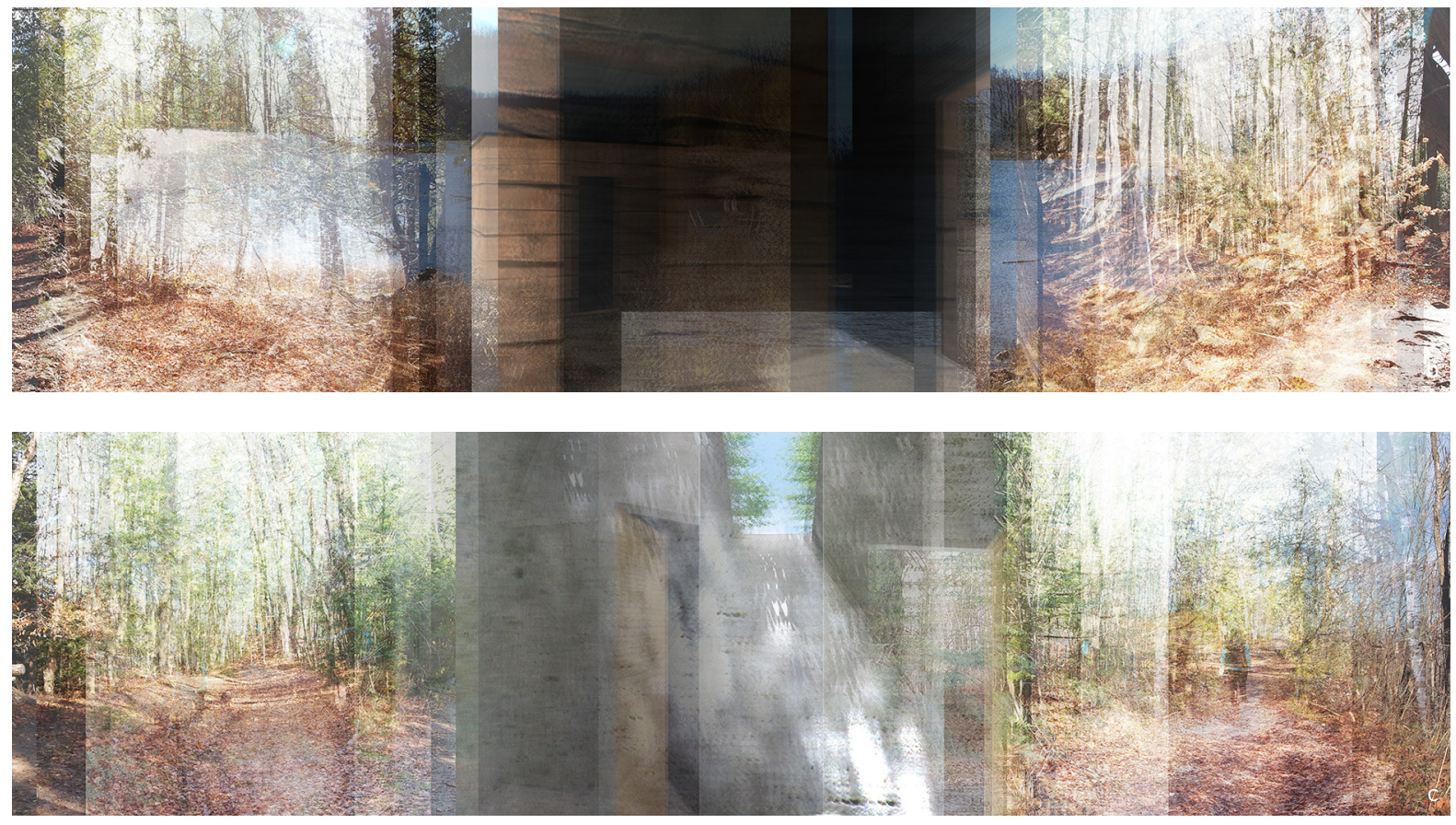
Figure 53: Orthographic Drawings for Air Armature
a. Site Plan
b. Interior Plan
() $0.0 \mathrm{~m}$ 2.0

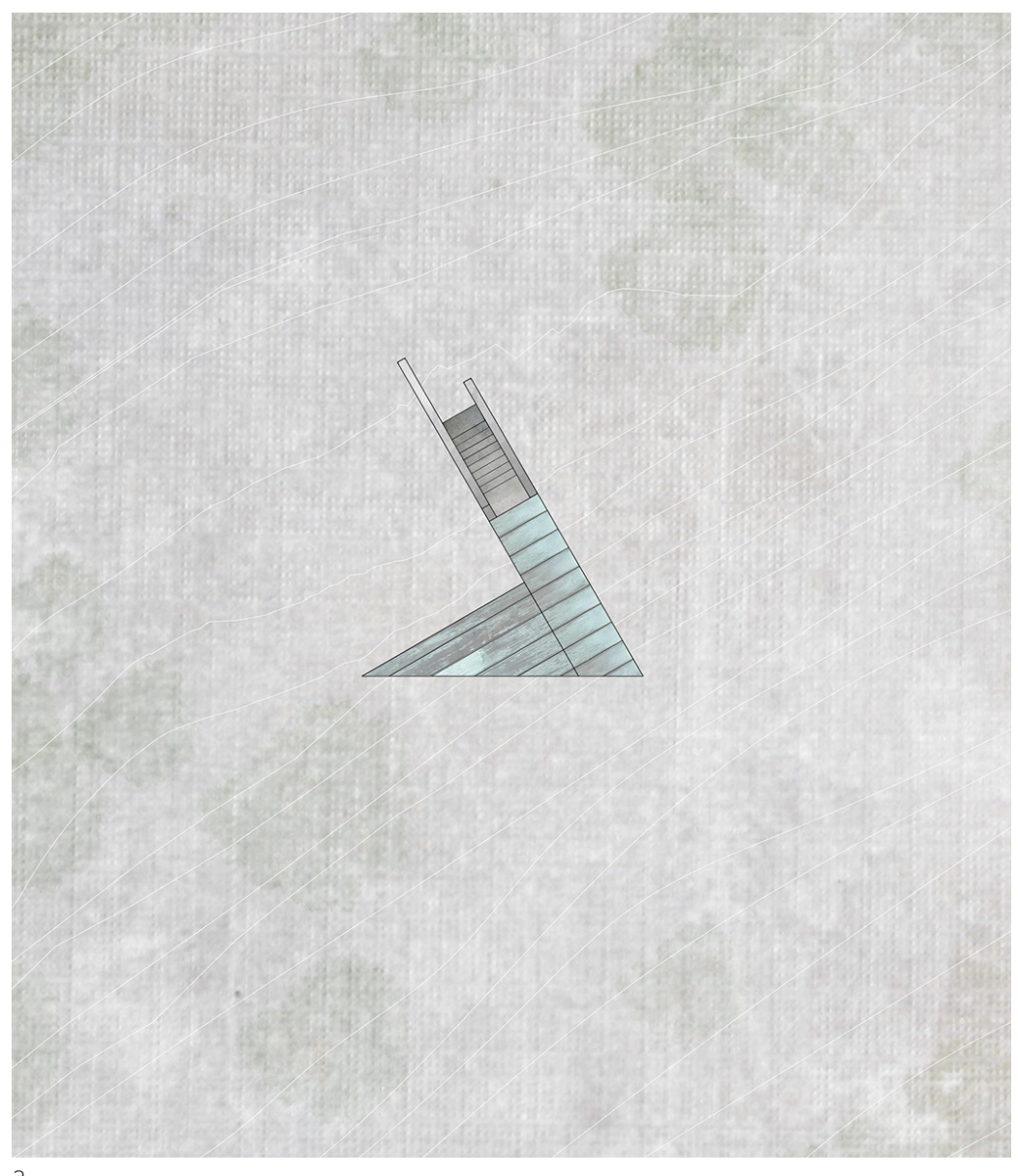




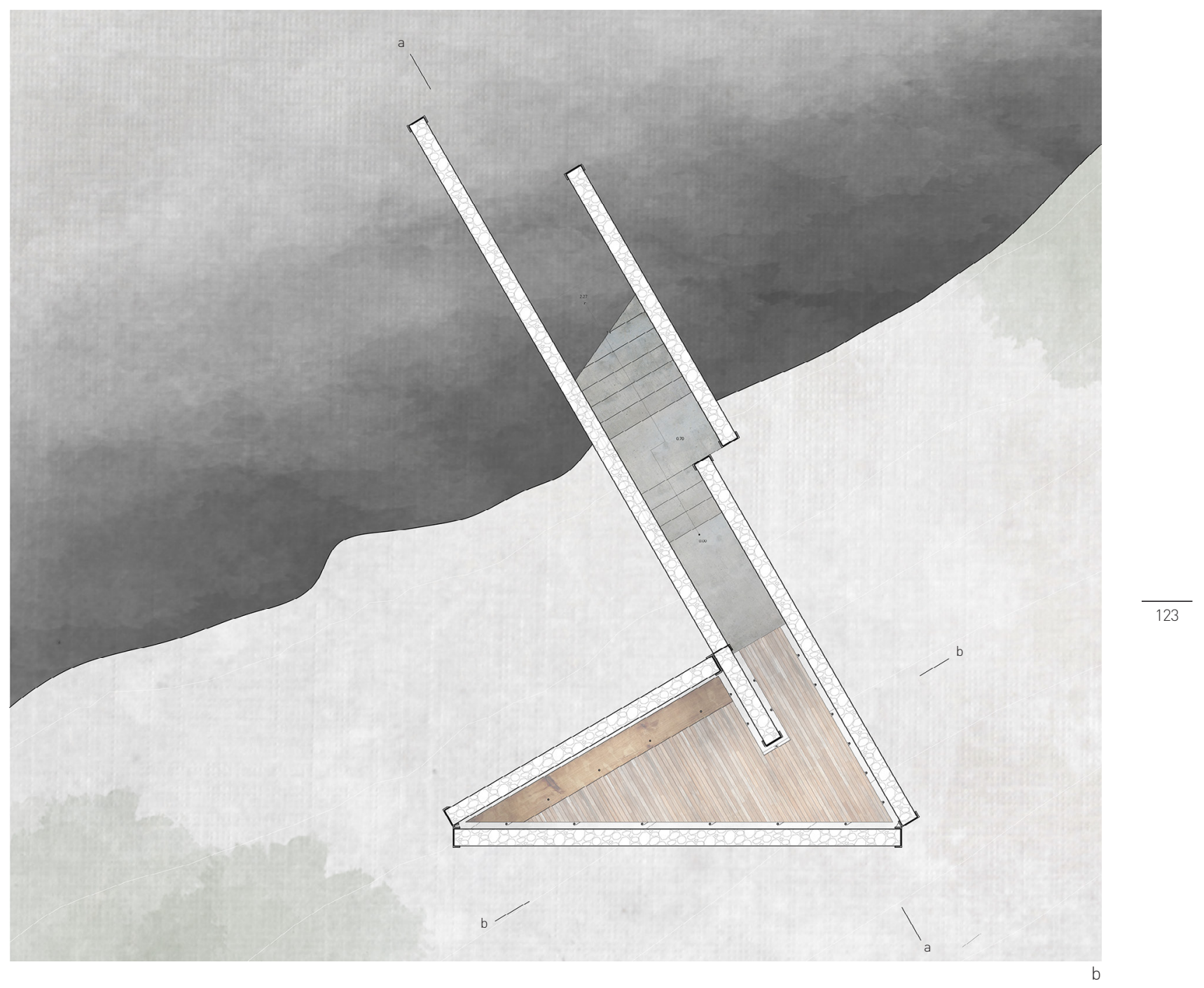




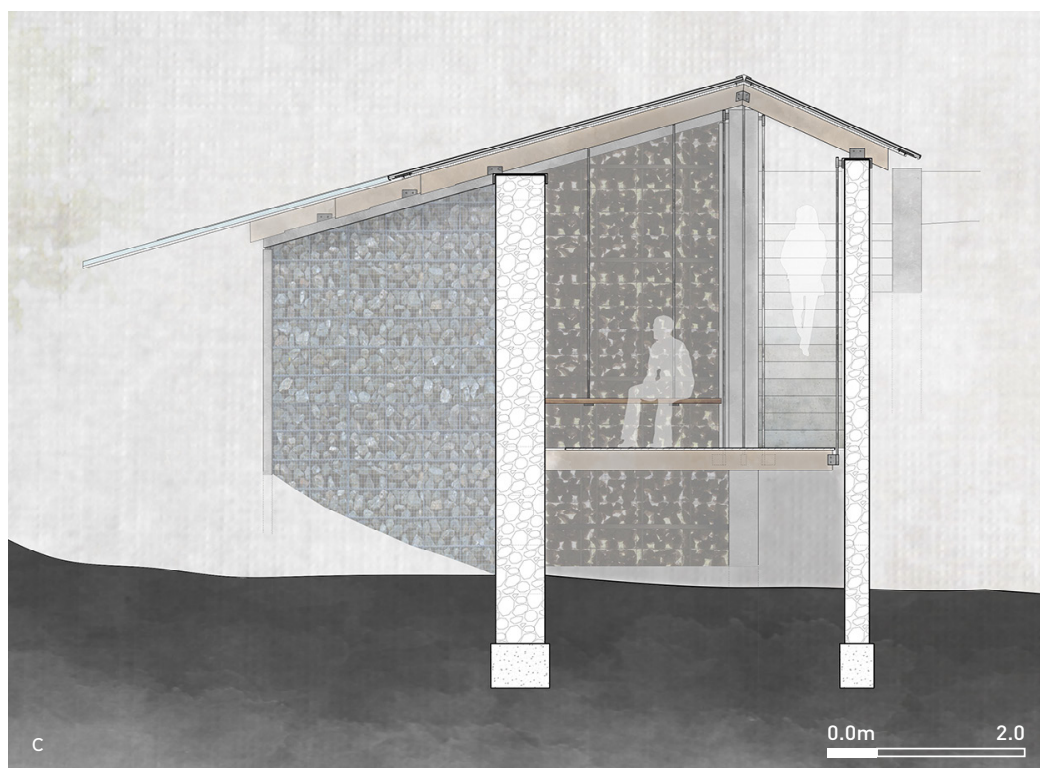

c. Section b-b

d. Detail of Interior Plan

1 gabion wall

2 gabion wall acting as a retaining wall

3 u-shaped steel corner column

4 steel plate welded to columns

5 hung wood bench

6 hung metal rod

7 metal attachment at base of rod to hold joists

8 metal rod holding hung bench

9 joist

10 poured concrete floor

11 wood decking

12 reveal between floor and

gabion walls

13 cut earth

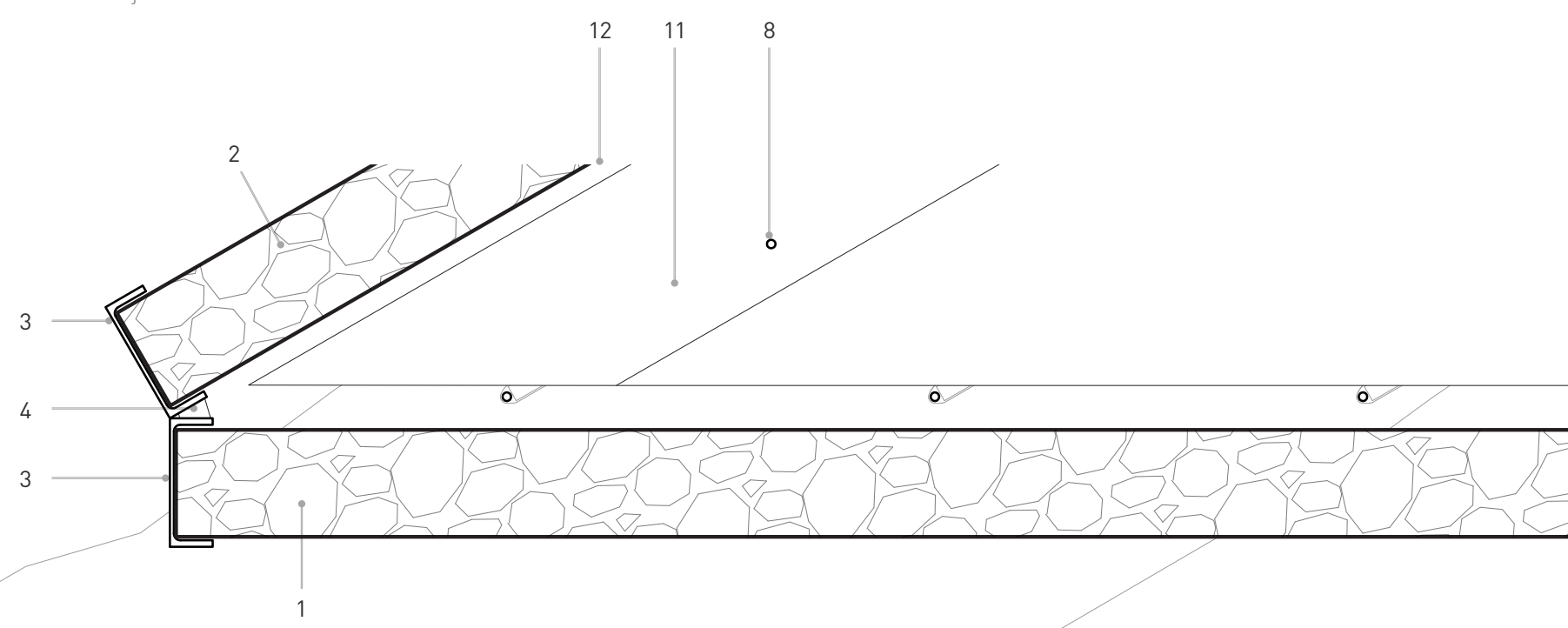


The stair goes down along the edge of the cliff, and coming out over it.

\section{e. Section a-a}

f. Detail of Section a-a

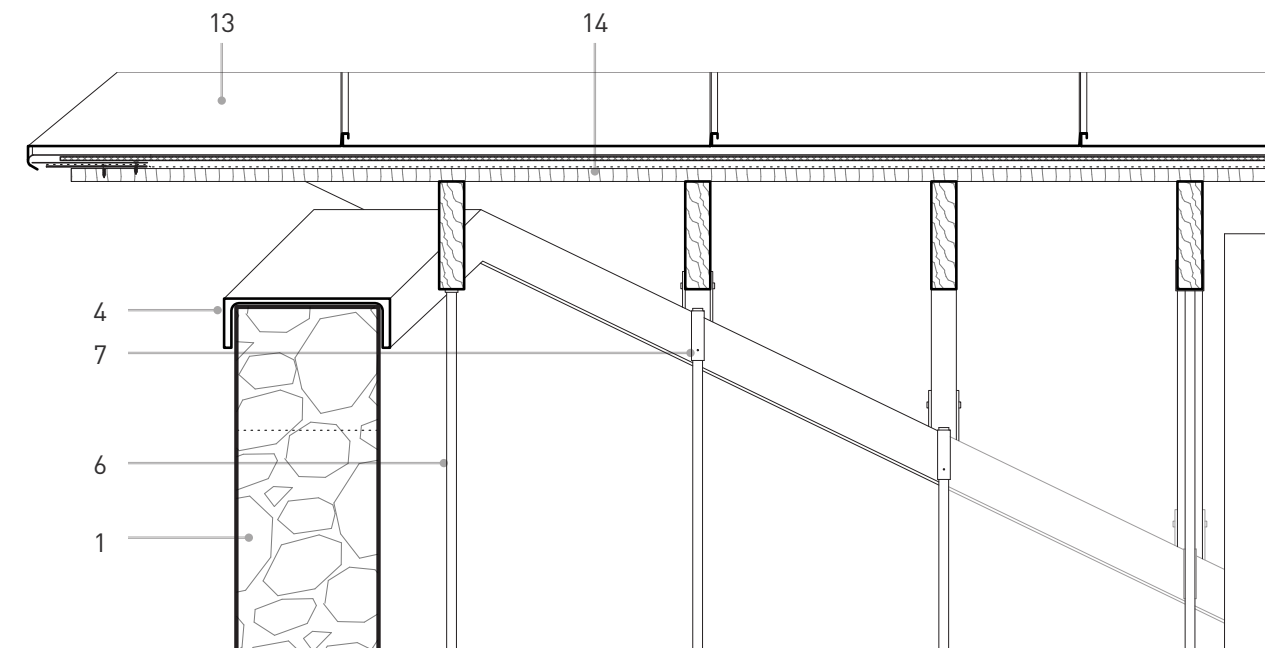

10

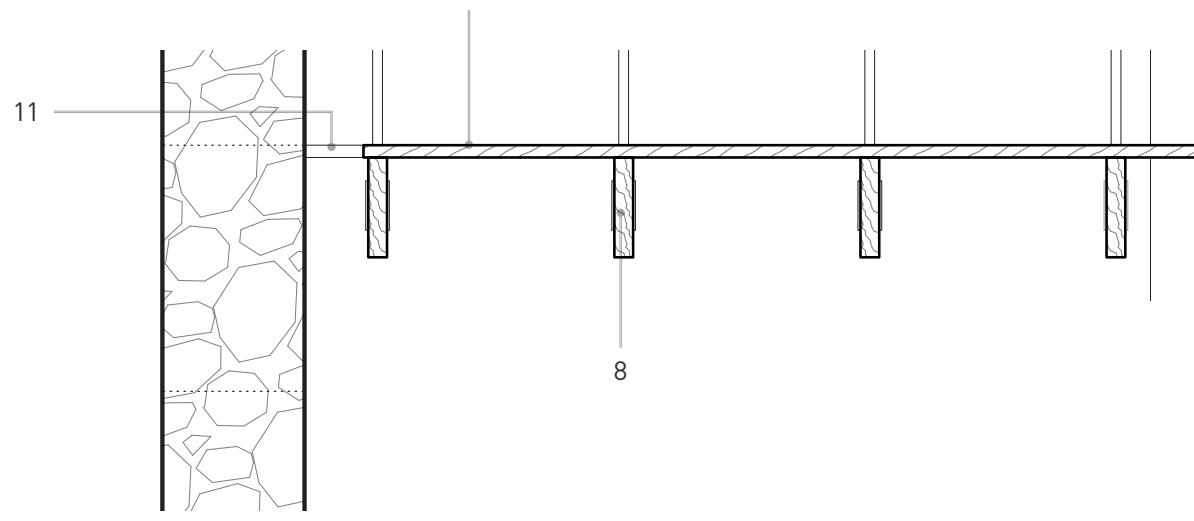

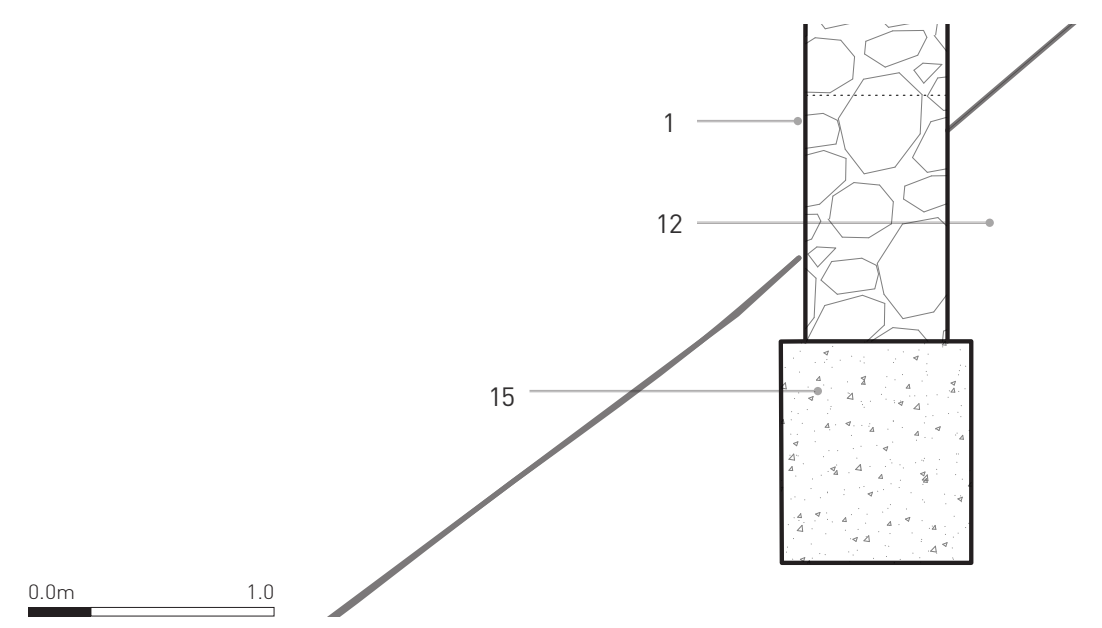




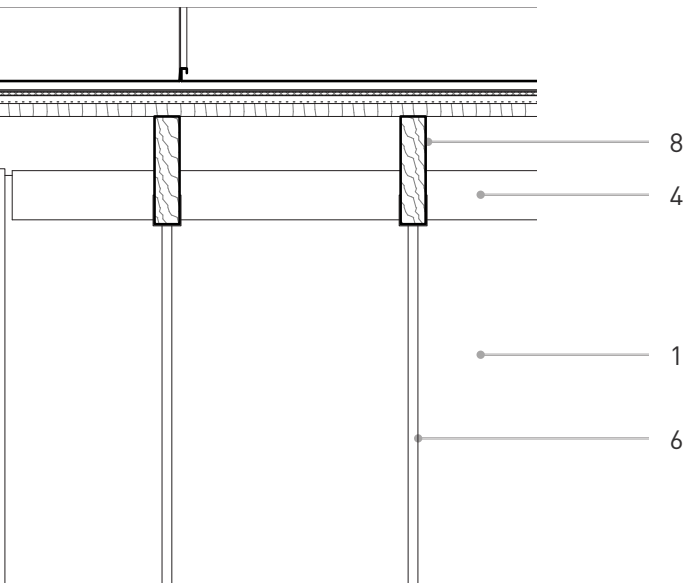

1 gabion wall

2 gabion wall acting as a retaining wall

3 u-shaped steel corner column

4 steel ring beam

5 hung wood bench

6 hung metal rod

7 metal attachment at top of rod welded to steel ring beam
8 joist

9 poured concrete floor

10 wood decking

11 reveal between floor and gabion walls

12 cut earth

13 rheinzink standing seam zinc roof

14 roof wood decking

15 foundation

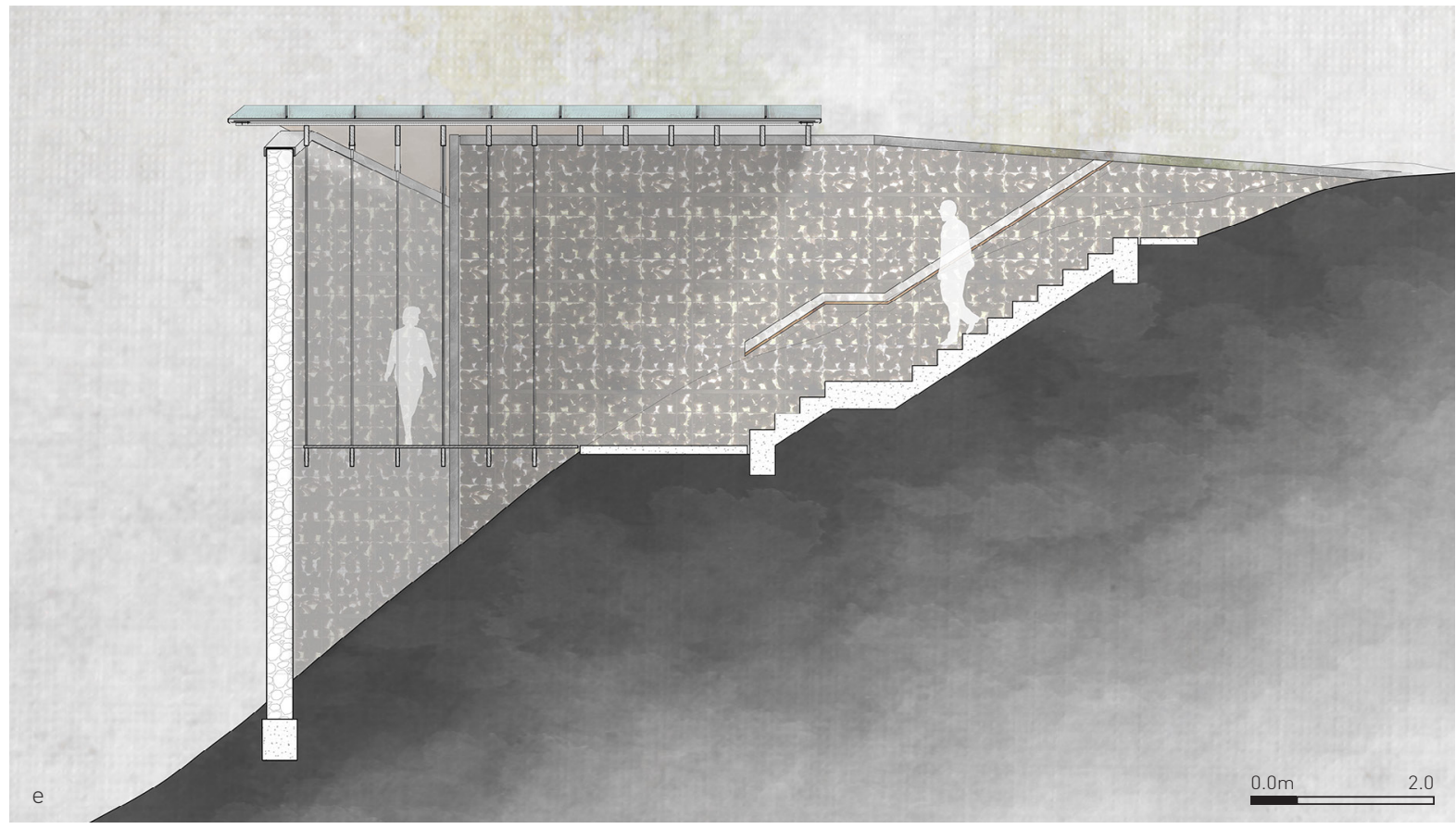




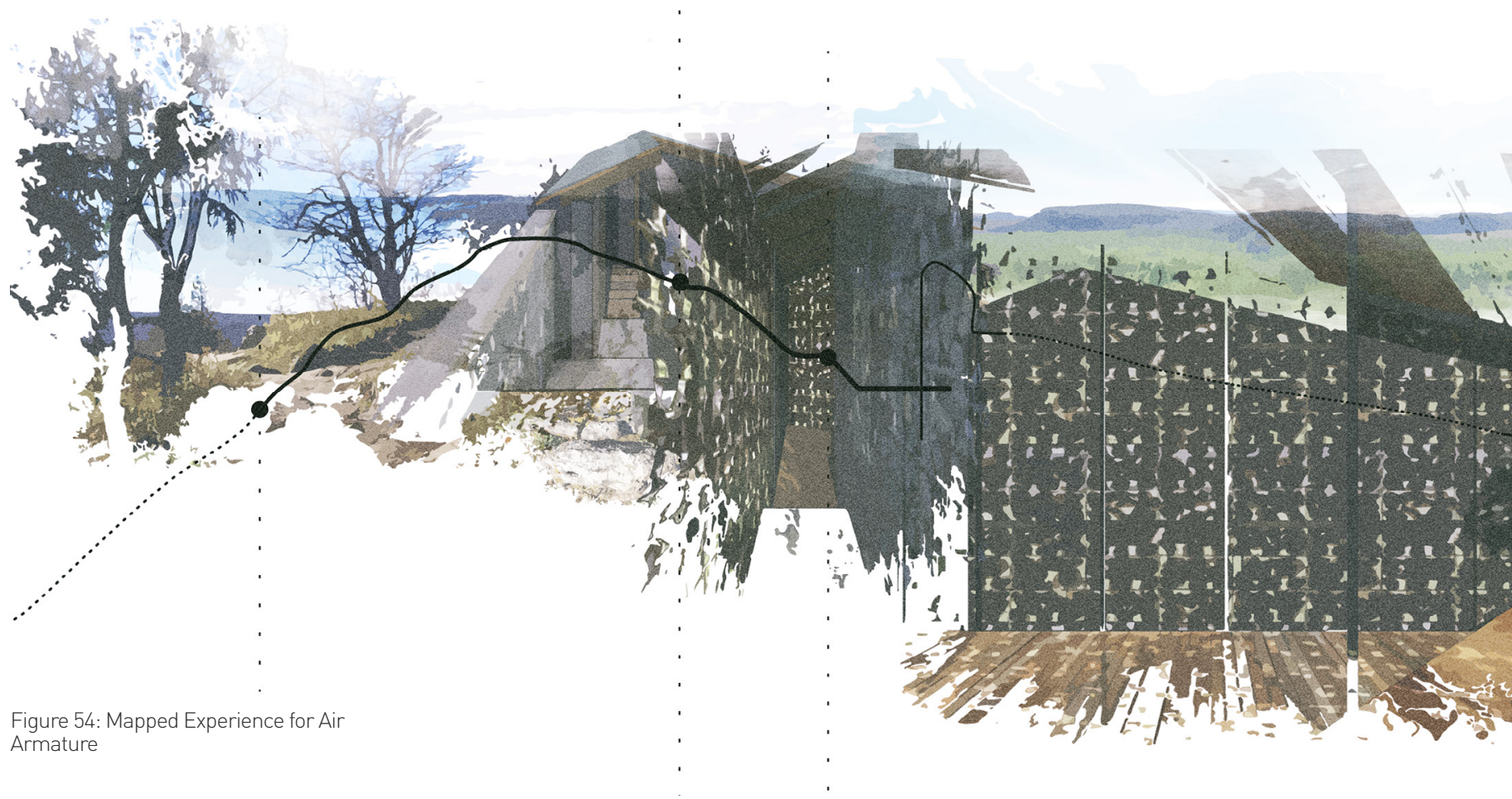



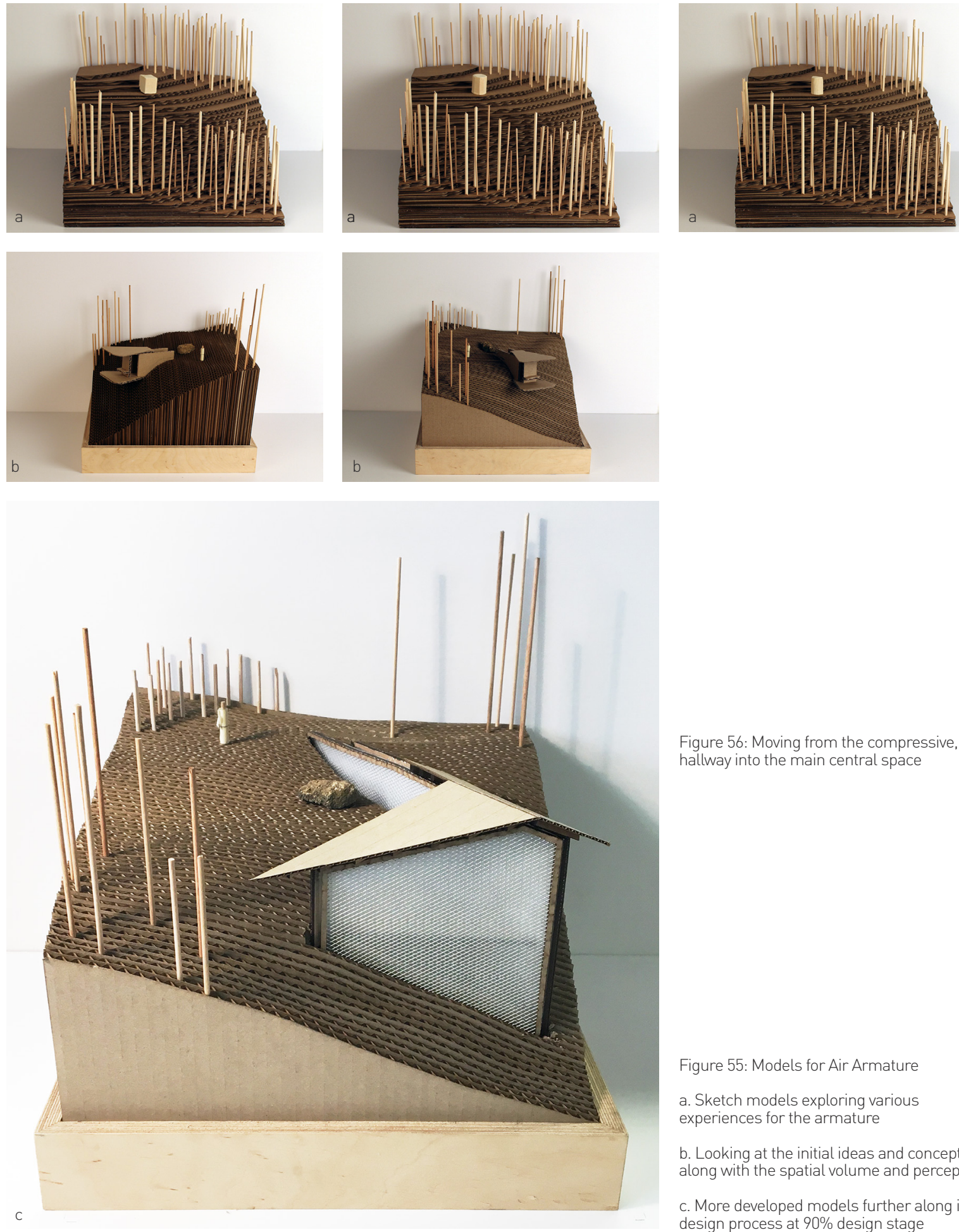

Figure 56: Moving from the compressive, dark hallway into the main central space

Figure 55: Models for Air Armature

a. Sketch models exploring various experiences for the armature

b. Looking at the initial ideas and concepts along with the spatial volume and perception

c. More developed models further along in the design process at $90 \%$ design stage 


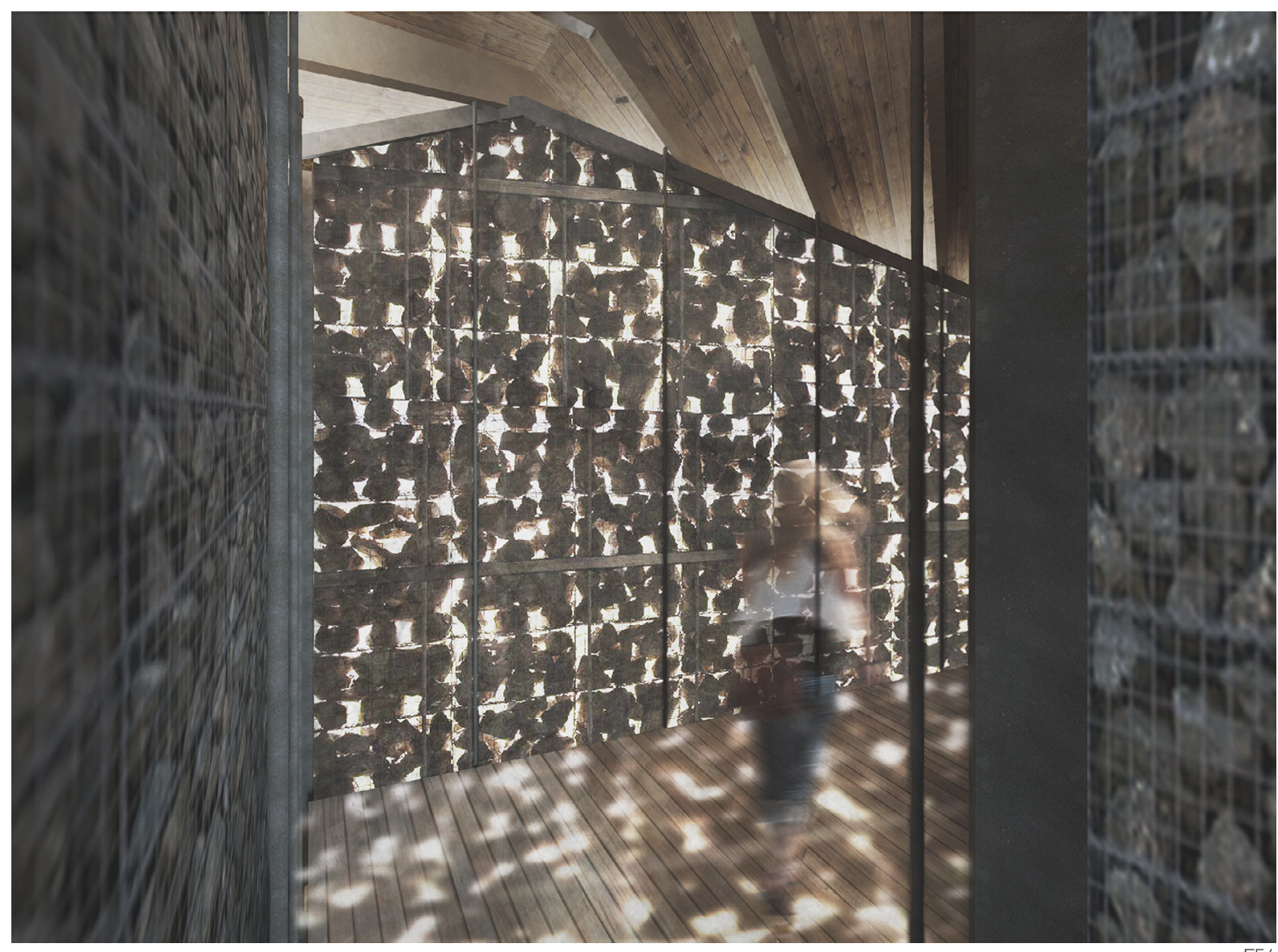


APPENDIX D

Figure 57: Orthographic Drawings for Water Armature
a. Site Plan
b. Interior Plan
(1) $0.0 \mathrm{~m} \quad 2.0$

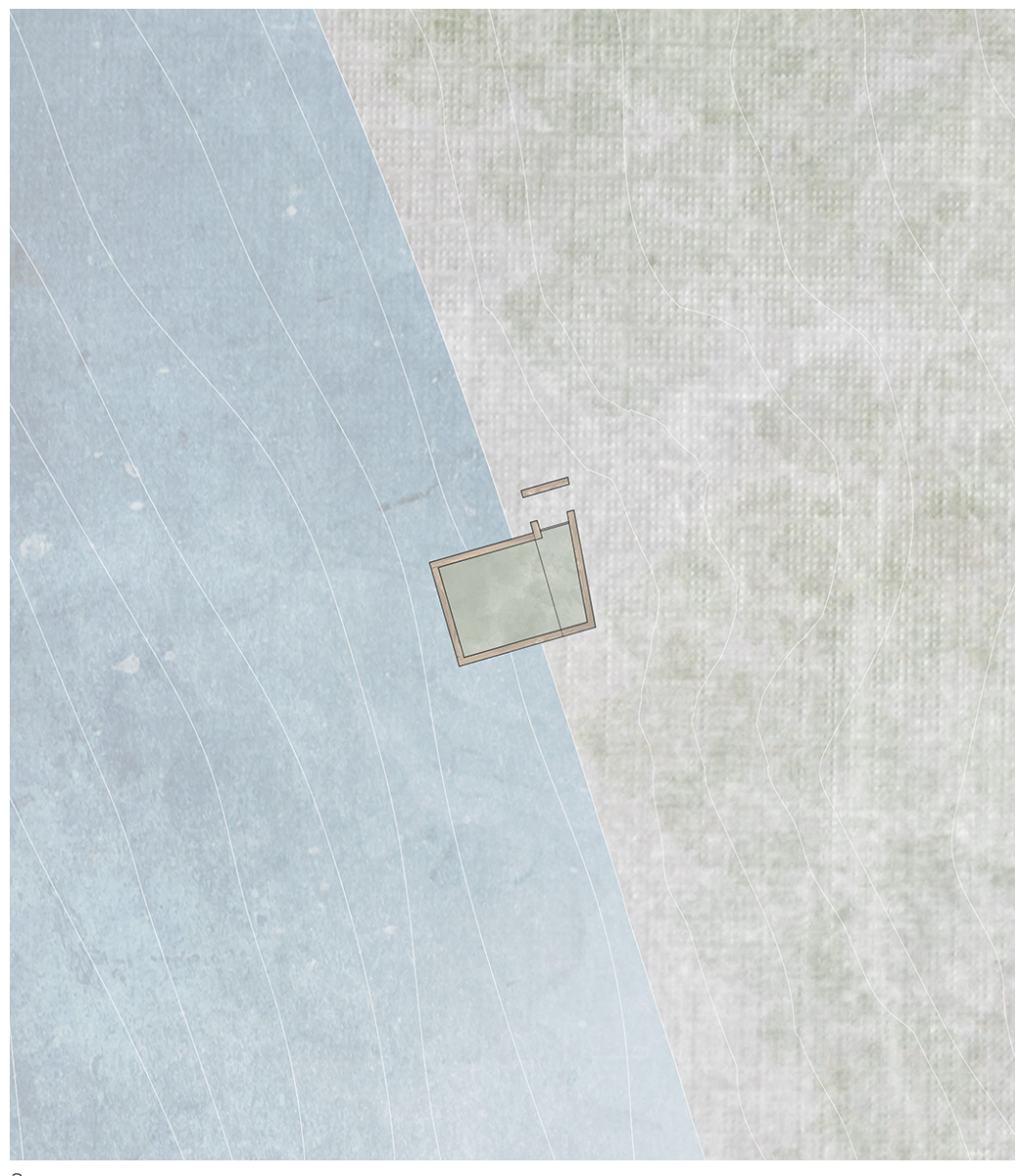




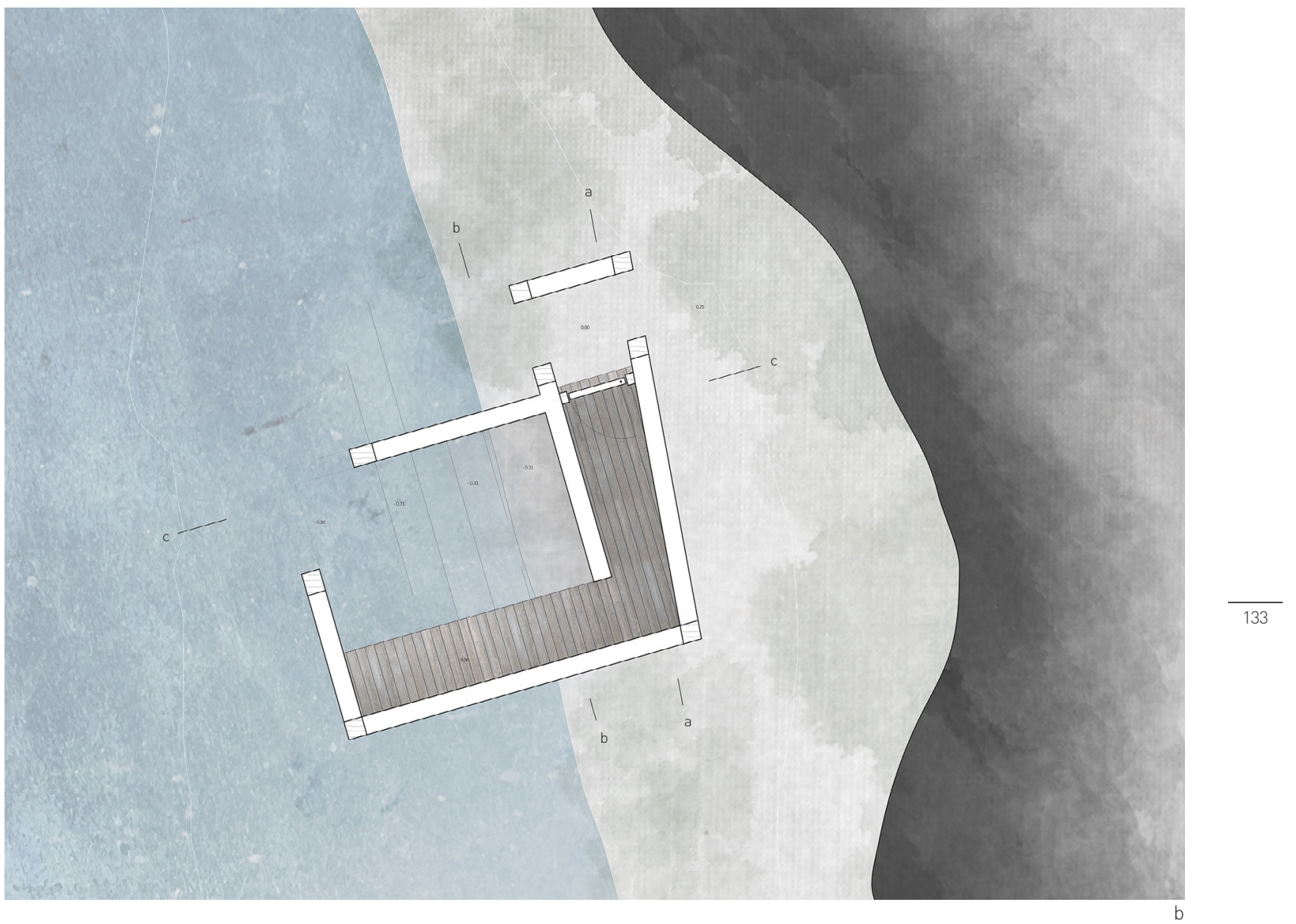


APPENDIX D

c. Section a-a

d. West Elevation

$0.0 \mathrm{~m} \quad 2.0$

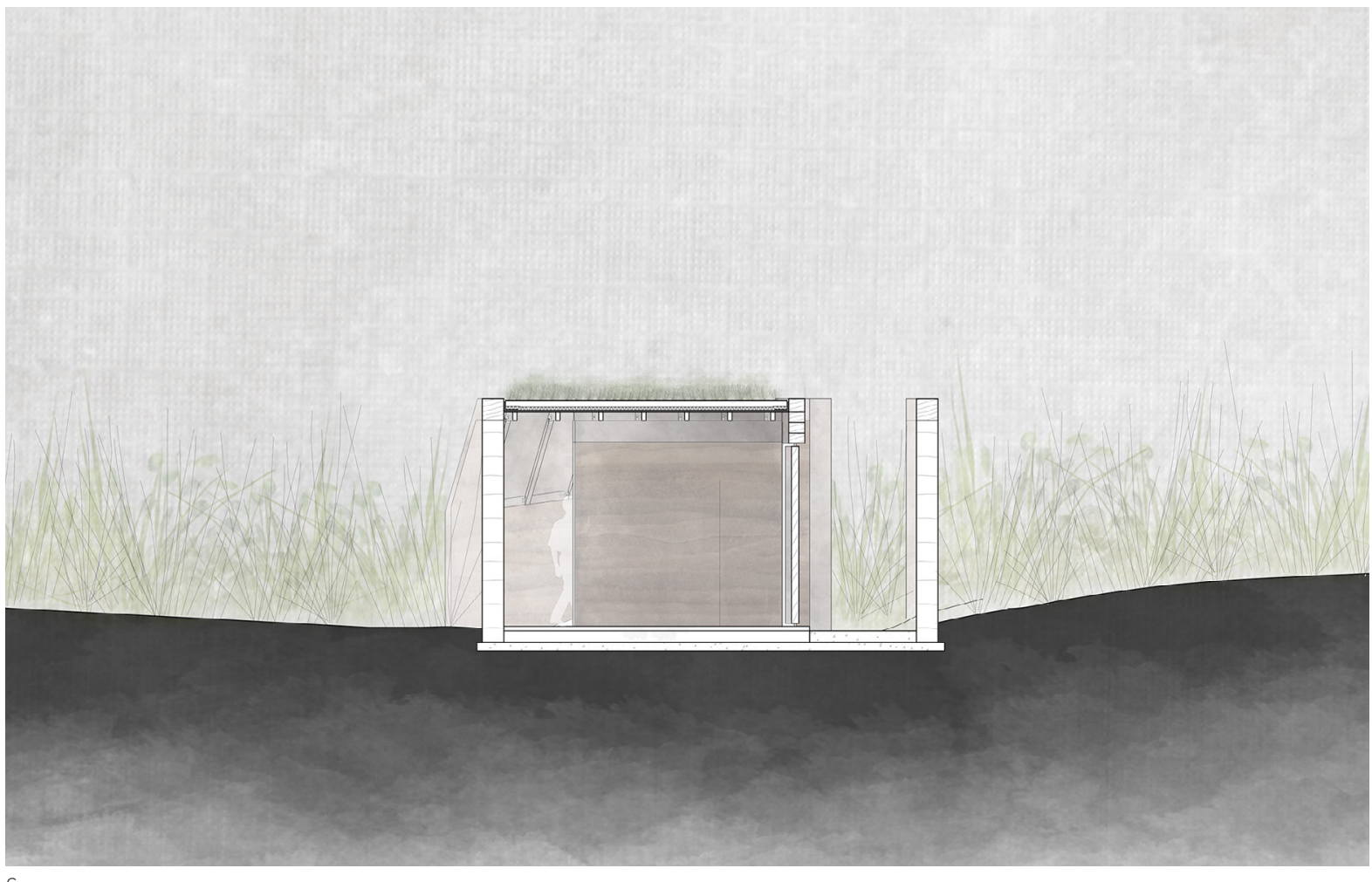


SCHEMATIC DESIGN | WATER ARMATURE

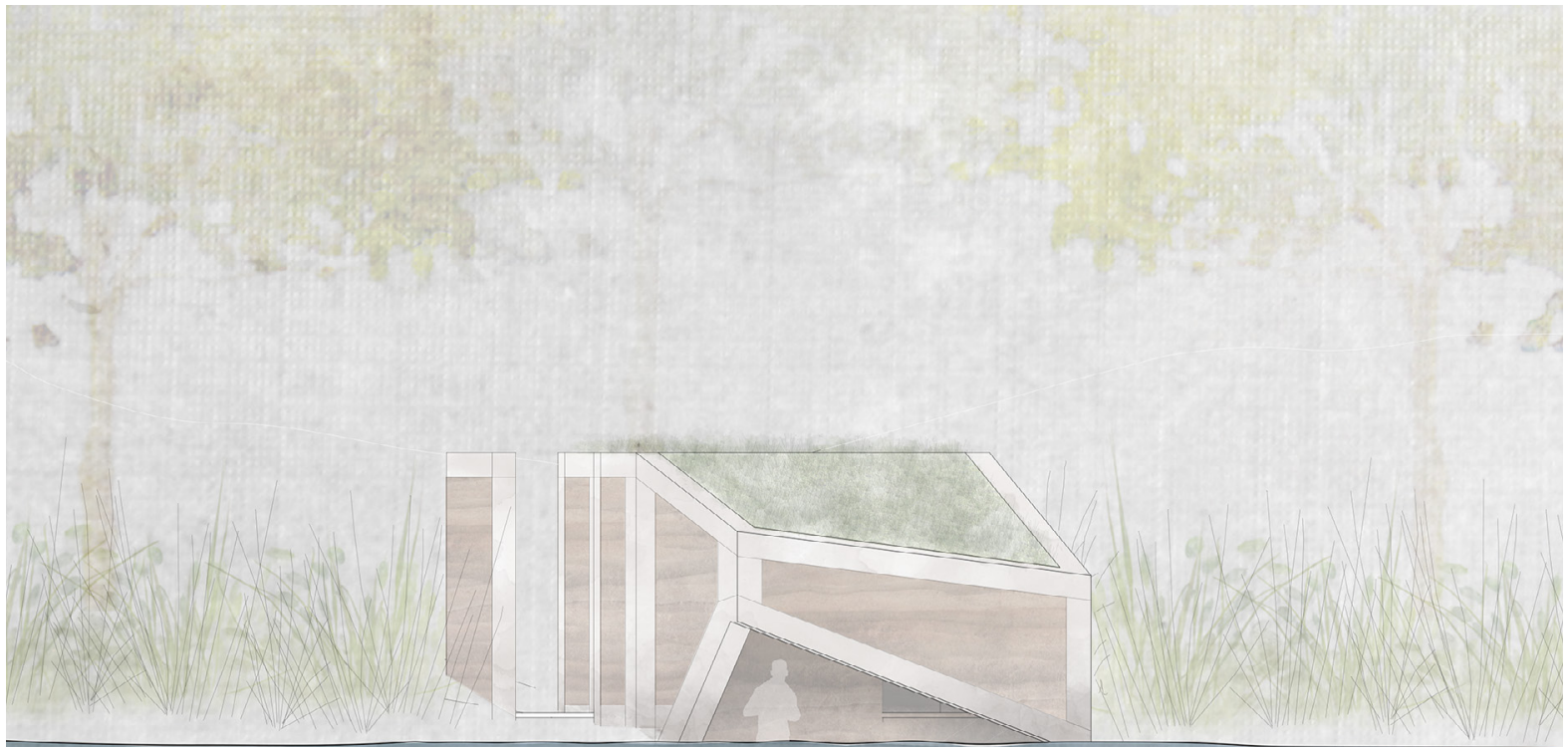


APPENDIX D

e. Section c-c

f. Detail of Section c-c

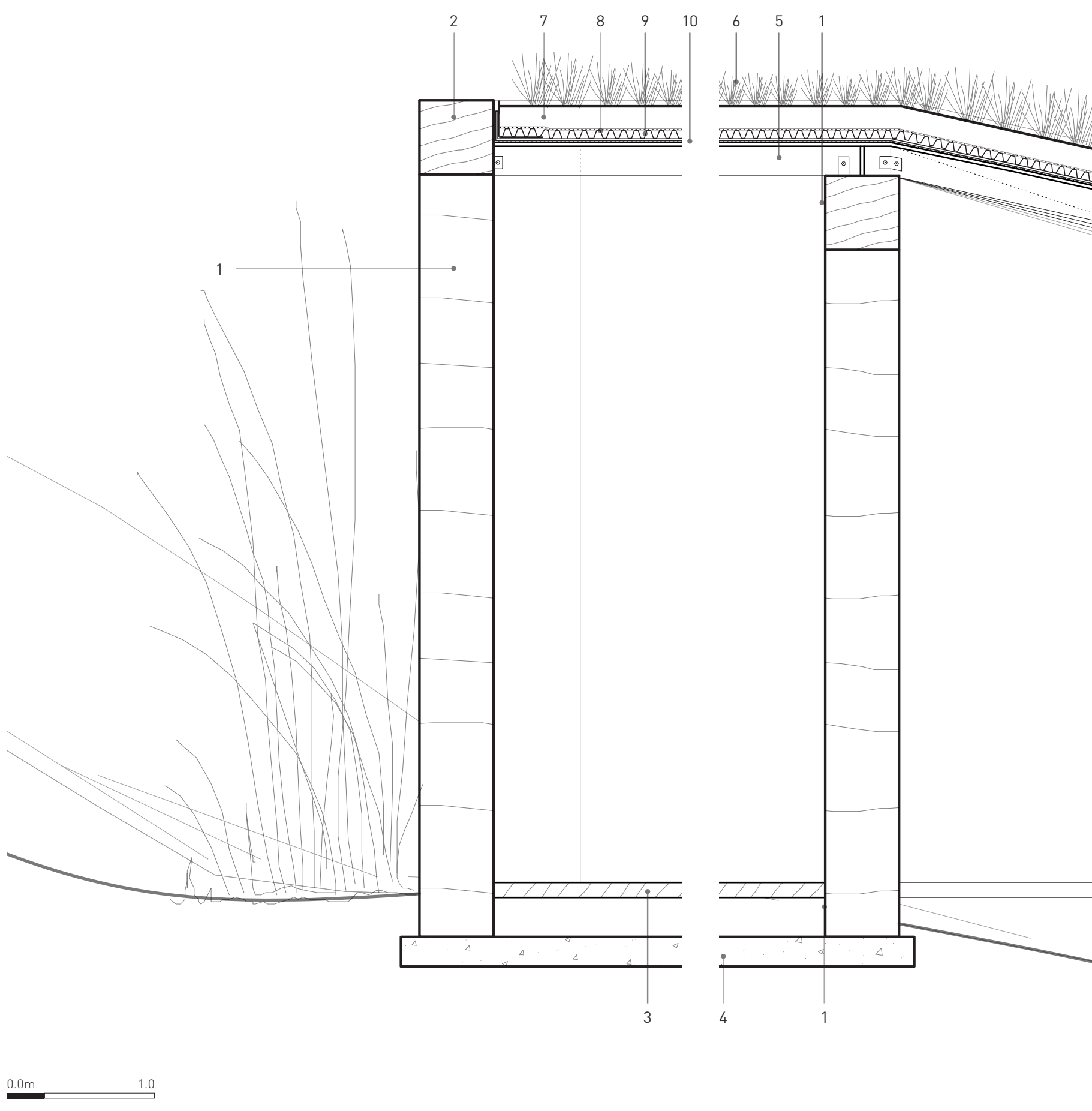




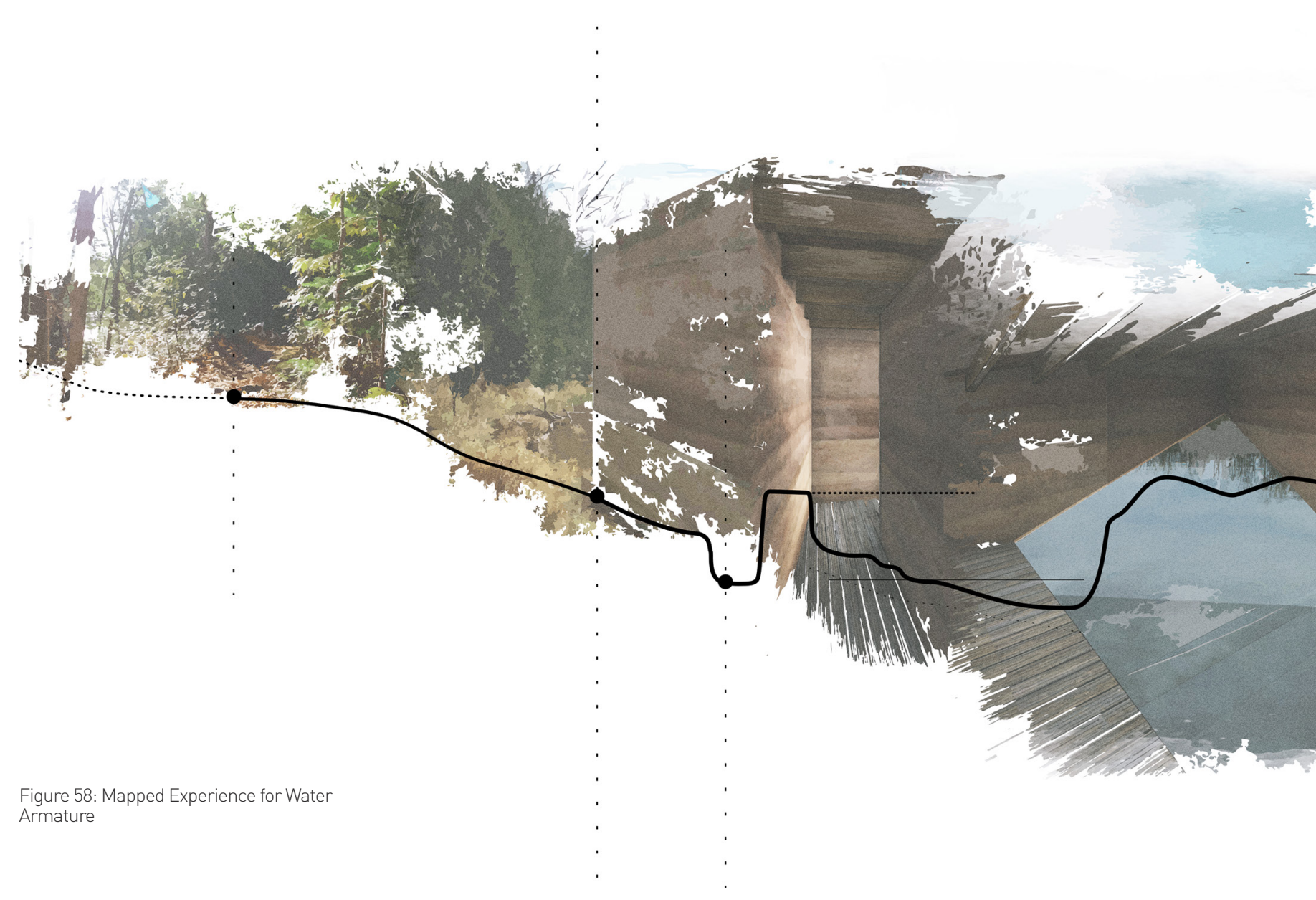




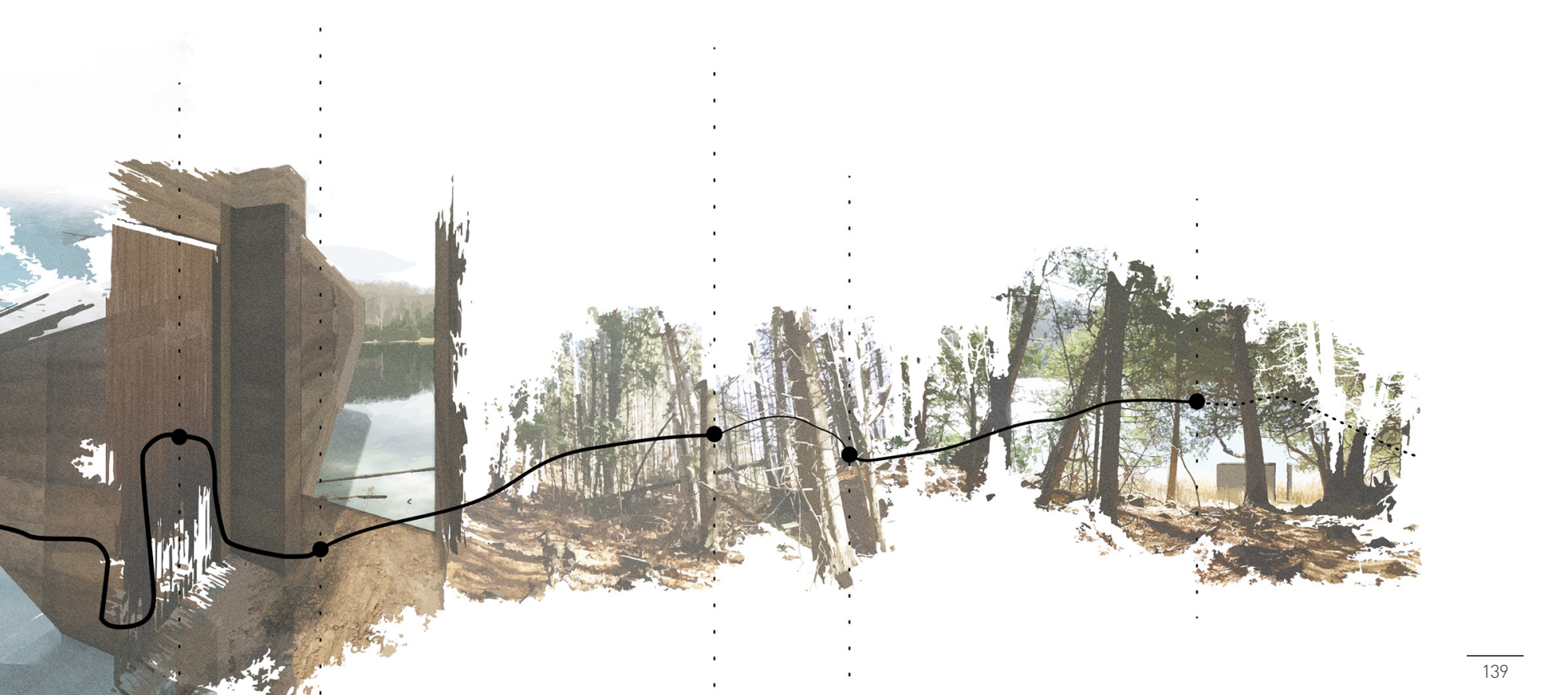



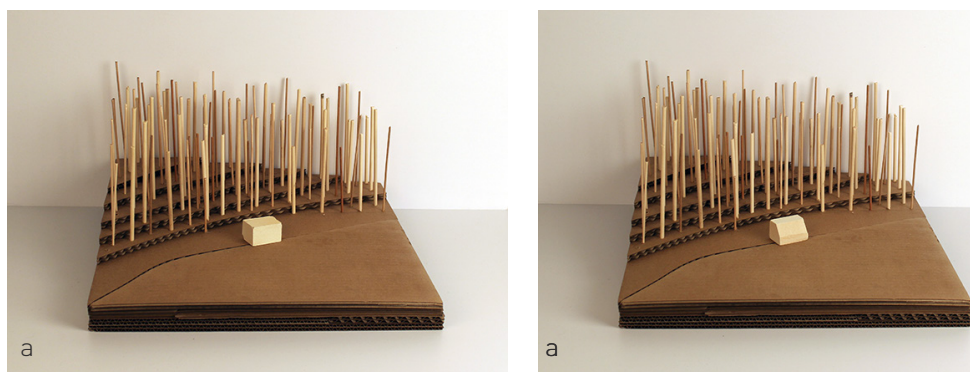

a
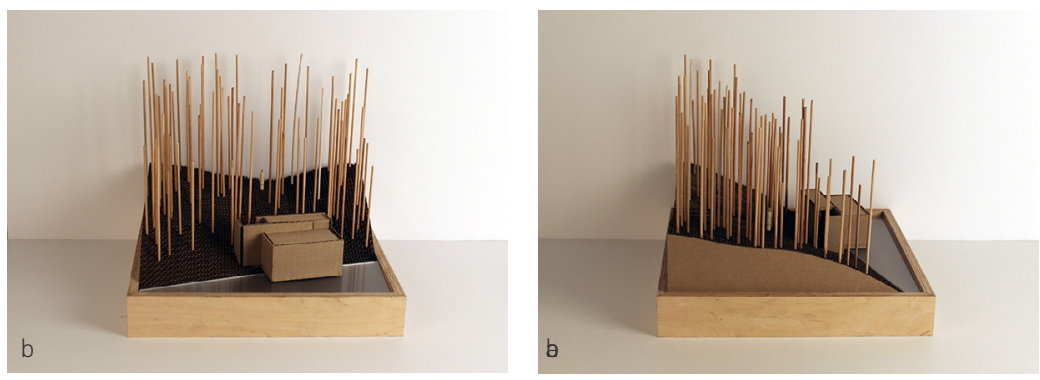

b

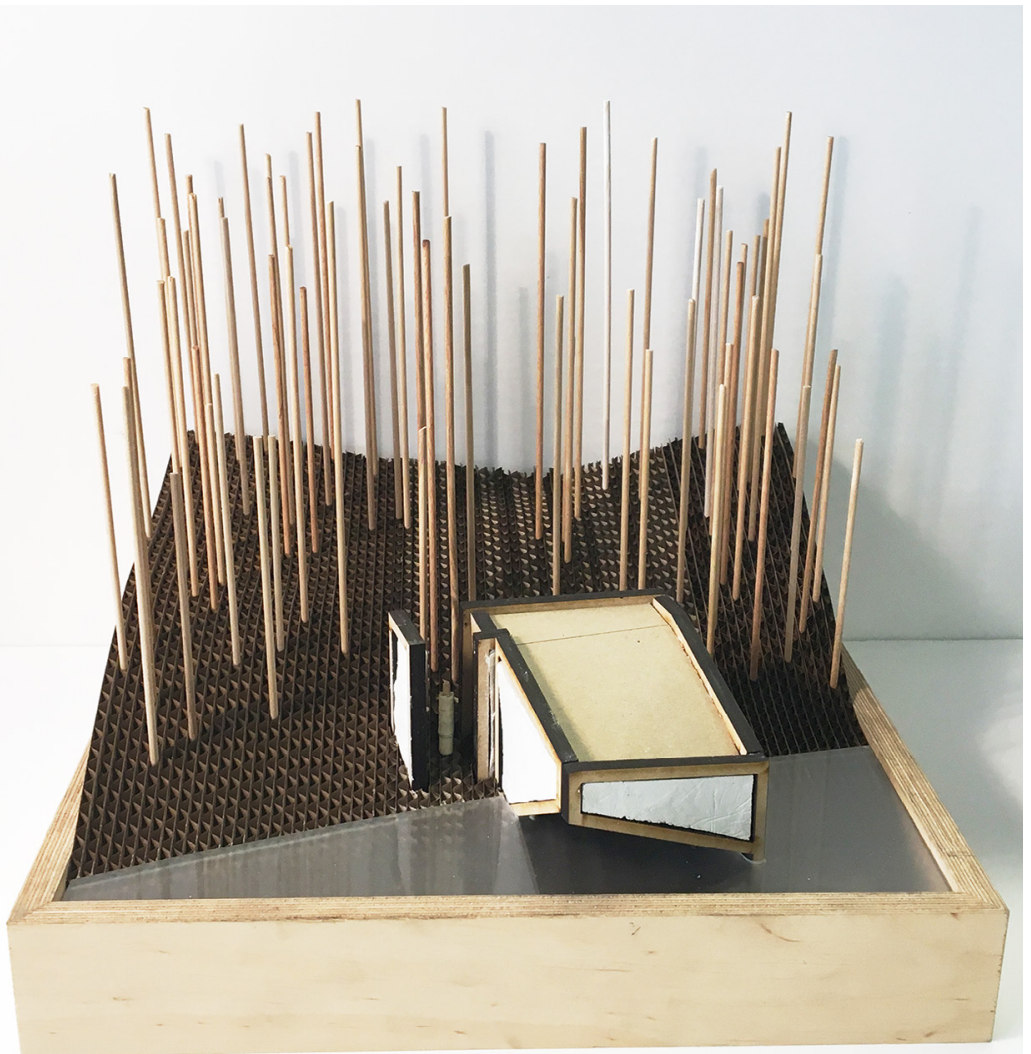

C
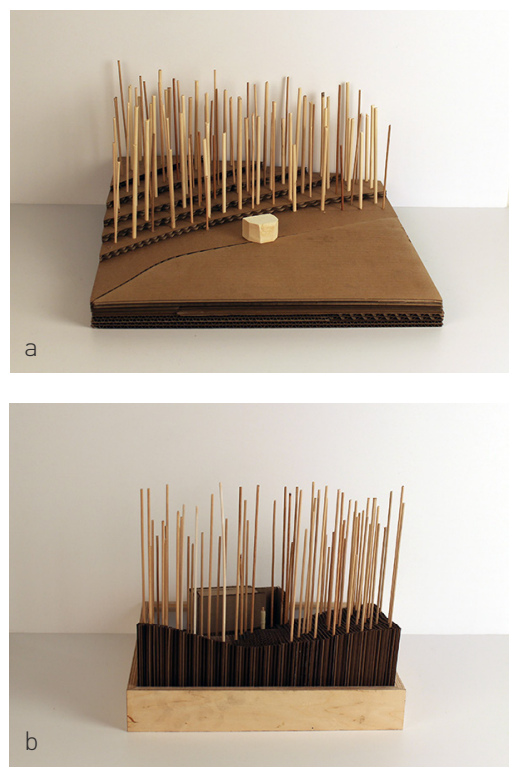

Figure 60: Sitting on the wood floor, extending out over the water.

Figure 59: Models for Water Armature a. Sketch models exploring various experiences for the armature

b. Looking at the initial ideas and concepts along with the spatial volume, including how the armature could become the transitional space of land and water

c. More developed models further along in the design process at $90 \%$ design stage 


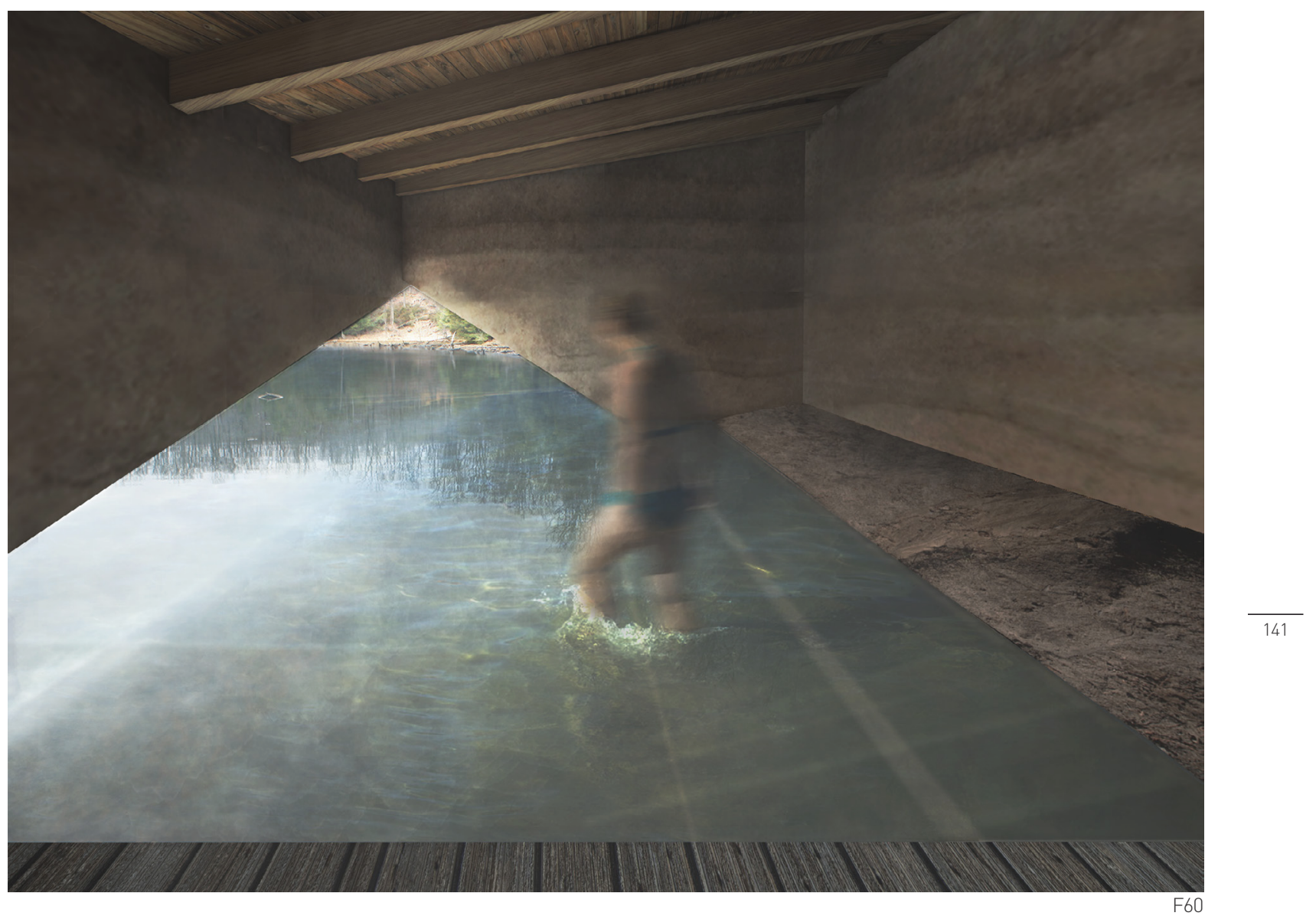


Figure 61: Orthographic Drawings for Earth Armature

a. Site plan

b. Conceptional order

c. Plan Q $1200 \mathrm{~mm}$ from ground

d. Plan la $2800 \mathrm{~mm}$ from ground

e. Plan la $4800 \mathrm{~mm}$ from ground

(1) $0.0 \mathrm{~m} \quad 2.0$

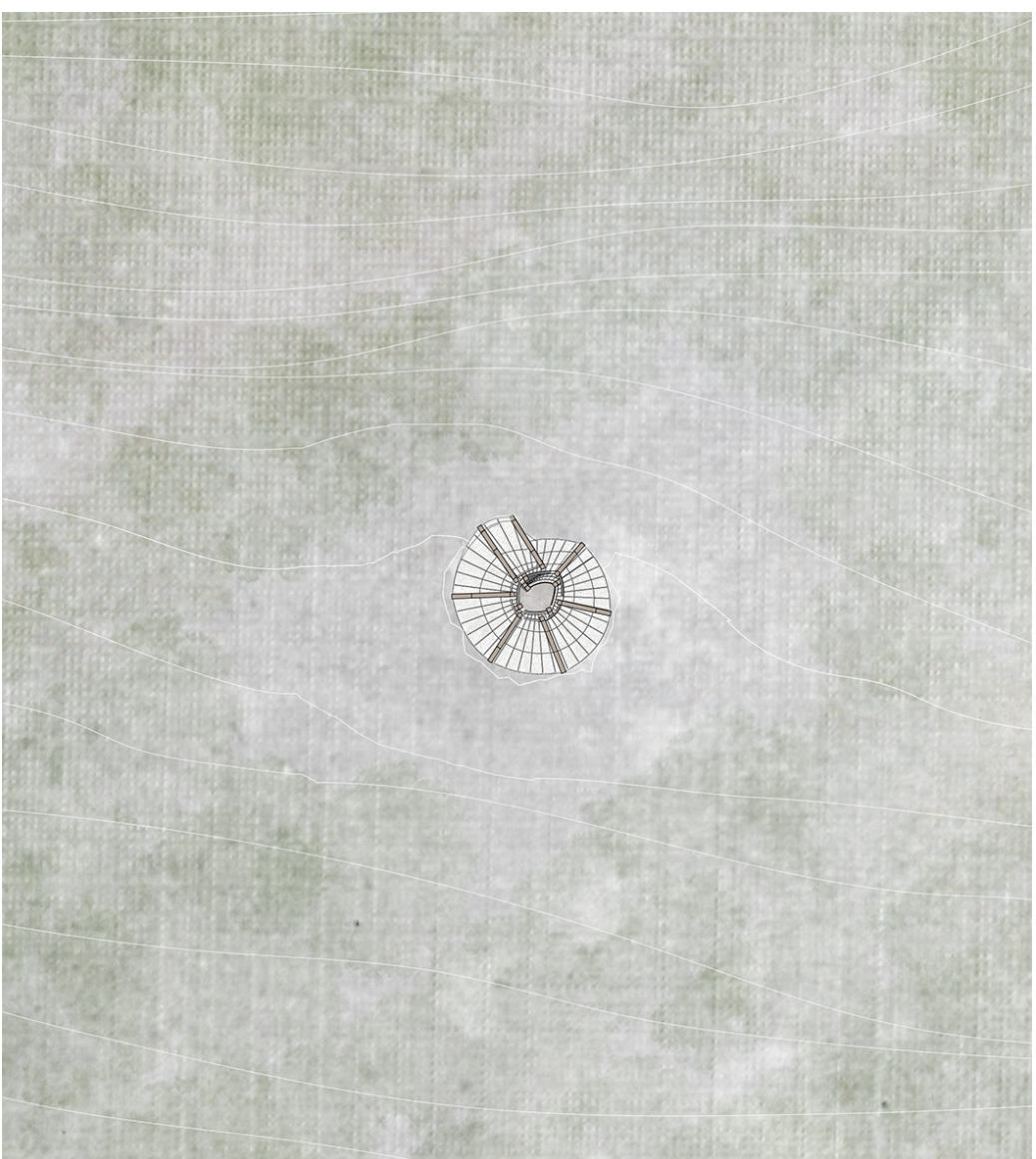

a 

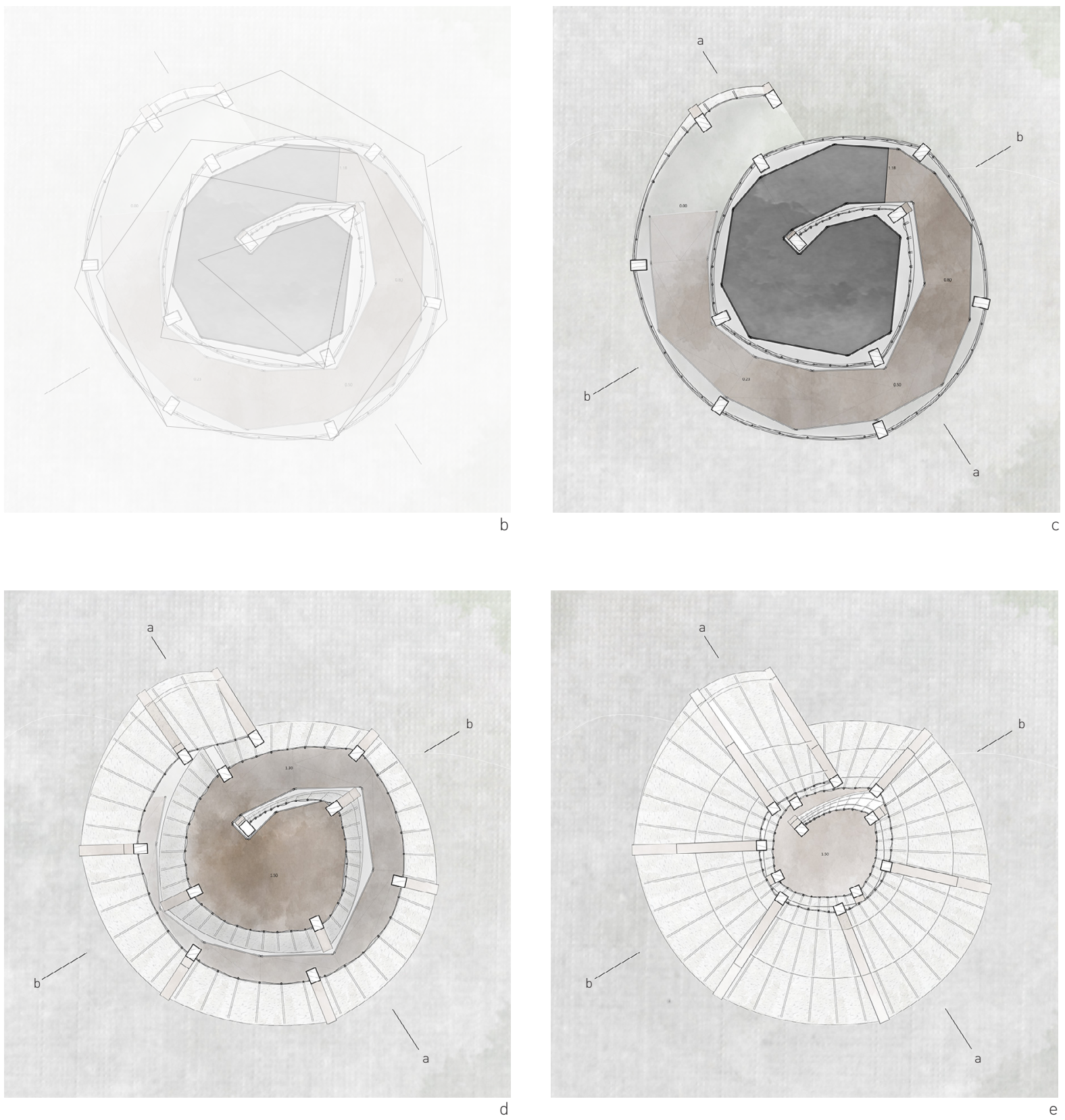
g. Detail of Plan la $1200 \mathrm{~mm}$ from ground
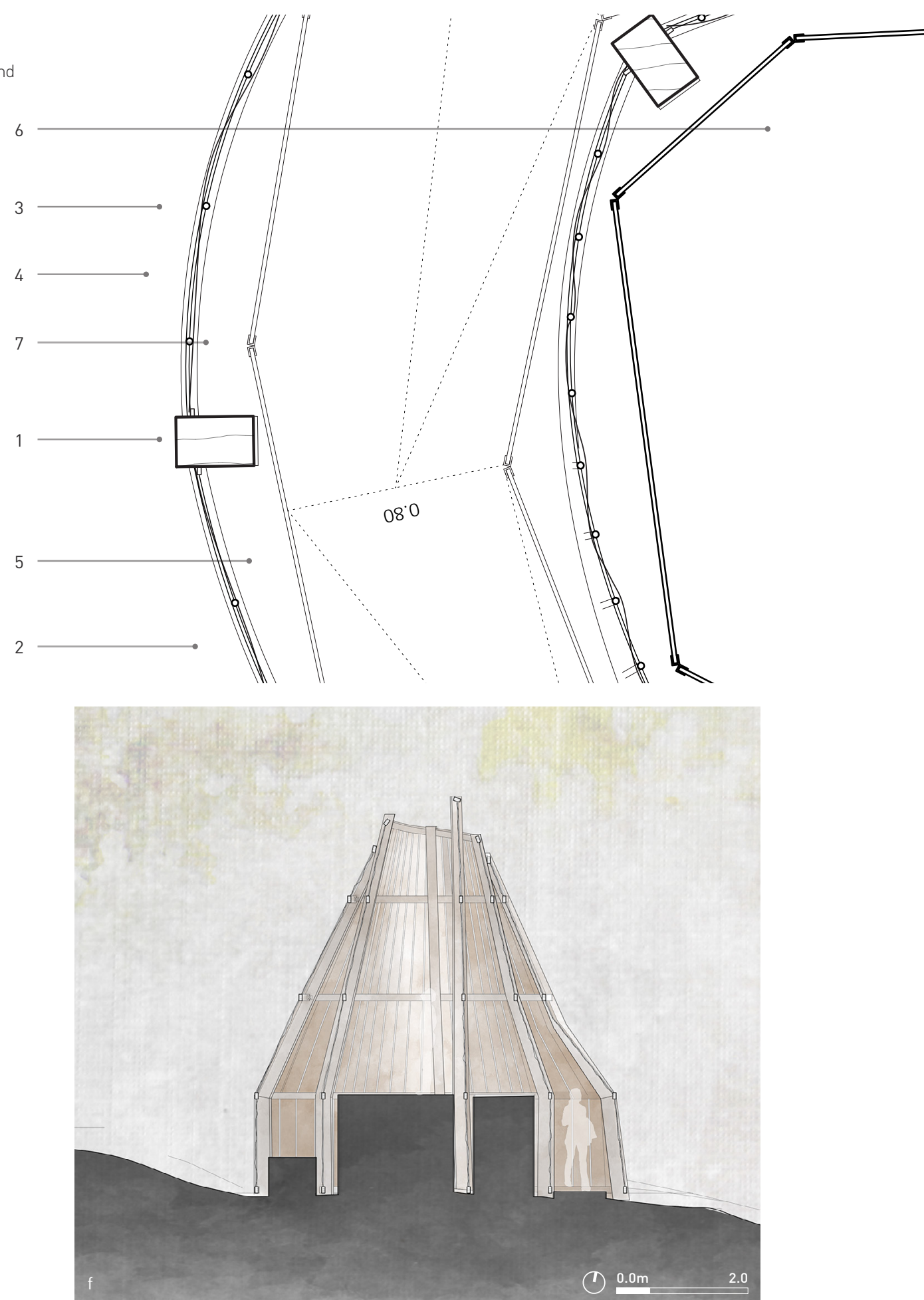


$$
\text { Q) }
$$


APPENDIX D

h. Section b-b

i. Detail of Section bob

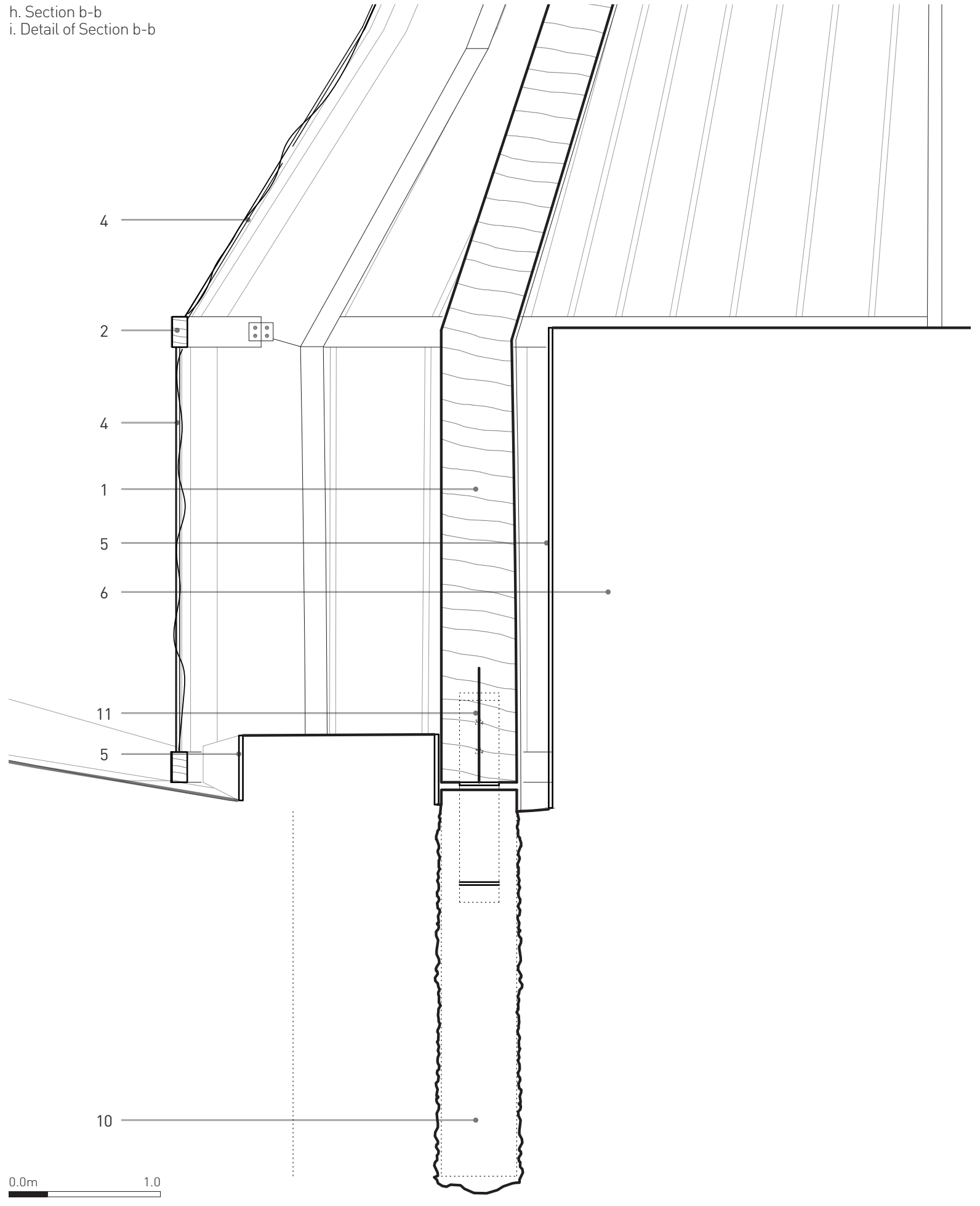


Figure 62: Mapped Experience for Earth Armature

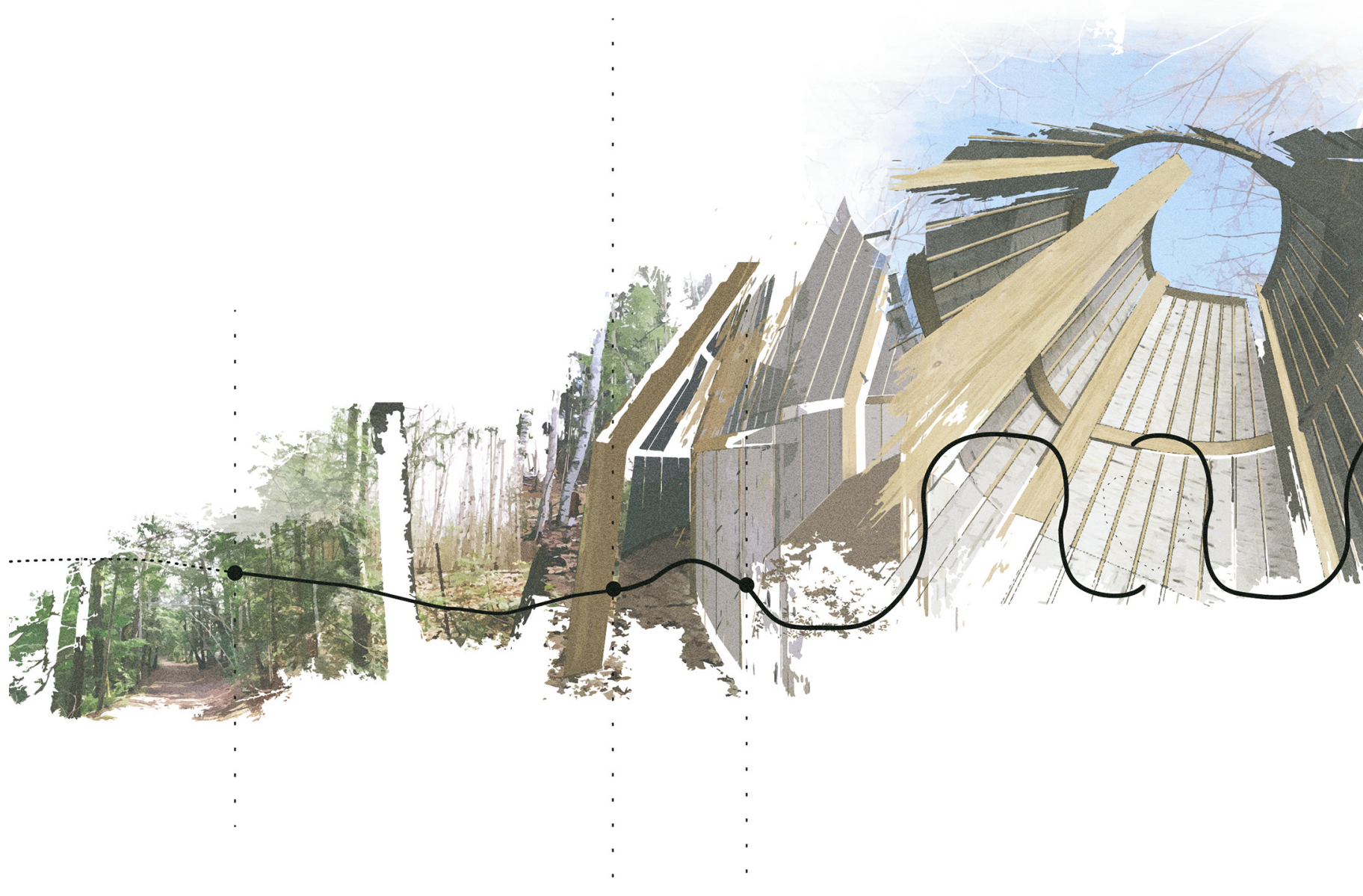



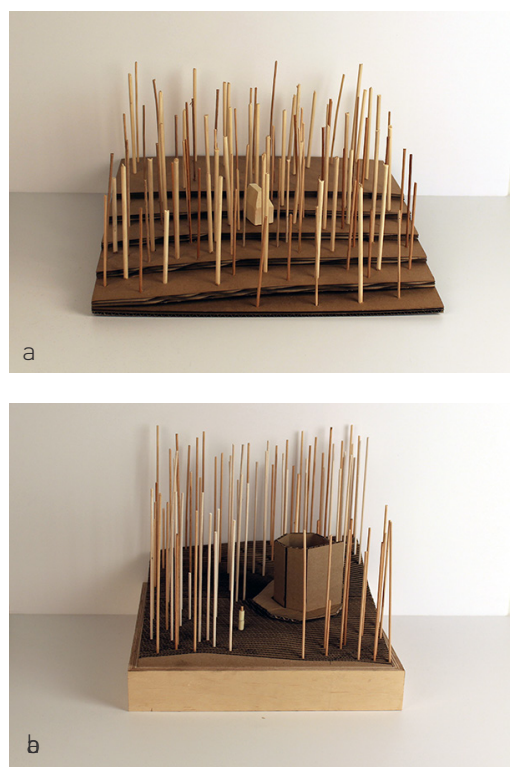
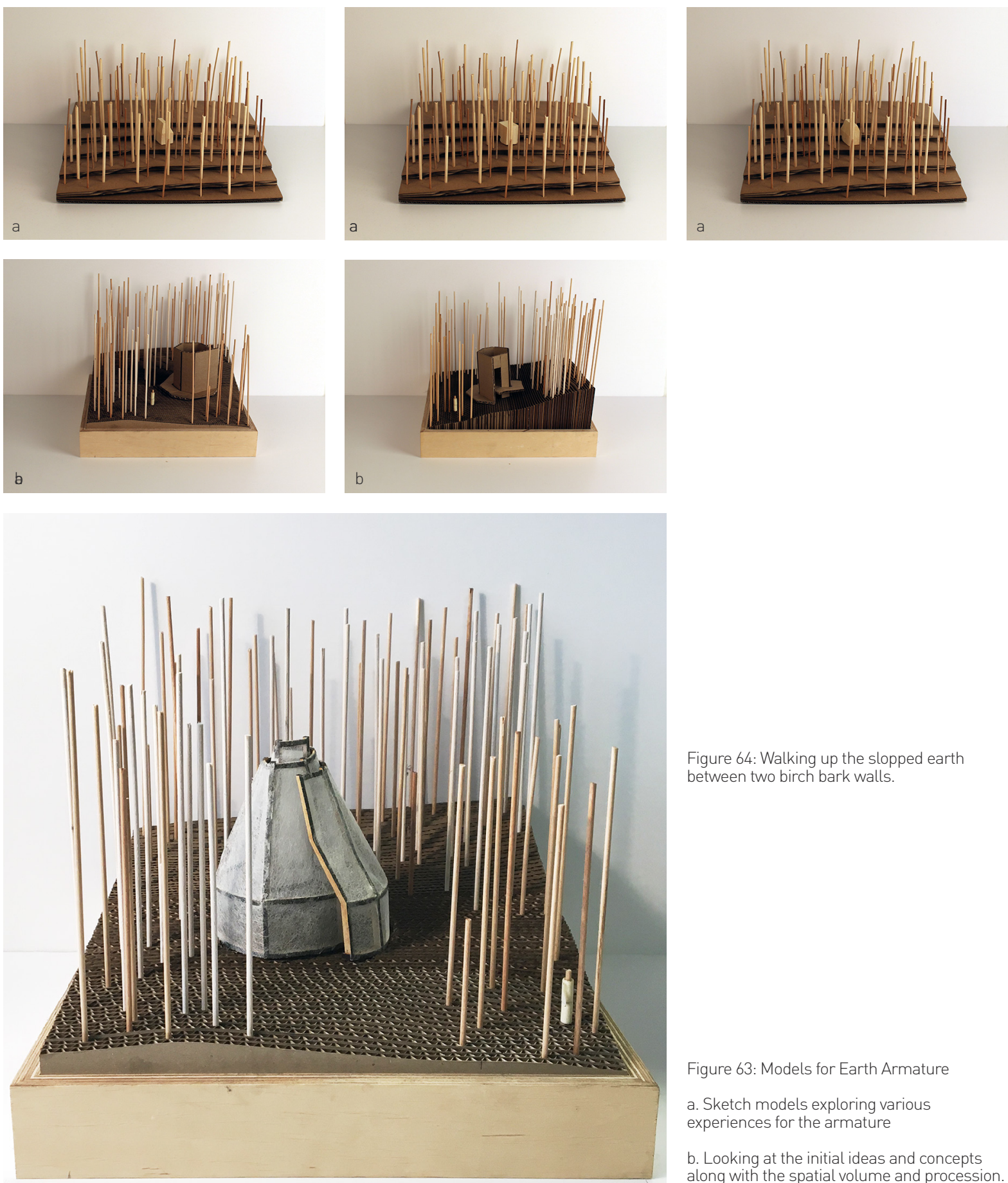

C
Figure 64: Walking up the slopped earth between two birch bark walls.

Figure 63: Models for Earth Armature a. Sketch models exploring various experiences for the armature

b. Looking at the initial ideas and concepts along with the spatial volume and procession.

c. More developed models further along in the design process at $90 \%$ design stage 


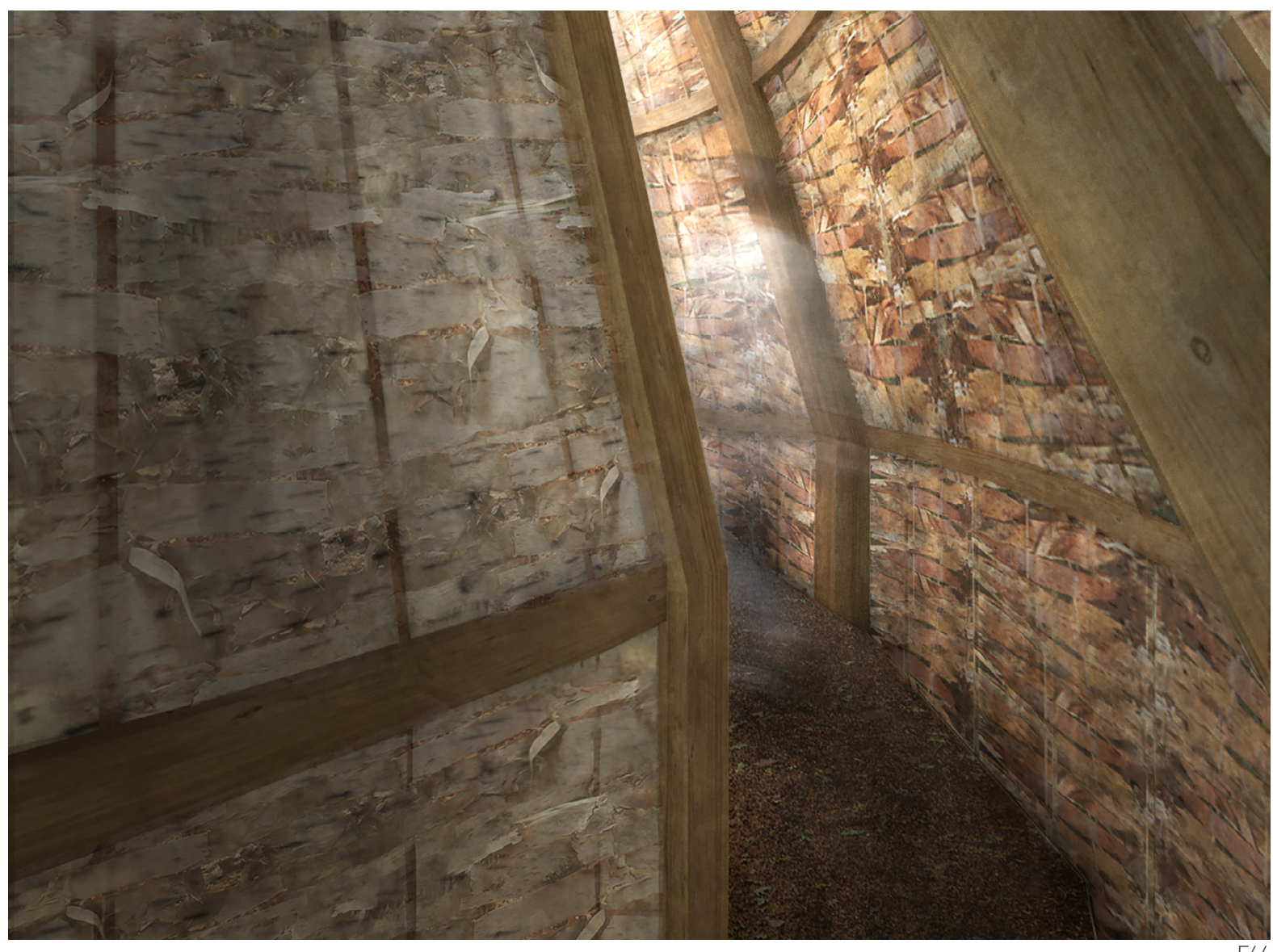




\section{APPENDIX E Material Installations}

Figure 65: Material Installation for Air Armature
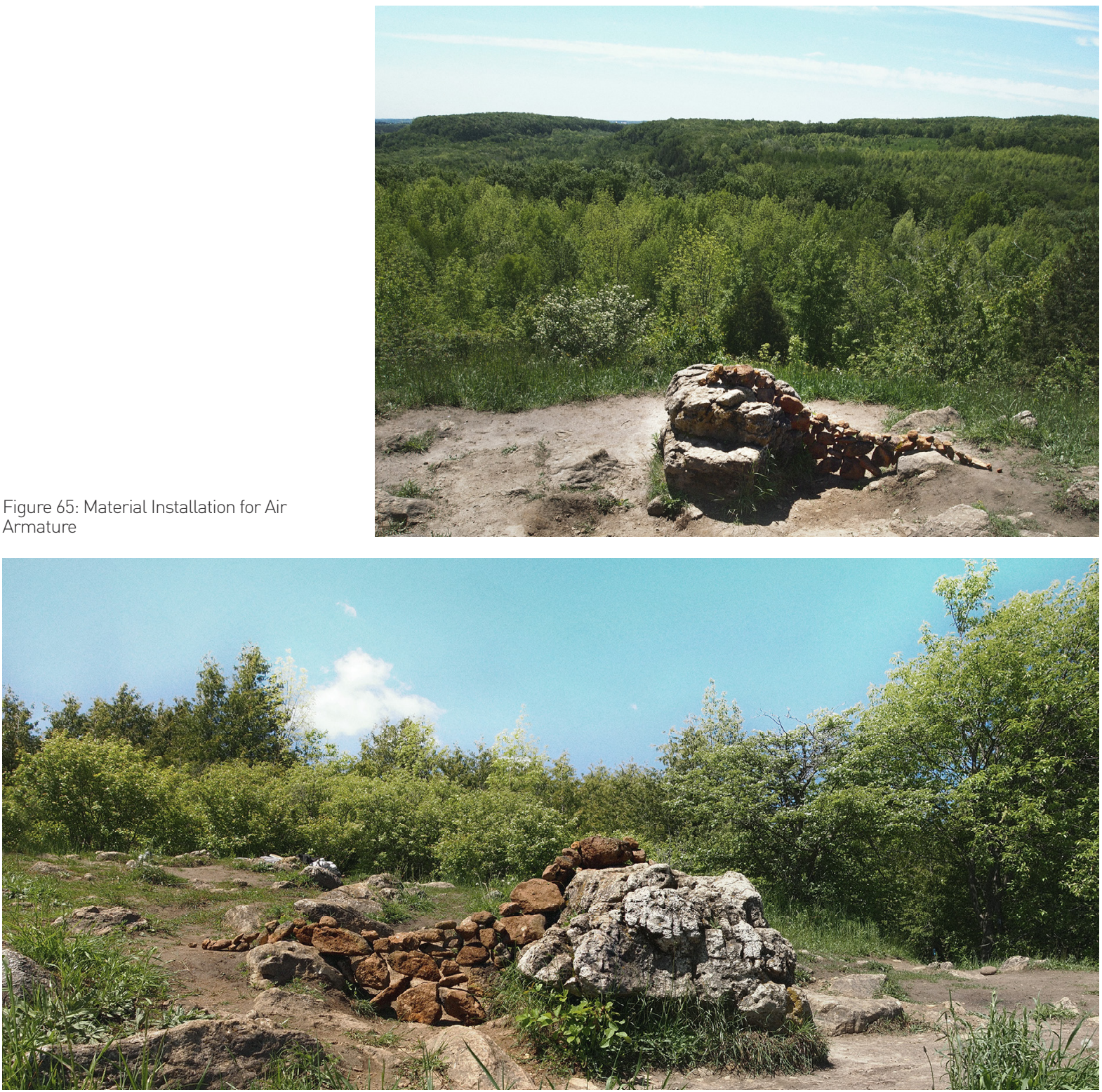

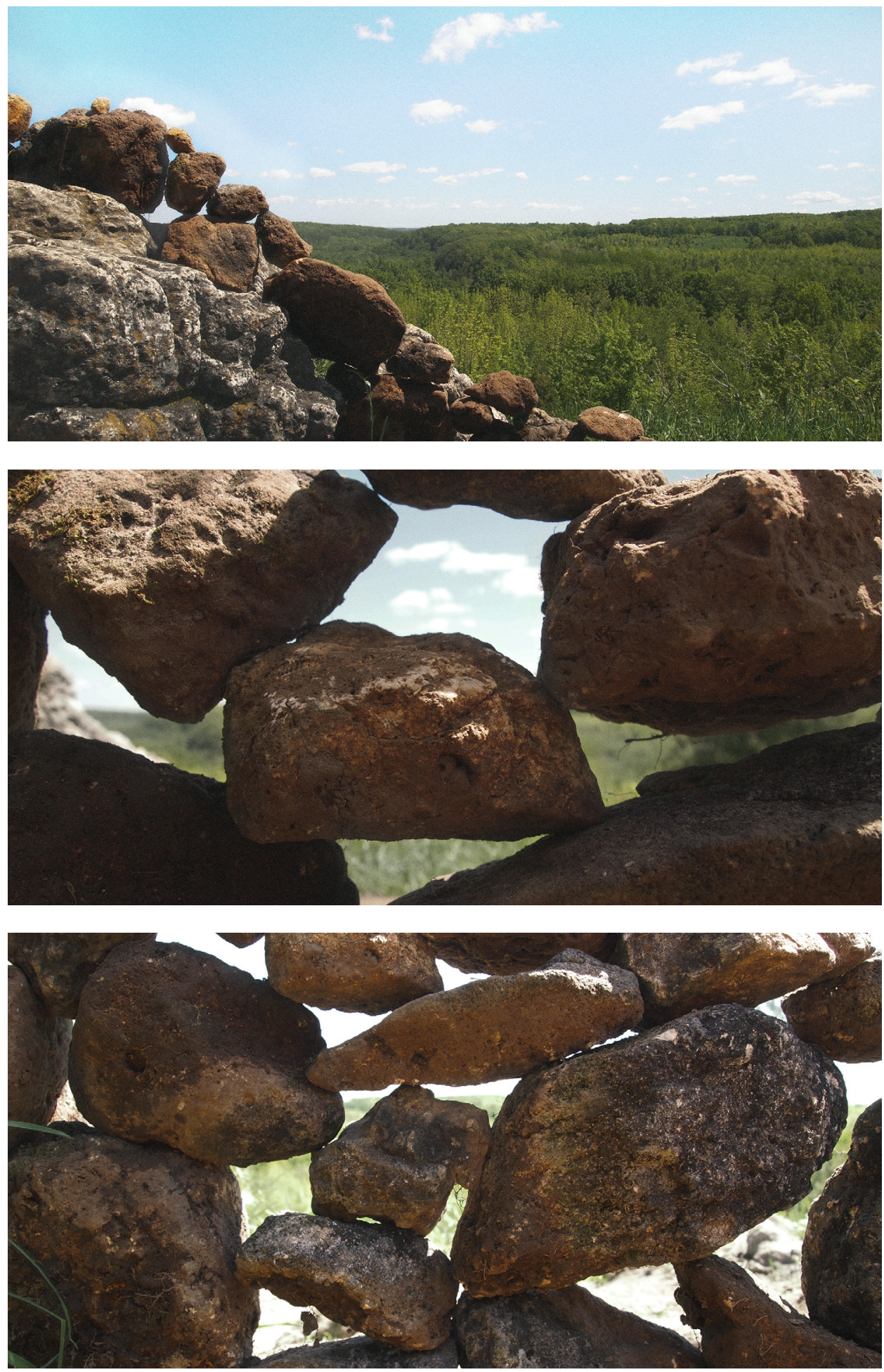


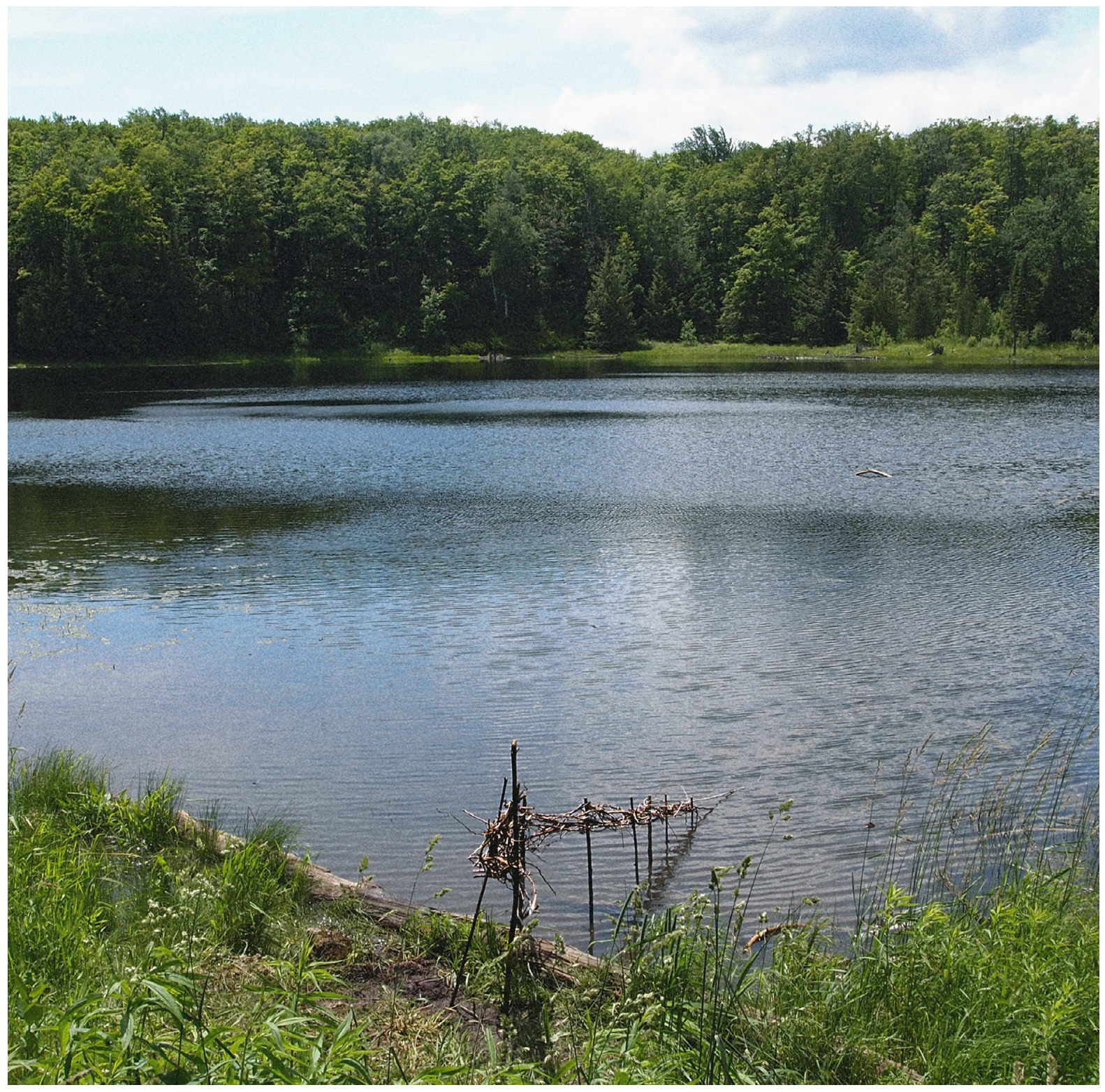



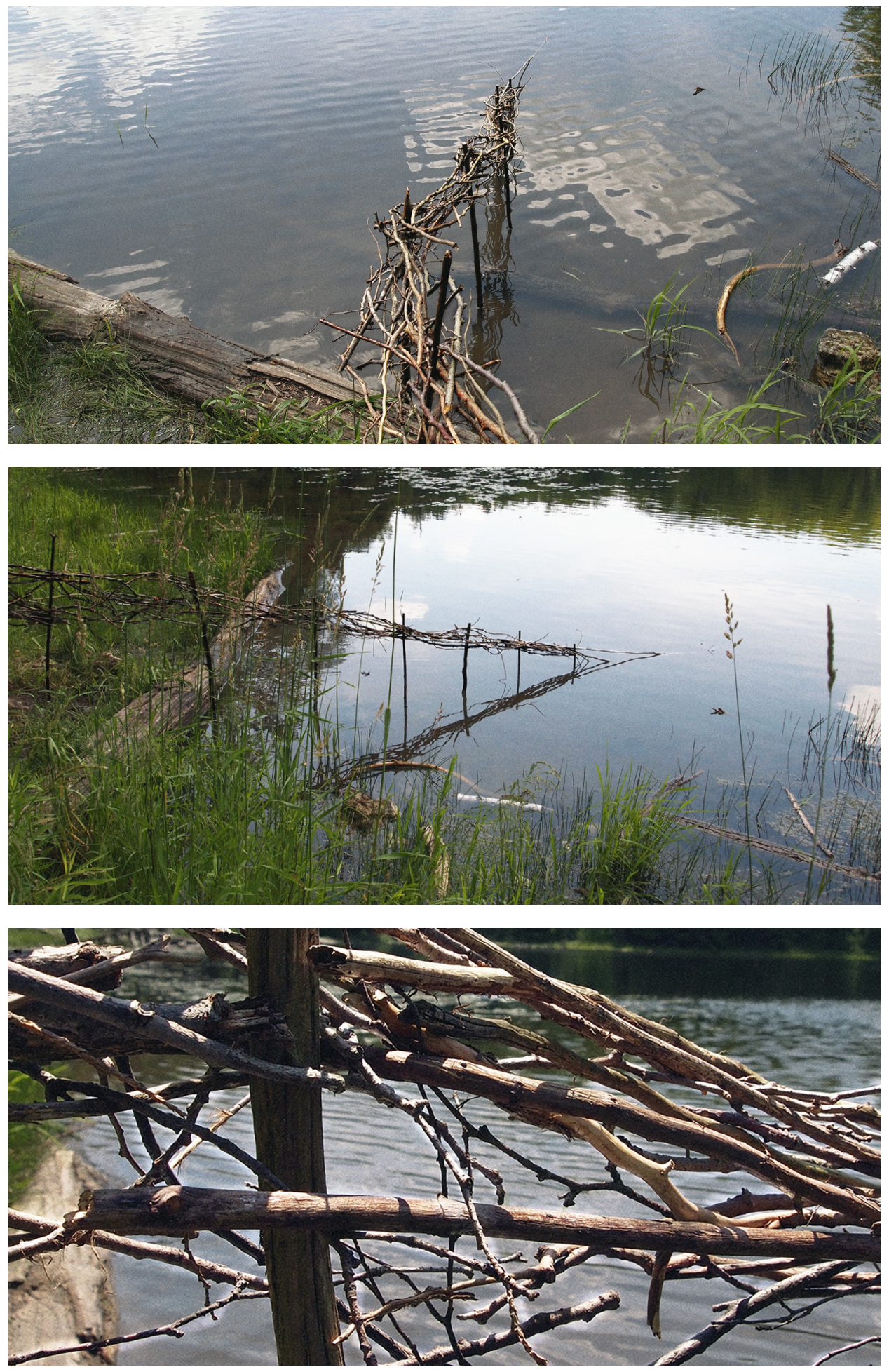


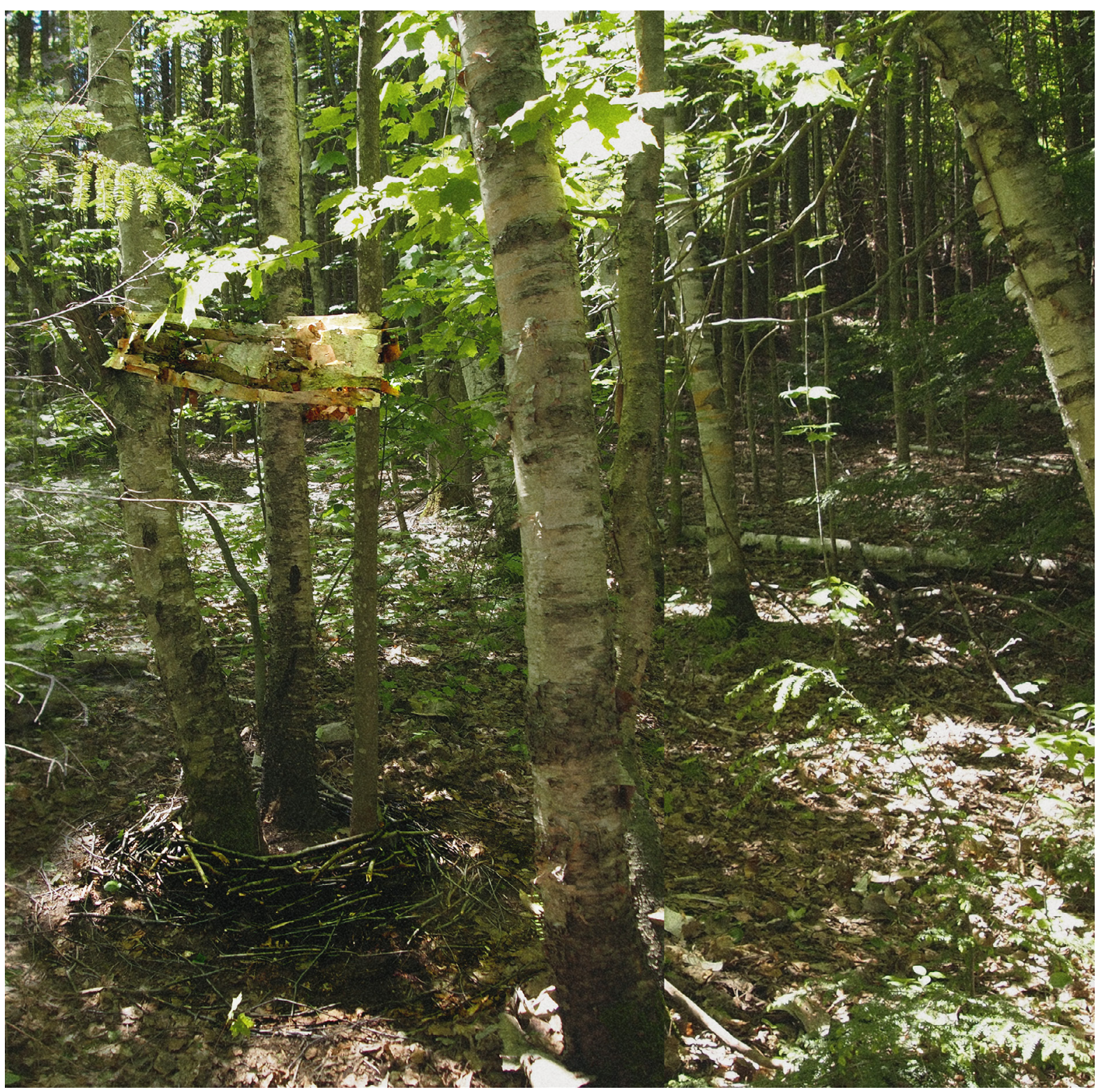



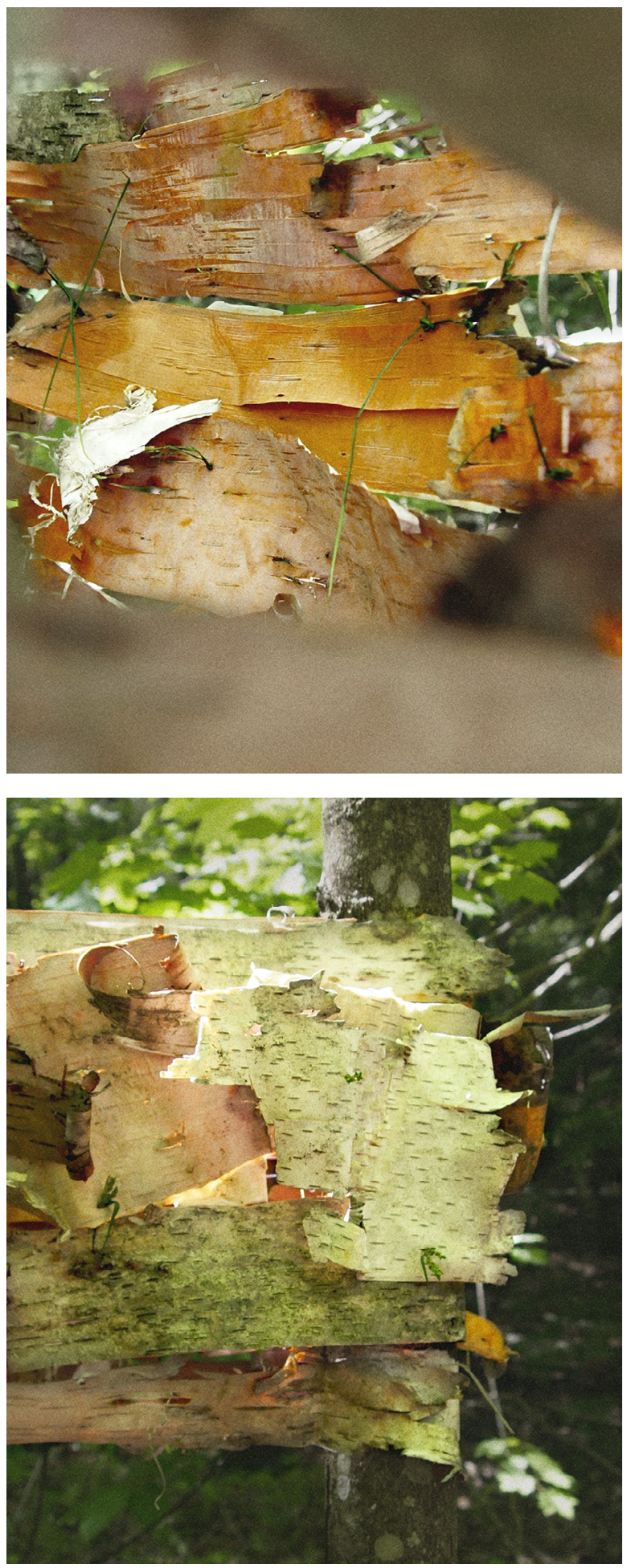

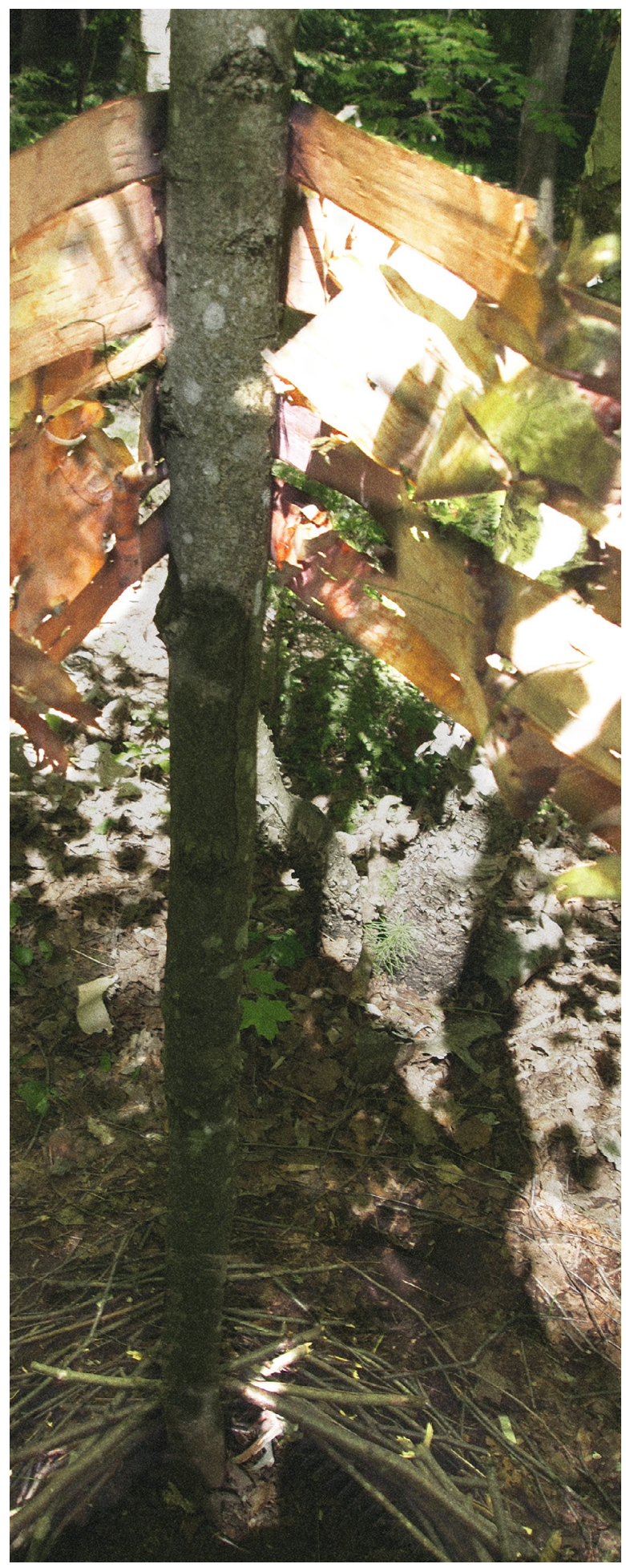




\section{APPENDIX F Final Design Drawings}

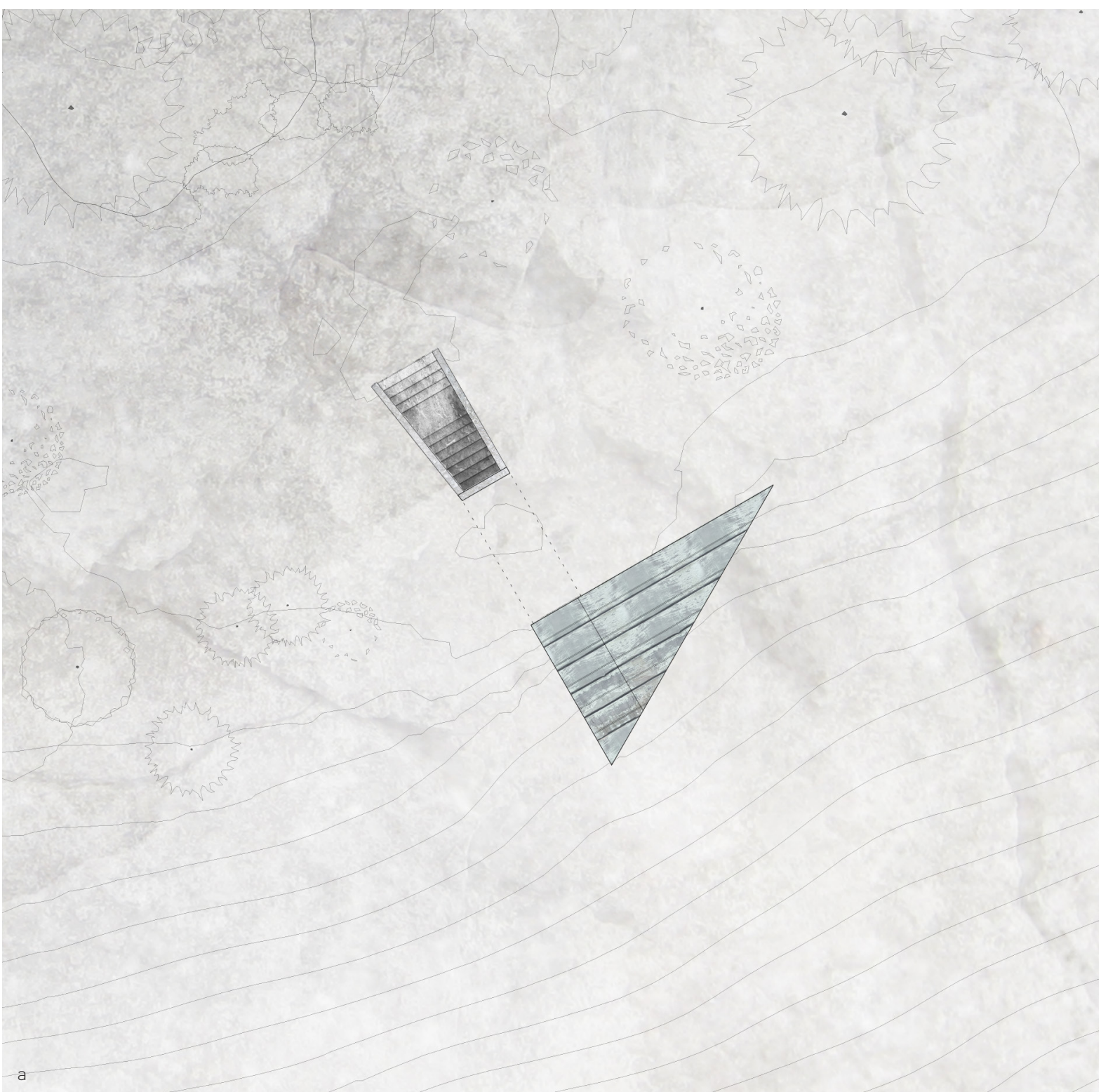


Figure 68: Final Orthographic drawings for Air Armature
a. Site Plan
b. Interior Plan
(1) $0.0 \mathrm{~m} \quad 2.0$

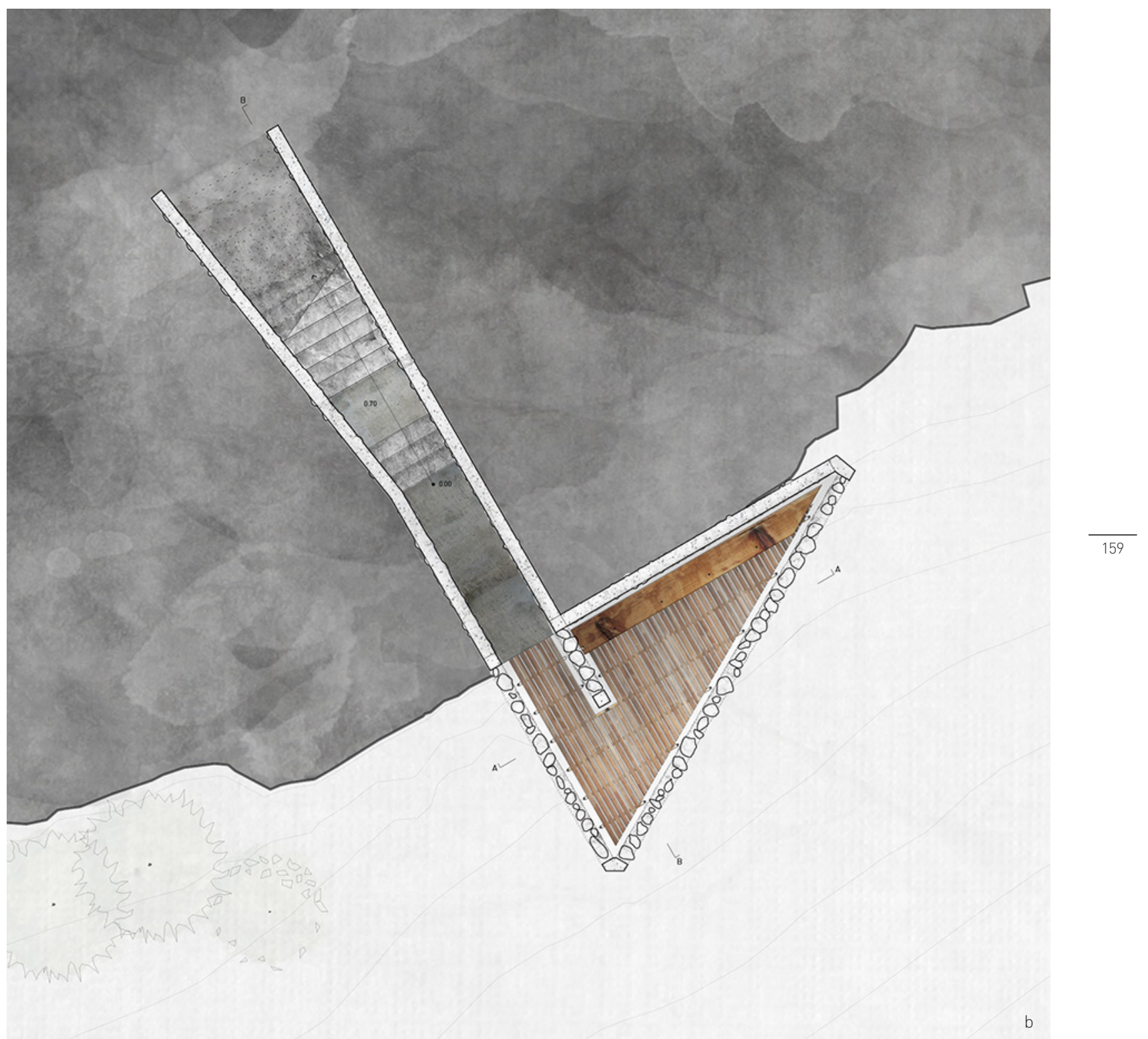


APPENDIX

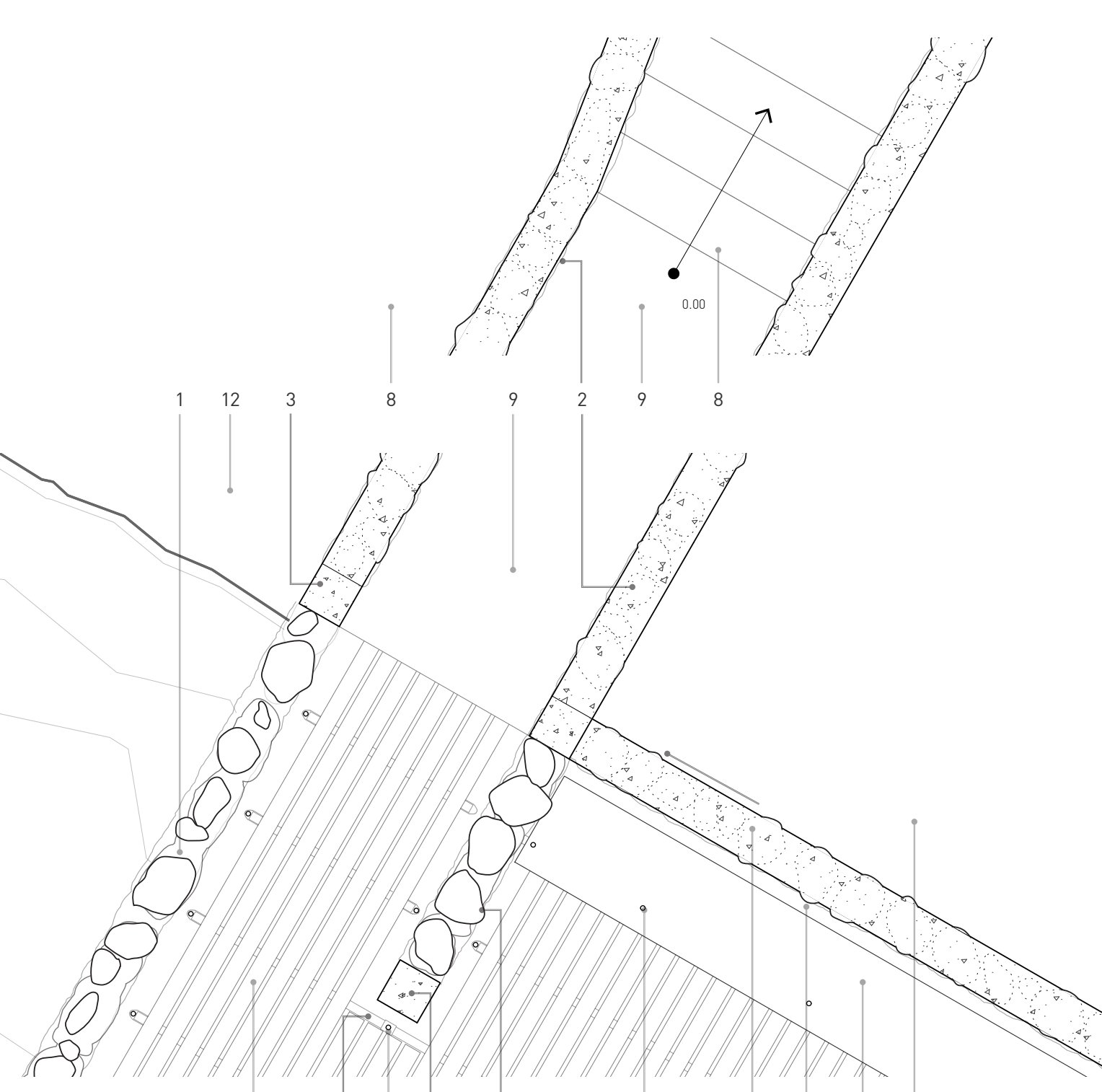

tail of Interior P $\mathrm{Pl}$

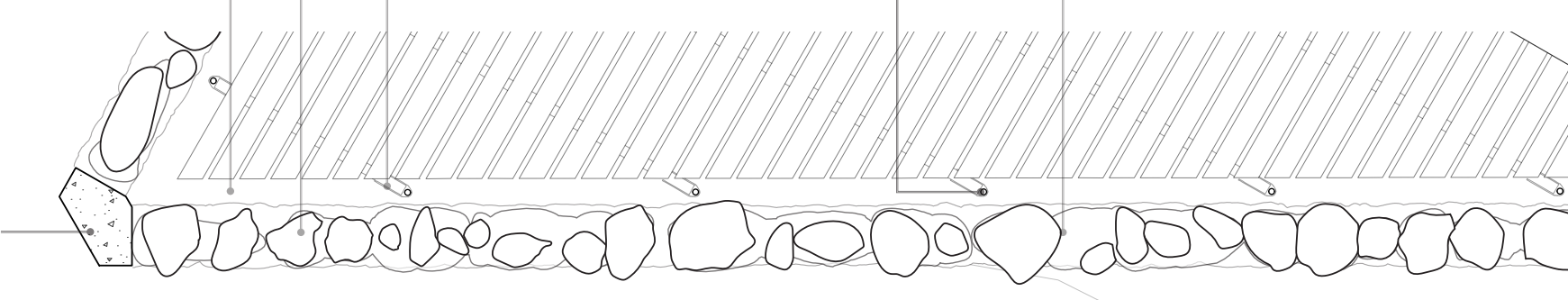


APPENDIX F

e. Section b-b

f. Detail of Section b-b

1 point mortar stone wal

2 stone embedded concrete retaining wall

3 concrete corner columns

4 hung wood bench

5 hung metal rod

6 metal connection at base/top of metal rod to hold joists

7 metal rod holding hung bench

8 joist

9 poured concrete floor

10 wood decking

11 reveal between floor and walls

12 cut earth

13 concrete ring beam

14 rheinzink standing seam zinc

15 roof wood decking

16 foundation

17 concrete roof covering

18 poured concrete landing

19 rough cut stone stairs

20 reveal between roof and ring beam

21 rafter
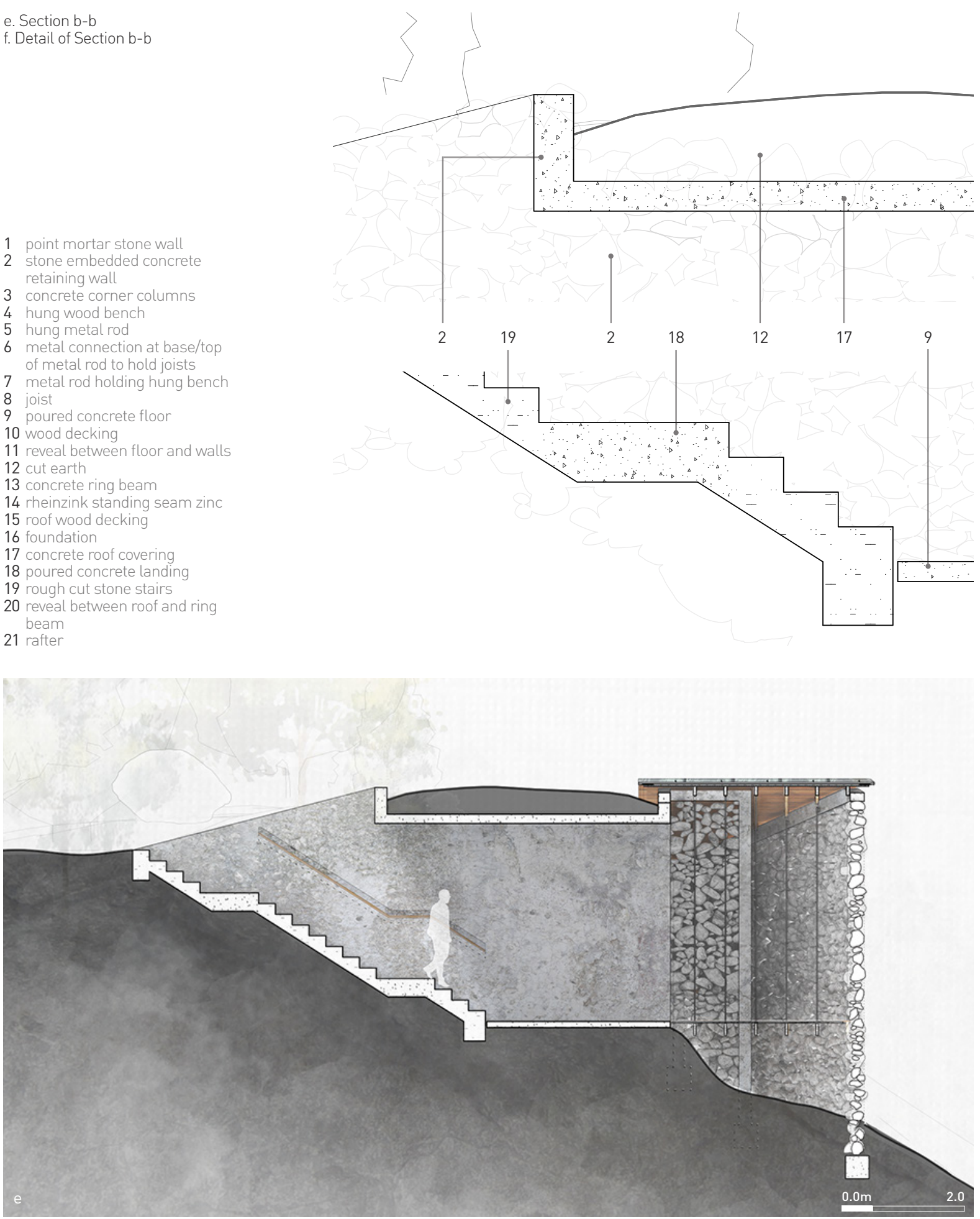

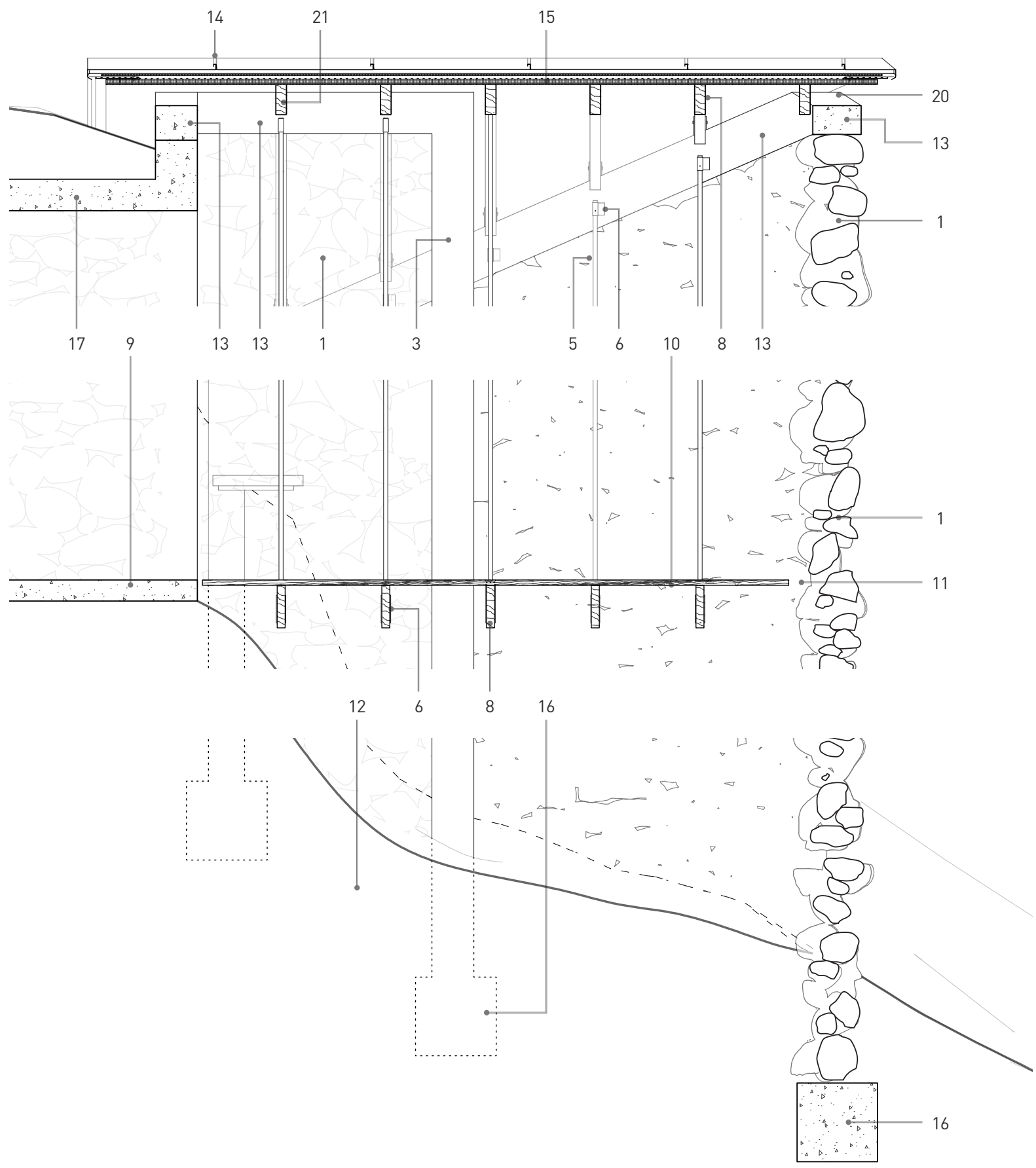
g. North Elevation

h South Elevation

$0.0 \mathrm{~m} \quad 2.0$

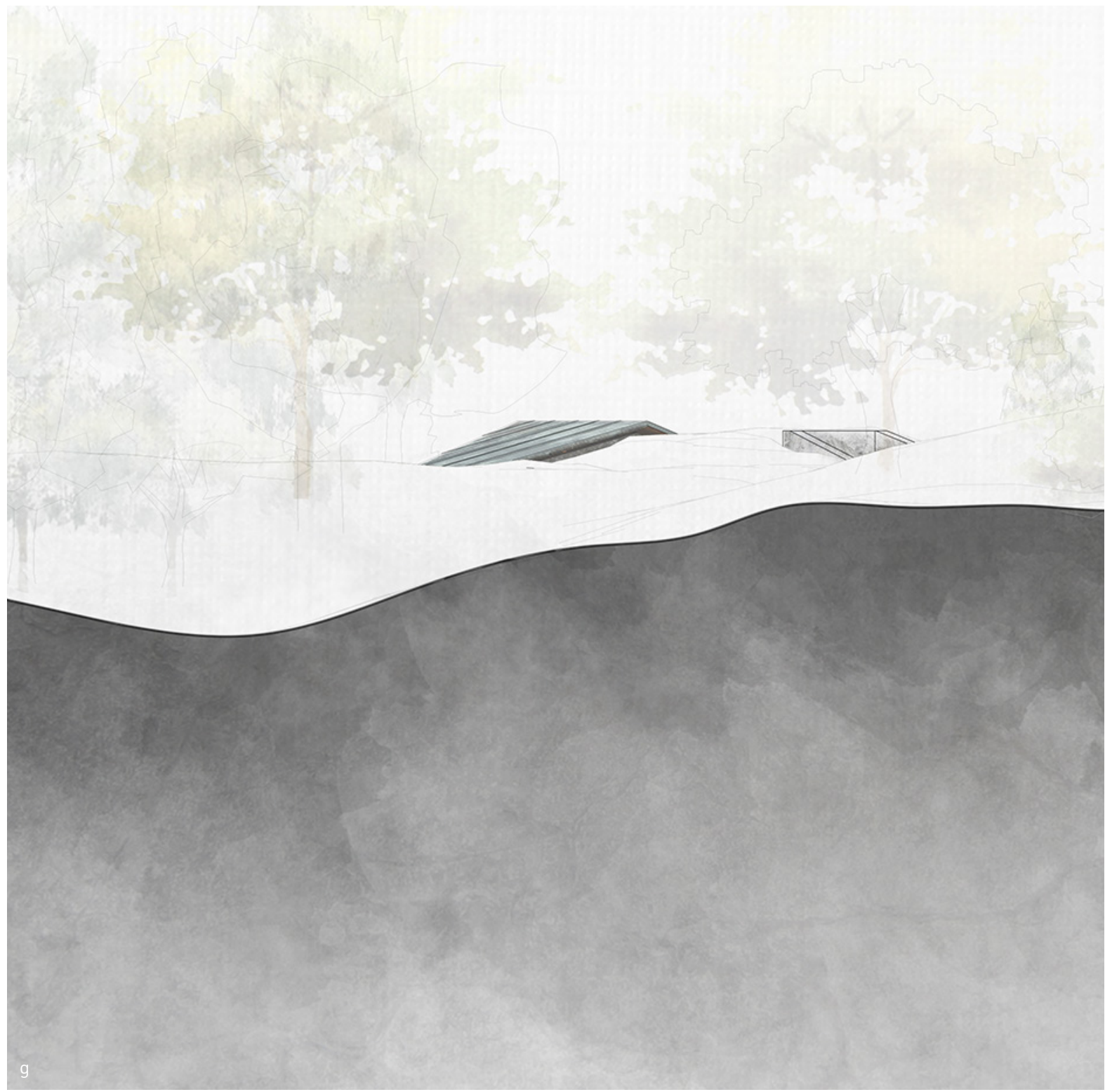




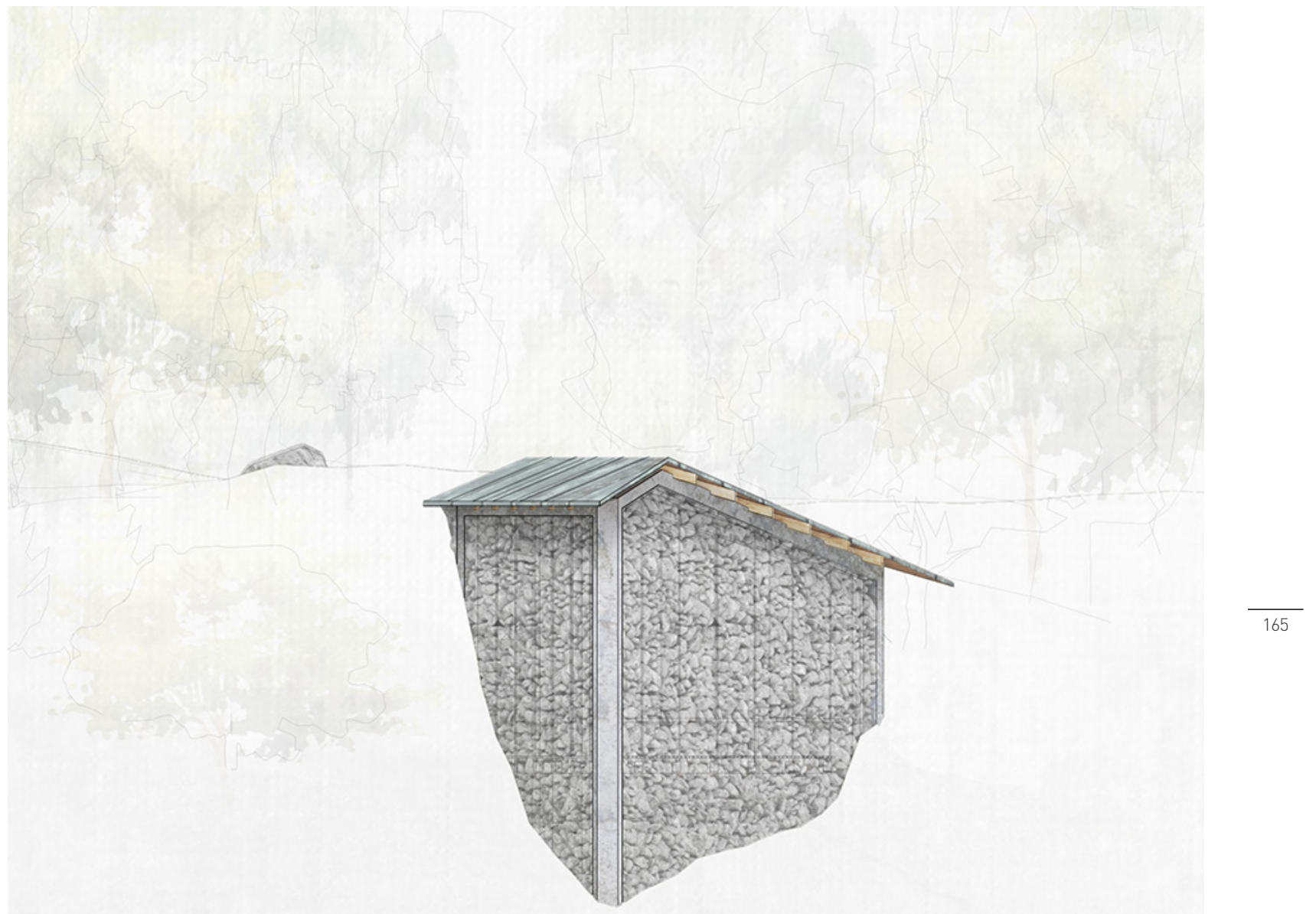



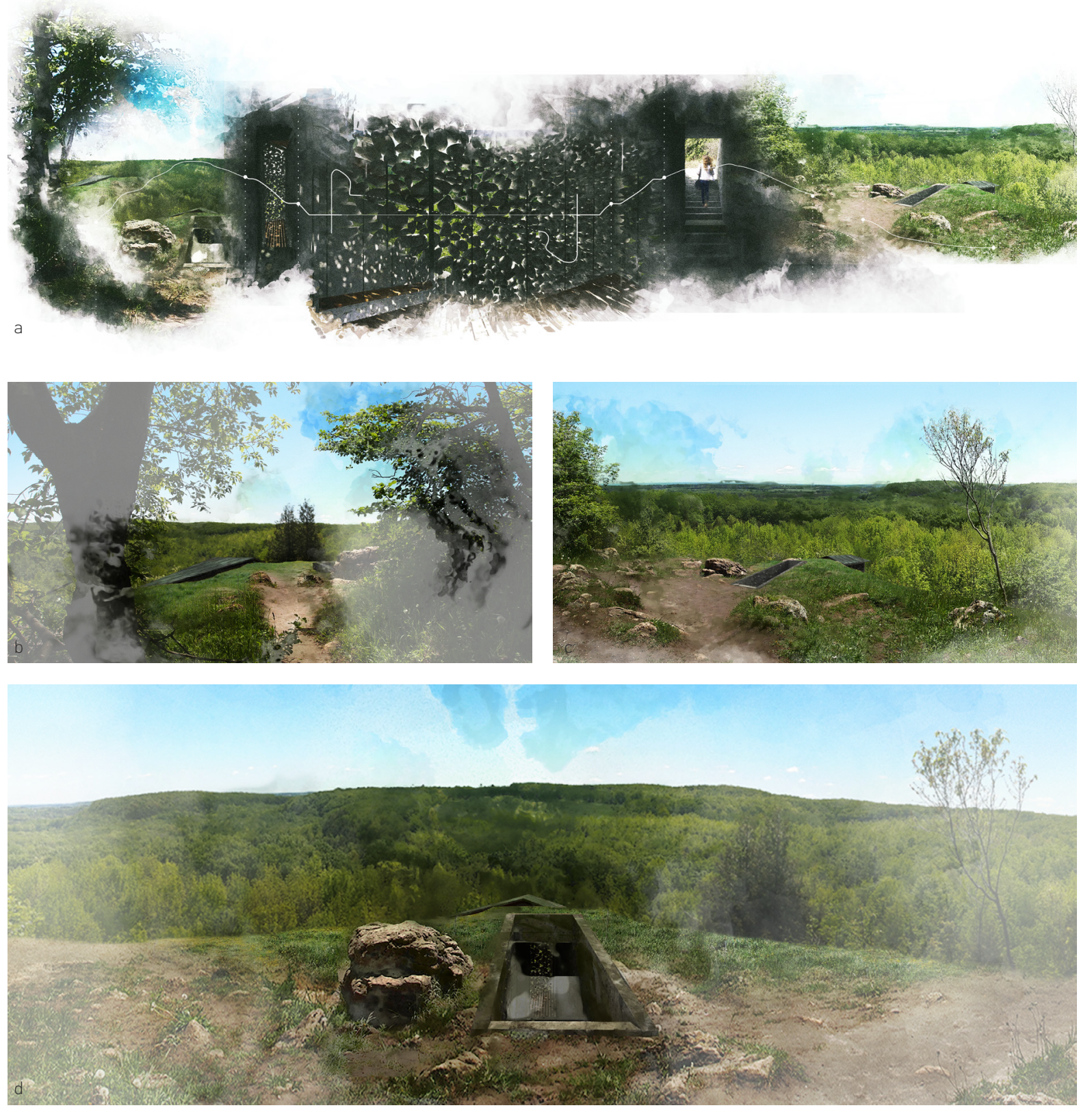
a. Mapped Experience of Air Armature b. Southwest view from trail c. Southeast view from trail d. Top of stairs looking South e. Decent down stairs f. Entering tunnel portion of stairs
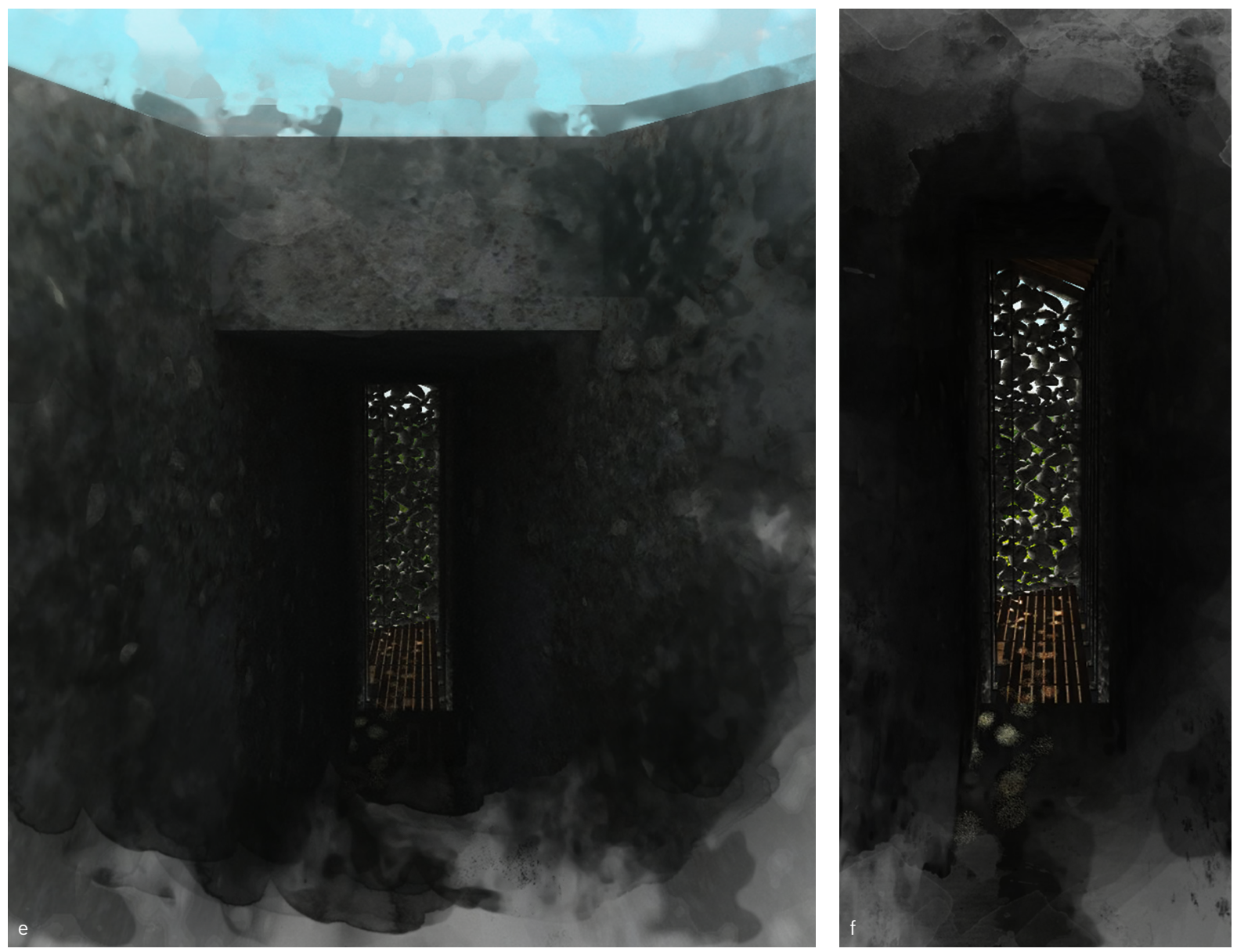


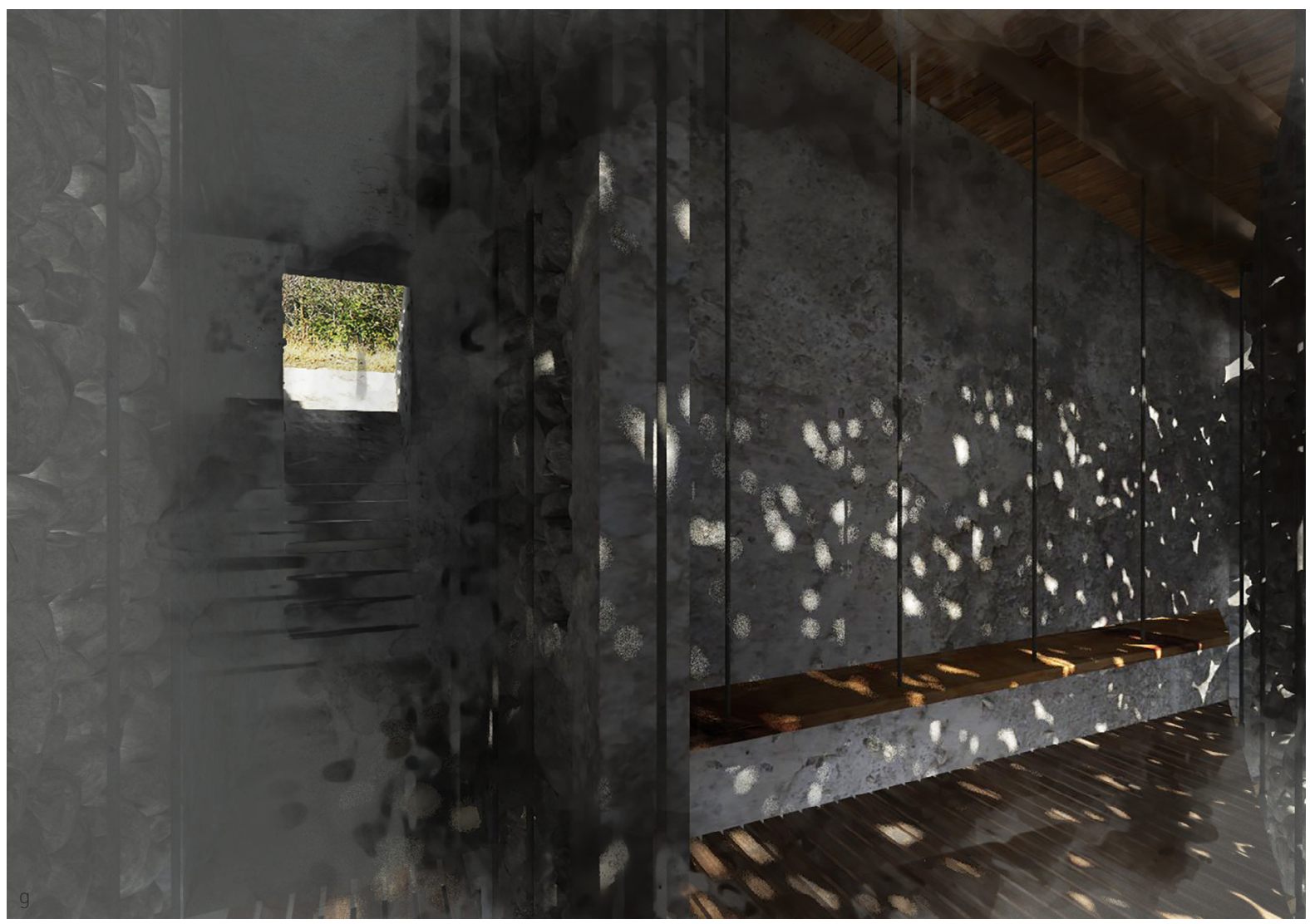



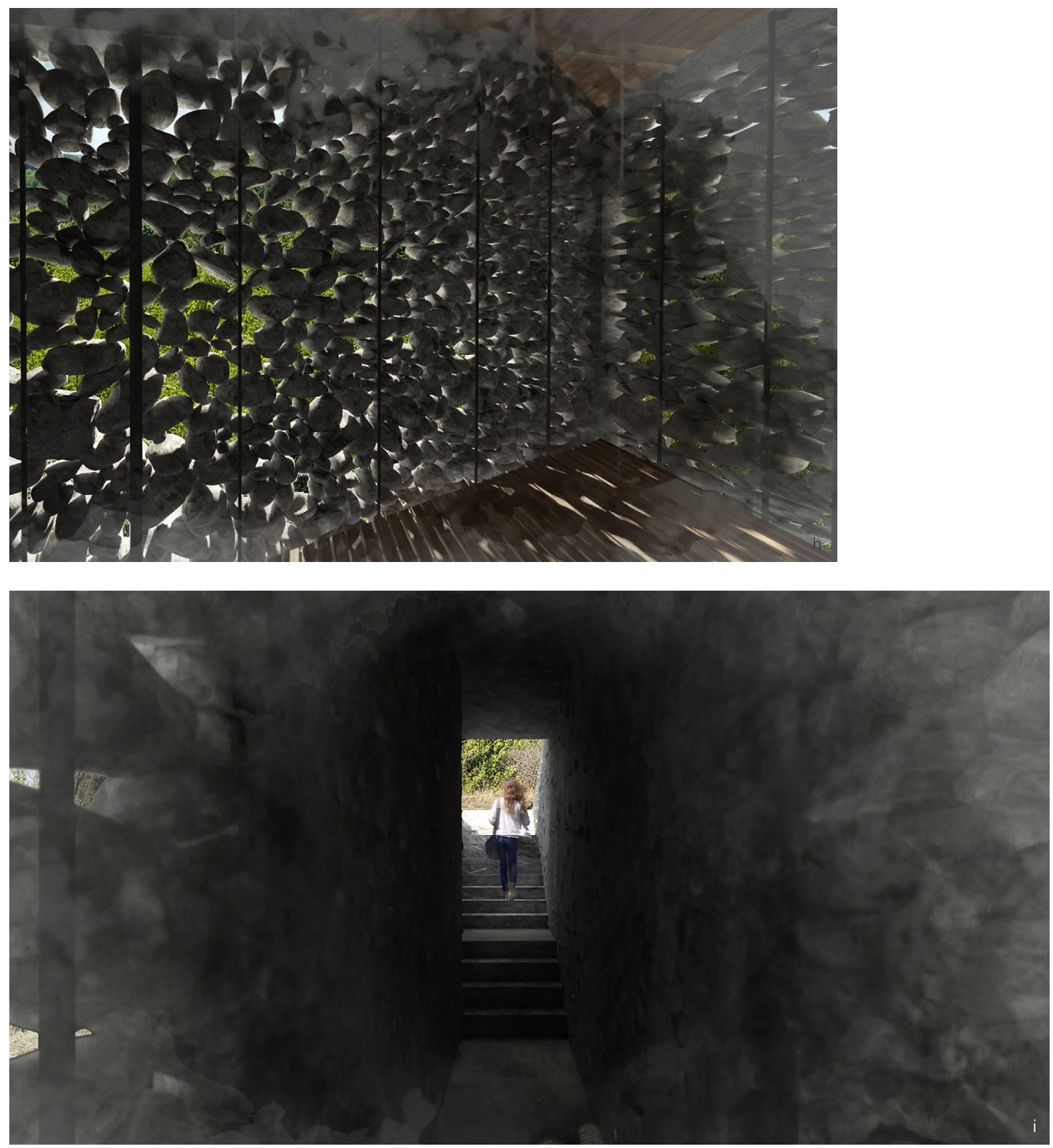
APPENDIX F

Figure 70: Final Orthographic drawings for Water Armature

a. Site Plan

(1) $0.0 \mathrm{~m} \quad 2.0$

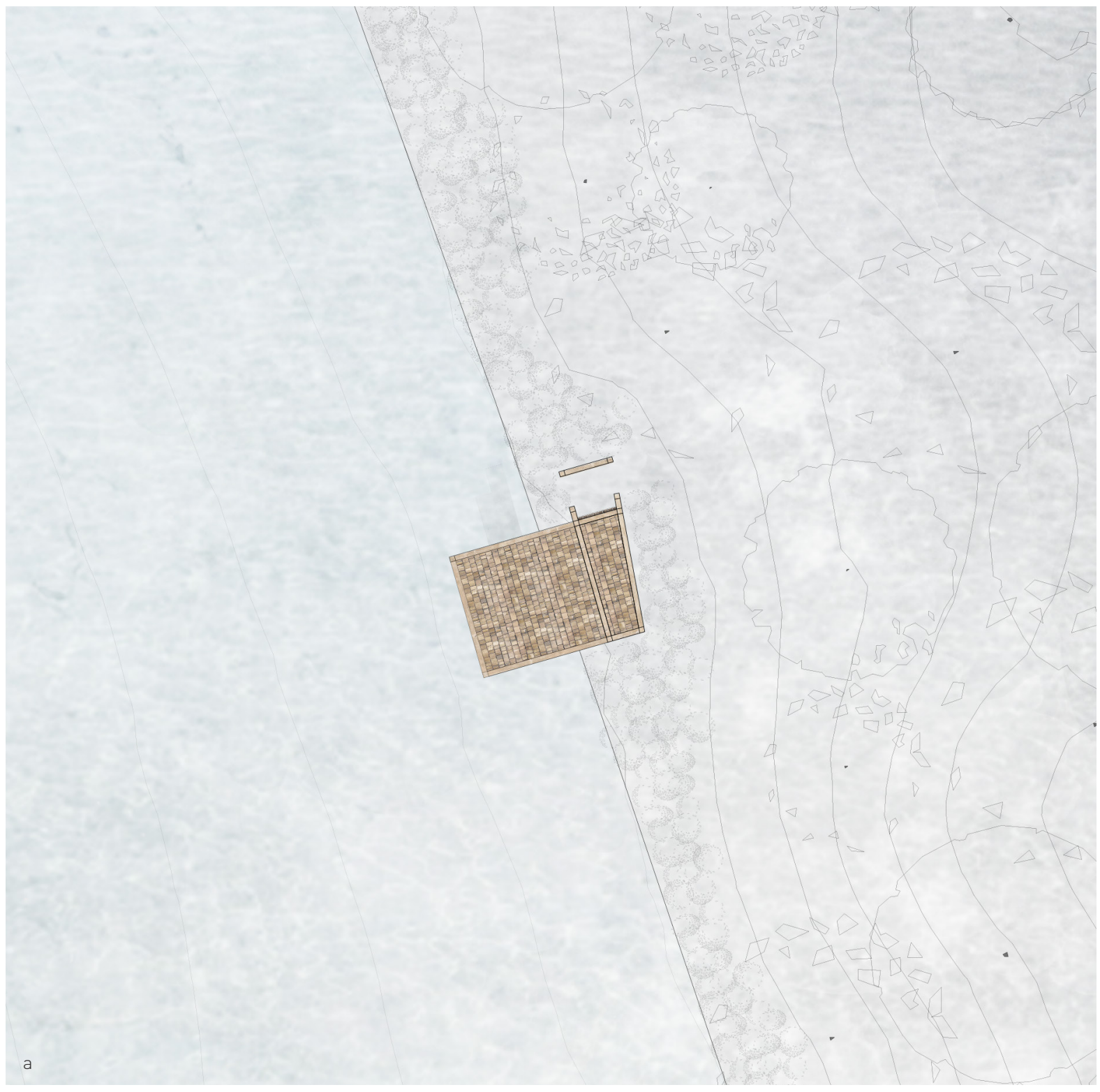




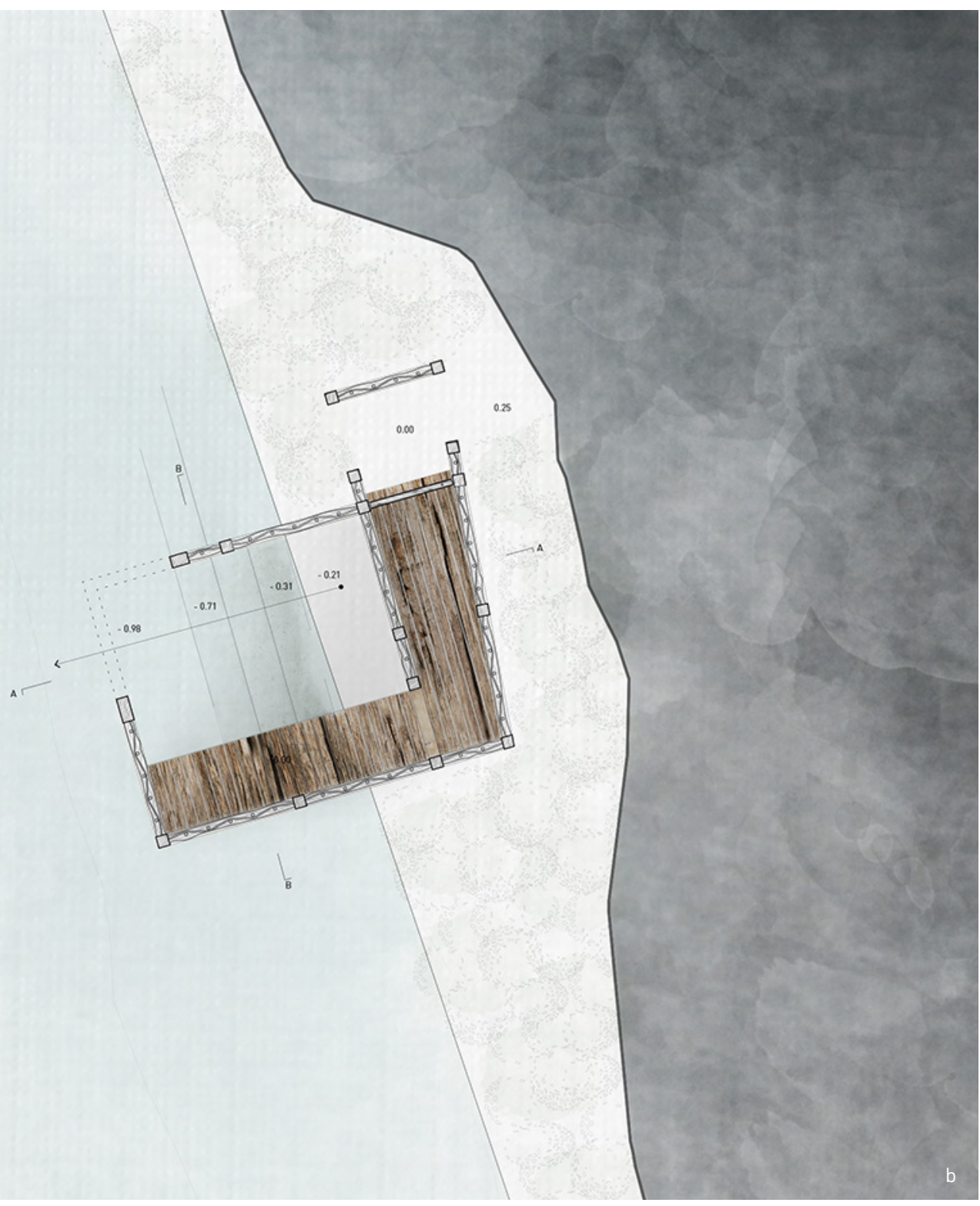


c. Section a-a

d. Section b-b

(1) $0.0 \mathrm{~m} \quad 2.0$

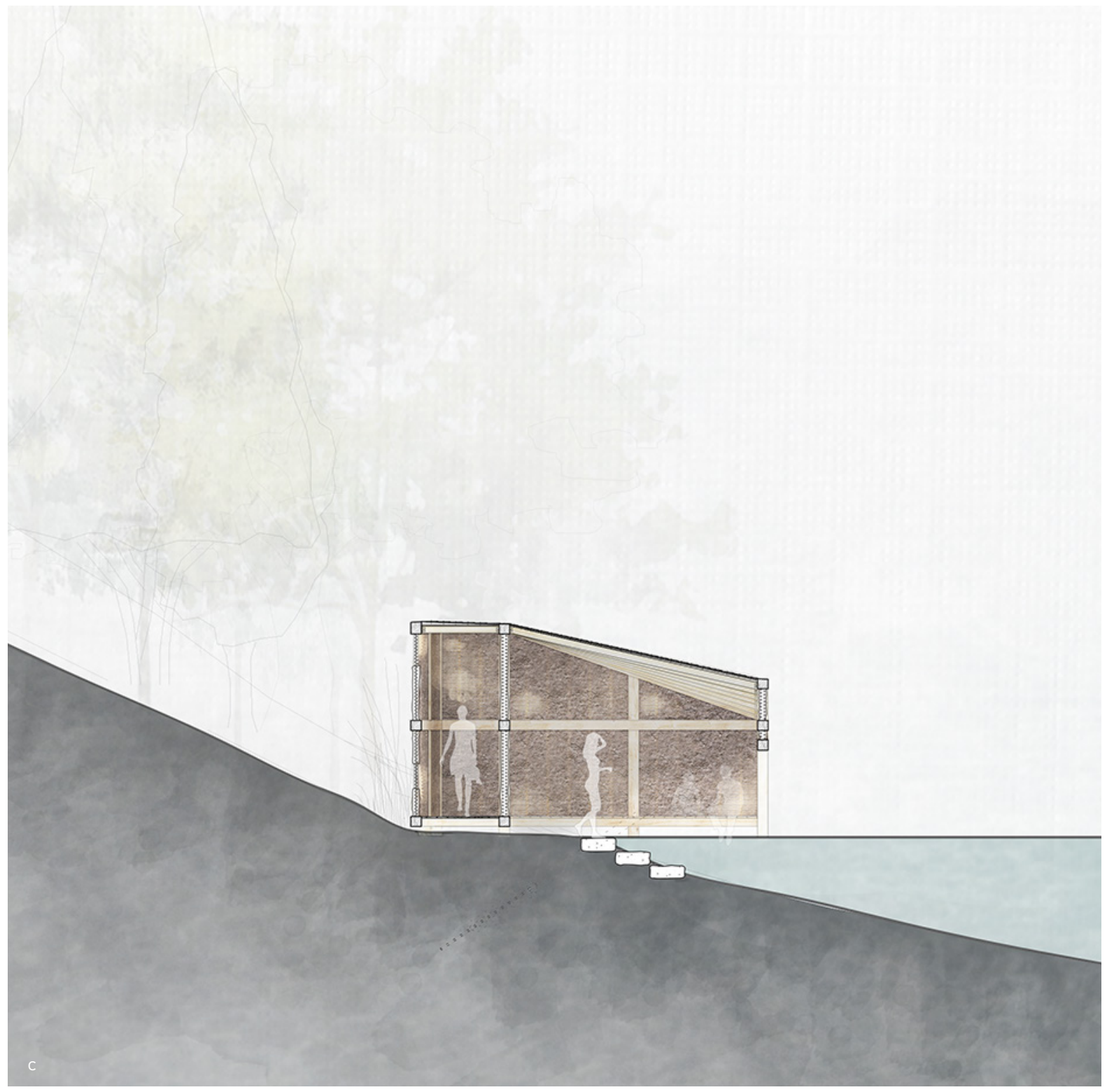




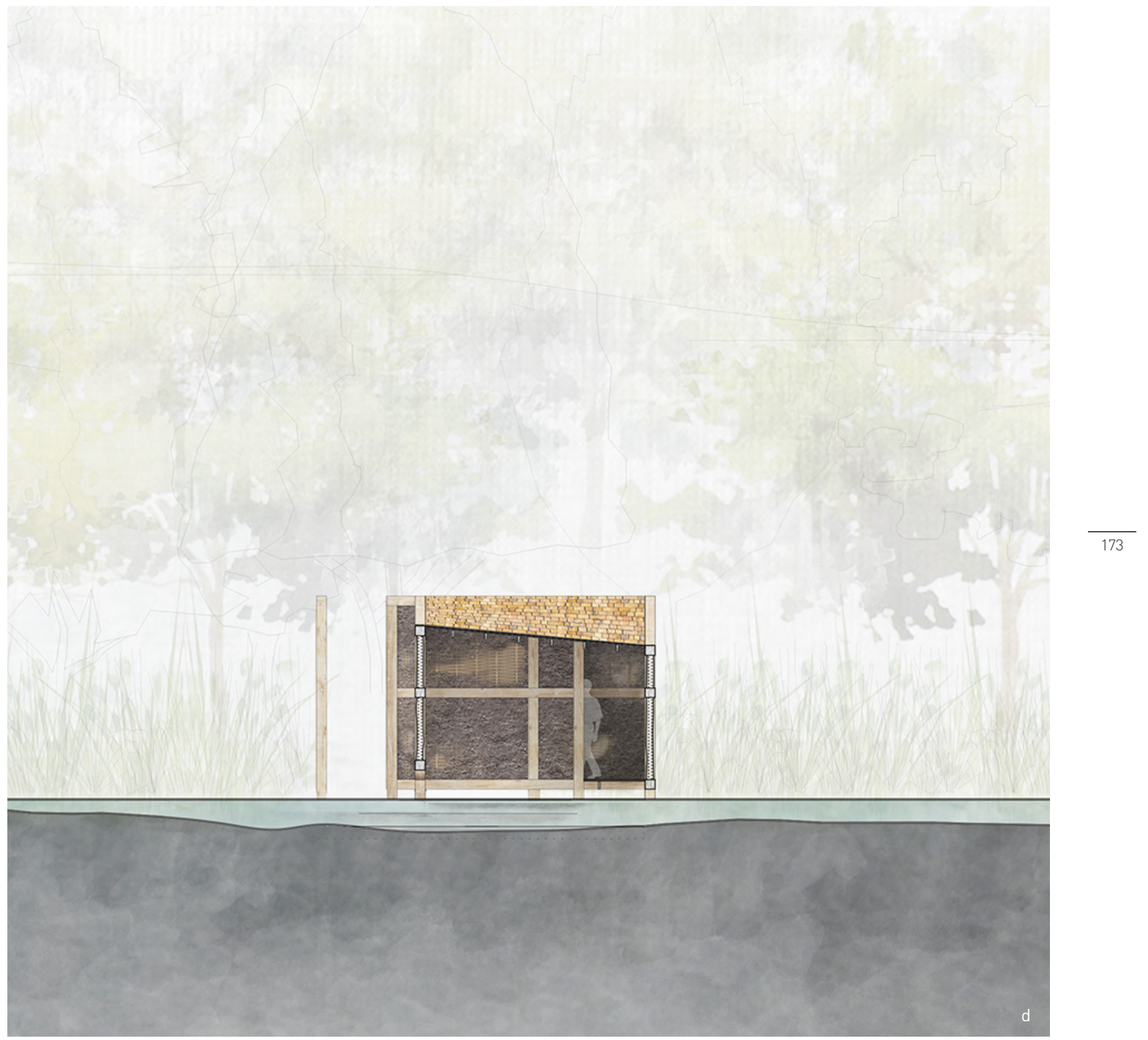


APPENDIX F
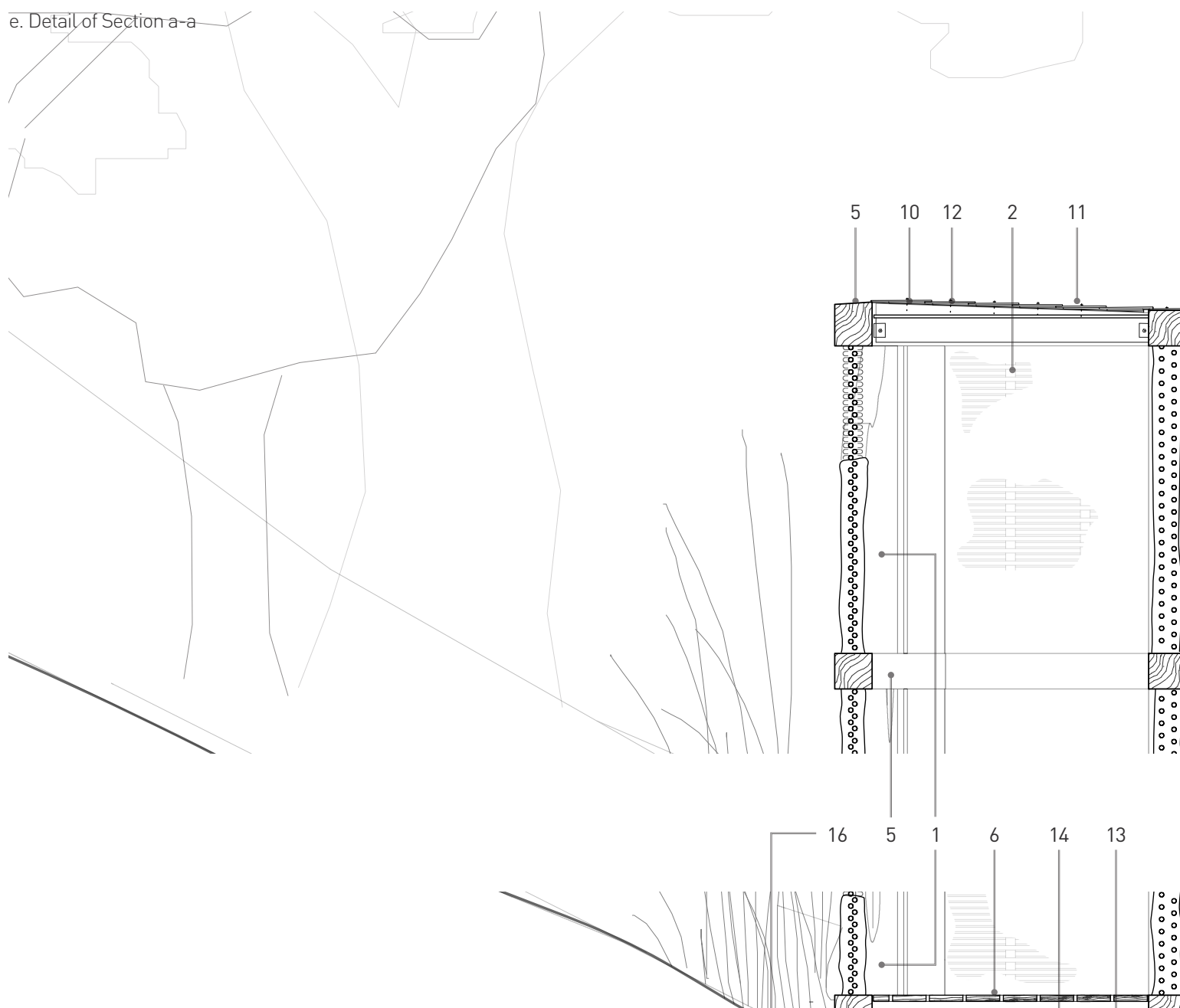

$\mid \begin{array}{ll}0 \\ \vdots \\ \vdots \\ \vdots \\ \vdots \\ \vdots \\ \vdots \\ \vdots\end{array}$

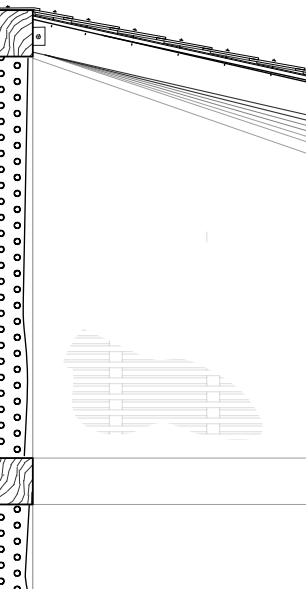


e. North Elevation

f. West Elevation

(1) $0.0 \mathrm{~m} \quad 2.0$

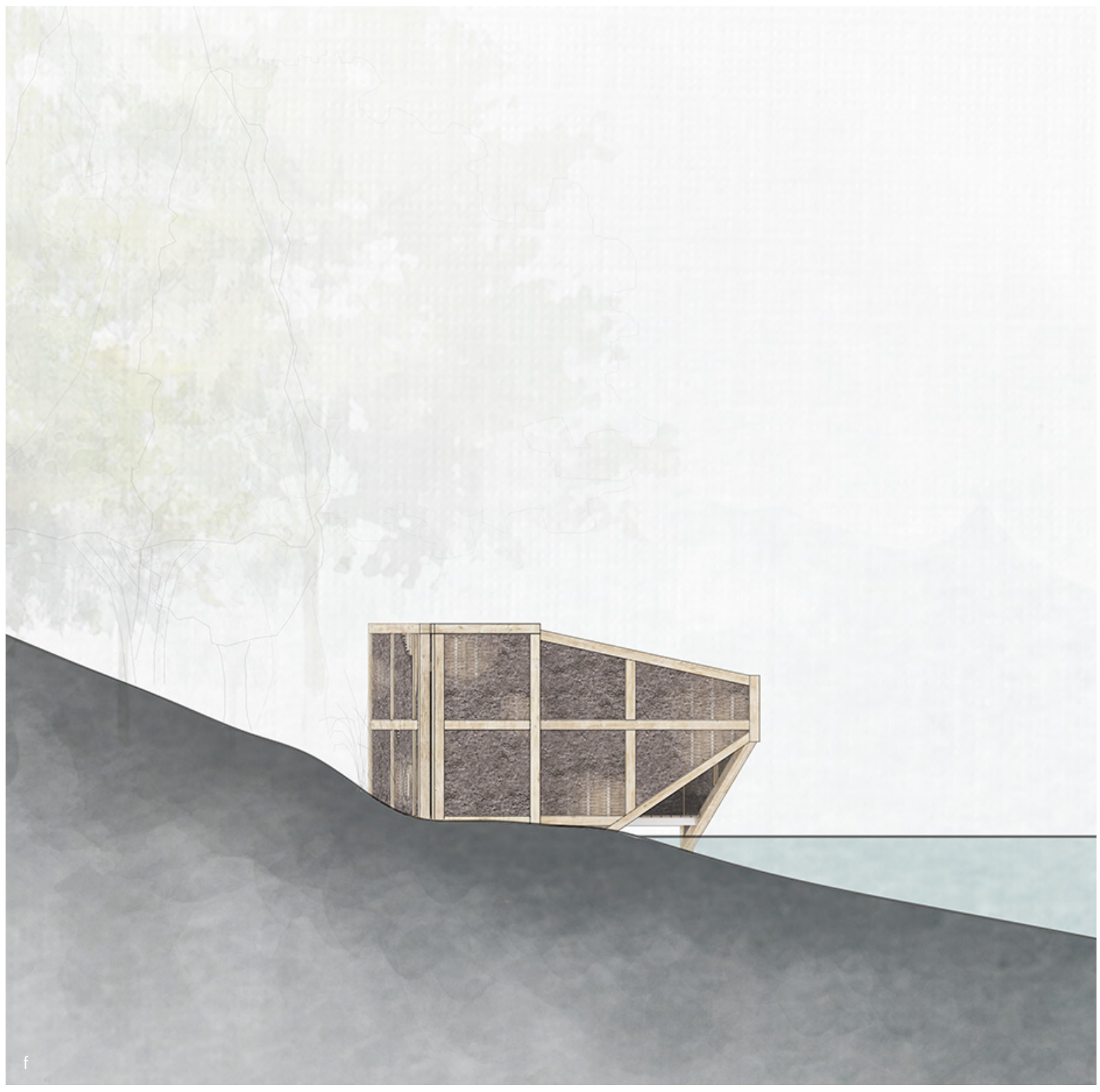


FINAL DESIGN DRAWINGS | WATER ARMATURE

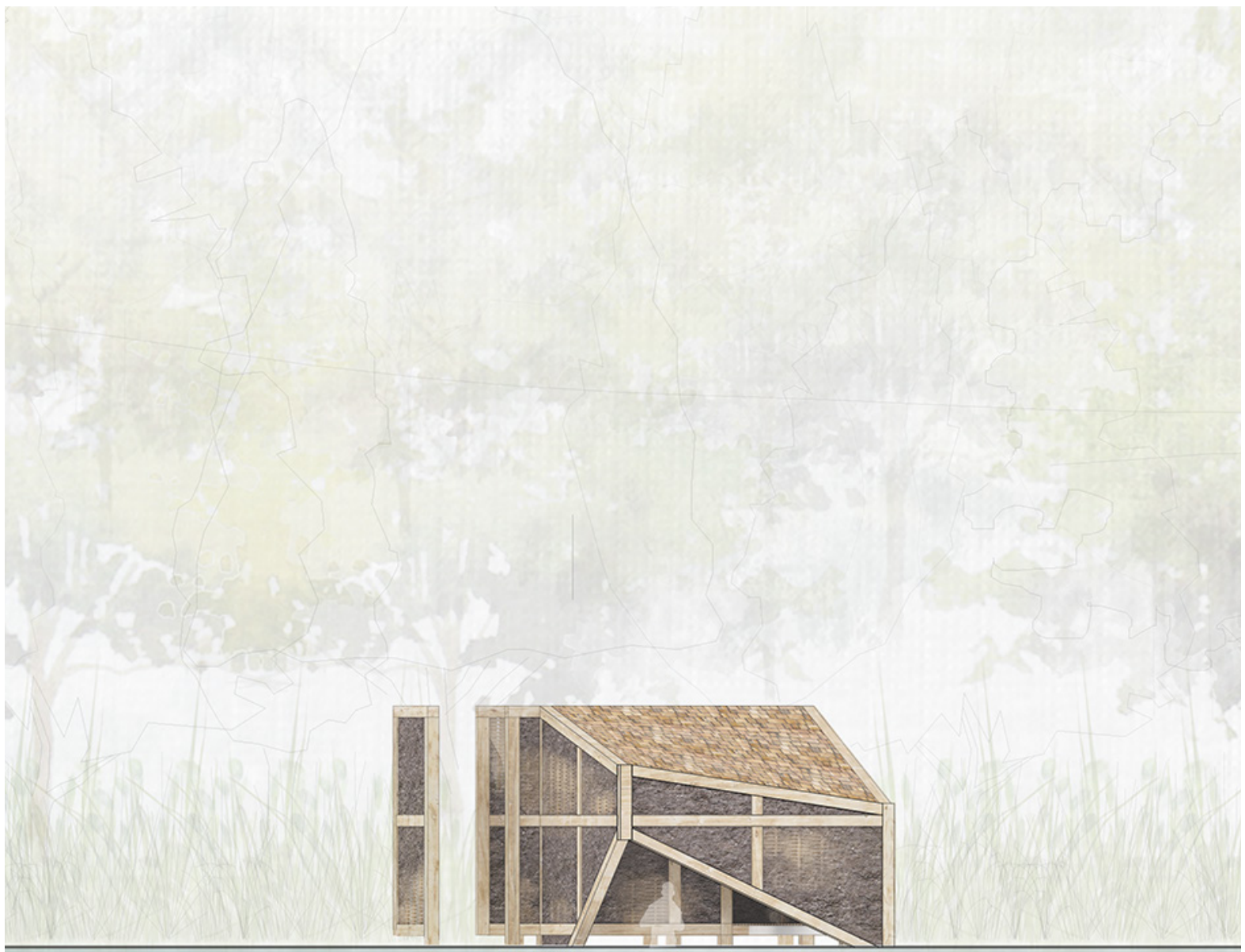


Figure 71: Atmospheric Representations of

Water Armature

a. Mapped Experience of Water Armature

b. View from pathway towards water

c. Between land and Armature

d. Entrance to Armature

e. Hallway in armature
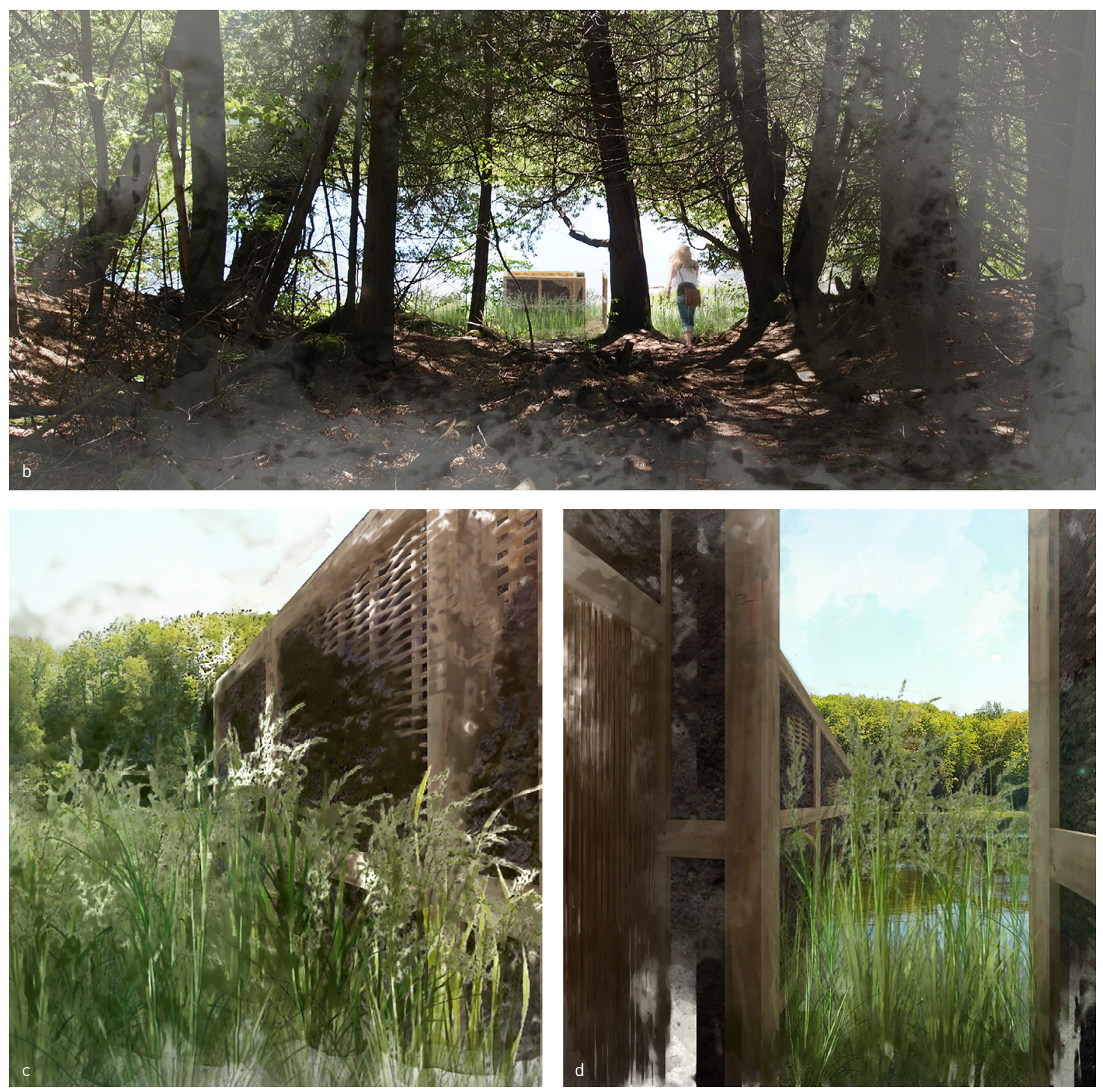

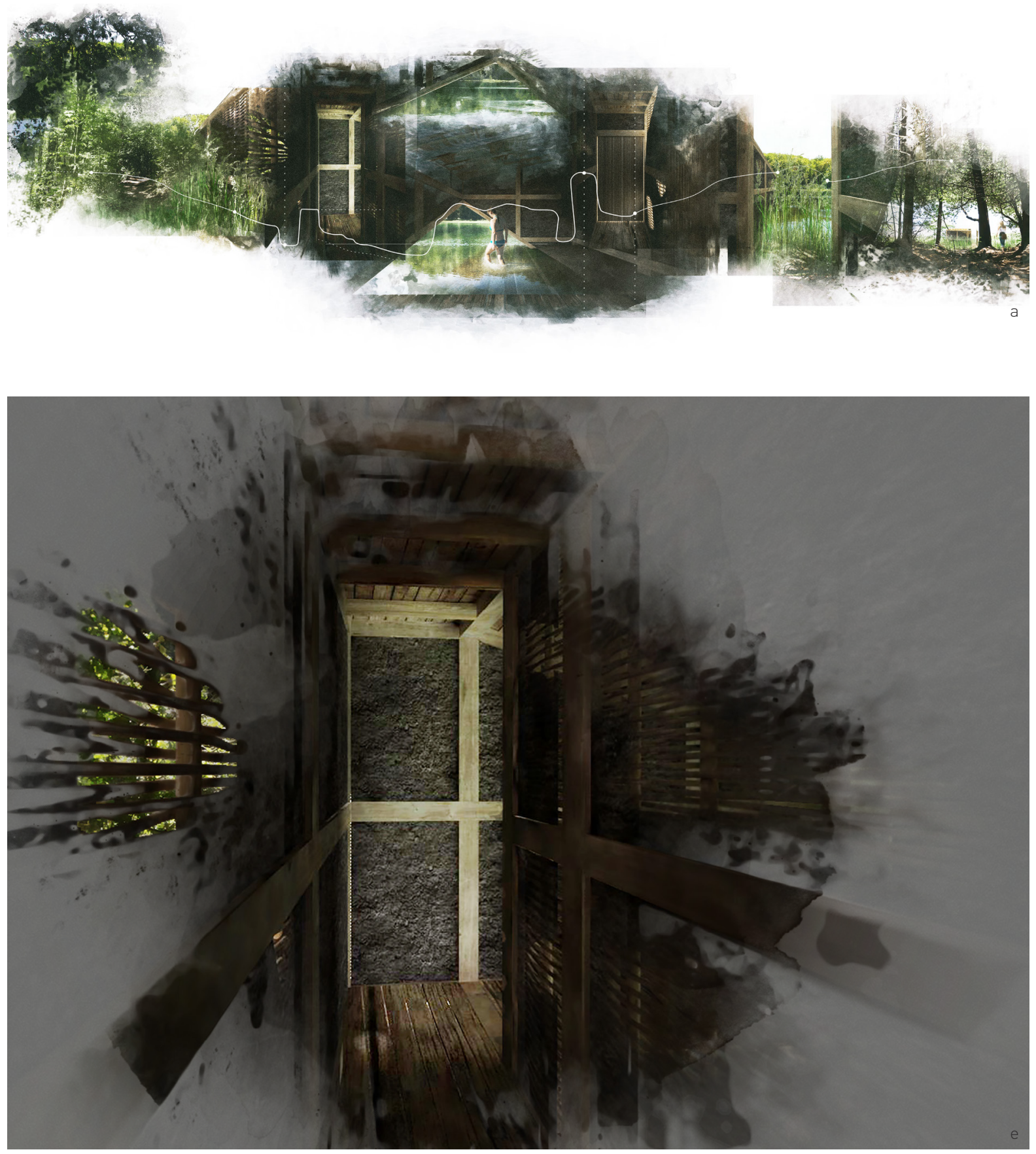


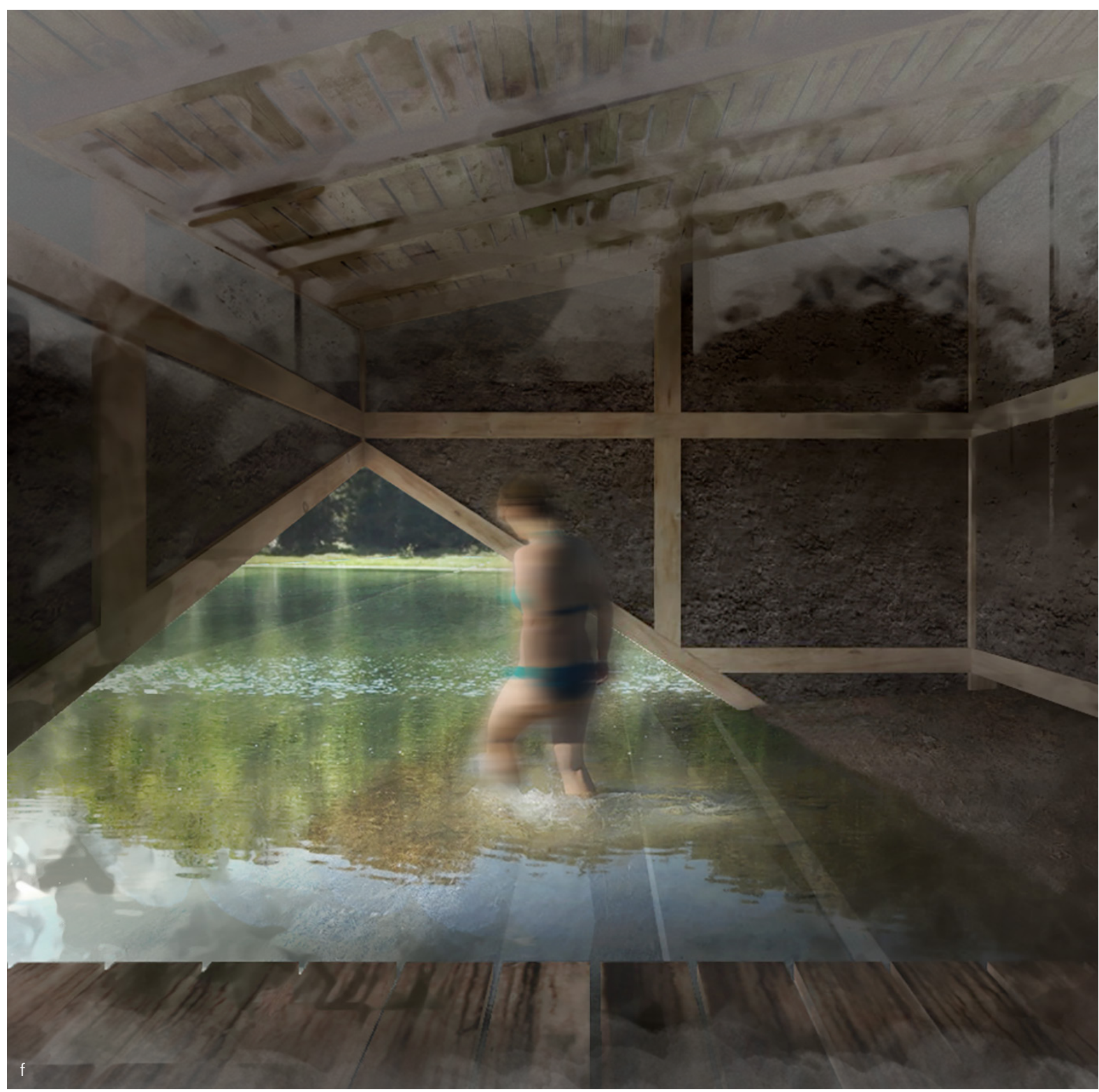



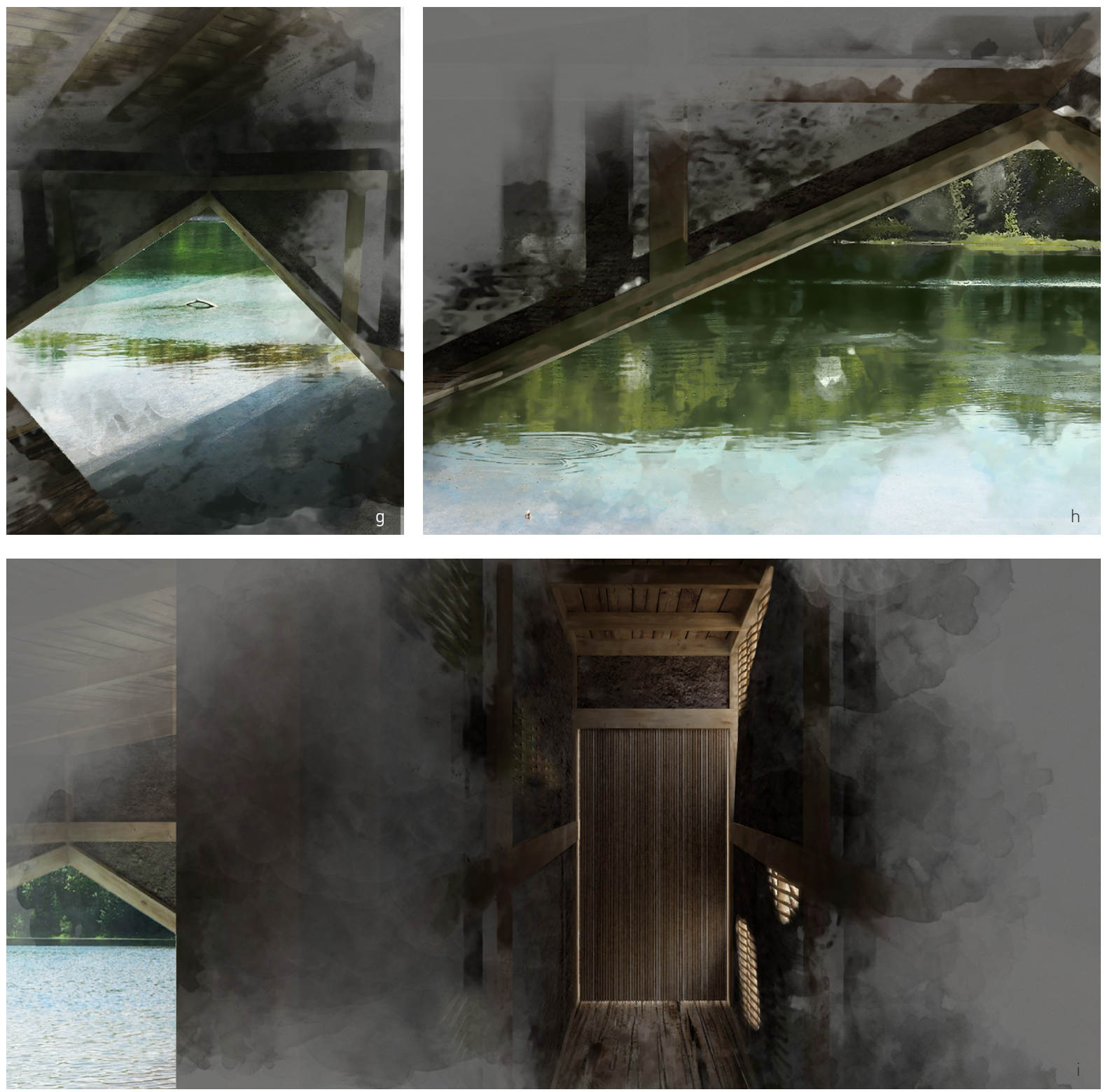
APPENDIX F

Figure 72: Final Orthographic drawings for Earth Armature

a. Site Plan

b. Interior Plan

(1) $0.0 \mathrm{~m}$

2.0

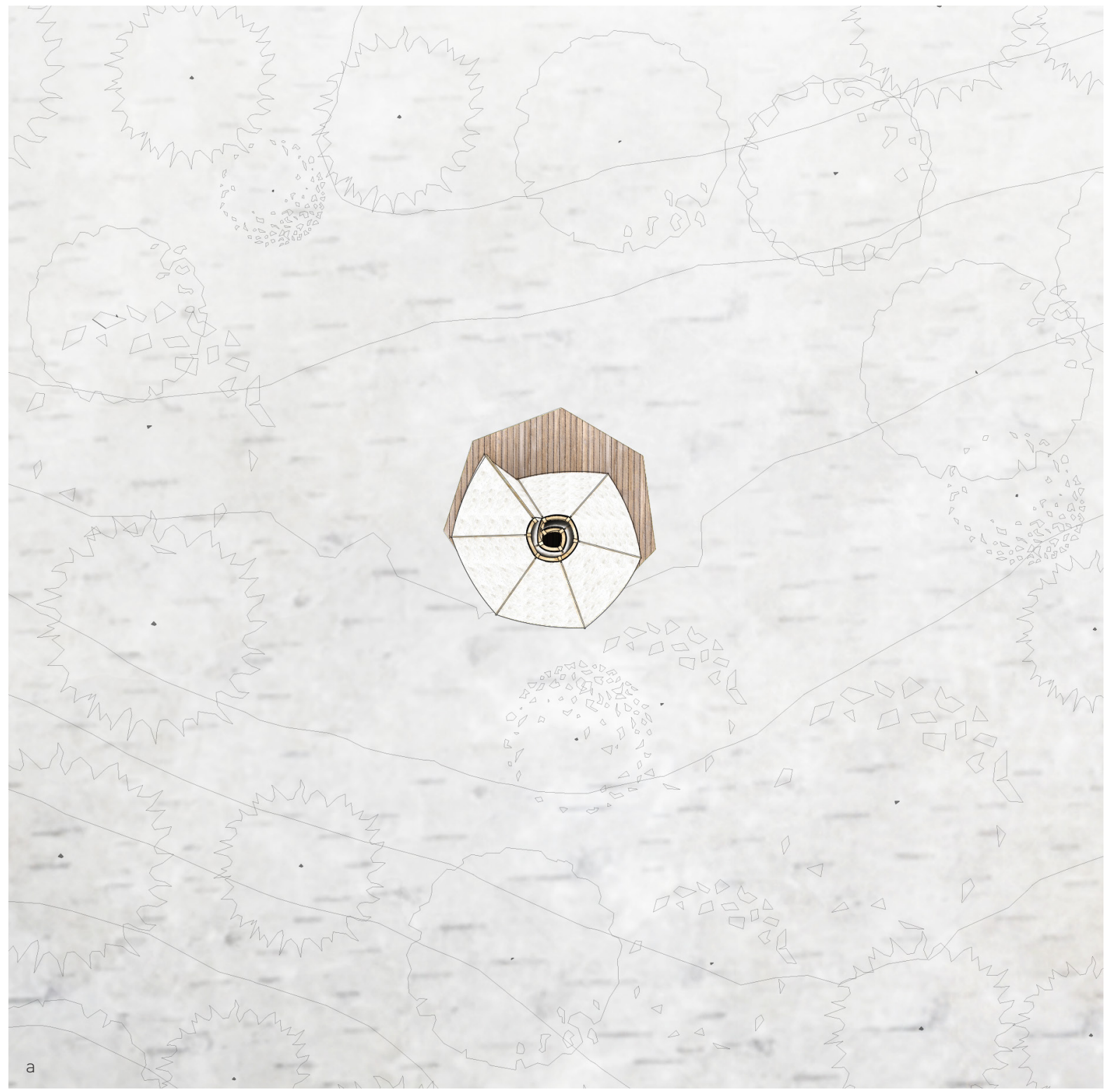




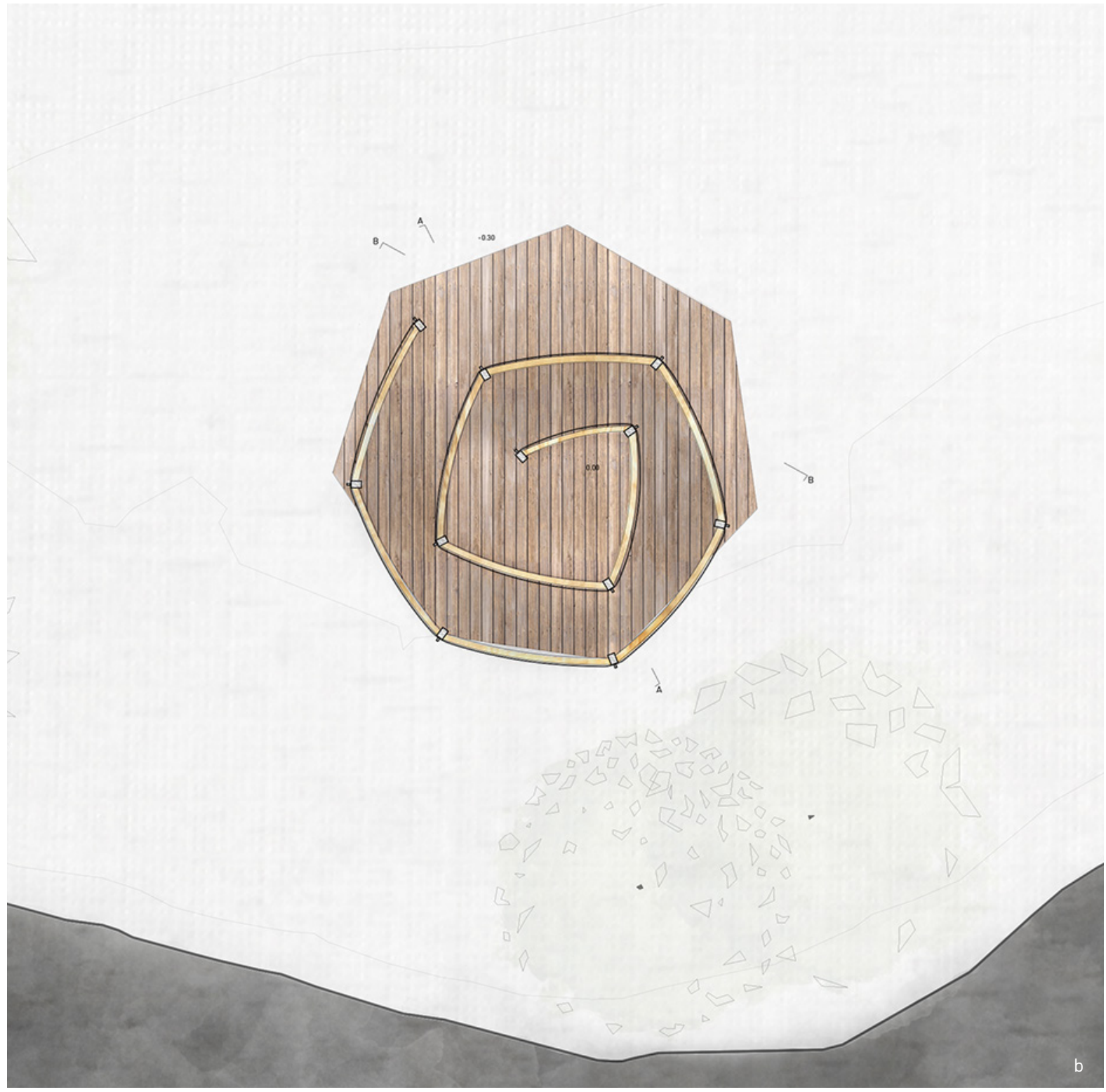


APPENDIX F

c. Detail of Interior Plan

d. Section b-b

1 vertical post structure

2 horizontal wood support

3 wood strip nailed attaching birch bark to main verticals

4 birch bark sewn into larger pieces

5 raised wood decking

6 wood decking beam

7 opening above

8 footing

9 steel saddle embedded in footing

10 steel saddle bolted into main vertical

11 wood joist
5

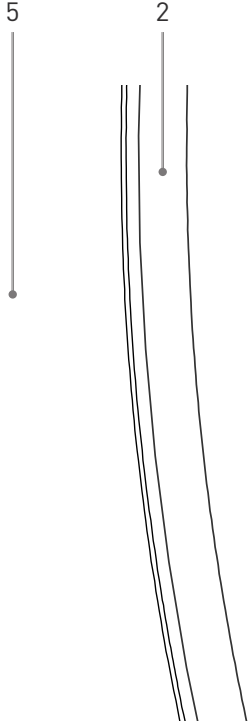

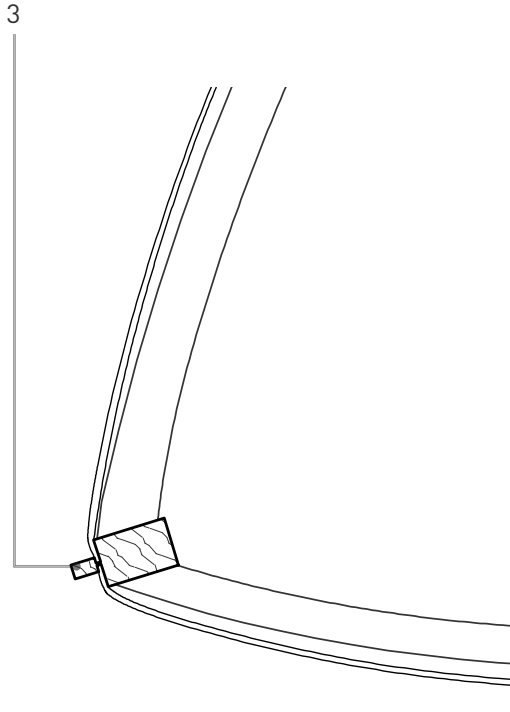

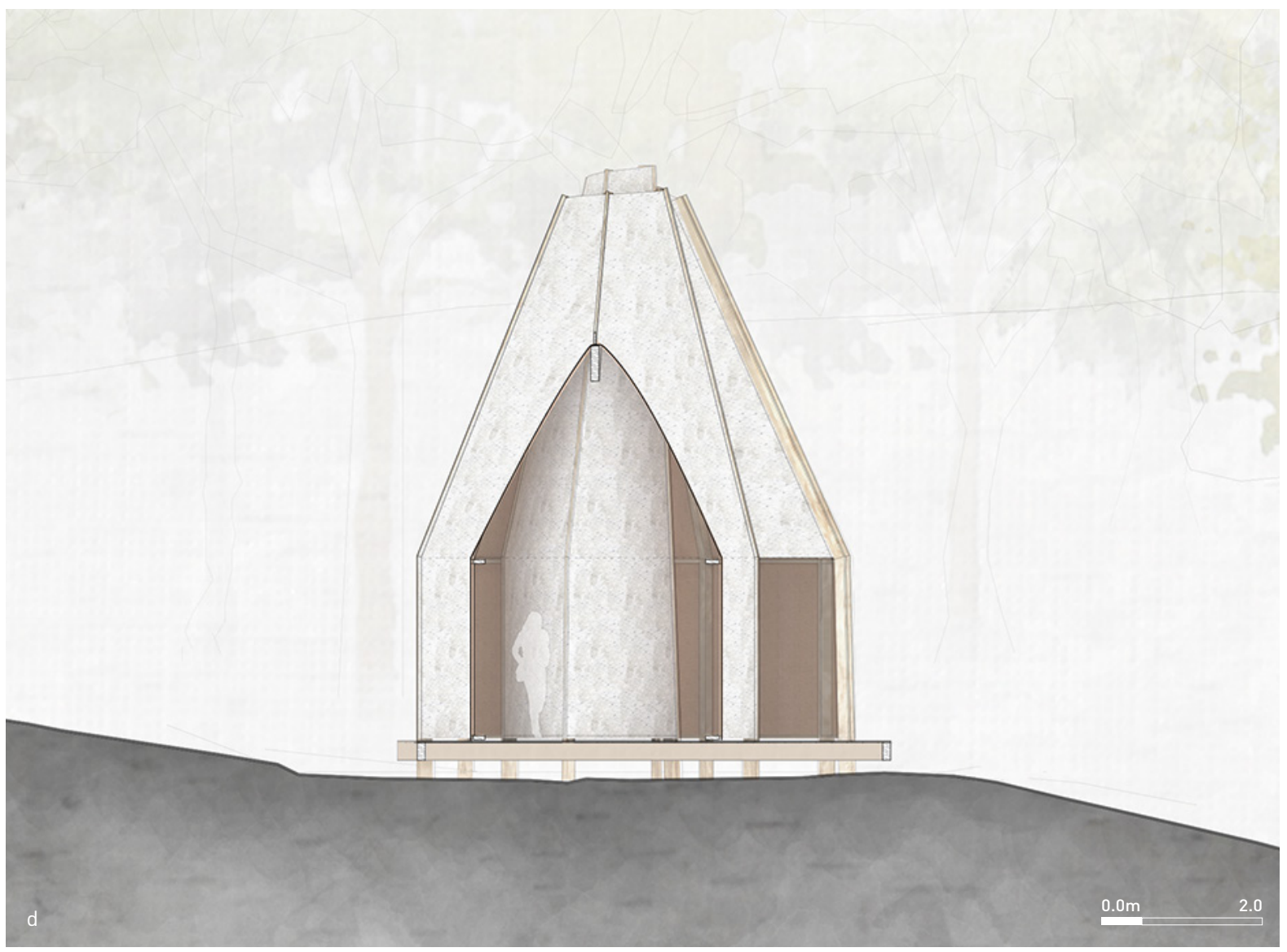


APPENDIX F

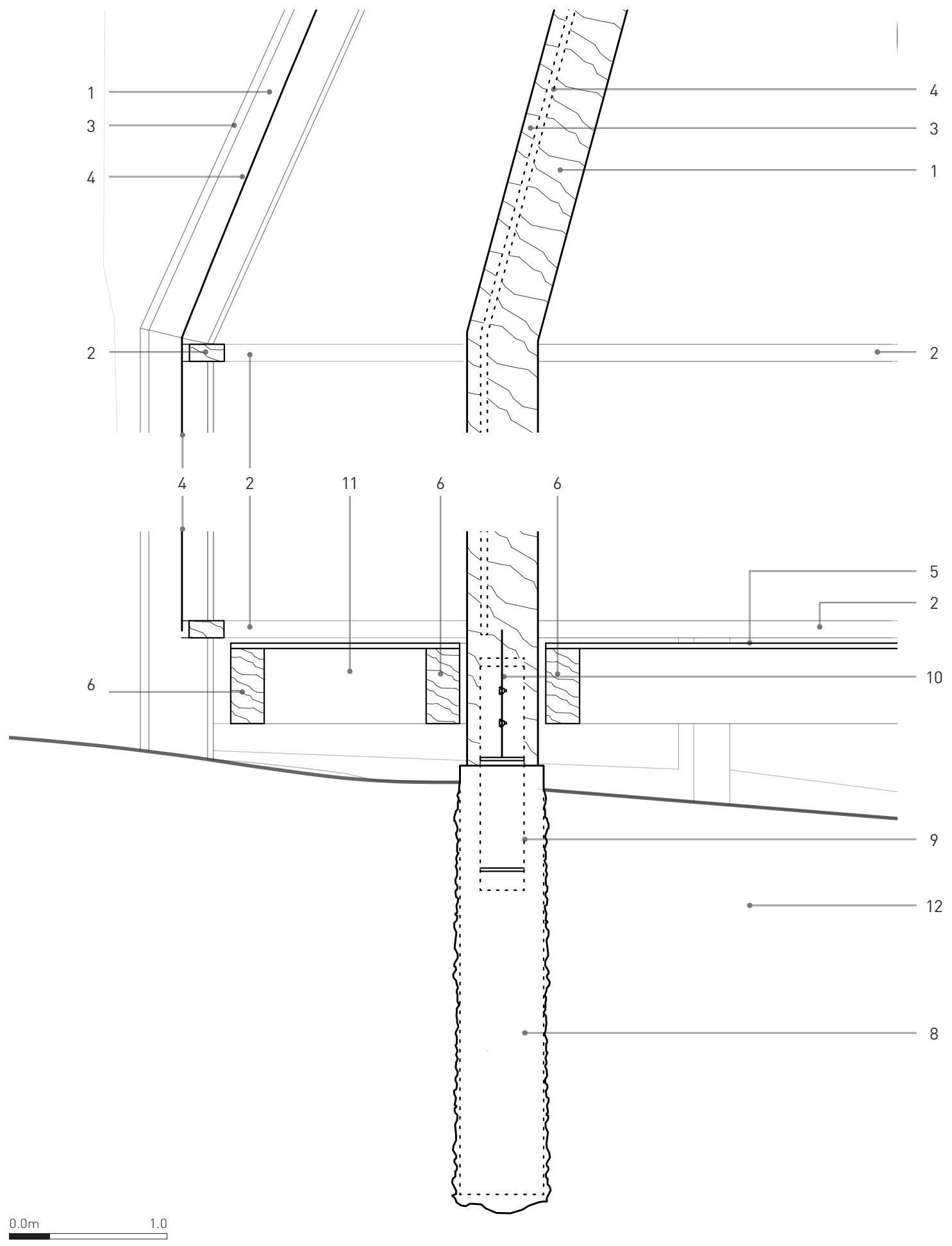


1 vertical post structure

2 horizontal wood support

3 wood strip nailed attaching birch bark to main verticals

4 birch bark sewn into larger pieces

5 raised wood decking

6 wood decking beam
7 opening above

8 footing

9 steel saddle embedded in footing

10 steel saddle bolted into main vertical

11 wood joist

12 cut ground e. Section a-a

f. Detail of Section a-a

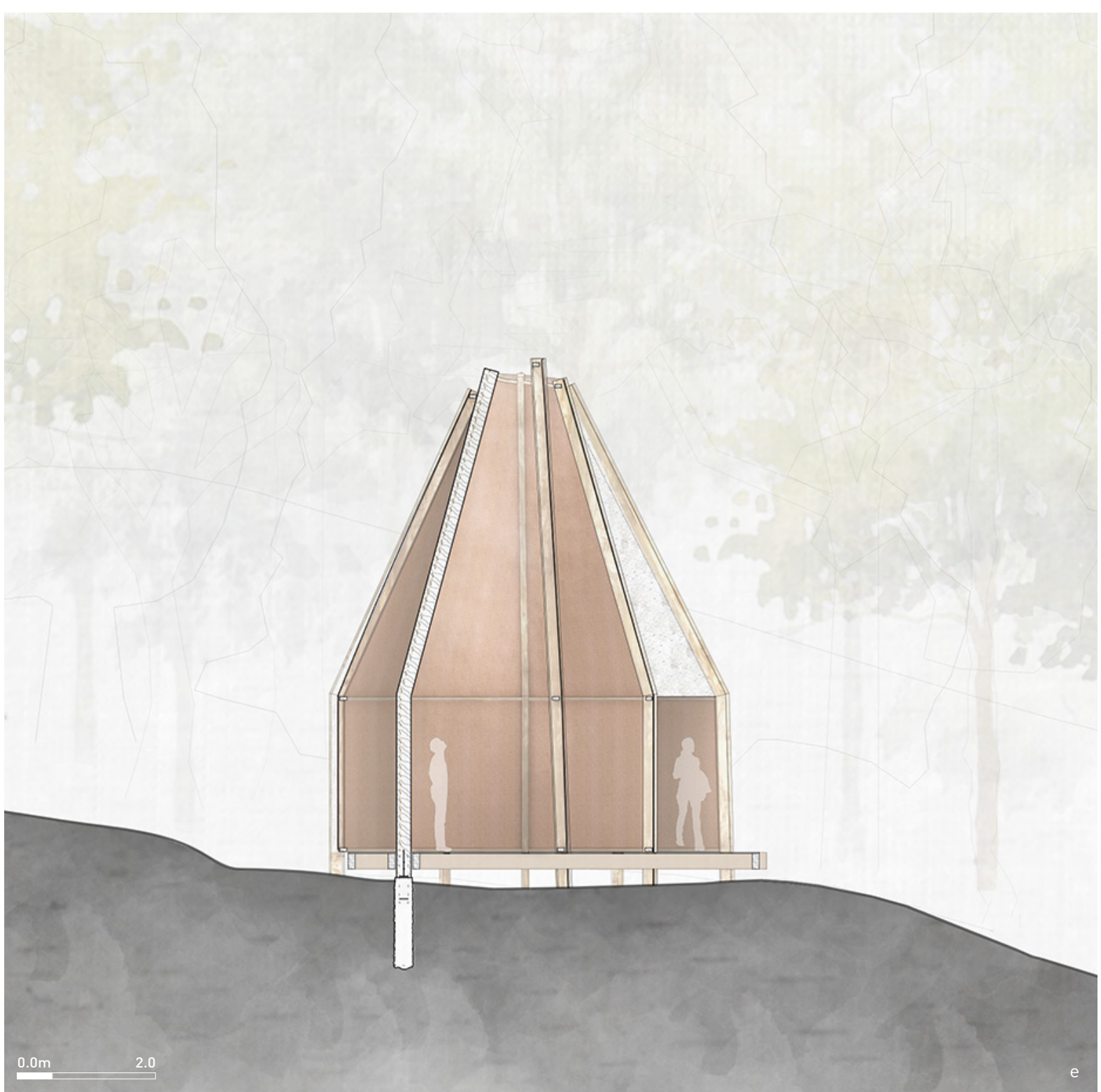


g. West Elevation

h. North Elevation

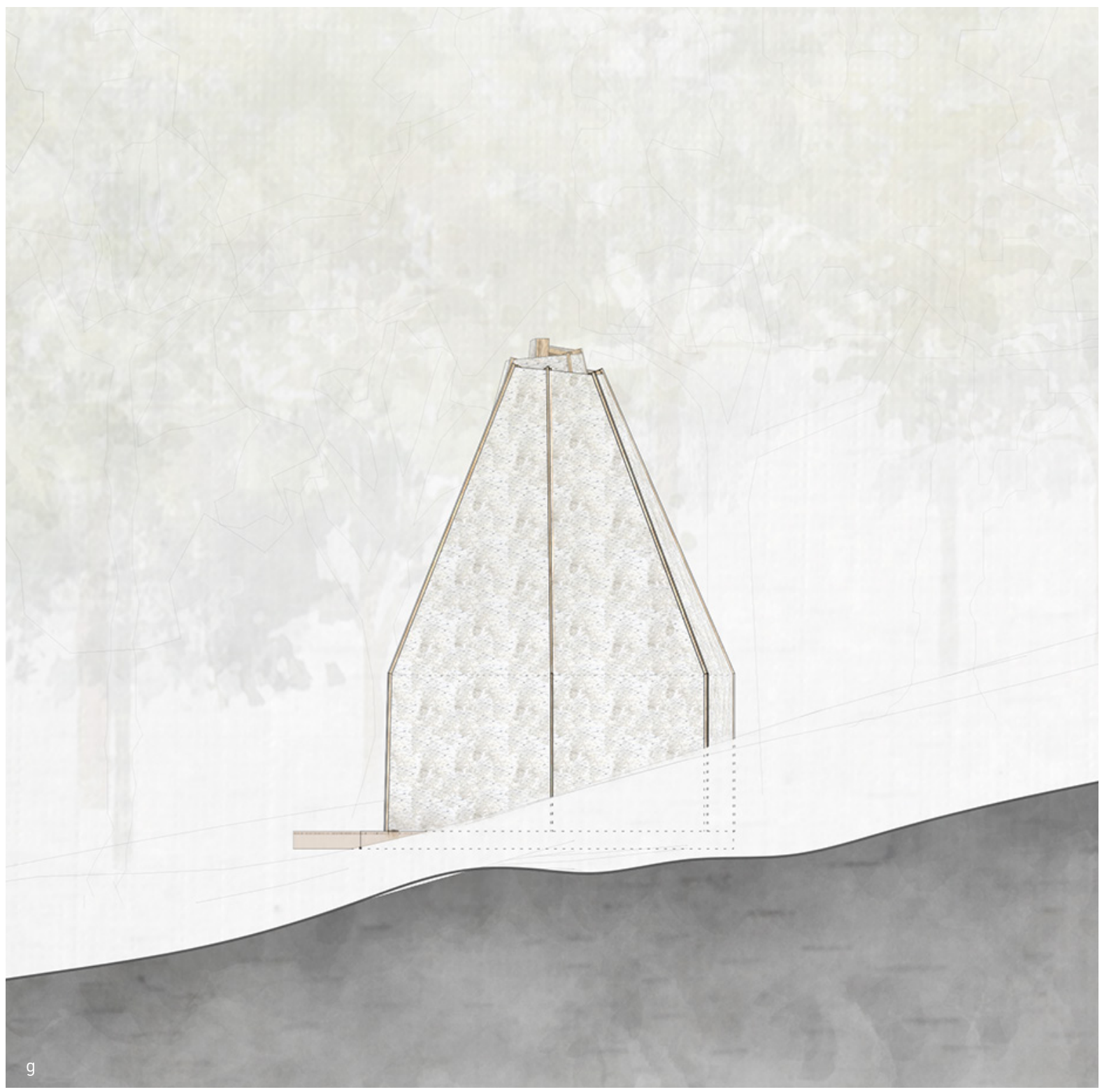


FINAL DESIGN DRAWINGS | EARTH ARMATURE

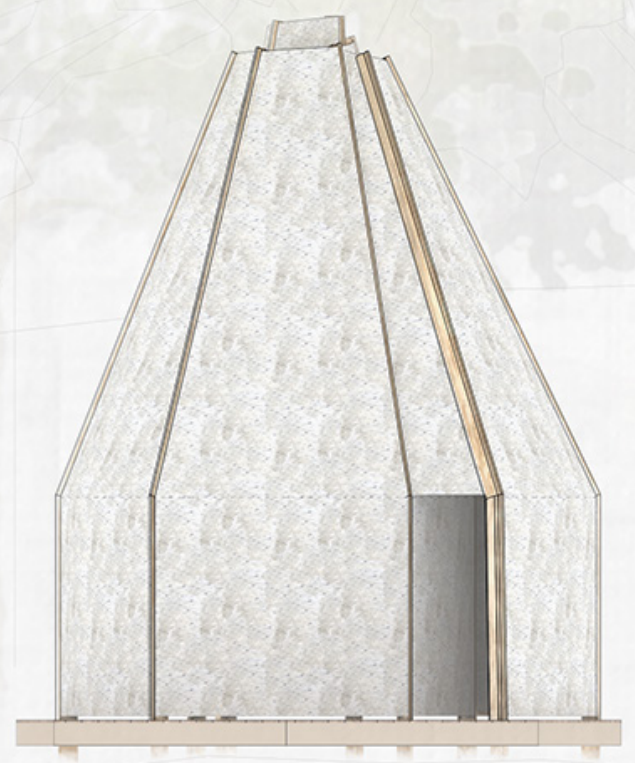


Figure 73: Atmospheric Representations

a. Mapped Experience of Earth Armature

b. Armature from trail, looking Southeast

c. Before entering armature

d. Moving towards center space

e. Moving towards center space, looking up
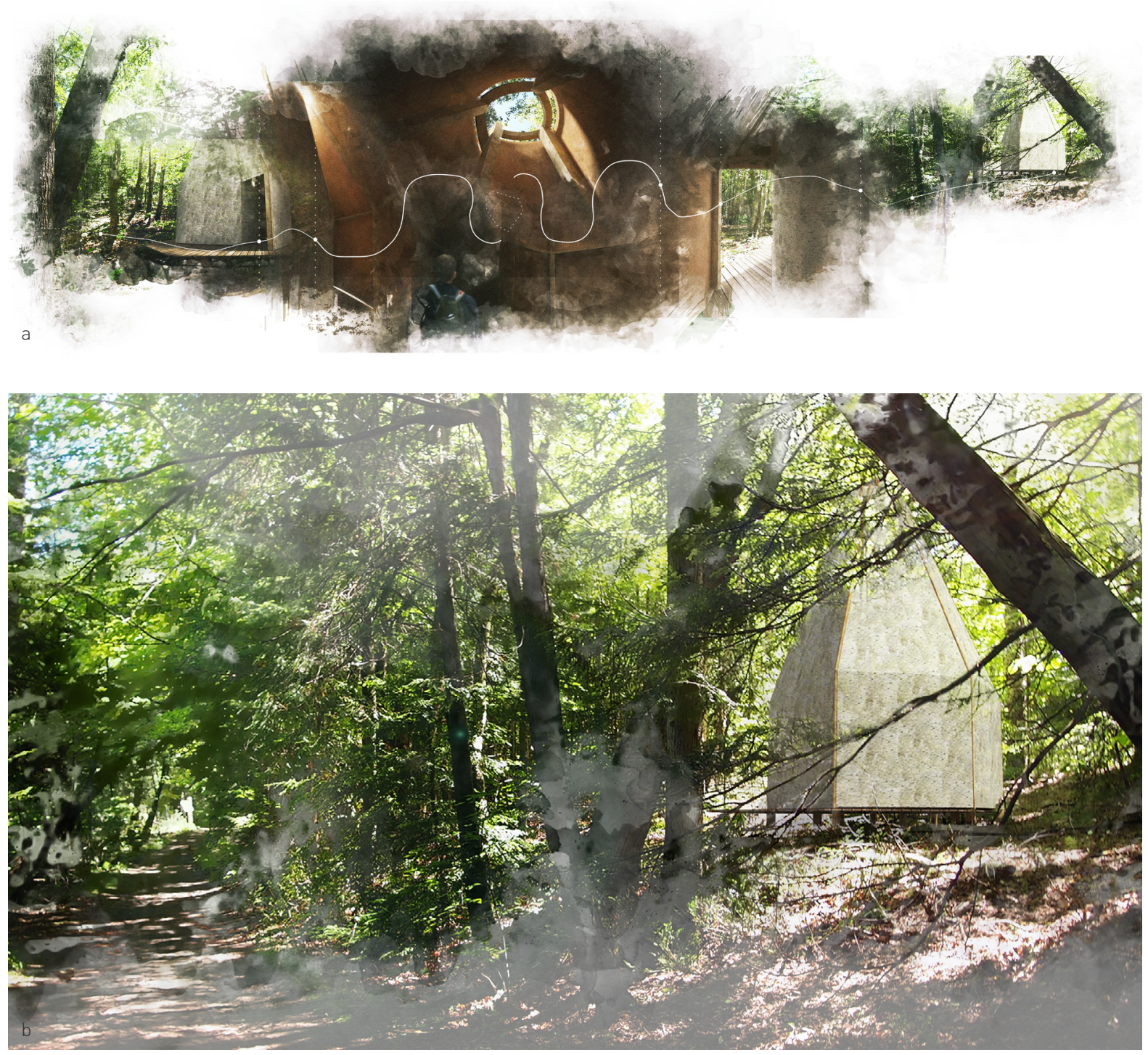


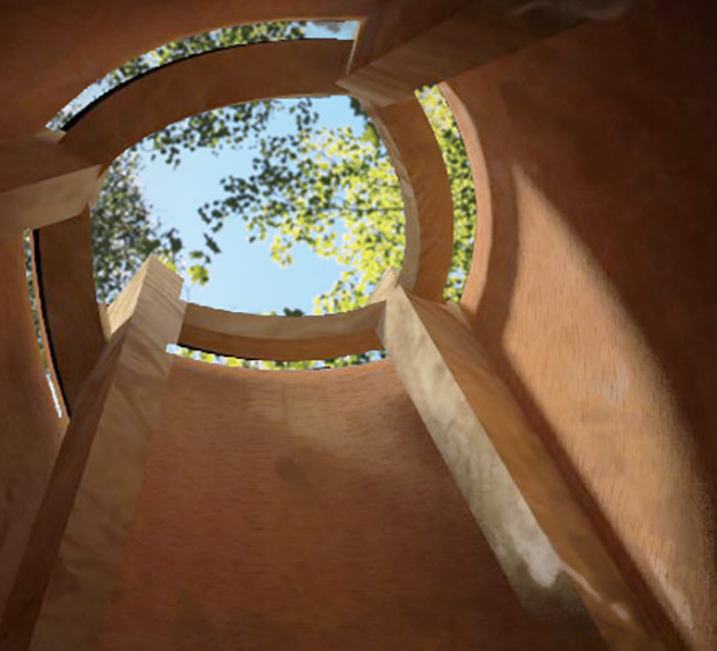



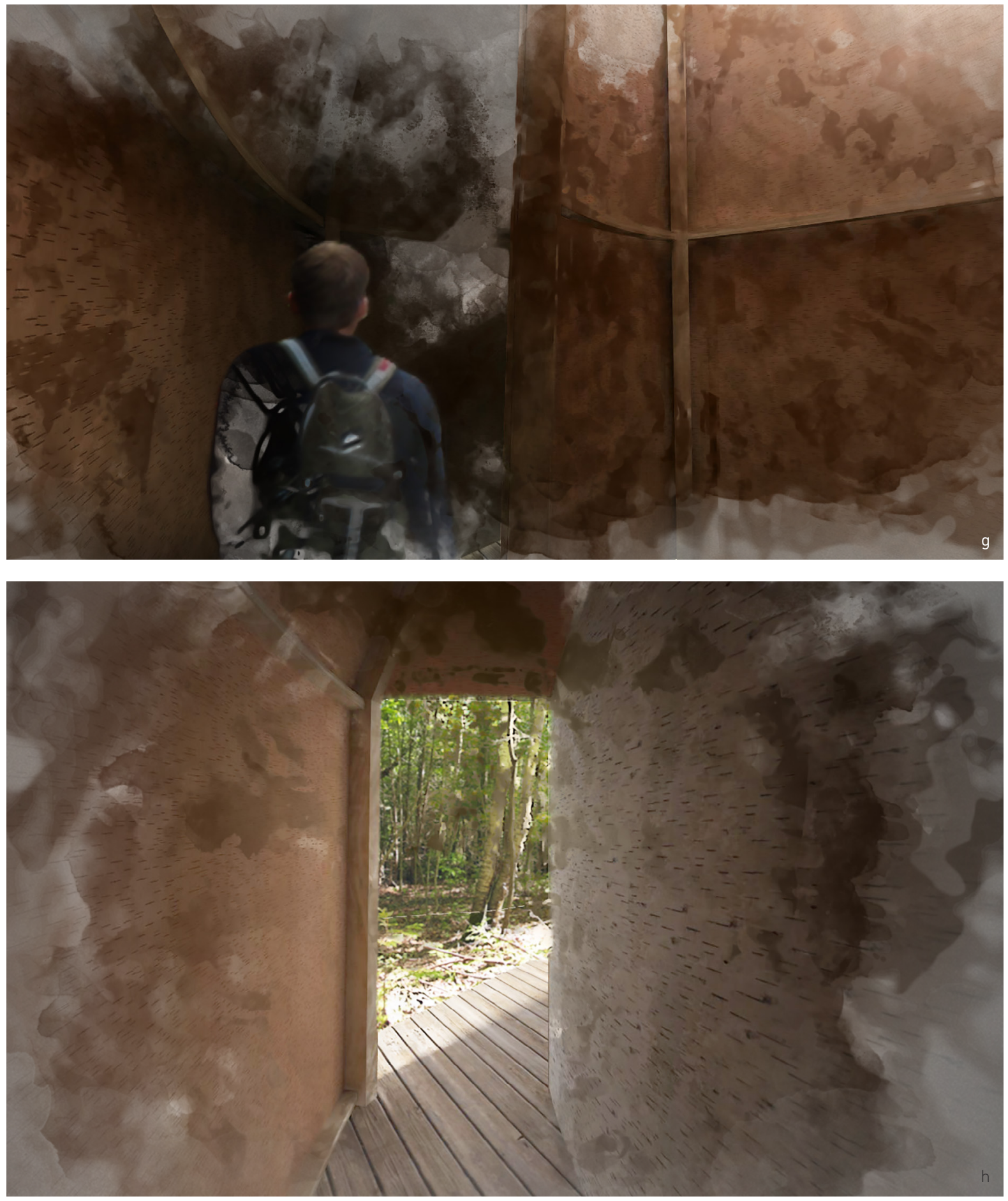


\section{APPENDIX G Final Design Drawings}

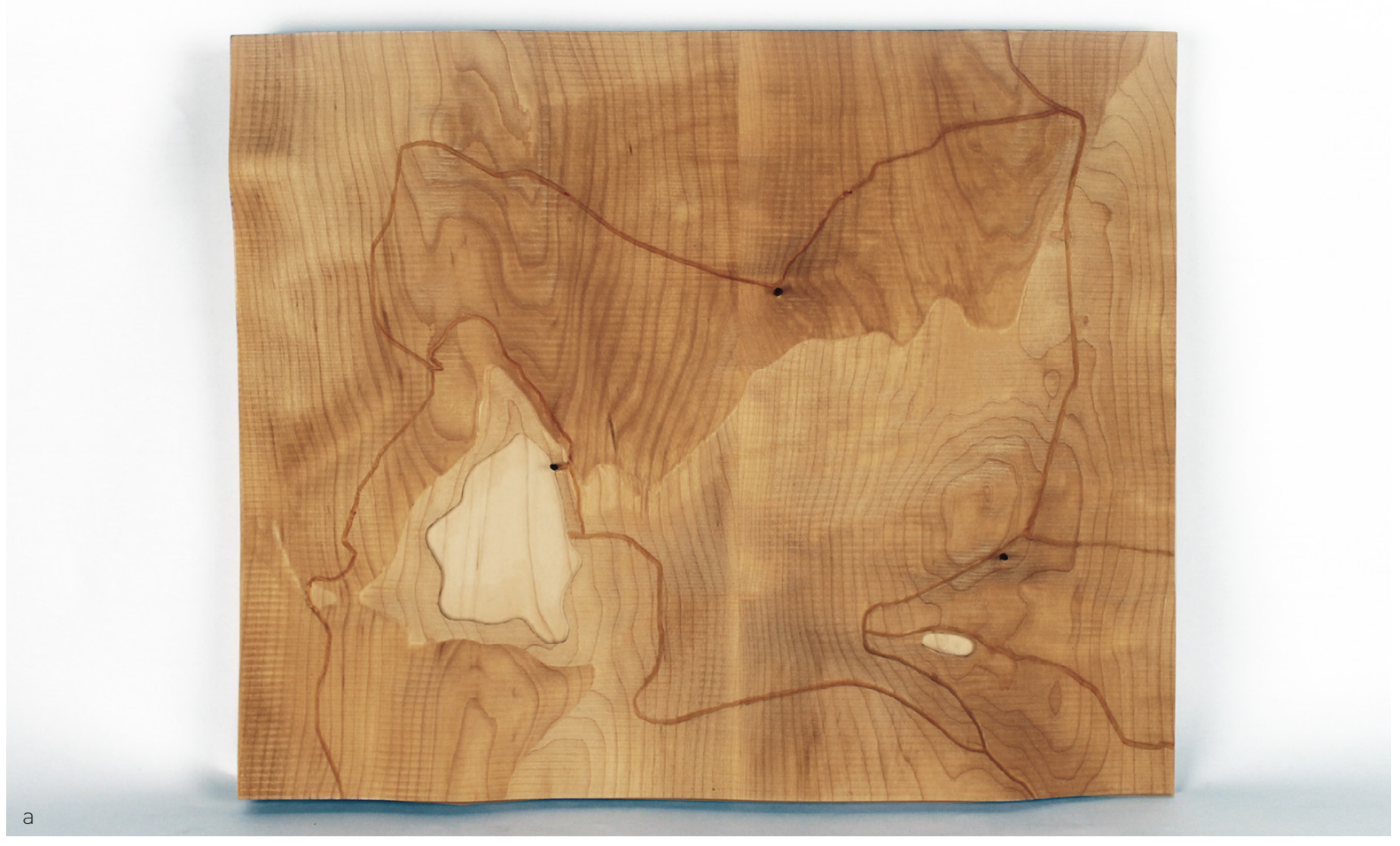

Figure 74: Final Design Models

a. Overall Context Model 1:2000

b. Air Armature Sectional Model 1:50

c. Water Armature Model 1:50

d. Earth Armature Model 1:50

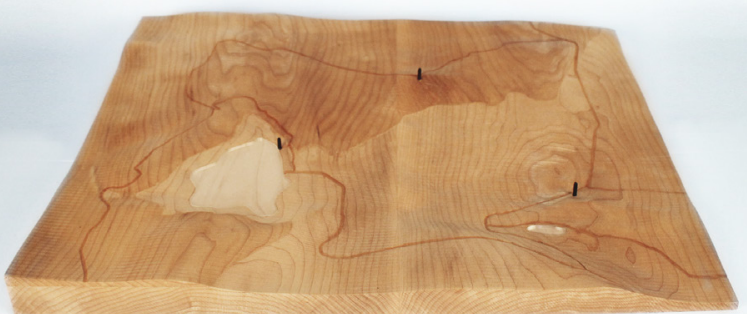



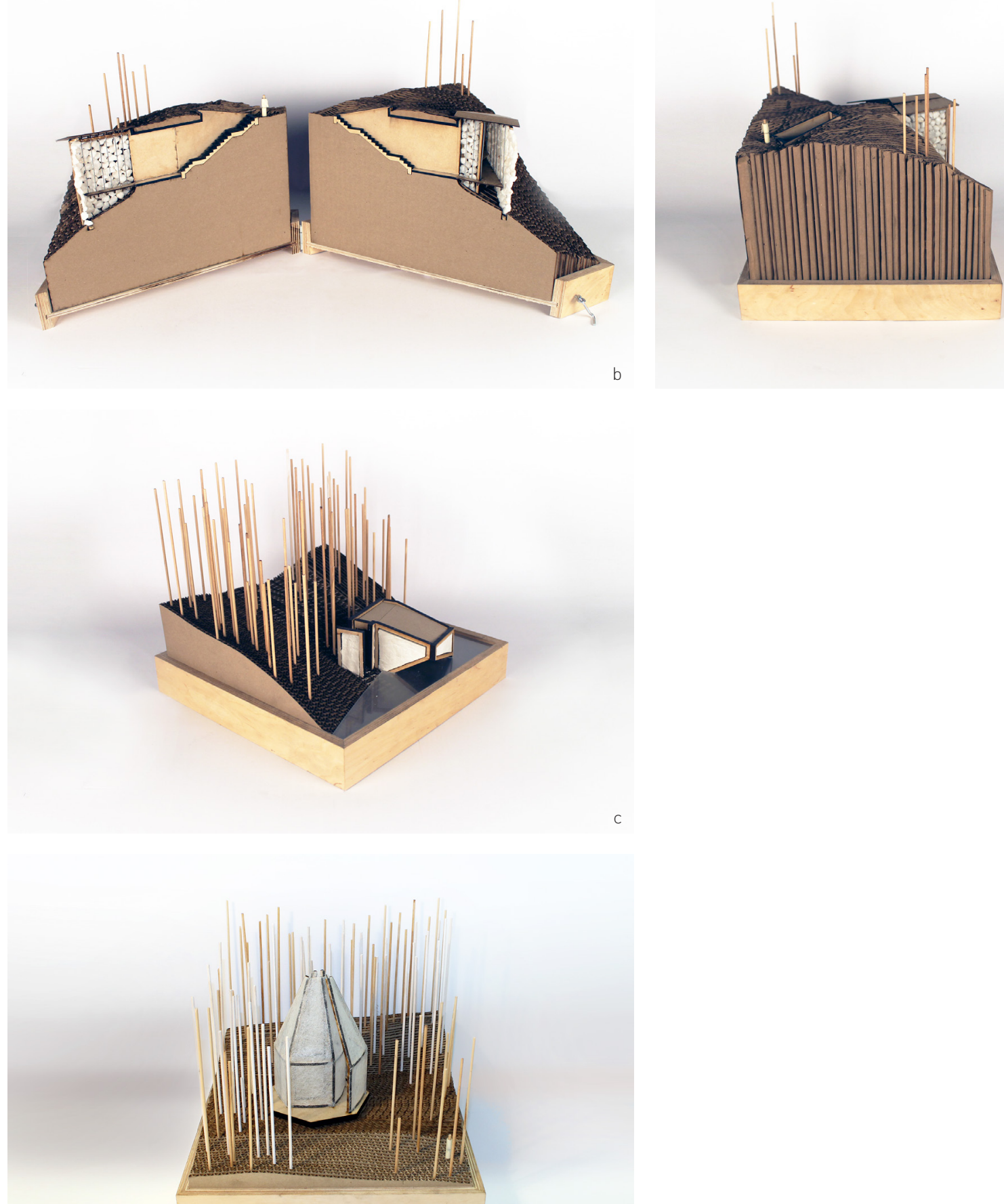


\section{BIBLIOGRAPHY}

Addington, Michelle. "The Phenomena of the Non-Visual." In Softspace : from a representation of form to a simulation of space, edited by Sean Lally, \& Jessica Young, 3851. London: Routledge, 2007.

Aizpuriete, Amanda, et al. Poetische Landschaft. II. Druck. Faltbuch - zur poetischen Landschaft. Edited by Brigitte Labs-Ehlert, \& Peter Zumthor. Detmold: Literaturbüro Ostwestfalen-Lippe, 1999

Bachelard, Gaston. The Poetics of Space. New York: Penguin Books, 2014.

Baudrillard, Jean. "The Aesthetic Suicide." In Mass, identity, Architecture: Architectural Writings of Jean Baudrillard., by Jean Baudrillard, edited by Proto Francesco, 125138. Chichester:Wiley-Academy, 2006.

Benzel, Katherine. "Spatial Relationships.” In The room in context : design beyond boundaries, by Katherine Benzel, 13-20. New York; Toronto: 1998, 1998.

Berke, Deborah. "Thoughts on the Everyday." In Architecture of the Everyday, edited by Steven Harris, \& Deborah Berke, 222-226. New York: Princeton Architectural Press, 1997.

Böhme, Gernot. Architektur und Atmosphäre. Munchen:Wilhelm Fink Verlag, 2006.

Bohme, Gernot.“Atmosphere as Mindful Physical Presence in Space.” OASE:Architectural Journal , no. 91 (2013): 20-32.

Böhme, Gernot. “Atmosphere as the Subject Matter of Architecture.” In Herzog \& de Meuron : natural history, edited by Philip Ursprung, 398-406. Montréal: Canadian Centre for Architecture, 2002.

Böhme, Gernot. "Encountering Atmosphere: A Reflection on the Concept of Atmosphere in the Work of Juhani Pallasmaa and Peter Zumthor." OASE: Architectural Journal, no. 91 (2013): 93-100. 
Bollnow, Otto Friedrich. Human Space. Edited by Joseph Kohlmaier. Translated by Christine Shuttleworth. London: Hyphen Press, 2011.

Borch, Christian. "The Politics of Atmospheres: Architecture, Power, and the Senses." In Architectural atmospheres: on the experience and politics of architecture, by Gernot Böhme, Ólafur Elíasson, Juhani Pallasma, \& Christian Borch, edited by Christian Borch, 60-89. Basel: BirkhäuserVerlag GmbH, 2014.

Borges, Jorge. This Craft of Verse. Edited by Mihailescu Calin-Andrei. Cambridge: Harvard University Press, 2000.

Botton, Alain de. The Architecture of Happiness. New York:Vintage Books, 2006.

de Certeau, Michel. "Spatial Stories." In The Practice of Everyday Life, by Michel de Certeau, translated by Steven Rendall, 115-130. London: University of California Press, 1984.

Dodds, George. "Desiring Landscapes/Landscapes of Desire: Scopic and Somatic in the Brion Sanctuary." In Body and Building: Essays on the Changing Relation of Body and Architecture, by George Dodds, \& Robert Tavernor, 304-318. London: The MIT Press, 2002.

Doty, Mark. Still Life with Oysters and Lemons. Boston: Beacon Press, 2001.

Frampton, Kenneth. "Corporeal Experience in the Architecture of Tadao Ando." In Body and Building: Essays on the Changing Relation of Body and Architecture, by Robert Tavernor George Dodds, 304-318. London: The MIT Press, 2002.

Gibson, James Jerome. Senses considered as perceptual systems. Boston: Houghton Mifflin, 1966.

Rivers and Tides: Andy Goldsworthy Working with Time. Directed by Thomas Riedelsheimer. Performed by Andy Goldsworthy. 2001.

Hall, Edward T. The Hidden Dimension. New York: Anchor Books, 1990.

Harbison, Robert. Thirteen Ways: Theoretical Investigations in Architecture. Massachusetts: MIT Press, 1997. 
Havik, Klaske, and Gus Tielens. “Concentrated Confidence:A Visit to Peter Zutnthor.” OASE:Architectural Journal, no. 91 (2013): 59-82.

Heidegger, Martin. "Building Dwelling Thinking." In Basic Writing: from Being and time (1927) to The task of thinking (1964), by Martin Heidegger, edited by David Farrell Krell, 343-363. San Francisco: HarperSanFrancisco, 1993.

Hejduk, John. Such Places as Memory. Cambridge:The MIT Press, 1998.

Hill, Jonathan. Immaterial Architecture. Oxon: Routledge, 2006.

Holl, Steven, Juhani Pallasmaa, and Alberto Pérez Gómez. Questions of perception: Phenomenology of architecture. San Francisco:William Stout Publishers, 2006.

Kahn, Louis. “The Room, the Street, and Human Agreement.” In Louis Kahn : essential texts, by Louis Kahn, 252-260. New York:W.W. Norton, 2003.

Koolhaas, Rem, and Bruce Mau. S, M, L, XL. Edited by Jennifer Sigler. Rotterdam: 010 Publishers, 1995.

Kuma, Kengo. Natural Architecture. Translated by Birnbaum, \& Alfred. Vol. 2. London: Architectural Association, 2015.

Lefebvre, Henri. “The Everyday and Everydayness.” In Architecture of the Everyday, edited by Steven Harrie, \& Deborah Berke, translated by Christine Levich, Alice Kaplin, \& Kristin Ross, 32-37. New York: Princeton Architectural Press, 1997.

Lobell, John. Between silence and light: spirit in the architecture of Louis T. Kahn. Boston: Shambhala Publications, Inc., 1979.

Malnar,Joy Monice, and FrankVodvarka. Sensory Design. Minneapolis: University of Minnesota Press, 2004.

Marbel, Scott. Architecture and Body. New York: Rizzoli , 1989. 
Massumi, Brian. "Building Experience." In Nox: Machining Architecture, by Lars Spuybroek, 322-331. New York: Thames \& Hudson, 2004.

Meisenheimer, Wolfgang. "Von den Hohlräumen in der Schale des Baukörpers = Of the hollow spaces in the skin of the architectural body." Daidalos, September 1984: 103-111.

Morris, David. The Sense of Space. Akbany: State University of New York Press, 2004.

Neutra, Richard. Life and Human Habitat = Mensch und Wohnen. Stuttgart:A. Koch Gmbh, 1956.

Norberg-Schulz, Christian. Intentions in Architecture. Cambridge:The MIT Press, 1965.

Pallasmaa, Juhani. "Hapticity and Time: Notes on a Fragile Architecture." The Architectural Review, May 2000: 78-84.

Pallasmaa, Juhani. “Landscapes of Architecture.” In Encounters : architectural essays, by Juhani Pallasmaa, edited by Peter MacKeith, 334-350. Helsinki: Rakennustieto Oy, 2005.

Pallasmaa, Juhani. "Lived Space." In Encounters : architectural essays, by Juhani Pallasmaa, edited by Peter MacKeith, 127-140. Helsinki: Rakennustieto Oy, 2005.

Pallasmaa, Juhani. "Orchestrating Architecture: Atmosphere in Frank Lloyd Wright's Buildings.” OASE: Architectural Journal, no. 91 (2013): 53-57.

Pallasmaa, Juhani. "Space, place, and Atmosphere: Peripheral Perception in Existential Experience." In Architetcural Atmopsheres: On Experience and Politics of Architecture, by Gernot Bohme, Ólafur Elíasson, Juhani Pallasma, \& Christian Borch, 18-41. Basel: BirkhäuserVerlag GmbH, 2014.

—. The Eyes of the Skin:Architecture and the Senses. London: John Wiley \& Sons Ltd., 2005.

Pallasmaa, Juhani. "The Geometry of Feeling: A Look at the Phenomenology of Architecture." In Theorizing a New Agenda for Architecture, by Juhani Pallasmaa, edited by Kate Nesbitt, 448-453. New York: Princeton Architectural Press, 1996. 
Pallasmaa, Juhani. “The Place of Man.” In Encounters : architectural essays, edited by Peter MacKeith, 71-85. Helsinki: Rakennustieto Oy, 2005.

Pilgrim, Richard B. "Intervals ("Ma") in Space and Time: Foundations for a Religio-Aesthetic Paradigm in Japan." History of religions 25, no. 3 (Feb 1986): 255-277.

Pizzagalli, Simone, Nicolò Privileggio, and Marc Schoonderbeek. Spaces, Poetics and Voids. Amsterdam: Architectura \& Natura Press, 2013.

Rasmussen, Steen Eiler. Experiencing Architecture. Cambridge:The MIT Press, 1959.

Robinson, Sarah. Nesting: Body, Dwelling, Mind. Richmond:William Stout Publishers, 2011.

Russell, Bertrand. Routledge Classics : History of Western Philosophy. London: Routledge, 2004.

Sharr, Adam. Heidegger for Architects. Abingdon: Routledge, 2007.

Spuybroek, Lars. The Architecture of Continuity: Essays and Conversations. Rotterdam:V2 Pub., 2008.

Tanizaki, Jun'ichiro- In Praise of Shadows. Translated by Thomas J. Harper. Stony Creek: Leete's Island Books, 1977.

Tielens, Gus, and Klaske Havik. "Atmosphere, Compassion and Embodied Experience: A Conversation about Atmospheere with Juhani Pallasmaa.” OASE: Architectural Journal 91 (2013): 33-52.

Tuan,Yi-fu. "Experiential Perspective." In Space and Place: The Perspective of Experience, by Yi-fu Tuan, 8-18. Minneapolis: University of Minnesota Press, 1977.

Valero Ramos, Elisa. Light in architecture : the intangible material. Newcastle: RIBA Publishing, 2015.

Verstegen, Ton. Gestures:Atmospheric Perception and Architecture. Arnhem:ArtEZ, 2009. 
Vesely, Dalibor. "The Architectonics of Embodiment." In Body and Building: Essays on the Changing Relation of Body and Architecture, edited by George Dodds, \& Robert Tavernor, 28-43. London:The MIT Press, 2002.

Wallace, David Foster. Infinite Jest : a novel. New York: Back Bay Books, 2006.

Wigley, Mark. “The Architecture of Atmosphere.” Daidalos, 1998: 18-27.

Wittgenstein, Ludwig. Tractatus Logico-Philosophicus. Translated by Frank P. Ramsey, \& Charles Kay Ogden. Austria: First published in W. Ostwald's Annalen der Naturphilosophie, 1921.

Zumthor, Peter. Atmospheres. Basel: Birkhäuser, 2006.

—. "Presence in Architecture, Seven Personal Observations." Lecture. The David Azrieli School of Architecture at Tel Aviv University, Nov 10, 2013.

—. Thinking Architecture. Basel: Birkhäuser, 2006. 


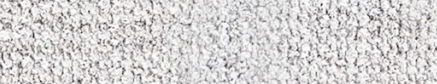

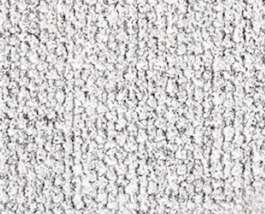

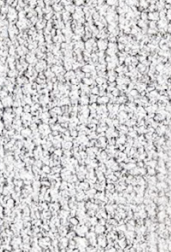

